UNIVERSIDADE DE SÃO PAULO

FACULDADE DE ECONOMIA, ADMINISTRAÇÃO E CONTABILIDADE DEPARTAMENTO DE ECONOMIA PROGRAMA DE PÓS-GRADUAÇÃO EM ECONOMIA

ESTUDO SOBRE O IMPACTO DA EXPANSÃO DAS UNIVERSIDADES FEDERAIS NO BRASIL

Henrique Eduardo Ferreira Vinhais

Orientador: Prof. Dr. Joaquim José Martins Guilhoto Coorientador: Prof. Dr. Marcos de Almeida Rangel 
Prof. Dr. João Grandino Rodas Reitor da Universidade de São Paulo

Prof. Dr. Reinaldo Guerreiro

Diretor da Faculdade de Economia, Administração e Contabilidade

Prof. Dr. Joaquim José Martins Guilhoto

Chefe do Departamento de Economia

Prof. Dr. Márcio Issao Nakane

Coordenador do Programa de Pós-Graduação em Economia 
HENRIQUE EDUARDO FERREIRA VINHAIS

\title{
ESTUDO SOBRE O IMPACTO DA EXPANSÃO DAS UNIVERSIDADES FEDERAIS NO BRASIL
}

\author{
Tese apresentada ao Programa de Pós- \\ Graduação em Economia da Faculdade de \\ Economia, Administração e Contabilidade da \\ Universidade de São Paulo, para obtenção do \\ título de Doutor em Ciências.
}

Orientador: Prof. Dr. Joaquim José Martins Guilhoto Coorientador: Prof. Dr. Marcos de Almeida Rangel

\section{Versão Corrigida}

(versão original disponível na Faculdade de Economia, Administração e Contabilidade)

\section{SÃo PAULO}


FICHA CATALOGRÁFICA

Elaborada pela Seção de Processamento Técnico do SBD/FEA/USP

Vinhais, Henrique Eduardo Ferreira

Estudo sobre o impacto da expansão das universidades federais no Brasil / Henrique Eduardo Ferreira Vinhais. -- São Paulo, 2013. $234 \mathrm{p}$.

Tese (Doutorado) - Universidade de São Paulo, 2013.

Orientador: Joaquim José Martins Guilhoto.

Coorientador: Marcos de Almeida Rangel.

1. Universidade pública - Brasil 2. Impacto 3. Insumo-produto 4. Econometria I. Universidade de São Paulo. Faculdade de Economia, Administração e Contabilidade. II. Título.

CDD - 378.05 
Em memória ao meu pai, Manuel dos Santos Moura Vinhais. 


\section{AGRADECIMENTOS}

Primeiramente, ao meu orientador, Prof. Dr. Joaquim José Martins Guilhoto, e ao meu coorientador, Prof. Dr. Marcos de Almeida Rangel, por todo apoio, paciência e confiança, e por seus ensinamentos ao longo da realização deste trabalho.

À minha mãe e ao meu irmão, que tanto me ajudaram nos momentos difíceis.

À Coordenação de Aperfeiçoamento de Pessoal de Nível Superior (CAPES) e ao Observatório da Educação - Projeto 3313 - CAPES/FEA-USP, pela bolsa concedida para a elaboração deste trabalho.

A todos os professores do Departamento de Economia da Faculdade de Economia, Administração e Contabilidade (FEA) da Universidade de São Paulo (USP), com os quais tive contato e tanto aprendi ao longo dos últimos anos.

Ao Prof. Dr. Fernando Balbino Botelho, pelas críticas e sugestões oferecidas na qualificação deste trabalho.

A todos os meus amigos e colegas do Programa de Pós-Graduação em Economia da FEA-USP, pela amizade e convivência.

À USP, pela fundamental contribuição na minha formação profissional e pessoal.

A todos que, direta ou indiretamente, colaboraram para a realização deste trabalho.

E, por fim, agradeço a Deus por me possibilitar cursar o doutorado e por sempre iluminar o meu caminho ao longo desta vida. 


\section{RESUMO}

Dado o recente quadro de expansão da rede de universidades públicas federais, no qual se destaca a construção de novos campi em diversos municípios brasileiros, este trabalho se propõe a estimar o impacto regional de curto prazo desta expansão. Para tanto, primeiramente utiliza-se a abordagem de Insumo-Produto através da matriz de insumo-produto microrregionalizada. Aplicando-se a expansão de gastos públicos com universidades federais como choque no setor Educação Pública, constata-se, para o período de 2004 a 2010, um efeito total de $\mathrm{R} \$ 19,9$ bilhões sobre valor bruto da produção e $\mathrm{R} \$ 11,5$ bilhões sobre valor adicionado, que representa 0,39\% sobre o PIB nacional e um efeito médio anual de R\$1,9 bilhão. Com relação a pessoal ocupado, há um efeito de 467 mil pessoas ocupadas. No nível local, constata-se que as microrregiões menores economicamente, e que receberam campi universitários, apresentam os maiores impactos relativos. Com relação à segunda abordagem da questão, entende-se a expansão pela implantação de novos campi universitários federais como um tratamento de política pública, que tem impacto no curto prazo sobre a renda domiciliar per capita local. Desta forma, estima-se econometricamente um efeito do tratamento sobre os tratados, com base no método de Diferenças em Diferenças com Pareamento por Escore de Propensão. Os resultados indicam um efeito positivo no período de 2000 a 2010 por volta de 3,3\% sobre a renda domiciliar per capita municipal, com o grupo de municípios com até 65 mil habitantes apresentando o maior efeito do tratamento, com valor de $5,2 \%$ sobre a renda. Apesar dos resultados destas duas abordagens não serem diretamente comparáveis, o efeito médio anualizado do tratamento é de $0,16 \%$ sobre o PIB per capita microrregional, segundo o método de Insumo-Produto, e de $0,27 \%$ sobre a renda domiciliar per capita das microrregiões tratadas, através do método econométrico. Em complemento à segunda abordagem e entendendo-se que a implantação de um novo campus pode trazer benefícios políticos futuros aos governantes locais, estima-se também o efeito político do tratamento sobre os municípios tratados. Os resultados indicam efeitos de $27 \%$ e $10 \%$ sobre a probabilidade de eleição em 2008 de partido pertencente à coligação política vencedora das eleições de 2004 e sobre a probabilidade de reeleição em 2008 do partido político do prefeito, respectivamente. Os resultados apontam para um efeito político superior ao efeito sobre a renda local, no curto prazo, beneficiando os grupos políticos estabelecidos no poder municipal. 


\begin{abstract}
Given the recent expansion of the federal universities' system in Brazil, which emphasizes the construction of new campuses in various municipalities, this study aims to estimate the shortrun regional economic impact of this expansion. Firstly we use the Input-Output approach through the Interregional Input-Output matrix with 558 micro-regions of the Brazilian economy. Applying the expansion of public spending on universities as a shock to the Public Education sector, for the period 2004 to 2010, we get a total effect of R $\$ 19.9$ billion of gross value of production and $\mathrm{R} \$ 11.5$ billion of value added, representing $0.39 \%$ of the national GDP and average annual effect of $\mathrm{R} \$ 1.9$ billion. With respect to employment, there is an effect of 467 thousand employed people. At the local level, it appears that the smaller regions economically, which received campuses, present the greatest relative impacts. Regarding the second approach to this issue, we interpreted the expansion from the implementation of new federal university campuses as a public policy treatment, which has short-run impact on the local per capita household income. Thus, it is estimated econometrically a treatment effect on the treated, based on Differences-in-Differences method with Matching by Propensity Score. The results indicate a positive effect in the period 2000-2010 around 3.3\% of municipal household per capita income, with the group of municipalities with up to 65,000 inhabitants presenting the greatest treatment effect, around 5.2\% on income. Although the results of these two approaches are not directly comparable, the annualized average treatment effect on the treated is $0.16 \%$ of micro-regional per capita GDP, according to the Input-Output method, and $0.27 \%$ of micro-regional per capita household income, by the econometric method. In addition to the second approach and understanding that the establishment of a new campus can bring future political benefits for local public administrators, we also estimated the political effect of the treatment on the treated municipalities. The results indicate effects of $27 \%$ and $10 \%$, respectively, on the probability of election in 2008 of a political party belonging to the 2004 winner political coalition and on the probability of re-election in 2008 of the political party of the mayor. The results point in the short-run to a greater political effect than the effect on local incomes, benefiting political groups established in municipal power.
\end{abstract}




\section{SUMÁRIO}

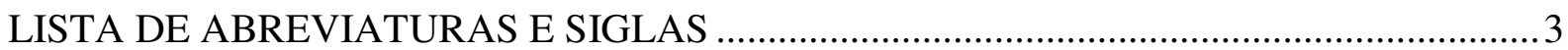

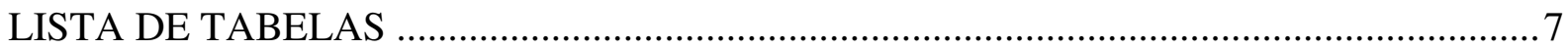

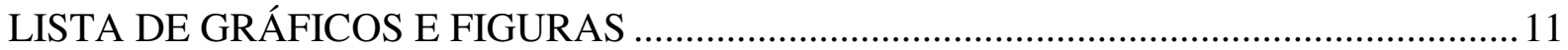

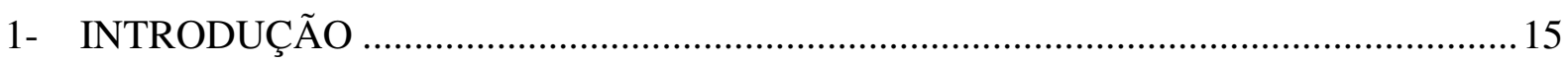

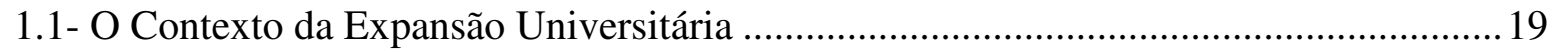

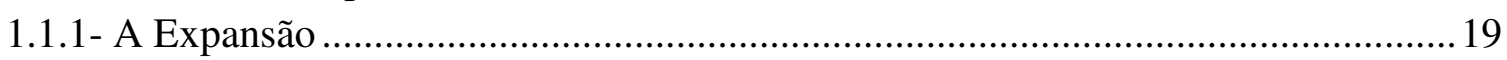

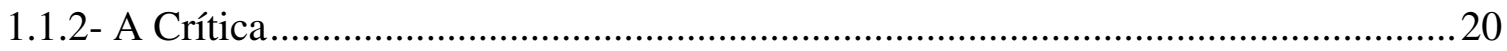

1.2- Revisão da Literatura de Impacto de Universidades..............................................23

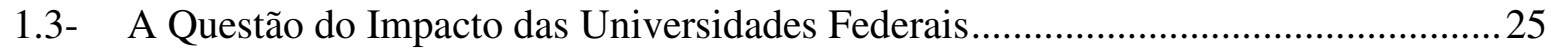

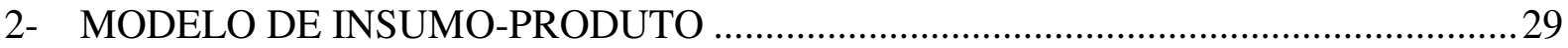

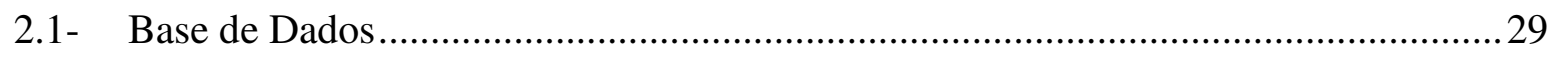

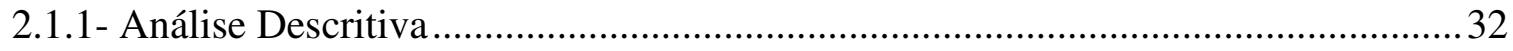

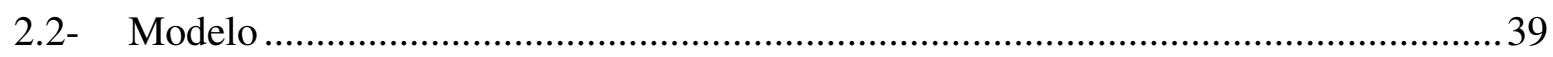

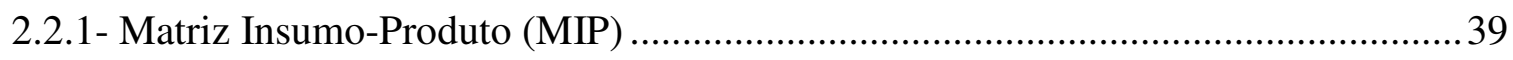

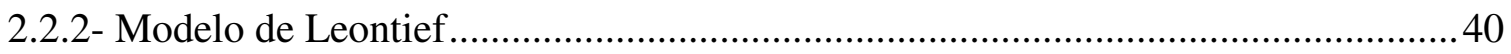

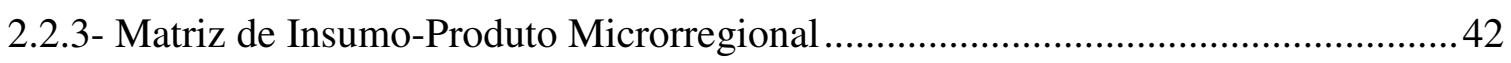

2.2.4- Geradores, Multiplicadores e Índices de Ligação ........................................................ 45

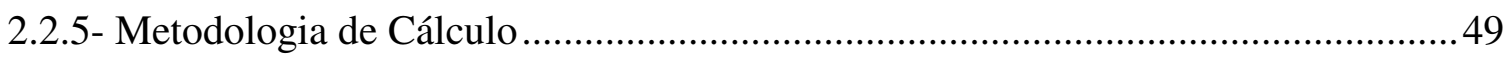

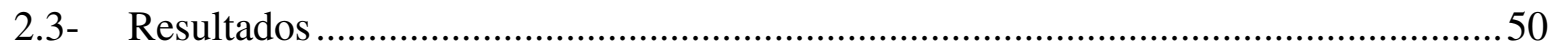

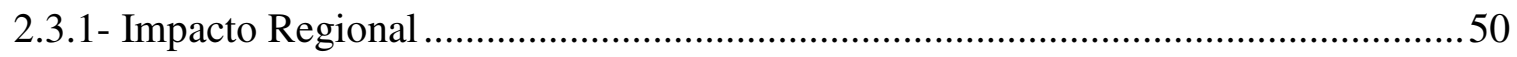

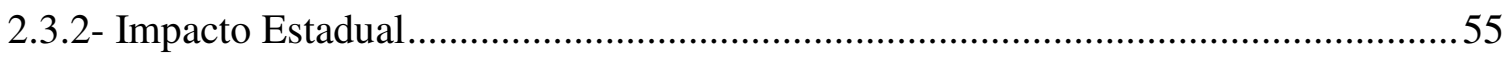

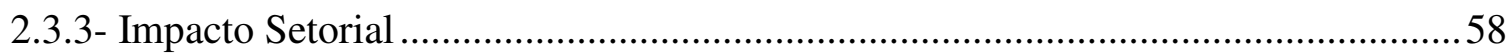

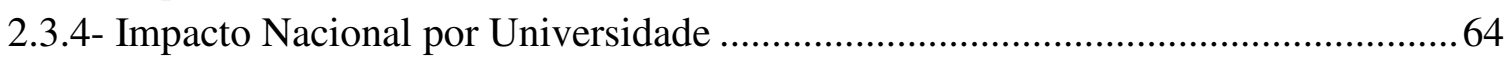

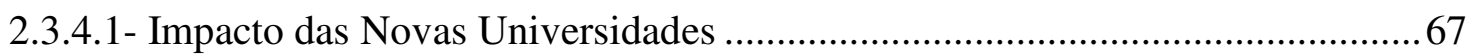

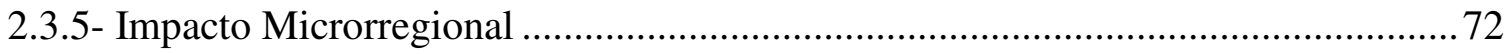

2.3.5.1 - Impacto Microrregional de cada Universidade ........................................... 72

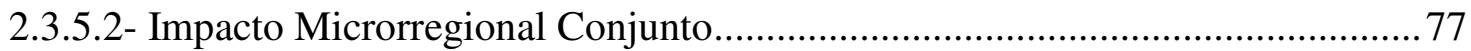

2.3.5.3- Distribuição Territorial do Impacto Microrregional Conjunto .......................... 81

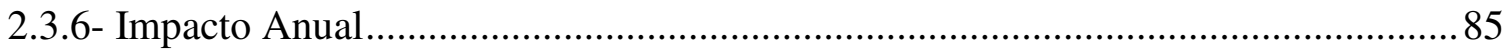

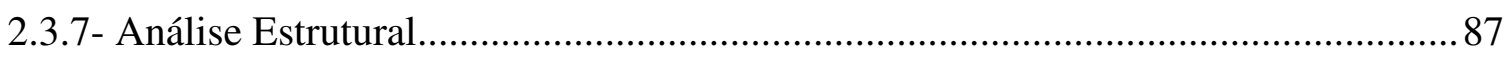

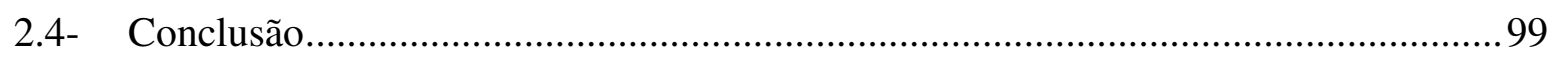

3- MODELO ECONOMÉTRICO DE EFEITO ECONÔMICO DO TRATAMENTO ......103

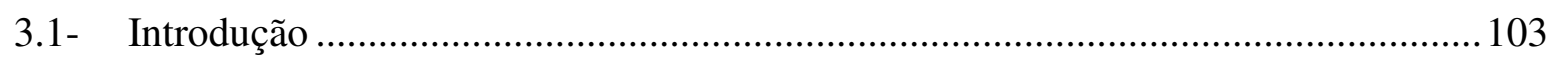

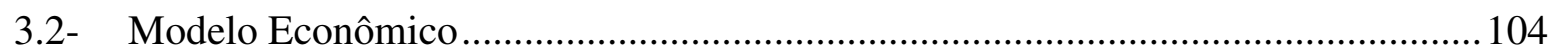

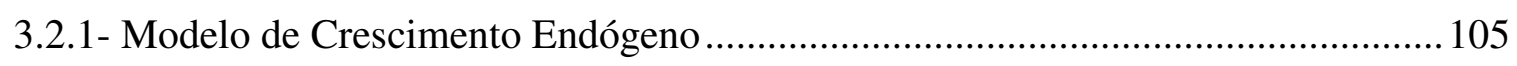

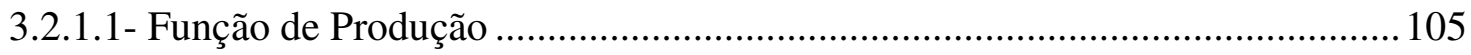

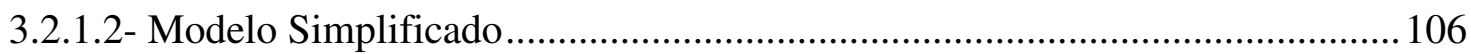

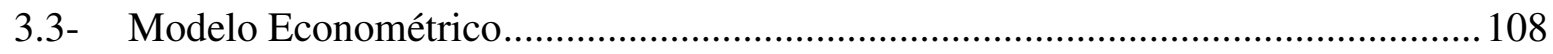

3.3.1- Efeito Médio do Tratamento nos Tratados ........................................................ 108 
3.3.1.1- Método de Diferenças-em-Diferenças com Pareamento por Escore de Propensão.

3.3.1.2- Análise de Sensibilidade com base nos Limites de Rosenbaum .................. 116

3.3.2- Estratégia de Identificação e Implementação do Método de Estimação ............... 118

3.3.2.1- Escolha do Grupo de Comparação ............................................................ 119

3.3.2.2- Implementação do Método de Estimação...................................................... 120

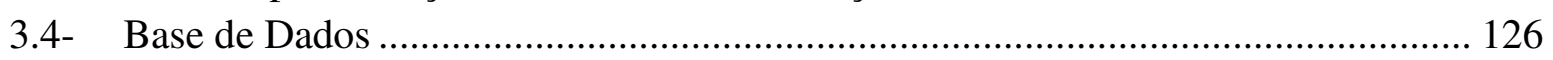

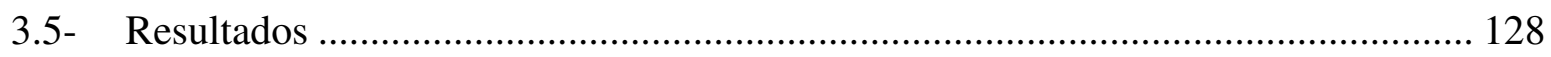

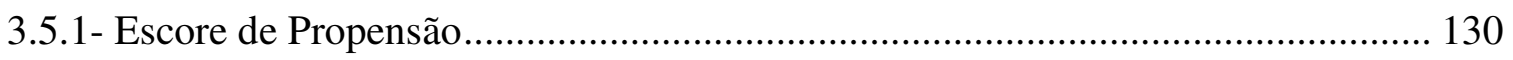

3.5.2- Diferenças-em-Diferenças com Pareamento por Escore de Propensão ................ 135

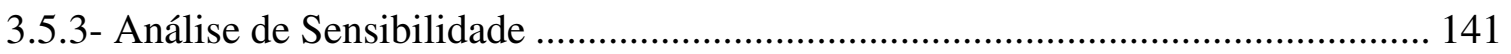

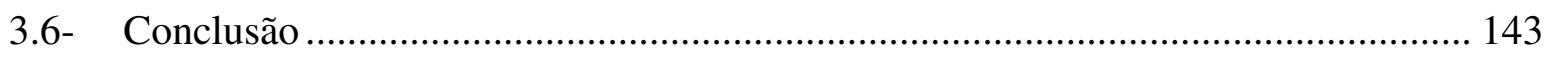

4- MODELO ECONOMÉTRICO DE EFEITO POLÍTICO DO TRATAMENTO............ 147

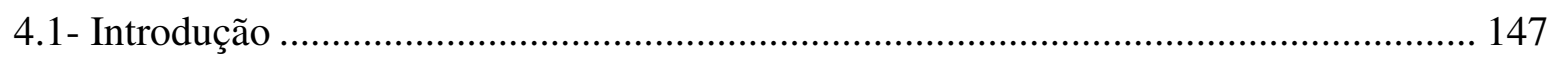

4.2- Revisão da Literatura de Teoria dos Ciclos Político-Econômicos.............................. 148

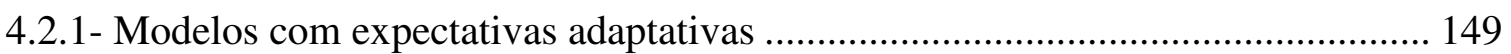

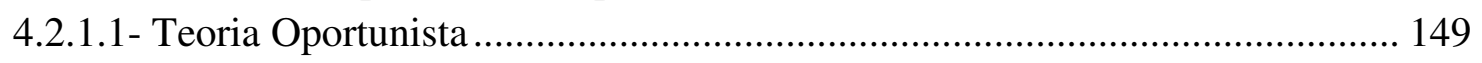

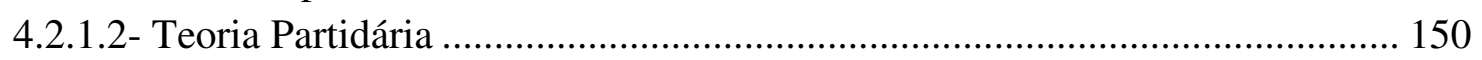

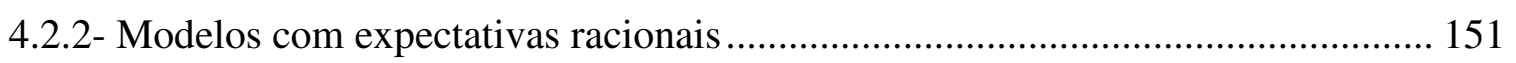

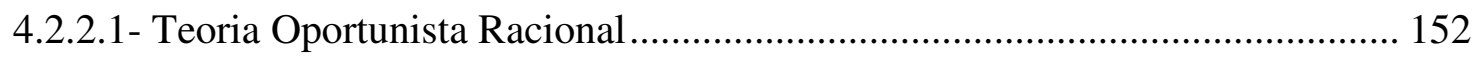

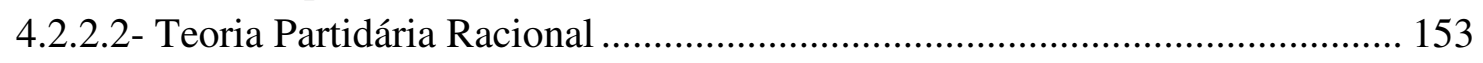

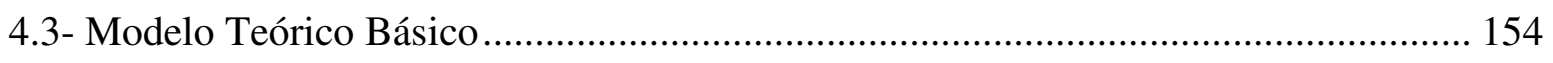

4.4- Implementação do Método de Estimação ................................................................... 156

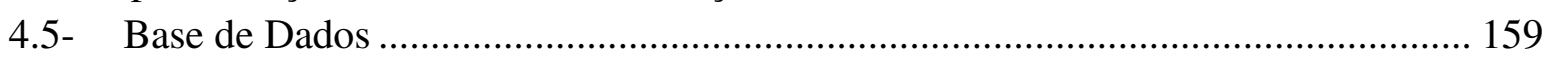

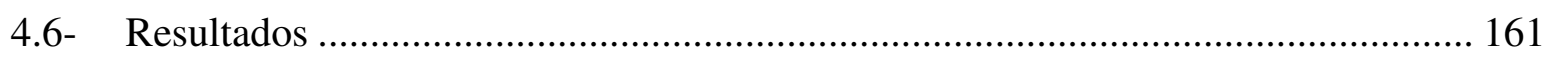

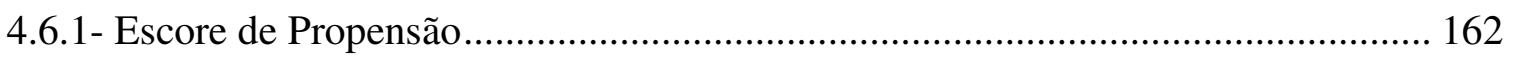

4.6.2- Diferenças-em-Diferenças com Pareamento por Escore de Propensão ................ 167

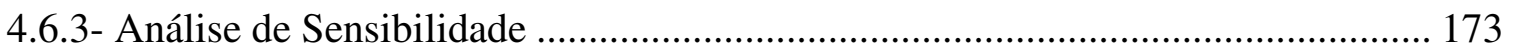

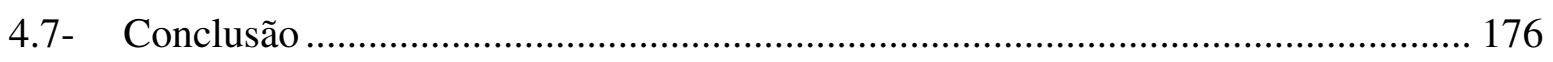

5- A EXPANSÃO E SEU IMPACTO REGIONAL ......................................................... 179

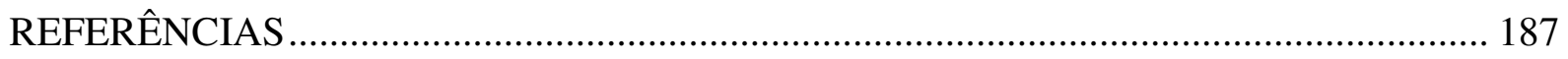

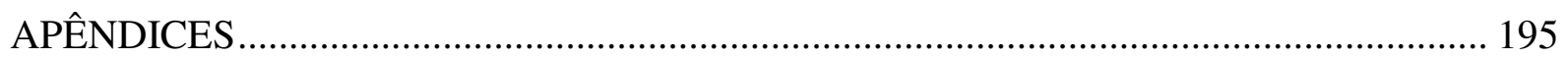




\section{LISTA DE ABREVIATURAS E SIGLAS}

ACE: American Council of Education AMC's: Áreas Mínimas Comparáveis

Andifes: Associação Nacional dos Dirigentes das Instituições Federais de Ensino Superior ATE: Average Treatment Effect (Efeito Médio do Tratamento)

ATT: Average Treatment Effect on the Treated (Efeito Médio do Tratamento sobre os Tratados)

CNE: Conselho Nacional de Educação

CPLP: Comunidade dos Países de Língua Portuguesa

CR\$: Cruzeiro Real

Cr\$: Cruzeiros

D.O.U.: Diário Oficial da União

DERSA-SP: Desenvolvimento Rodoviário S/A

EAA: Escola de Agronomia da Amazônia

EFOA: Escola de Farmácia e Odontologia de Alfenas

Fafeid: Faculdades Federais Integradas de Diamantina

Fafeod: Faculdade Federal de Odontologia de Diamantina

FCAP: Faculdade de Ciências Agrárias do Pará

FCM: Faculdade Católica de Medicina

FFFCMPA: Fundação Faculdade Federal de Ciências Médicas de Porto Alegre

FMTM: Faculdade de Medicina do Triângulo Mineiro

FURG: Universidade Federal do Rio Grande

IBGE: Instituto Brasileiro de Geografia e Estatística

IES: Instituições de Ensino Superior

INDA: Instituto Nacional de Desenvolvimento Agrário

INEP: Instituto Nacional de Estudos e Pesquisas Educacionais Anísio Teixeira

INPC: Índice Nacional de Preços ao Consumidor

IPEA: Instituto de Pesquisa Econômica Aplicada

LDB: Lei de Diretrizes e Bases da Educação Nacional

LOA: Lei Orçamentária Anual

MARE: Ministério da Administração Federal e da Reforma do Estado

MEC: Ministério da Educação

MIP: Matriz de Insumo-Produto

NASA: National Aeronautics and Space Administration (Agência Espacial Norte-Americana)

NEREUS-USP: Núcleo de Economia Regional e Urbana da Universidade de São Paulo

PAC: Plano de Aceleração do Crescimento

PALOP: Países Africanos de Língua Oficial Portuguesa

PBL: Índice Puro de Ligação para Trás

PBLN: Índice Puro Normalizado para Trás

PDE: Plano de Desenvolvimento da Educação

PFL: Índice Puro de Ligação para Frente

PFLN: Índice Puro Normalizado para Frente

PIB: Produto Interno Bruto

PNAD: Pesquisa Nacional por Amostra de Domicílios

PO: Pessoal Ocupado

PTL: Índice Puro Total das Ligações

PTLN: Índice Puro Normalizado Total 
R\$: Real (moeda)

REUNI: Programa de Apoio a Planos de Reestruturação e Expansão das Universidades Federais

SIAFI: Sistema Integrado de Administração Financeira

SIMEC: Painel de Controle do Ministério da Educação

UFABC: Fundação Universidade Federal do ABC

UFAC: Universidade Federal do Acre

UFAL: Universidade Federal de Alagoas

UFAM: Universidade Federal do Amazonas

UFBA: Universidade Federal da Bahia

UFCE: Universidade Federal do Ceará

UFCG: Universidade Federal de Campina Grande

UFCSPA: Fundação Universidade Federal de Ciências da Saúde de Porto Alegre

UFERSA: Universidade Federal Rural do Semi-Árido

UFES: Universidade Federal do Espírito Santo

UFF: Universidade Federal Fluminense

UFFS: Universidade Federal da Fronteira Sul

UFGD: Fundação Universidade Federal da Grande Dourados

UFGO: Universidade Federal de Goiás

UFJF: Universidade Federal de Juiz de Fora

UFLA: Universidade Federal de Lavras

UFMA: Universidade Federal do Maranhão

UFMG: Universidade Federal de Minas Gerais

UFMS: Universidade Federal de Mato Grosso do Sul

UFMT: Universidade Federal de Mato Grosso

UFOP: Universidade Federal de Ouro Preto

UFOPA: Universidade Federal do Oeste do Pará

UFPA: Universidade Federal do Pará

UFPB: Universidade Federal da Paraíba

UFPE: Universidade Federal de Pernambuco

UFPEL: Universidade Federal de Pelotas

UFPI: Universidade Federal do Piauí

UFPR: Universidade Federal do Paraná

UFRA: Universidade Federal Rural da Amazônia

UFRB: Universidade Federal do Recôncavo da Bahia

UFRGS: Universidade Federal do Rio Grande do Sul

UFRJ: Universidade Federal do Rio de Janeiro

UFRN: Universidade Federal do Rio Grande do Norte

UFRPE: Universidade Federal Rural de Pernambuco

UFRR: Universidade Federal de Roraima

UFRRJ: Universidade Federal Rural do Rio de Janeiro

UFS: Universidade Federal de Sergipe

UFSC: Universidade Federal de Santa Catarina

UFSCAR: Universidade Federal de São Carlos

UFSJ: Universidade Federal de São João Del Rei

UFSM: Universidade Federal de Santa Maria

UFT: Fundação Universidade Federal do Tocantins

UFTM: Universidade Federal do Triângulo Mineiro

UFU: Universidade Federal de Uberlândia

UFV: Universidade Federal de Viçosa 
UFVJM: Universidade Federal dos Vales do Jequitinhonha e Mucuri

UNB: Universidade de Brasília

UNESP: Universidade Estadual Paulista Júlio Mesquita Filho

UNICAMP: Universidade Estadual de Campinas

UNIFAL: Universidade Federal de Alfenas

UNIFAP: Universidade Federal do Amapá

UNIFEI: Universidade Federal de Itajubá

UNIFESP: Universidade Federal de São Paulo

UNILA: Universidade Federal da Integração Latino Americana

UNILAB: Universidade da Integração Internacional da Lusofonia Afro-Brasileira

UNIPAMPA: Fundação Universidade Federal do Pampa

UNIR: Fundação Universidade Federal de Rondônia

UNIRIO: Universidade Federal do Estado do Rio de Janeiro

UNIVASF: Fundação Universidade Federal do Vale do São Francisco

URV: Unidade Real de Valor

US\$: Dólar (moeda)

USP: Universidade de São Paulo

UTFPR: Universidade Tecnológica Federal do Paraná

VA: Valor Adicionado

VBP: Valor Bruto da Produção 


\section{LISTA DE TABELAS}

Tabela 1.1 - Acesso ao Ensino Superior

Tabela 2.1 - Presença de Universidades Federais por Estado e Região...................................33

Tabela 2.2 - Gastos Totais do Período 2000-2010 com Universidades Federais por Estado ..35 Tabela 2.3 - Variação dos Gastos Anuais 2000-2010 com Universidades Federais por Estado

Tabela 2.4 - Efeitos da Expansão sobre o Setor Educação Pública no Período 2004-2010 ...59

Tabela 2.5 - Efeitos da Expansão das Universidades Novas no Período 2004-2010 . .69

Tabela 2.6 - Maiores Efeitos Absolutos Microrregionais por Universidade da Expansão no

Período 2004-2010

Tabela 2.7 - Maiores Efeitos Absolutos Microrregionais Conjuntos da Expansão no Período 2004-2010

Tabela 2.8 - Choques e Impactos Econômicos Anuais da Expansão no Período 2004-2010.. 85 Tabela 3.1 - Evolução do Número de Não-Tratados na Construção do Grupo de Controle .. 129 Tabela 3.2 - Modelo Probit de Escolha do Tratamento. 131

Tabela 3.3 - Efeito da Expansão de Campi Universitários Federais sobre Renda Per Capita

Tabela 3.4 - Efeito da Expansão de Campi Universitários Federais com Interação pelo Tamanho Populacional do Município .

Tabela 3.5 - Número de Municípios Tratados e Controles nos Subgrupos Amostrais.......... 139 Tabela 3.6 - Efeito da Expansão de Campi Universitários Federais sobre Renda Per Capita

Por Grupo

Tabela 3.7 - Estimador da Análise de Sensibilidade $(\Gamma)$ para o Efeito do Tratamento sobre a

Renda nos Municípios Tratados

Tabela 4.1 - Evolução do Número de Não-Tratados na Construção do Grupo de Controle .. 162

Tabela 4.2 - Modelo Probit de Escolha do Tratamento.

Tabela 4.3 - Efeito da Expansão de Campi Universitários Federais sobre Reeleição Política em 2008

Tabela 4.4 - Efeito da Expansão de Campi Universitários Federais com Interação pelo

Tamanho Populacional do Município

Tabela 4.5 - Número de Municípios Tratados e Controles nos Subgrupos Amostrais para

Reeleição

Tabela 4.6 - Efeito da Expansão de Campi Universitários Federais sobre Reeleição Política em 2008 por Grupo.

Tabela 4.7 - Estimador da Análise de Sensibilidade ( $Г)$ para o Efeito do Tratamento sobre a

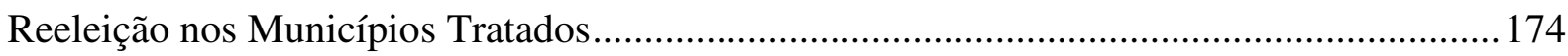

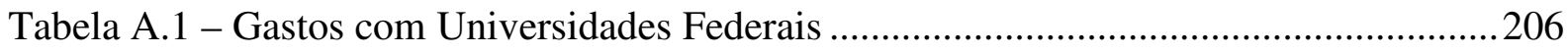

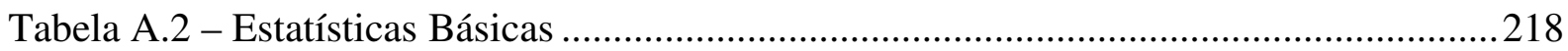

Tabela A.3 - Modelo Probit de Escolha do Tratamento $(\mathrm{R}=0,1)$........................................220

Tabela A.4 - Evolução do Número de Não-Tratados na Construção do Grupo de Controle $(\mathrm{P}=0,05)$ 
Tabela A.5 - Efeito da Expansão de Campi Universitários Federais sobre Renda per Capita $(\mathrm{P}=0,05)$ 221

Tabela A.6 - Efeito da Expansão de Campi Universitários Federais com Interação pelo Tamanho Populacional do Município ( $\mathrm{P}=0,05)$.

Tabela A.7 - Número de Municípios Tratados e Controles nos Subgrupos Amostrais $(\mathrm{P}=0,05)$

Tabela A.8 - Efeito da Expansão de Campi Universitários Federais sobre Renda per Capita por Grupo $(\mathrm{P}=0,05)$

Tabela A.9 - Estimador da Análise de Sensibilidade $(\Gamma)$ para o Efeito do Tratamento sobre a

Renda nos Municípios Tratados $(\mathrm{P}=0,05)$.

Tabela A.10 - Evolução do Número de Não-Tratados na Construção do Grupo de Controle $(\mathrm{P}=0,2)$

Tabela A.11 - Efeito da Expansão de Campi Universitários Federais sobre Renda per Capita $(\mathrm{P}=0,2)$

Tabela A.12 - Efeito da Expansão de Campi Universitários Federais com Interação pelo Tamanho Populacional do Município $(\mathrm{P}=0,2)$. 225

Tabela A.13 - Número de Municípios Tratados e Controles nos Subgrupos Amostrais $(\mathrm{P}=0,2)$

Tabela A.14 - Efeito da Expansão de Campi Universitários Federais sobre Renda per Capita por Grupo $(\mathrm{P}=0,2)$ 226

Tabela A.15 - Estimador da Análise de Sensibilidade $(\Gamma)$ para o Efeito do Tratamento sobre a Renda nos Municípios Tratados $(\mathrm{P}=0,2)$. 226 Tabela A.16 - Modelo Probit de Escolha do Tratamento (R=0,1) Controlando por Número de Rodovias. 227

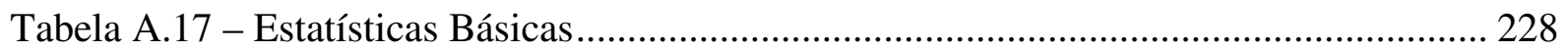

Tabela A.18 - Modelo Probit de Escolha do Tratamento $(\mathrm{R}=0,1)$....................................... 228

Tabela A.19 - Evolução do Número de Não-Tratados na Construção do Grupo de Controle $(\mathrm{P}=0,05)$

Tabela A.20 - Efeito da Expansão de Campi Universitários Federais sobre Reeleição Política em $2008(\mathrm{P}=0,05)$. 229

Tabela A.21 - Efeito da Expansão de Campi Universitários Federais com Interação pelo

Tamanho Populacional do Município $(\mathrm{P}=0,05)$.

Tabela A.22 - Número de Municípios Tratados e Controles nos Subgrupos Amostrais para

Reeleição $(\mathrm{P}=0,05)$.

Tabela A.23 - Efeito da Expansão de Campi Universitários Federais sobre Reeleição Política em 2008 por Grupo $(\mathrm{P}=0,05)$ 231

Tabela A.24 - Estimador da Análise de Sensibilidade $(\Gamma)$ para o Efeito do Tratamento sobre a Reeleição nos Municípios Tratados ( $\mathrm{P}=0,05)$. 231

Tabela A.25 - Evolução do Número de Não-Tratados na Construção do Grupo de Controle $(\mathrm{P}=0,2)$ 232

Tabela A.26 - Efeito da Expansão de Campi Universitários Federais sobre Reeleição Política em $2008(\mathrm{P}=0,2)$. 232

Tabela A.27 - Efeito da Expansão de Campi Universitários Federais com Interação pelo

Tamanho Populacional do Município $(\mathrm{P}=0,2)$. 
Tabela A.28 - Número de Municípios Tratados e Controles nos Subgrupos Amostrais para Reeleição $(\mathrm{P}=0,2)$ 233 Tabela A.29 - Efeito da Expansão de Campi Universitários Federais sobre Reeleição Política em 2008 por Grupo $(\mathrm{P}=0,2)$...... 234 Tabela A.30 - Estimador da Análise de Sensibilidade $(\Gamma)$ para o Efeito do Tratamento sobre a Reeleição nos Municípios Tratados $(\mathrm{P}=0,2)$ 234 


\section{LISTA DE GRÁFICOS E FIGURAS}

Gráfico 1.1 - Número de Universidades Federais

Gráfico 2.1 - Evolução do Número de Universidades Federais por Ano de Credenciamento 32 Figura 2.1 - Microrregiões com Universidades Federais no ano de 2010

Gráfico 2.2 - Evolução de Gastos e Número de Matrículas Anuais em Universidades Federais no Período 2000-2010

Gráfico 2.3 - Efeitos Regionais da Expansão sobre Valor Bruto da Produção no Período

2004-2010.

Gráfico 2.4 - Efeitos Regionais da Expansão sobre Valor Adicionado no Período 2004-2010

Gráfico 2.5 - Efeitos Regionais da Expansão sobre Pessoal Ocupado no Período 2004-201054 Gráfico 2.6 - Efeitos Estaduais da Expansão sobre Valor Bruto da Produção no Período 20042010

Gráfico 2.7 - Efeitos Estaduais da Expansão sobre Valor Adicionado no Período 2004-2010

Gráfico 2.8 - Efeitos Estaduais da Expansão sobre Pessoal Ocupado no Período 2004-2010 57 Gráfico 2.9 - Efeitos Setoriais da Expansão sobre Valor Bruto da Produção no Período 20042010

Gráfico 2.10 - Efeitos Setoriais da Expansão sobre Valor Adicionado no Período 2004-2010

Gráfico 2.11 - Efeitos Setoriais da Expansão sobre Pessoal Ocupado no Período 2004-201063

Gráfico 2.12 - Efeitos da Expansão sobre Valor Bruto da Produção por Universidade no

Período 2004-2010

Gráfico 2.13 - Efeitos da Expansão sobre Valor Adicionado por Universidade no Período

2004-2010. 66

Gráfico 2.14 - Efeitos da Expansão sobre Pessoal Ocupado por Universidade no Período 2004-2010.

Gráfico 2.15 - Efeitos da Expansão das Universidades Novas sobre Valor Bruto da Produção no Período 2004-2010

Gráfico 2.16 - Efeitos da Expansão das Universidades Novas sobre Valor Adicionado no Período 2004-2010

Gráfico 2.17 - Efeitos da Expansão das Universidades Novas sobre Pessoal Ocupado no

Período 2004-2010

Gráfico 2.18 - Efeitos da Expansão sobre Valor Bruto da Produção por Universidade para as

Microrregiões com Maiores Efeitos Relativos sobre PIB no Período 2004-2010 .73

Gráfico 2.19 - Efeitos da Expansão sobre Valor Adicionado por Universidade para as

Microrregiões com Maiores Efeitos Relativos sobre PIB no Período 2004-2010

Gráfico 2.20 - Efeitos da Expansão sobre Pessoal Ocupado por Universidade para as Microrregiões com Maiores Efeitos Relativos sobre PIB no Período 2004-2010

Gráfico 2.21 - Efeitos da Expansão sobre Valor Bruto da Produção para as Microrregiões com Maiores Efeitos Relativos sobre PIB no Período 2004-2010 
Gráfico 2.22 - Efeitos da Expansão sobre Valor Adicionado para as Microrregiões com Maiores Efeitos Relativos sobre PIB no Período 2004-2010

Gráfico 2.23 - Efeitos da Expansão sobre Pessoal Ocupado para as Microrregiões com Maiores Efeitos Relativos sobre PIB no Período 2004-2010

Figura 2.2 - Distribuição Territorial dos Efeitos da Expansão sobre Valor Bruto da Produção no Período 2004-2010.

Figura 2.3 - Distribuição Territorial dos Efeitos da Expansão sobre Valor Adicionado no

Período 2004-2010.

Figura 2.4 - Distribuição Territorial dos Efeitos da Expansão sobre Pessoal Ocupado no

Período 2004-2010

Gráfico 2.24 - Evolução Anual dos Choques e Impactos Econômicos por Região Geográfica no Período 2004-2010

Gráfico 2.25 - Multiplicadores de Produção do Tipo II da Economia Brasileira (2004 e 2009)

Gráfico 2.26 - Multiplicadores de Emprego da Economia Brasileira (2004 e 2009)............. 89

Gráfico 2.27 - Geradores de Emprego da Economia Brasileira (2004 e 2009)...................... 90

Gráfico 2.28 - Índices de Ligação de Hirschman-Rasmussen para Trás e para Frente (2004) 91

Gráfico 2.29 - Índices de Ligação de Hirschman-Rasmussen para Trás e para Frente (2009) 92

Gráfico 2.30 - Índices Puros de Ligação Normalizados para Trás (2004 e 2009) .................. 94

Gráfico 2.31 - Índices Puros de Ligação Normalizados para Frente (2004 e 2009) ............... 95

Gráfico 2.32 - Índices Puros de Ligação Normalizados Totais (2004 e 2009) ....................... 96

Gráfico 2.33 - Razão dos Índices Puros de Ligação Normalizados Totais (2009/2004) ........ 97

Gráfico 3.1 - Distribuições de Escores de Propensão Antes do Pareamento ......................... 134

Gráfico 3.2 - Distribuições de Escores de propensão Após o Pareamento ............................ 134

Gráfico 3.3 - Distribuição do Efeito do Tratamento sobre o Escore de Propensão ............... 137

Gráfico 4.1 - Distribuições de Escores de Propensão Antes do Pareamento ......................... 166

Gráfico 4.2 - Distribuições de Escores de Propensão Após o Pareamento .............................. 166

Gráfico 4.3 - Distribuição do Efeito do Tratamento sobre o Escore de Propensão .............. 169

Gráfico A.1 - Efeitos Percentuais Regionais da Expansão sobre Valor Bruto da Produção no

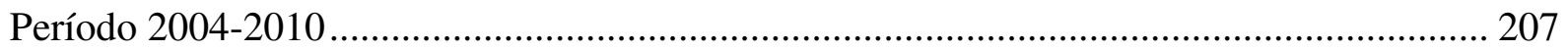

Gráfico A.2 - Efeitos Percentuais Regionais da Expansão sobre Valor Adicionado no Período

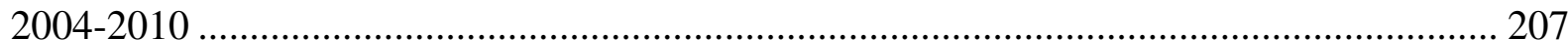

Gráfico A.3 - Efeitos Percentuais da Expansão Regionais sobre Pessoal Ocupado no Período

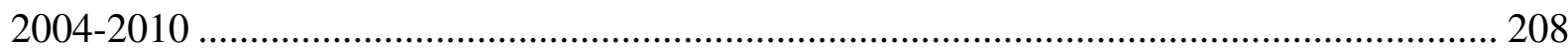

Gráfico A.4 - Efeitos Percentuais Estaduais da Expansão sobre Valor Bruto da Produção no

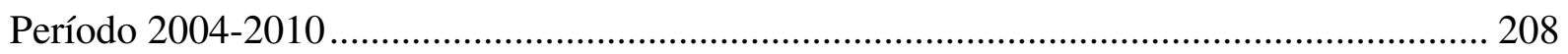

Gráfico A.5 - Efeitos Percentuais Estaduais da Expansão sobre Valor Adicionado no Período

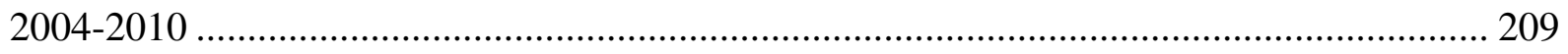

Gráfico A.6 - Efeitos Percentuais Estaduais da Expansão sobre Pessoal Ocupado no Período

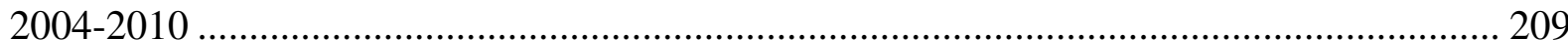

Gráfico A.7 - Efeitos Percentuais Setoriais da Expansão sobre Valor Bruto da Produção no

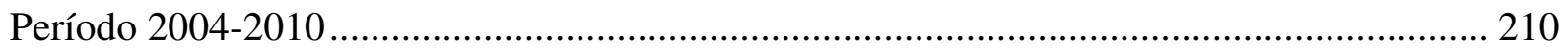

Gráfico A.8 - Efeitos Percentuais Setoriais da Expansão sobre Valor Adicionado no Período 
Gráfico A.9 - Efeitos Percentuais Setoriais da Expansão sobre Pessoal Ocupado no Período 2004-2010

Gráfico A.10 - Efeitos Percentuais da Expansão sobre Valor Bruto da Produção por Universidade no Período 2004-2010.

Gráfico A.11 - Efeitos Percentuais da Expansão sobre Valor Adicionado por Universidade no Período 2004-2010

Gráfico A.12 - Efeitos Percentuais da Expansão sobre Pessoal Ocupado por Universidade no Período 2004-2010 212

Gráfico A.13 - Efeitos Percentuais da Expansão das Universidades Novas sobre Valor Bruto da Produção no Período 2004-2010.

Gráfico A.14 - Efeitos Percentuais da Expansão das Universidades Novas sobre Valor

Adicionado no Período 2004-2010.

Gráfico A.15 - Efeitos Percentuais da Expansão das Universidades Novas sobre Pessoal Ocupado no Período 2004-2010.

Gráfico A.16 - Efeitos Percentuais da Expansão sobre Valor Bruto da Produção por Universidade para as Microrregiões com Maiores Efeitos Relativos sobre PIB no Período 2004-2010.

Gráfico A.17 - Efeitos Percentuais da Expansão sobre Valor Adicionado por Universidade para as Microrregiões com Maiores Efeitos Relativos sobre PIB no Período 2004-2010 .....215 Gráfico A.18 - Efeitos Percentuais da Expansão sobre Pessoal Ocupado por Universidade para as Microrregiões com Maiores Efeitos Relativos sobre PIB no Período 2004-2010 .....215 Gráfico A.19 - Efeitos Percentuais da Expansão sobre Valor Bruto da Produção para as Microrregiões com Maiores Efeitos Relativos sobre PIB no Período 2004-2010

Gráfico A.20 - Efeitos Percentuais da Expansão sobre Valor Adicionado para as Microrregiões com Maiores Efeitos Relativos sobre PIB no Período 2004-2010 216

Gráfico A.21 - Efeitos Percentuais da Expansão sobre Pessoal Ocupado para as Microrregiões com Maiores Efeitos Relativos sobre PIB no Período 2004-2010 


\section{1- INTRODUÇÃO}

A busca pela ampliação da participação da população no ensino superior vem cada vez mais se destacando nas discussões sobre educação no Brasil. O reconhecimento da importância estratégica da educação no processo de crescimento socioeconômico fez com que no Brasil venha ocorrendo um forte aumento no investimento em educação, desde o nível fundamental ao superior. Na tentativa de minimizar o déficit educacional do Brasil, tem-se buscado expandir o aprendizado aos estudantes, através da ampliação do acesso à educação.

Esta necessidade de expansão da Educação Superior no Brasil é evidenciada quando se analisa o acesso dos jovens entre 18 e 24 anos ao ensino superior. Enquanto que no País tal acesso é de $19 \%^{1}$, em alguns locais do mundo chega a ser de $70 \%$, como pode ser observado na tabela abaixo ${ }^{2}$.

\section{Tabela 1.1 - Acesso ao Ensino Superior}

\begin{tabular}{lr}
\hline Local & Acesso \\
\hline Brasil & $19 \%$ \\
Argentina & $35 \%$ \\
Cuba & $50 \%$ \\
Coréia do Sul & $60 \%$ \\
EUA & $60 \%$ \\
Canadá & $62 \%$ \\
Escandinávia & $70 \%$ \\
\hline
\end{tabular}

Fonte: Elaboração própria com base em dados da Associação Nacional dos Dirigentes das Instituições Federais de Ensino Superior (Andifes)

\footnotetext{
${ }^{1}$ Fonte: Censo Demográfico 2010 do IBGE. Informação sobre o percentual de pessoas entre 18 e 24 anos com pelo menos nível superior completo ou cursando no mínimo o nível superior.

${ }^{2}$ Comparativos entre países sobre o acesso ao ensino superior da população entre 18 e 24 anos de idade precisam ser analisados com certa ressalva, pois muitos países do mundo apresentam o ensino profissional-técnico como parte integrante do ensino superior. Entretanto, esta tabela é apresentada, pois tais dados sobre acesso são um dos principais pontos utilizados na justificativa com relação à expansão dos gastos com o ensino superior público federal no Brasil.
} 
A fim de expandir não apenas o número de cursos de nível superior, mas também a estrutura de ensino, desde 1998, o Brasil vem implementando uma série de medidas, buscando, com isso, promover o crescimento do ensino superior público.

Neste processo de expansão do ensino superior, observam-se três fases. Na primeira fase, entre os anos de 1998 e 2002, houve a expansão do número de vagas e cursos de nível superior nas sedes das universidades federais existentes. Na fase seguinte, que se estendeu de 2003 a 2006, ampliou-se a oferta de cursos e vagas através da expansão em direção ao interior de diversos estados brasileiros, buscando atender à forte demanda das respectivas regiões. Podem-se destacar nesta fase a criação de novas universidades federais e a criação e consolidação dos campi universitários das instituições já existentes. Por fim, iniciou-se a terceira fase da expansão do ensino superior, com o Decreto $\mathrm{n}^{\circ}$ 6.096, de 24 de abril de 2007, que instituiu o Programa de Apoio a Planos de Reestruturação e Expansão das Universidades Federais (REUNI). Tal programa é uma das ações integrantes do Plano de Desenvolvimento da Educação (PDE) em reconhecimento ao papel estratégico das universidades federais para o desenvolvimento econômico e social, e tem sua conclusão prevista para 2012.

Dentre os principais objetivos do REUNI estão:

- Garantir às universidades as condições necessárias para a ampliação do acesso e permanência na educação superior;

- Assegurar a qualidade por meio de inovações acadêmicas;

- Promover a articulação entre os diferentes níveis de ensino, integrando a graduação, a pósgraduação, a educação básica e a educação profissional e tecnológica;

- Otimizar o aproveitamento dos recursos humanos e da infraestrutura das instituições federais de educação superior.

O Programa REUNI também elencou como principais metas: a elevação gradual da taxa de conclusão média dos cursos de graduação presenciais para 90\%; elevação gradual da relação aluno/professor para 18 alunos por professor; aumento mínimo de $20 \%$ nas matrículas de graduação; e o prazo de cinco anos, a partir de 2007, para o cumprimento das metas. 
Considerando os últimos anos, observa-se que foram criadas 17 universidades federais $^{3}$ (com base no ano de criação de cada universidade pela legislação federal), como se pode acompanhar no gráfico a seguir.

\section{Gráfico 1.1 - Número de Universidades Federais}

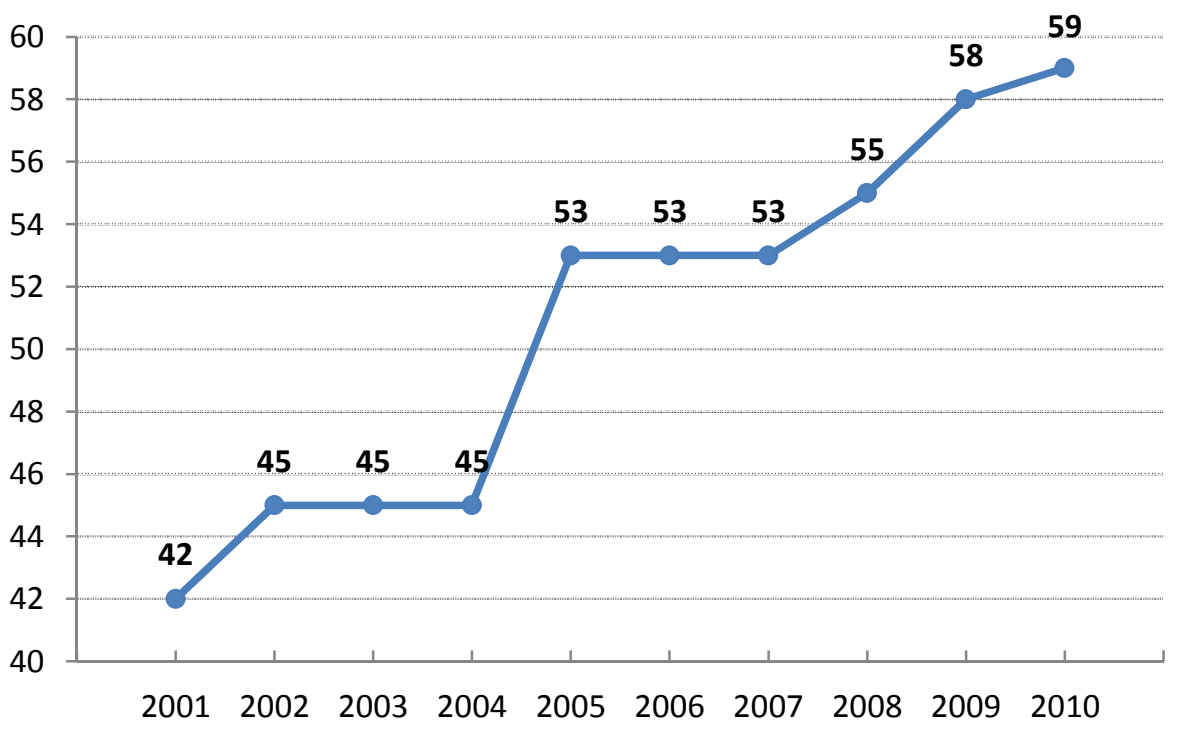

Obs.: Utiliza-se o ano de criação da universidade pela legislação federal. Fonte: Elaboração própria com base em dados do Ministério da Educação (MEC)

Entretanto é importante frisar que sete destas universidades já existiam como faculdades. Assim, no período entre 2001 e 2010 foram efetivamente criadas dez novas universidades federais, conforme apresentado a seguir.

As instituições já existentes que foram transformadas em universidades são:

- Universidade Federal Rural do Semi-Árido - UFERSA (RN);

- Universidade Federal Rural da Amazônia - UFRA (AM)

- Universidade Federal do Triângulo Mineiro - UFTM (MG);

- Universidade Tecnológica Federal do Paraná - UTFPR (PR);

- Universidade Federal de Alfenas - UNIFAL (MG);

- Universidade Federal dos Vales do Jequitinhonha e Mucuri - UFVJM (MG);

- Universidade Federal de Ciências da Saúde de Porto Alegre - UFCSPA (RS).

\footnotetext{
${ }^{3}$ No Apêndice A, apresenta-se o histórico destas universidades.
} 
Já as novas universidades efetivamente são:

- Universidade Federal da Grande Dourados - UFGD (MS);

- Universidade Federal do Recôncavo da Bahia - UFRB (BA);

- Universidade Federal do ABC - UFABC (SP);

- Universidade Federal do Pampa - UNIPAMPA (RS);

- Universidade Federal da Fronteira Sul - UFFS (SC);

- Universidade Federal do Oeste do Pará - UFOPA (PA);

- Universidade Federal de Campina Grande - UFCG (PB);

- Universidade Federal do Vale do São Francisco - UNIVASF (PE);

- Universidade Federal da Integração Latino-Americana - UNILA (PR);

- Universidade da Integração Internacional Lusofonia Afro-Brasileira - UNILAB (CE).

Vale ressaltar que o fato destas instituições serem consideradas efetivamente novas não significa que elas não tenham proveniência. Algumas foram criadas a partir de cursos já oferecidos em determinados municípios por universidade federal já existente. Por exemplo, a Universidade Federal de Campina Grande (UFCG) é proveniente da Universidade Federal da Paraíba (UFPB) que já oferecia cursos na cidade de Campina Grande - PB antes da implantação da UFCG em 2002. Contudo, não havia campus universitário e a UFCG, como instituição, não existia antes de 2002.

Além disso, é importante mencionar a Universidade Federal do Tocantins (UFT), que foi criada por lei federal e credenciada no Ministério da Educação (MEC) em 2000, não pertencendo inicialmente à lista de universidades efetivamente novas no período 2001-2010. Entretanto, esta universidade somente iniciou suas atividades em maio de $2003 .^{4}$

Neste processo de expansão do ensino superior, os efeitos das medidas adotadas podem ser percebidos, inicialmente, pelos expressivos números do programa de expansão para o interior das universidades federais, e em seguida pelos resultados do Programa REUNI. Além disso, cabe destacar a oportunidade que a reestruturação acadêmica e as inovações propostas pelas universidades podem significar para a educação superior pública do país.

\footnotetext{
${ }^{4}$ Para efeito de mensuração dos impactos estimados neste trabalho, a UFT é considerada como uma nova universidade do período 2001-2010, ainda que seu credenciamento no MEC tenha ocorrido em 2000 e sua criação por lei federal seja datada de 23 de outubro de 2000.
} 
Este trabalho se pauta neste cenário apresentado acima para estimar o impacto regional de curto prazo desta expansão universitária federal. Entretanto, antes de detalhar os objetivos deste trabalho, é importante contextualizar tal expansão.

\section{1- O Contexto da Expansão Universitária}

Esta expansão universitária descrita até aqui está inserida não somente num contexto econômico, como será abordado neste trabalho, mas também no contexto de desenvolvimento do ensino superior. A compreensão ampla deste cenário é fundamental para o estudo da expansão das universidades federais e análise de seu impacto.

A literatura de Educação sobre o Ensino Superior no Brasil apresenta um ponto de vista diferente do que será tratado neste trabalho sobre a expansão da rede de universidades federais no Brasil, uma vez que destaca o efeito desta expansão sobre o sistema universitário. É importante contextualizar de forma sucinta alguns pontos destacados desta literatura sobre a questão.

\subsection{1- A Expansão}

Como já mencionado, o Brasil vem implementando uma série de medidas desde 1998 visando expandir não apenas o número de cursos e vagas de nível superior, mas também a estrutura de ensino, buscando, com isso, promover o crescimento do ensino superior público.

Este crescimento vem ocorrendo num ambiente de inexistência de uma norma legal de ensino superior consolidada. Lima, Azevedo e Catani (2008) destaca que o que existe é um conjunto de leis (entre elas, a Lei de Diretrizes e Bases da Educação Nacional - LDB), medidas provisórias e resoluções ministeriais e do Conselho Nacional de Educação (CNE) que, pouco a pouco, vem delineando o modelo universitário. 
Neste contexto, a expansão recente do sistema de universidades federais foi iniciada em 1998 com o aumento do número de vagas e cursos nas sedes das universidades existentes. A partir de 2003, este processo foi intensificado com a expansão da oferta de cursos e vagas em direção ao interior dos estados brasileiros, ocorrendo a implantação de novos campi e universidades. Em 2007, foi proposto o Programa de Apoio a Planos de Reestruturação e Expansão das Universidades Federais (REUNI) com o Decreto no 6.096/2007, contextualizado no Plano de Desenvolvimento da Educação (PDE), que é oficializado como a política educacional geral de governo, e parte integrante do Plano de Aceleração do Crescimento (PAC), lançado no início do mesmo ano. Lima, Azevedo e Catani (2008) lembra que de forma semelhante ao conceito de contrato de gestão, instrumento inspirado nas propostas do Ministério da Administração Federal e da Reforma do Estado (MARE), da época do Ministro Bresser Pereira, o REUNI condiciona o financiamento ao cumprimento de metas previamente acordadas.

É importante acrescentar que esta expansão da rede de universidades federais surge não apenas como parte das reformas gerencialistas do Estado, mas também como resposta à forte expansão do ensino superior privado que vem ocorrendo deste os anos 1990. Léda e Mancebo (2009) afirma que, nas últimas décadas, no Brasil, têm-se aprofundado a expansão do setor privado, destacando também que a legislação atual pouco limita este movimento. Chaves e Araújo (2011) apresenta o cenário de expansão do setor privado, com base no Censo da Educação Superior, destacando o acentuado crescimento deste frente ao setor público. Das 922 Instituições de Ensino Superior (IES) existentes no Brasil em 1996, 211 eram públicas $(22,9 \%)$ e 711 eram privadas $(77,1 \%)$. No ano de 2009, eram 2.314 IES no país, sendo 245 (10,6\%) públicas e $2.069(89,4 \%)$ privadas. Portanto, o crescimento das IES no período foi de $151 \%$, sendo que as públicas cresceram $16,1 \%$ e as privadas $191 \%$.

\subsection{2- A Crítica}

$\mathrm{Na}$ literatura de Educação, a expansão do sistema de universidades federais, em especial o REUNI, vem recebendo diversas críticas, podendo-se destacar a expansão da oferta de vagas e cursos, sem o devido aporte financeiro necessário, e o foco quantitativo, sem comprometimento com a qualidade no sistema. 
Há evidências da visão da existência de certa capacidade ociosa no sistema de universidades federais. O artigo $1^{\circ}$ do Decreto 6.096/2007 diz: "Fica instituído o Programa de Apoio a Planos de Reestruturação e Expansão das Universidades Federais - REUNI, com o objetivo de criar condições para a ampliação do acesso e permanência na educação superior, no nível de graduação, pelo melhor aproveitamento da estrutura física e de recursos humanos existentes nas universidades federais.” Percebe-se já na introdução deste decreto a ideia de existência de capacidade ociosa no sistema, ao se mencionar o termo "melhor aproveitamento". Sabe-se que realmente há esta ociosidade na estrutura física no período noturno em alguns cursos de determinadas instituições. Entretanto, o uso de toda esta eventual capacidade ociosa levaria à necessidade de contratação de novos funcionários, incluindo professores. Com isto, pode-se entender o mencionado termo para uso sobre a estrutura física, mas é difícil a inferência de conclusão a respeito do aproveitamento dos recursos humanos. Até onde se pôde pesquisar para a elaboração deste trabalho, a literatura caminha para a vertente de sobrecarga dos recursos humanos (funcionários, em especial professores), como se pode constatar em Mancebo (2008).

Léda e Mancebo (2009) defende que tal expansão do acesso à educação superior não se deveria pautar pela edição de medidas legais baseadas num imediatismo pragmático, meramente quantitativo, em ondas de expansão feitas às pressas e sem garantias para a qualidade do ensino.

Franco et al (2010) destaca também o forte comprometimento da questão da indissociabilidade entre ensino-pesquisa-extensão, definida tanto no Artigo 207 da Constituição Federal de 1988 quanto no Artigo 52 da LDB. O foco prioritário no ensino, com pouco investimento no nível científico e técnico, pode levar ao sucateamento e à precarização das universidades federais no Brasil (Léda e Mancebo, 2009).

Chaves e Araújo (2011) apresenta alguns indicadores globais utilizados pela Universidade Federal do Pará (UFPA) com relação às metas pactuadas no REUNI. No indicador de vagas anuais, por exemplo, percebe-se uma previsão de ampliação significativa, progredindo de 5.277, no ano de 2007, para 8.625, em 2012, o que representa um acréscimo de mais de $60 \%$ na oferta de vagas no período. Já o número de professores equivalentes evolui de 2.871,00, em 2007, para 3.685,15, em 2012, correspondendo a um aumento aproximado de $30 \%$. Desta forma, infere-se que a UFPA vem expandindo as matrículas em mais de $60 \%$, e apenas, aproximadamente em $30 \%$ o seu corpo docente. Isto é apresentado como forte 
indicativo da intensificação do trabalho docente, considerando o limitado quadro de professores, em determinados cursos, particularmente os ofertados nos campi do interior do estado do Pará.

A literatura de Educação destaca a carência de dados financeiros disponíveis confiáveis para o período da expansão do sistema universitário, comprometendo a análise quantitativa da situação nacional. Assim, o que mais se observa nesta literatura é a análise de casos pontuais em que a própria universidade federal disponibiliza tais informações aos pesquisadores, como se pode observar no caso da UFPA (Chaves e Araújo, 2011). Tal questão será abordada no próximo item deste capítulo.

Para Lugão et al (2010), a crítica principal ao REUNI se encontra na precarização da formação profissional e do trabalho docente. Como muitos autores já mencionados, estes autores também defendem que a elevação do número de alunos por turma e a criação de cursos de curta duração são uma forma de acelerar a formação e desvinculá-la da pesquisa, transformando as universidades públicas em meras universidades de ensino. Além disso, alertam que a expansão das vagas desvinculadas sem uma infraestrutura adequada pode superlotar as salas de aula e deteriorar a qualidade do ensino.

Por fim, vale destacar que na intenção o Decreto 6.096/2007 busca uma qualidade acadêmica através de: flexibilidade curricular nos cursos de graduação; oferta de formação e apoio pedagógico aos docentes (utilização de práticas pedagógicas modernas e o uso de tecnologias de apoio à aprendizagem); disponibilidade de mecanismos de inclusão social a fim de garantir igualdade de oportunidades de acesso e permanência na universidade pública a todos os cidadãos. Entretanto, na prática, o que se observa, sendo relatado em diversos artigos aqui mencionados, é o foco em metas quantitativas. Araújo e Pinheiro (2010) alerta que a dificuldade de medição de alguns objetivos pode conduzir as avaliações do MEC para aspectos estritamente quantitativos (exemplo: redução da taxa de evasão, aumento das matrículas, redução das vagas ociosas, relação aluno/professor, taxa média de aprovação dos cursos) em detrimento de metas qualitativas. 


\section{2- Revisão da Literatura de Impacto de Universidades}

O objetivo deste trabalho segue Elliot et al. (1998), que defende que o objetivo de um estudo de impacto é mensurar o aumento na atividade regional atribuível à presença de uma universidade.

Para tanto, é importante inicialmente apresentar as potenciais influências da universidade na economia regional no curto e longo prazo. No curto prazo, tem-se o que na literatura é chamado "relações para trás" (Backward linkages), em que se destacam impactos devido a gastos como: despesas e investimentos diretos da universidade (implantação e manutenção de estabelecimentos); salários dos professores e funcionários universitários e respectivos impactos diretos sobre a demanda de bens e serviços; e os gastos dos estudantes (provenientes ou não da região). Já no longo prazo, que são evidenciadas as "relações para frente" (Forward linkages), há também efeitos de conhecimento, referentes basicamente ao lado da oferta, ou seja, referentes à expansão do capital humano (aumento de escolaridade, qualificação da mão-de-obra, criação de novas empresas), crescimento da área de pesquisa, e atração de capital e de mão-de-obra mais qualificada para a região.

Assim, como se pretende estudar o impacto da expansão recente das universidades federais no País, o modelo utilizado neste trabalho consequentemente trabalhará com os impactos de curto prazo ("relações para trás") do lado da demanda, pois são os únicos possíveis de mensuração no período recente.

Os impactos de universidades mencionados anteriormente são classificados por Stokes e Coomes (1998) em impactos sobre gastos locais e sobre conhecimento. Argumenta-se que, durante os anos iniciais, os impactos sobre gastos são maiores do que os sobre conhecimento. Todavia, ao longo do tempo os benefícios do conhecimento sobre a renda dos graduados vão aumentando até que excedem o impacto sobre os gastos. Empiricamente há evidências que apontam que universidades localizadas em pequenas comunidades, que atraem estudantes de fora, geram efeitos relevantes sobre os gastos, mas têm impactos pequenos sobre o conhecimento. Já as localizadas em grandes comunidades, com economias mais desenvolvidas, geram importantes efeitos sobre o conhecimento, mas mínimos efeitos sobre os gastos. 
Goddard e Kempton (2011) apresentam uma detalhada descrição dos diversos impactos de uma universidade. Siegfried, Sanderson e McHenry (2007) descreve abordagens metodológicas e problemas comuns aos estudos sobre o impacto econômico de universidades. Estes estudos apontam para diversos problemas na mensuração dos benefícios locais de uma universidade. Especificamente, são mencionados problemas relativos à especificação do contrafactual, à definição do local, à identificação dos gastos, à tendência de dupla-contagem de impactos econômicos, ao papel dos impostos locais, e à omissão de benefícios de spillovers locais.

Tendo como foco o lado da demanda, as atividades da universidade geram um relevante impulso sobre a economia local. Quando a universidade, como uma organização, demanda insumos com o objetivo de gerar produtos para sociedade (maior nível educacional e de pesquisa), isto acarreta um impacto sobre a região onde esta universidade se localiza. Podem-se destacar as seguintes atividades que envolvem a universidade:

- demanda de bens e serviços (públicos e privados), que na sua maioria são providos localmente;

- emprego de pessoas, que em média têm maior qualificação, provocando um aumento na renda média local;

- geração de atividades adicionais (conferências, seminários, etc.), que por sua vez demandam hotéis, restaurantes, etc.

Apesar da predominância na literatura de estudos sob a metodologia de InsumoProduto, observam-se métodos diretos de cálculo do efeito (como o método ACE - American Council of Education), em que os impactos são estimados a partir de informações bastantes detalhadas provenientes de pesquisas de campo com os agentes principais que têm relacionamento com a universidade. Obviamente tais métodos diretos envolvem um grande esforço com relação à coleta das informações, além de serem muito custosos. Dada esta característica, os respectivos trabalhos em geral consideram estudos de casos de universidades específicas, como por exemplo, Booth e Jarrett (1976) para a universidade de Rhode Island. 
Entre os diversos estudos considerando a metodologia de Insumo-Produto, classificada como um método indireto de estimação, podem-se mencionar: Felsenstein (1996), que estima alguns dos impactos associados com a Universidade de Northwestern sobre a região metropolitana de Chicago; Harris (1997), que mede o impacto local da Universidade de Portsmouth; Kelly, McLellan e McNicoll (2009), que estuda o impacto das universidades sobre a economia, expandindo a análise de uma universidade para o conjunto de universidades do Reino Unido.

Para o Brasil, Rolim e Kureski (2010) pode ser considerado o principal estudo de impacto econômico de universidades com base na matriz de insumo-produto nacional. Especificamente, estuda o impacto econômico de curto prazo das universidades federais com base na matriz insumo-produto de 2004 e no total de despesas destas universidades proveniente do Censo do Ensino Superior de 2005.

Com relação à literatura de econometria aplicada, aqui vale frisar que, até onde se pôde pesquisar, não foi encontrado nenhum estudo na literatura que trata o efeito de uma universidade sobre a atividade de uma região com base na metodologia econométrica de efeito do tratamento sobre os tratados. O trabalho que guarda a maior relação com o assunto é Duflo (2001) que, num cenário de expansão da rede de ensino fundamental na Indonésia, estima o efeito da construção de escolas sobre escolaridade e renda. Portanto, este trabalho é inédito, à medida que considera a implantação de um campus universitário como um tratamento de política pública no município e, através de técnicas econométricas, busca estimar o efeito médio de curto prazo do tratamento sobre os municípios tratados.

\section{3- A Questão do Impacto das Universidades Federais}

Primeiramente, é importante delimitar o enfoque deste trabalho para o campo econômico, sem adentrar em questões sobre o modelo da expansão e do REUNI, a melhoria da qualidade do ensino e a autonomia universitária, no contexto de expansão do ensino superior público federal. Desta forma, o enfoque principal deste trabalho é o estudo do impacto da expansão recente das universidades federais brasileiras. 
Dado o momento recente desta expansão, os resultados estimados neste trabalho se referem aos impactos de curto prazo, pois são os únicos possíveis de mensuração no período. Entendendo-se a expansão do ensino público federal através da interiorização das universidades já existentes via construção de novos campi e através da construção de novas universidades, pode-se abordar a questão tanto como expansão de gastos públicos quanto como implantação de uma política pública. Neste cenário, observa-se basicamente a possibilidade de estudo sob duas abordagens da literatura econômica. A primeira trata o problema através do modelo de Insumo-Produto, entendendo esta expansão como um insumo setorial com consequentes resultados econômicos. A segunda forma entende a expansão como um tratamento de política pública num contexto de inferência causal com base em técnicas econométricas.

Especificamente, com relação à primeira abordagem, tem-se como base da metodologia Miller e Blair (2009), que apresenta os fundamentos do método de InsumoProduto. Especificamente sobre o impacto econômico de universidades federais brasileiras, vale mencionar Rolim e Kureski (2010). Para a abordagem econométrica, vale destacar os seguintes trabalhos que servem de base para o estudo proposto. Em Duflo (2001), como já mencionado, estima-se o efeito da construção de escolas sobre a escolaridade e renda na Indonésia. Para a estimação do efeito do tratamento sobre os tratados, toma-se como base o trabalho de Meghir e Palme (2003), que estima o efeito do impacto de uma reforma no sistema educacional sueco sobre a renda dos indivíduos com elevada habilidade e pais com baixa escolaridade.

Com isso, este trabalho é dividido basicamente em três partes, em que a primeira utiliza a abordagem de Insumo-Produto, e as outras duas se fundamentam na abordagem econométrica. Especificamente, a primeira parte aborda a questão com base no modelo de Insumo-Produto, em que a expansão é tratada como um choque sobre o setor Educação Pública. A segunda parte trata o problema de estimação do efeito médio do tratamento sobre as regiões tratadas sob o método de Diferenças-em-Diferenças com Pareamento por Escore de Propensão (Matching por Propensity Score). Especificamente, busca-se inicialmente verificar a existência de seleção no tratamento, ou seja, entender quais características foram determinantes para a implantação do programa de expansão em determinadas regiões em detrimento de outras. Assim, com base nesta seleção, estima-se o efeito do tratamento sobre os tratados. Como extensão desta segunda abordagem, considerando que a um novo campus universitário federal pode trazer benefícios políticos futuros aos administradores públicos 
considerados responsáveis pelo processo decisório de sua implantação no município, apresenta-se um capítulo sobre o efeito político do tratamento sobre os municípios tratados com relação à reeleição da coligação ou partido político. Em complemento a estas três partes, apresentam-se um capítulo final com os principais resultados e contribuições deste trabalho à literatura econômica. Por fim, são apresentados os resultados complementares no Apêndice. 


\section{2- MODELO DE INSUMO-PRODUTO}

Inicialmente, aborda-se a questão do impacto regional da expansão do ensino superior público federal a partir do modelo de Insumo-Produto. Diferentemente de Rolim e Kureski (2010), estuda o impacto econômico de curto prazo das universidades federais com base na matriz insumo-produto de 2004 e no total de despesas destas universidades, propondo-se então o estudo do impacto da expansão recente do sistema superior federal. Assim, este capítulo pretende estudar o efeito econômico da expansão das universidades federais, com enfoque microrregional, utilizando a matriz Insumo-Produto. Especificamente, com base no aumento dos gastos do governo federal em ensino superior no período de expansão das universidades federais, calcula-se sua contribuição para o desenvolvimento local e nacional, ou seja, seu impacto na economia.

Ainda que, na literatura de impacto econômico de universidades, o método de InsumoProduto seja bastante utilizado, este capítulo aborda a questão da expansão sob um enfoque microrregional, expandindo as análises nacionais ou de uma única universidade geralmente abordadas. Desta forma, analisa o impacto da expansão das universidades federais utilizando uma matriz insumo-produto com 558 microrregiões e 55 setores, nunca antes tratado na literatura, até onde se pôde pesquisar.

Este capítulo se inicia com a descrição e contextualização da base de dados utilizada para o estudo. Apresenta-se então o modelo teórico de insumo-produto, bem como a metodologia de cálculo. Em seguida, analisam-se os resultados por diferentes níveis regionais e setoriais. Além disso, apresenta-se uma análise estrutural da economia brasileira, finalizando-se com as conclusões.

\section{1- Base de Dados}

Um alicerce fundamental deste estudo é a pesquisa sobre o histórico das 59 universidades federais, buscando identificar as expansões e criações de novos 
estabelecimentos nos últimos anos, com especial atenção às 17 novas instituições. Além disso, é importante acompanhar este processo pelo aspecto geográfico, ou seja, identificando as cidades onde se localizam os estabelecimentos, e suas respectivas vizinhanças.

Com relação aos dados financeiros de gastos federais com a expansão do ensino superior público federal, será utilizado o Sistema Integrado de Administração Financeira (SIAFI), abrindo-se as despesas públicas efetivamente pagas às universidades federais por município. Esta informação detalhada é fundamental para a identificação dos gastos com investimentos em expansão. Além disso, é preciso abrir os gastos com custeio, uma vez que uma nova ou maior estrutura requer maiores gastos com manutenção. Tal informação está disponível em banco de dados Access no site da Câmara dos Deputados, contendo a execução do Orçamento da União pela Lei Orçamentária Anual (LOA) para cada ano, com base no SIAFI.

Cabe detalhar a identificação dos gastos da União com universidades federais nos municípios brasileiros. Com base nos dados supracitados do SIAFI, o choque aplicado no setor Educação Pública da microrregião em análise representa a expansão de gastos públicos da União com universidades federais. Tais gastos são identificados de acordo com o órgão e município ao qual é destinado. Ainda que estes gastos orçamentários tenham sido aprovados no ano anterior à sua execução, são considerados apenas os gastos efetivamente pagos pelo governo federal através dos respectivos órgãos. Para a composição destes gastos, somam-se às despesas pagas no ano $\mathrm{t}$ (referentes ao orçamento aprovado no ano anterior, $\mathrm{t}-1$ ), as despesas referentes a Restos a Pagar pagos (despesas orçamentárias inscritas de anos anteriores, porém pagas apenas no ano t). Desta forma, são consideradas todas as despesas efetivamente pagas num determinado ano, independente do ano orçado.

Inicialmente, na base do SIAFI, são identificadas as unidades orçamentárias correspondentes às universidades federais. Dado o foco da expansão recente nas universidades, não foram considerados órgãos sem relação direta com universidades, como por exemplo, centros federais de educação tecnológica, institutos, fundações, e comandos da Aeronáutica e do Exército. Os institutos, fundações e hospitais-escola com relação orçamentária direta com determinada universidade tiveram seus gastos realocados para respectiva unidade orçamentária universitária, respeitando-se a informação do município destinatário do orçamento. Buscando-se identificar tais gastos, são considerados apenas os relacionados com a subfunção Ensino Superior. Dada a grande diversidade de ações e 
programas, e respectiva falta de homogeneidade na contabilização das subcontas, os gastos federais não foram separados considerando tais informações. Entretanto, foi possível identificar algumas ações relacionadas com a expansão do ensino superior e que estavam contabilizadas em universidades preexistentes, uma vez que as novas universidades ainda não possuíam órgão específico. Em tais casos, a identificação da universidade nova na descrição da ação possibilitou a realocação para o respectivo novo órgão. Desta forma, foi possível localizar os gastos de todas as 59 universidades federais credenciadas até 2010 .

Uma vez identificados os gastos de todas as universidades, utilizou-se a base de dados do Censo do Ensino Superior para a obtenção do número de matrículas anuais por universidade e município, o que possibilitou a distribuição dos respectivos gastos aos municípios onde existiam cursos e/ou campi universitários. Nos anos em que a universidade apresentou gastos, mas não tinha matrículas, foram consideradas as informações de matrículas do ano posterior ao caso. Isto basicamente ocorreu nos anos de construção das universidades novas, pois ainda não estavam em funcionamento. Desta forma, não houve perda de informações sobre os gastos federais com universidades.

Especificamente, com relação à matriz de insumo-produto da estrutura produtiva brasileira, é utilizada a matriz do ano de 2004, representando o cenário econômico inicial. Esta matriz é caracterizada em 558 microrregiões e 55 setores, representando as relações produtivas inter-regionais. Desta forma, totalizam-se 30.690 microrregiões-setores de InsumoProduto, resultando em uma matriz com 941.876 .100 elementos ${ }^{5}$. Assumindo-se a hipótese de que a estrutura produtiva brasileira não sofreu significativa alteração ao longo do período até 2010; aplica-se anualmente um choque de gastos públicos sobre as microrregiões que receberam expansão universitária. Tal choque é direcionado ao setor Educação Pública da respectiva microrregião, uma vez que a matriz insumo-produto não apresenta a identificação de educação superior pública federal na matriz.

Todos os valores apresentados neste trabalho foram convertidos para Reais do ano de 2010, através do deflator implícito do Produto Interno Bruto (PIB).

\footnotetext{
${ }^{5}$ Esta matriz Insumo-Produto microrregionalizada é resultado de estudo elaborado pelo NEREUS-USP (Núcleo de Economia Regional e Urbana da Universidade de São Paulo) e cedida para este trabalho pelo coordenador do estudo, Prof. Dr. Joaquim José Martins Guilhoto.
} 


\subsection{1- Análise Descritiva}

Com o procedimento descrito acima, obtêm-se os gastos da União com universidades federais, num total de 59 instituições, distribuídas pelas 27 unidades da federação, compreendendo 219 microrregiões (382 municípios).

\section{Gráfico 2.1 - Evolução do Número de Universidades Federais por Ano de Credenciamento}

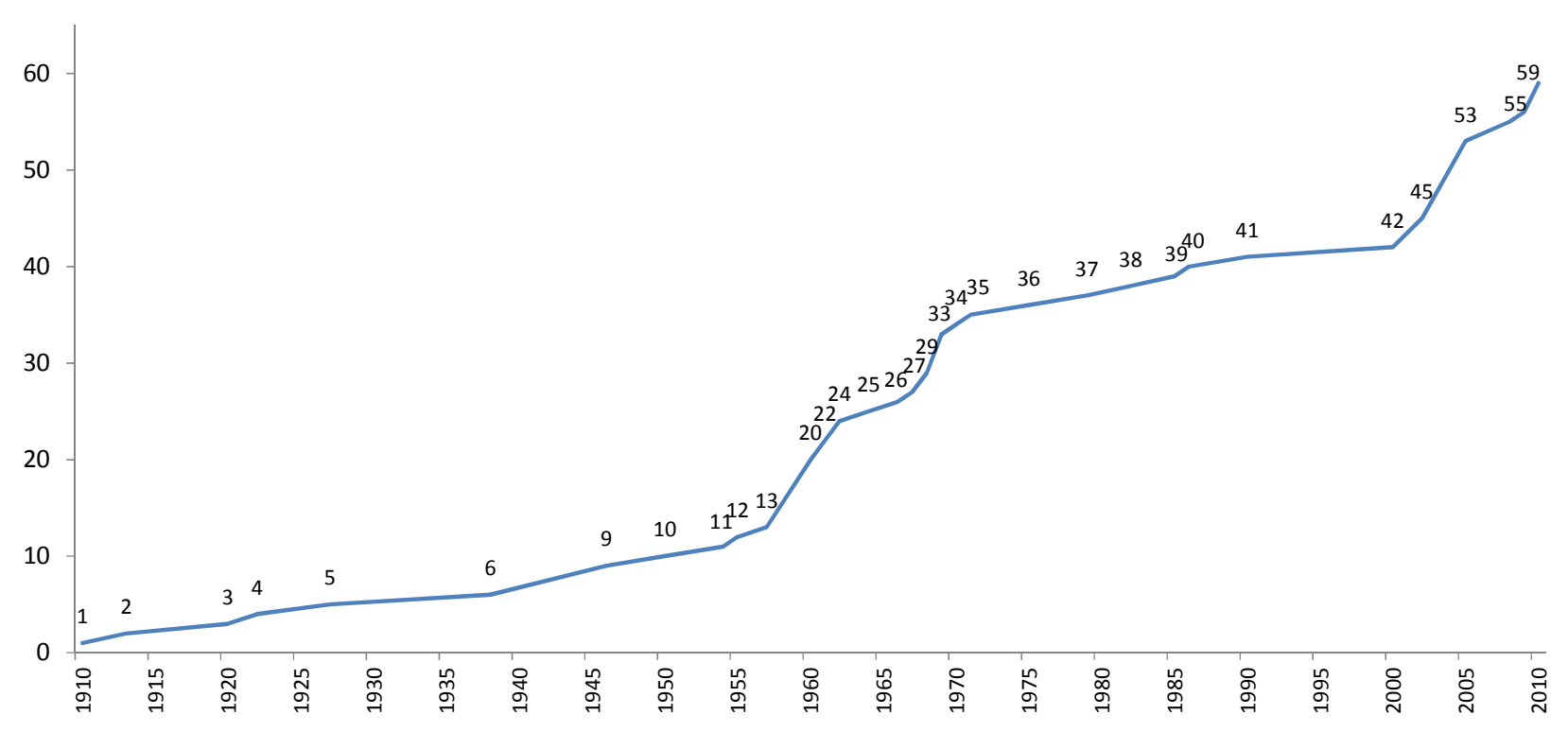

Fonte: Elaboração própria com base no SIAFI e MEC.

A evolução do número de universidades federais no Brasil é suave ao longo da primeira metade do século passado, e mostra, na década de 1960, uma forte expansão. Entre os anos de 1970 e 2000, tal evolução volta a ser suave, sendo retomado um quadro de forte expansão nos anos 2000. Os anos que apresentaram o maior número de novos credenciamentos de universidades federais foram 1960 (sete universidades) e 2005 (oito universidades).

Quando se analisa a distribuição de universidades federais por estado, Minas Gerais apresenta o maior número, com 11 universidades, sendo três credenciadas após 2000. Mesmo 
no período recente de expansão, Minas Gerais foi o estado que mais recebeu universidades. Entretanto, quanto à região, a Nordeste foi a que recebeu mais universidades novas (cinco), num total de 17 universidades federais no Brasil.

Tabela 2.1 - Presença de Universidades Federais por Estado e Região ${ }^{6}$

\begin{tabular}{|c|c|c|c|}
\hline \multicolumn{2}{|c|}{ Região } & \multicolumn{2}{|l|}{ Estado } \\
\hline Nome & Quantidade & Nome & Quantidade \\
\hline \multirow{7}{*}{ Norte } & \multirow{7}{*}{9} & Rondônia & 1 \\
\hline & & Acre & 1 \\
\hline & & Amazonas & 1 \\
\hline & & Roraima & 1 \\
\hline & & Pará & 3 \\
\hline & & Amapá & 1 \\
\hline & & Tocantins & 1 \\
\hline \multirow{9}{*}{ Nordeste * } & \multirow{9}{*}{17} & Maranhão & 1 \\
\hline & & Piauí * & 2 \\
\hline & & Ceará & 2 \\
\hline & & Rio Grande do Norte & 2 \\
\hline & & Paraiba & 2 \\
\hline & & Pernambuco * & 3 \\
\hline & & Alagoas & 1 \\
\hline & & Sergipe & 1 \\
\hline & & Bahia * & 3 \\
\hline \multirow{4}{*}{ Sudeste } & \multirow{4}{*}{19} & Minas Gerais & 11 \\
\hline & & Espírito Santo & 1 \\
\hline & & Rio de Janeiro & 4 \\
\hline & & São Paulo & 3 \\
\hline \multirow{3}{*}{ Sul } & \multirow{3}{*}{11} & Paraná & 3 \\
\hline & & Santa Catarina & 2 \\
\hline & & Rio Grande do Sul & 6 \\
\hline \multirow{4}{*}{ Centro-Oeste } & \multirow{4}{*}{5} & Mato Grosso do Sul & 2 \\
\hline & & Mato Grosso & 1 \\
\hline & & Goiás & 1 \\
\hline & & Distrito Federal & 1 \\
\hline Brasil * & 61 & Brasil * & 61 \\
\hline
\end{tabular}

Fonte: Elaboração própria com base no SIAFI e MEC.

\footnotetext{
6 * As universidades federais na sua maioria apresentam todos os seus campi dentro dos limites do estado onde está a sua sede, com exceção da Universidade Federal do Vale do São Francisco (UNIVASF) que, apesar da sede ser em Petrolina-PE, também possui campi nos estados do Piauí e Bahia. Por isso, o número total de universidades analisadas é 59, mas há uma mesma universidade presente em 3 estados, totalizando uma presença de 61.
} 
Considerando a evolução da presença de universidades federais no Brasil, das 558 microrregiões existentes, 364 não possuem campus universitário, 102 possuíam campus no ano de 2000 e 107 microrregiões receberam campus ao longo no período 2001-2010. Além disso, destas que receberam campus, 15 microrregiões já possuíam outros campus de universidade federal e 92 microrregiões que não tinham campus em 2000, passaram a possuir campus de universidade federal em 2010. Observa-se também uma concentração de novos campi na região Nordeste, que apresenta 38 microrregiões recebendo campus no período analisado, seguida pela região Centro-Oeste, com 24 microrregiões nesta situação.

Figura 2.1 - Microrregiões com Universidades Federais no ano de 2010

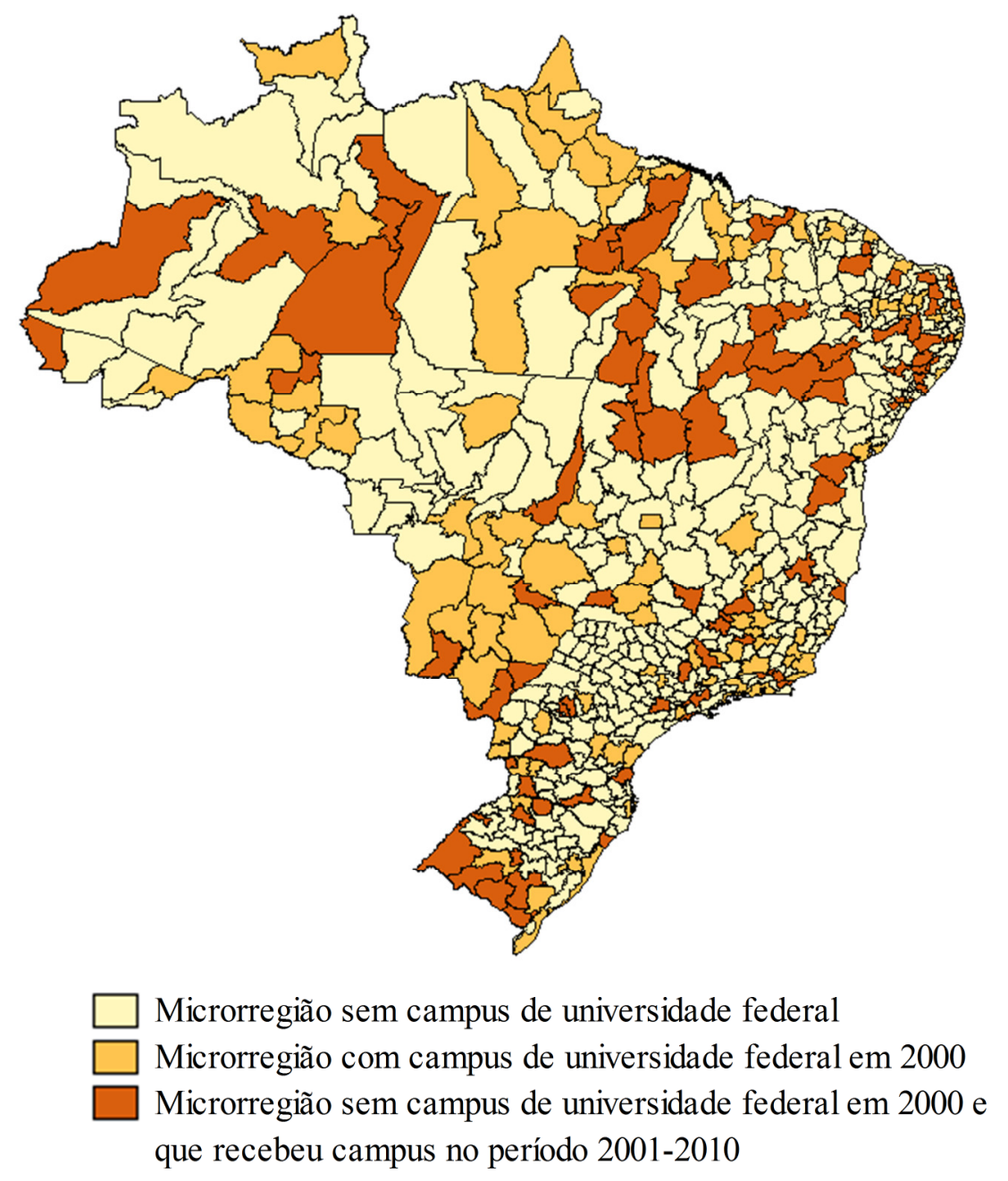

Fonte: Elaboração própria com base em dados do MEC. 
Com relação ao volume de gastos públicos federais destinados às universidades analisadas $^{7}$, o estado que recebeu o maior volume monetário entre os anos de 2000 e 2010 foi o estado do Rio de Janeiro (R \$ 18,29 bilhões), seguido por Minas Gerais (R \$ 17,83 bilhões). Entretanto, ponderando-se pelo número de universidades instaladas, o Distrito Federal recebeu uma média de $\mathrm{R} \$ 6,64$ bilhões por universidade, enquanto que Rio de Janeiro e Minas Gerais receberam R \$ 4,57 bilhões e R \$ 1,62 bilhão, respectivamente, por universidade. A média nacional foi de $\mathrm{R} \$ 1,96$ bilhão por universidade.

Tabela 2.2 - Gastos Totais do Período 2000-2010 com Universidades Federais por

Estado

\begin{tabular}{|c|c|c|c|c|}
\hline \multicolumn{2}{|c|}{ Região } & \multicolumn{3}{|c|}{ Estado } \\
\hline Nome & R\$ Bilhão & Nome & R\$ Bilhão & $\mathrm{R} \$ \mathrm{Bi} /$ univ \\
\hline \multirow{7}{*}{ Norte } & \multirow{7}{*}{8,93} & Rondônia & 0,66 & 0,66 \\
\hline & & Acre & 0,91 & 0,91 \\
\hline & & Amazonas & 1,93 & 1,93 \\
\hline & & Roraima & 0,50 & 0,50 \\
\hline & & Pará & 4,07 & 1,36 \\
\hline & & Amapá & 0,30 & 0,30 \\
\hline & & Tocantins & 0,55 & 0,55 \\
\hline \multirow{9}{*}{ Nordeste } & \multirow{9}{*}{30,99} & Maranhão & 1,89 & 1,89 \\
\hline & & Piauí & 1,89 & 0,94 \\
\hline & & Ceará & 4,07 & 2,03 \\
\hline & & Rio Grande do Norte & 4,31 & 2,16 \\
\hline & & Paraiba & 5,76 & 2,88 \\
\hline & & Pernambuco & 5,17 & 1,72 \\
\hline & & Alagoas & 2,04 & 2,04 \\
\hline & & Sergipe & 1,40 & 1,40 \\
\hline & & Bahia & 4,47 & 1,49 \\
\hline \multirow{4}{*}{ Sudeste } & \multirow{4}{*}{43,53} & Minas Gerais & 17,83 & 1,62 \\
\hline & & Espírito Santo & 2,42 & 2,42 \\
\hline & & Rio de Janeiro & 18,29 & 4,57 \\
\hline & & São Paulo & 4,98 & 1,66 \\
\hline \multirow{3}{*}{ Sul } & \multirow{3}{*}{21,62} & Paraná & 5,60 & 1,87 \\
\hline & & Santa Catarina & 4,58 & 2,29 \\
\hline & & Rio Grande do Sul & 11,43 & 1,91 \\
\hline \multirow{4}{*}{ Centro-Oeste } & \multirow{4}{*}{14,35} & Mato Grosso do Sul & 2,44 & 1,22 \\
\hline & & Mato Grosso & 2,42 & 2,42 \\
\hline & & Goiás & 2,86 & 2,86 \\
\hline & & Distrito Federal & 6,64 & 6,64 \\
\hline Brasil & 119,43 & Brasil & 119,43 & 1,96 \\
\hline
\end{tabular}

Fonte: Elaboração própria com base no SIAFI

\footnotetext{
${ }^{7}$ Os gastos contemplados neste trabalho consideram investimentos e manutenção do sistema de universidades federais. Por falta de exatidão na distribuição no SIAFI destes gastos em investimentos e manutenção, optou-se por considerar os gastos agregados e sua expansão no tempo.
} 
Com relação aos gastos anuais do governo federal com a implantação e manutenção das universidades federais, observa-se um orçamento em torno de $\mathrm{R} \$ 10$ bilhões na primeira metade da década, crescendo constantemente na segunda metade e chegando a R 14 bilhões em 2010. Ao todo, entre os anos de 2000 e 2010, foram gastos quase R $\$ 120$ bilhões com as universidades federais. Para efeito de comparação, em 2010, o orçamento fiscal das universidades estaduais do Estado de São Paulo totalizou R \$ 6,5 bilhões; com R \$ 3,3 bilhões, R \$ 1,7 bilhão, e R\$ 1,5 bilhão, para a Universidade de São Paulo (USP), a Universidade Estadual de Campinas (UNICAMP), e a Universidade Estadual Paulista Júlio Mesquita Filho (UNESP), respectivamente ${ }^{8}$. Do ponto de vista internacional, o orçamento da Harvard University nos Estados Unidos, considerando apenas as receitas, é de aproximadamente US\$ 3,8 bilhões $\left(\mathrm{R} \$ 6,7 \text { bilhões }^{9}\right)^{10}$. Apesar do montante de $\mathrm{R} \$ 14$ bilhões aparentemente ser elevado, se for considerado o orçamento das três universidades estaduais mencionadas ou da Harvard University, constata-se que este corresponde a praticamente metade do orçamento do governo brasileiro com as 59 universidades federais em 2010, onde se destaca a Universidade Federal do Rio de Janeiro (UFRJ) com quase R\$ 1 bilhão de orçamento.

Quando se analisa a variação de gastos entre os anos de 2000 e 2010, pela tabela a seguir, observa-se que o estado de Minas Gerais recebeu a maior expansão de gastos, do ponto de vista absoluto ( $\mathrm{R}$ \$ 661,68 milhões). Considerando a expansão relativa, o estado de São Paulo se destaca, apresentando uma variação de $+133 \%$ nos gastos da União com universidades federais. O estado com a menor expansão é a Paraíba $(+2,2 \%)$. Vale lembrar que todos os estados receberam variação positiva de gastos com universidades federais.

\footnotetext{
${ }^{8}$ Obtido no relatório Orçamento do Estado 2010, elaborado para Secretaria de Economia e Planejamento do Estado de São Paulo.

${ }^{9}$ Considerando taxa de câmbio comercial para compra de 1,76 Reais para um Dólar (média para o ano de 2010).

${ }^{10}$ Obtido no relatório Annual Fiscal Report of Harvard University (Fiscal Year 2010-2011).
} 
Tabela 2.3 - Variação dos Gastos Anuais 2000-2010 com Universidades Federais por Estado

\begin{tabular}{|c|c|c|c|c|c|c|}
\hline \multirow[b]{2}{*}{ Estado } & \multicolumn{4}{|c|}{ Gastos } & \multicolumn{2}{|c|}{ Variação } \\
\hline & $\begin{array}{c}2000 \\
\text { (R\$ milhão) }\end{array}$ & $\begin{array}{c}\text { Participação } \\
2000(\%)\end{array}$ & $\begin{array}{c}2010 \\
\text { (R\$ milhão) }\end{array}$ & $\begin{array}{c}\text { Participação } \\
2010(\%)\end{array}$ & $\begin{array}{l}\text { Absoluta } \\
\text { (R\$ milhão) }\end{array}$ & $\begin{array}{c}\text { Percentual } \\
(\%)\end{array}$ \\
\hline Rondônia & 50,58 & 0,5 & 84,60 & 0,6 & 34,02 & 67,3 \\
\hline Acre & 75,19 & 0,7 & 103,09 & 0,7 & 27,90 & 37,1 \\
\hline Amazonas & 162,46 & 1,6 & 226,18 & 1,6 & 63,72 & 39,2 \\
\hline Roraima & 33,80 & 0,3 & 65,06 & 0,5 & 31,26 & 92,5 \\
\hline Pará & 336,02 & 3,3 & 485,09 & 3,5 & 149,06 & 44,4 \\
\hline Amapá & 20,89 & 0,2 & 38,54 & 0,3 & 17,65 & 84,5 \\
\hline Tocantins & 0,00 & 0,0 & 117,59 & 0,8 & 117,59 & - \\
\hline Maranhão & 169,85 & 1,7 & 221,15 & 1,6 & 51,30 & 30,2 \\
\hline Piauí & 143,23 & 1,4 & 261,69 & 1,9 & 118,46 & 82,7 \\
\hline Ceará & 329,03 & 3,2 & 468,00 & 3,4 & 138,97 & 42,2 \\
\hline Rio Grande do Norte & 364,47 & 3,6 & 502,93 & 3,6 & 138,46 & 38,0 \\
\hline Paraiba & 613,04 & 6,0 & 626,60 & 4,5 & 13,55 & 2,2 \\
\hline Pernambuco & 409,81 & 4,0 & 615,18 & 4,4 & 205,37 & 50,1 \\
\hline Alagoas & 176,64 & 1,7 & 215,27 & 1,5 & 38,63 & 21,9 \\
\hline Sergipe & 106,33 & 1,0 & 178,77 & 1,3 & 72,44 & 68,1 \\
\hline Bahia & 357,28 & 3,5 & 490,54 & 3,5 & 133,26 & 37,3 \\
\hline Minas Gerais & 1489,41 & 14,6 & 2151,08 & 15,4 & 661,68 & 44,4 \\
\hline Espírito Santo & 194,10 & 1,9 & 284,79 & 2,0 & 90,69 & 46,7 \\
\hline Rio de Janeiro & 1631,32 & 16,0 & 1843,66 & 13,2 & 212,35 & 13,0 \\
\hline São Paulo & 335,28 & 3,3 & 781,23 & 5,6 & 445,95 & 133,0 \\
\hline Paraná & 476,76 & 4,7 & 658,57 & 4,7 & 181,82 & 38,1 \\
\hline Santa Catarina & 417,08 & 4,1 & 470,16 & 3,4 & 53,08 & 12,7 \\
\hline Rio Grande do Sul & 1000,33 & 9,8 & 1289,33 & 9,3 & 289,00 & 28,9 \\
\hline Mato Grosso do Sul & 211,10 & 2,1 & 273,04 & 2,0 & 61,95 & 29,3 \\
\hline Mato Grosso & 223,86 & 2,2 & 281,78 & 2,0 & 57,93 & 25,9 \\
\hline Goiás & 221,56 & 2,2 & 361,05 & 2,6 & 139,48 & 63,0 \\
\hline Distrito Federal & 627,85 & 6,2 & 843,34 & 6,1 & 215,49 & 34,3 \\
\hline Brasil & $10.177,26$ & 100,0 & $13.938,31$ & 100,0 & $3.761,06$ & 37,0 \\
\hline
\end{tabular}

Fonte: Elaboração própria com base no SIAFI

A região Norte apresenta aumento relativo de gastos acima da média nacional em todos os estados. Com a implantação da UFT, o estado de Tocantins deixou de ser a única unidade federativa brasileira sem a presença de universidade federal. Vale frisar que das 27 unidades federativas, 18 receberam expansão relativa de gastos acima da média nacional.

Com base no gráfico abaixo, observa-se que a significativa expansão de gastos já mencionada foi acompanhada por um aumento de $65 \%$ no número de matrículas em 
universidades federais, saindo de 460 mil em 2000 para quase 800 mil matrículas em 2010. Vale ressaltar que estes números representam apenas as matrículas em instituições federais classificadas como universidades pelo MEC. Levando-se em consideração o número de matrículas em todo o sistema de ensino superior federal ${ }^{11}$, tal número atinge o patamar de um milhão em 2010.

\section{Gráfico 2.2 - Evolução de Gastos e Número de Matrículas Anuais em Universidades Federais no Período 2000-2010}

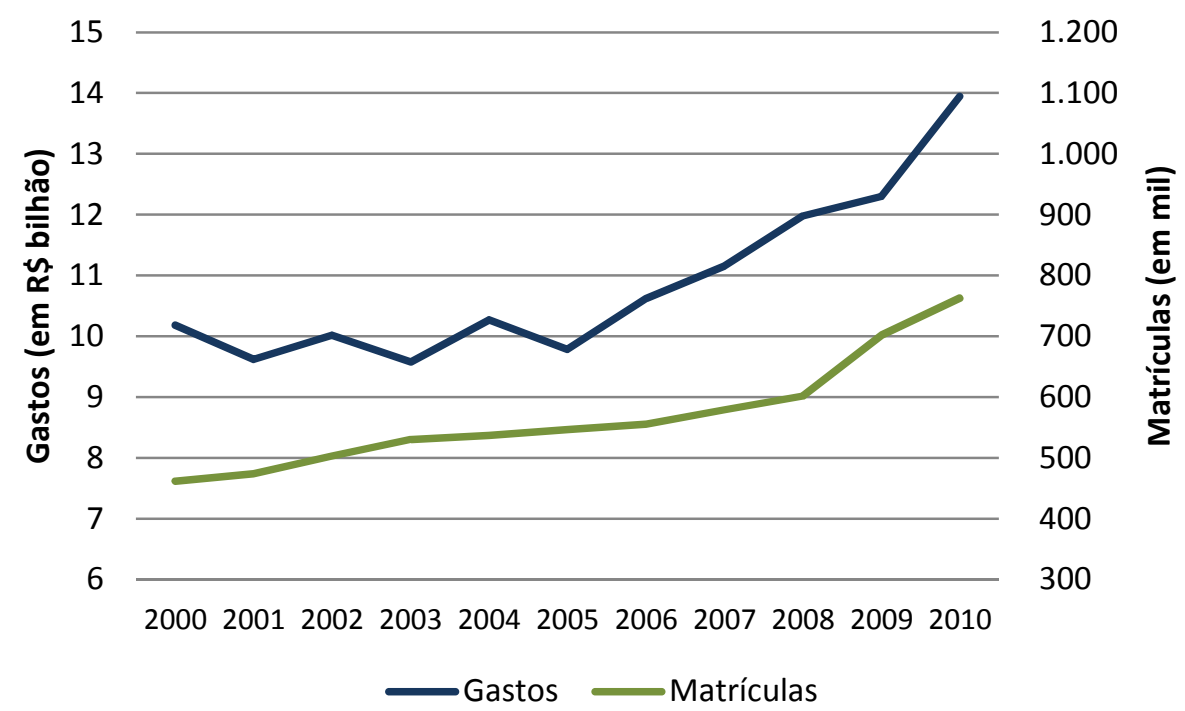

Fonte: Elaboração própria com base no SIAFI

Com relação aos gastos por universidades, a tabela com os gastos separados por universidade se encontra no Apêndice deste trabalho. Observa-se que os gastos com universidades federais se mantem por volta de 10 bilhões entre 2000 e 2005, apresentando posteriormente um padrão monotônico positivo, chegando a 14 bilhões em 2010. Evidenciase então uma expansão de gastos a partir de 2005, que será base do estudo proposto neste capítulo $^{12}$. Dentre as universidades, vale destacar a Universidade Federal do Rio de Janeiro que no período recebeu mais de $\mathrm{R} \$ 10$ bilhões, seguida pela Universidade de Brasília com R \$ 6,6 bilhões e pela Universidade Federal de Minas Gerais com R \$ 5,9 bilhões.

\footnotetext{
${ }^{11} \mathrm{O}$ sistema de ensino superior federal compreende centros tecnológicos, institutos, além das universidades.

${ }^{12}$ Vale ressaltar que, no período analisado neste trabalho, observou-se uma expansão de gastos da União em diversos setores. Ainda que esta expansão tenha ocorrido de forma geral, houve impacto sobre a economia brasileira, que no contexto deste trabalho é mensurado a partir do setor Educação Pública.
} 
Portanto, dado o grande volume de investimento da União nas universidades federais e consequente forte expansão dos gastos, como evidenciado no último gráfico, pretende-se neste trabalho estimar o impacto desta expansão sobre a economia.

\section{2- $\quad$ Modelo}

\subsection{1- Matriz Insumo-Produto (MIP)}

Utilizando-se a metodologia apresentada em Guilhoto e Sesso Filho (2005 e 2010), é possível a construção da matriz de insumo-produto de 2004, com base nos dados das contas nacionais do mesmo ano. Tal metodologia, ao estimar as margens de comércio, transporte, imposto e importação, as subtrai dos valores da Tabela de Usos com valores a preços do consumidor, obtendo a Tabela de Usos com valores a preços básicos (oferta nacional a preços básicos) (matriz $U$ ). Com isso, constrói-se a matriz de Usos (setor por setor) com oferta nacional a preços básicos segundo tecnologia baseada na indústria ${ }^{13}$. E a partir desta, obtémse a matriz de Insumo-Produto setor por setor que apresenta: os fluxos de consumo intermediário entre os setores (matriz Z); a demanda por produtos finais de cada setor (desagregada, geralmente, em consumo das famílias, gastos do governo, formação bruta de capital fixo, variação de estoques e exportações) (matriz $Y$ ); o valor adicionado (decomposto em remuneração de empregados, excedente operacional bruto, impostos líquidos de subsídios etc.) (matriz $W$ ); e a produção total gerada pela economia em um determinado período (matriz $X)$.

Pela metodologia Guilhoto e Sesso Filho (2005 e 2010), a Matriz de Insumo-Produto (MIP) é construída a partir da Tabela de Usos de bens e serviços $(U)$ e pela Tabela de Produção $(V)$. A tabela $U$ é uma matriz produto por setor que apresenta quanto cada setor e cada componente da demanda final consumiu de bens e serviços (em termos de insumos, bens

\footnotetext{
${ }^{13}$ A tecnologia baseada na indústria assume que o mix de produção de um dado setor pode ser alterado, entretanto este setor mantém sua participação constante no mercado de bens que produz (Guilhoto, 2009). Sobre as outras hipóteses com relação ao modo de produção e participação no mercado de produtos, consultar Miller e Blair (2009).
} 
finais e valor adicionado). A tabela $\mathrm{V}$, por sua vez, é uma matriz setor por produto que mostra quanto cada setor produziu de bens e serviços.

Para a obtenção da MIP (setor por setor) com a tecnologia baseada na indústria, é necessário calcular a matriz $D$ (matriz de market share), que apresenta, para cada produto, a participação dos setores que o produz. Logo,

$$
D=V(\hat{q})^{-1}
$$

Onde $\hat{q}$ é o vetor diagonalizado da produção total de produtos verificada na matriz de produção. Portanto, a matriz de fluxos interindustriais de bens $(Z)$ é o resultado da matriz $U$ pré-multiplicada por $D$. A matriz $Z$ possui dimensão n por $\mathrm{n}$, sendo $\mathrm{n}$ o número de setores. $\mathrm{O}$ vetor de demanda agregada (vetor $Y$ ), de dimensão n por um, é igual ao produto de $D$ pelo total da produção industrial verificada na matriz de usos $\left(Y_{U}\right)$. Já a produção total $(X)$, dada por um vetor $\mathrm{n}$ por um, corresponde à soma dos elementos de cada linha de $Z$ com os valores do vetor $Y .^{14}$

$Z=D . U$

$Y=D . Y_{U}$

$X=Z i+Y$

\subsection{2- Modelo de Leontief}

No Modelo de Leontief, a produção total da economia $(X)$ é resultado da soma entre a produção destinada para o consumo intermediário dos diferentes setores da economia $(Z)$ e a demanda final $(Y)$, conforme mostra a última equação acima (Guilhoto, 2009). A matriz de fluxos interindustriais de bens $(Z)$ e a produção total oferecem as informações necessárias para o cálculo da matriz de coeficientes técnicos diretos $(A)$. O coeficiente técnico $\left(a_{i j}\right)$ mensura, em valores monetários, quanto o setor j usou de bens do setor i para sua produção

\footnotetext{
${ }^{14} \mathrm{O}$ vetor i é um vetor de números 1 , de dimensão nx 1 , que permite somar os elementos de cada linha de $\mathrm{Z}$, de tal modo que $Z i$ fornece o total de consumo intermediário por setor.
} 
total. Ou seja, apresenta a proporção de insumos vendidos ao setor j pelo setor i em relação à produção total do setor $\mathrm{j}$.

$a_{i j}=\frac{z_{i j}}{x_{j}}$

Onde $a_{i j}$ é o coeficiente técnico, $z_{i j}$ representa as vendas intersetoriais do setor $\mathrm{i}$ ao setor $\mathrm{j}$ (matriz Z) e $x_{j}$ é a produção total do setor j (matriz $X$ ).

Portanto, matricialmente, esta equação pode ser representada como:

$X=A X+Y$

Quando há um aumento na demanda final, ocorrem não apenas efeitos diretos na produção de insumos, mas também se desencadeiam efeitos indiretos. Resolvendo a equação (2.6), obtém-se a produção total necessária para satisfazer a demanda final:

$$
X=(I-A)^{-1} Y
$$

Onde $(I-A)^{-1}=L$ é a matriz de coeficientes diretos e indiretos ou, simplesmente, a matriz inversa de Leontief. Tal matriz permite a obtenção dos efeitos diretos e indiretos sobre a produção. Cada elemento de $L\left(l_{i j}\right)$ deve ser entendido como sendo a produção total do setor i necessária para produzir uma unidade da demanda final do setor j (Guilhoto, 2009).

Para se calcular o efeito induzido é necessário tornar endógeno o consumo e a renda das famílias no modelo de insumo-produto, desta forma, ao invés de utilizar a matriz $A$ descrita acima, tem-se:

$\bar{A}=\left[\begin{array}{cc}A & H_{c} \\ H_{r} & 0\end{array}\right]$

Onde $\bar{A}$ é a nova matriz de coeficientes técnicos $(n+1) \mathrm{x}(n+1)$ contendo a renda $\left(H_{r}\right)$ e o consumo $\left(H_{c}\right)$ das famílias.

Da mesma forma, os novos vetores de produção total $\bar{X}((n+1) \times 1)$ e de demanda final $\bar{Y}((n+1) \times 1)$ são representados respectivamente por:

$\bar{X}=\left[\begin{array}{c}X \\ X_{n+1}\end{array}\right]$ 
$\bar{Y}=\left[\begin{array}{c}Y \\ Y_{n+1}\end{array}\right]$

Onde os novos componentes $X_{n+1}$ e $Y_{n+1}$ estão relacionados à endogeneização do consumo e da renda das famílias.

O sistema de Leontief passa a ser representado como:

$\bar{X}=(I-\bar{A})^{-1} \bar{Y}$

Vale ressaltar que tal modelo é formulado sobre a hipótese de que a relação entre $X \mathrm{e}$ $Y$, ou entre $\bar{X}$ e $\bar{Y}$, é linear e homogênea, ou seja, cada mercadoria é fornecida por uma única atividade, com rendimento constante de escala. Há ainda a hipótese de aditividade, em que o efeito total da produção é a soma dos efeitos separados.

\subsection{3- Matriz de Insumo-Produto Microrregional}

Com base no modelo original de Leontief, desenvolvido para uma economia nacional, apresentado anteriormente, pode-se ampliá-lo para análises de economias regionais com várias regiões interligadas, ou seja, modelos inter-regionais. Neste caso, a estrutura de análise apresenta algumas diferenças que serão abordadas neste item.

No sistema inter-regional, há uma troca de relações entre as regiões, que são expressas através do fluxo de bens que se destinam tanto ao consumo intermediário como à demanda final.

Por simplificação, pode-se apresentar o modelo com base nos fluxos intersetoriais e inter-regionais de bens para as microrregiões hipotéticas L e M, com dois setores, como se segue:

$Z_{i j}^{L L}$ - fluxo monetário do setor i para o setor j da microrregião L,

$Z_{i j}^{M L}$ - fluxo monetário do setor i da microrregião $\mathrm{M}$, para o setor $\mathrm{j}$ da microrregião L. 
Pode-se montar a matriz:

$Z=\left[\begin{array}{ll}Z_{i j}^{L L} & Z_{i j}^{L M} \\ Z_{i j}^{M L} & Z_{i j}^{M M}\end{array}\right]$

Onde,

$Z_{i j}^{L L}$ e $Z_{i j}^{M M}$, representam matrizes dos fluxos monetários intrarregionais, e

$Z_{i j}^{L M}$ e $Z_{i j}^{M L}$, representam matrizes dos fluxos monetários inter-regionais.

Considerando a equação de Leontief,

$X_{i}=z_{i 1}+z_{i 2}+\ldots+z_{i i}+\ldots+z_{i n}+Y_{i}$

Onde, $X_{i}$ indica o total da produção do setor i, $z_{i n}$ o fluxo monetário do setor i para o setor n, e $Y_{i}$ é demanda final por produtos do setor i.

É possível aplicá-la às microrregiões,

$X_{1}^{L}=z_{11}^{L L}+z_{12}^{L L}+z_{11}^{L M}+z_{12}^{L M}+Y_{1}^{L}$

Onde $X_{1}^{L}$ é o total do bem 1 produzido na microrregião L.

Considerando os coeficientes de insumo microrregional para $\mathrm{L}$ e $\mathrm{M}$, têm-se os coeficientes intrarregionais:

$a_{i j}^{L L}=\frac{z_{i j}^{L L}}{X_{j}^{L}} \quad \rightarrow \quad z_{i j}^{L L}=a_{i j}^{L L} \cdot X_{j}^{L}$

Onde, podem-se definir os $a_{i j}^{L L}$ como coeficientes técnicos de produção, e que representam quanto, o setor j da microrregião L, compra do setor i da microrregião L

$a_{i j}^{M M}=\frac{z_{i j}^{M M}}{X_{j}^{M}} \rightarrow z_{i j}^{M M}=a_{i j}^{M M} \cdot X_{j}^{M}$

Onde, podem-se definir os $a_{i j}^{M M}$ como coeficientes técnicos de produção, que representam a quantidadeque o setor $\mathrm{j}$ da microrregião $\mathrm{M}$ compra do setor i da microrregião $\mathrm{M}$.

Além disso, têm-se os coeficientes inter-regionais:

$a_{i j}^{M L}=\frac{z_{i j}^{M L}}{X_{j}^{L}} \quad \rightarrow \quad z_{i j}^{M L}=a_{i j}^{M L} \cdot X_{j}^{L}$ 
Podem-se definir os $a_{i j}^{M L}$ como coeficientes técnicos de produção que representam quanto o setor $\mathrm{j}$ da microrregião L compra do setor i da microrregião $\mathrm{M}$ e

$a_{i j}^{L M}=\frac{z_{i j}^{L M}}{X_{j}^{M}} \quad \rightarrow \quad z_{i j}^{L M}=a_{i j}^{L M} \cdot X_{j}^{M}$

Onde os $a_{i j}^{L M}$ correspondem aos coeficientes técnicos de produção que representam a quantidade que o setor $\mathrm{j}$ da microrregião M compra do setor i da microrregião L.

Aplicando-se estes coeficientes à equação de Leontief para a microrregião L, tem-se:

$X_{1}^{L}=a_{11}^{L L} \cdot X_{1}^{L}+a_{12}^{L L} \cdot X_{2}^{L}+a_{11}^{L M} \cdot X_{1}^{M}+a_{12}^{L M} \cdot X_{2}^{M}+Y_{1}^{L}$

As produções para os demais setores são obtidas de forma similar.

Isolando-se $Y_{1}^{L}$ e colocando-se em evidência $X_{1}^{L}$, tem-se:

$\left(1-a_{11}^{L L}\right) \cdot X_{1}^{L}-a_{12}^{L L} \cdot X_{2}^{L}-a_{11}^{L M} \cdot X_{1}^{M}-a_{12}^{L M} \cdot X_{2}^{M}=Y_{1}^{L}$

As demais demandas finais podem ser obtidas similarmente.

Portanto, de acordo com $A^{L L}=Z^{L L} \cdot\left(\hat{X}^{L}\right)^{-1}$, constrói-se a matriz $A^{L L}$, para os 2 setores, onde $A^{L L}$ representa a matriz de coeficientes técnicos intrarregionais de produção. Analogamente, podem-se definir $A^{L M}, A^{M M}$ e $A^{M L}$.

Definem-se agora as seguintes matrizes:

$$
\begin{aligned}
& A=\left[\begin{array}{ccc}
A^{L L} & \vdots & A^{L M} \\
\cdots & \cdots & \cdots \\
A^{M L} & \vdots & A^{M M}
\end{array}\right] \\
& X=\left[\begin{array}{c}
X^{L} \\
\cdots \\
X^{M}
\end{array}\right] \\
& Y=\left[\begin{array}{c}
Y^{L} \\
\cdots \\
Y^{M}
\end{array}\right]
\end{aligned}
$$

O sistema inter-regional completo de insumo-produto é representado por: 
$(I-A) \cdot X=Y$,

e as matrizes podem ser dispostas da seguinte forma:

$\left\{\left[\begin{array}{ccc}I & \vdots & 0 \\ \cdots & \cdots & \cdots \\ 0 & \vdots & I\end{array}\right]-\left[\begin{array}{ccc}A^{L L} & \vdots & A^{L M} \\ \cdots & \cdots & \cdots \\ A^{M L} & \vdots & A^{M M}\end{array}\right]\right\}\left[\begin{array}{c}X^{L} \\ \cdots \\ X^{M}\end{array}\right]=\left[\begin{array}{c}Y^{L} \\ \cdots \\ Y^{M}\end{array}\right]$

Efetuando-se estas operações, obtêm-se os modelos básicos necessários à análise interregional, isto é:

$\left(I-A^{L L}\right) X^{L}-A^{L M} X^{M}=Y^{L}-A^{M L} X^{L}+\left(I-A^{M M}\right) X^{M}=Y^{M}$

Por fim, chega-se ao sistema de Leontief inter-regional de forma:

$X=(I-A)^{-1} Y$

\subsection{4- Geradores, Multiplicadores e Índices de Ligação}

Com o modelo apresentado, podem-se medir os impactos de variações na demanda (ou dos componentes da demanda) sobre produção, emprego e valor adicionado, entre outras variáveis. O coeficiente direto $(k)$ de uma dessas variáveis $(K)$ pode ser obtido mediante $o$ quociente, para cada setor, entre o valor utilizado da variável em questão na produção total e a produção total do setor correspondente, tal como expresso abaixo:

$k_{i}=K_{i} / X_{i}$

A partir destes coeficientes diretos, obtém-se o gerador de uma determinada variável, ou seja, o montante gerado direta e indiretamente da variável $K$ para cada unidade monetária produzida para a demanda final, relacionando a produção para a demanda final com uma dada variável da economia. Assim, o gerador de uma variável $K$ é representado por:

$G K_{j}=\sum_{i=1}^{n} l_{i j} k_{i}$ 
Obtém-se o multiplicador da variável $K$ pela razão entre gerador e o respectivo coeficiente direto. $\mathrm{O}$ multiplicador associa o efeito direto de uma variável sobre seu efeito total (direto e indireto) na economia. ${ }^{15}$

$$
M K_{j}=G K_{j} / k_{i}
$$

Além dos geradores e multiplicadores, há outros indicadores que representam as interrelações entre os setores e o poder de encadeamento de cada setor dentro da economia, como os índices de Hirschman-Rasmussen e os índices puros de ligação, para frente e para trás, ${ }^{16}$ que permitem identificar os setores chave da economia. Os índices de ligação para frente possibilitam verificar o quanto um determinado setor é demandado para a produção dos demais, enquanto os índices de ligação para trás mensuram o quanto um setor demanda de outros setores da economia.

O índice de Hirschman-Rasmussen para trás é obtido a partir da matriz $L^{*}$ (média de todos os elementos de $L$ ) e de $L_{*_{j}}$ (soma de uma coluna de $L$ ), conforme a seguir.

$$
B L_{j}=\left(L_{*_{j}} / n\right) / L^{*}
$$

Já para a dedução deste índice para frente, é preciso definir a matriz de coeficientes na linha $(F)$ obtidos a partir da matriz de consumo intermediário $(Z)$.

$$
F=\hat{x}^{-1} \cdot Z
$$

Com isso, define-se a matriz de Ghosh $(G)$, com elementos $g_{i j}$, de forma semelhante à inversa da matriz de Leontief:

$$
G=(I-F)^{-1}
$$

Sendo $G^{*}$ a média de todos os elementos de $G$ e $G_{i^{*}}$ a soma dos elementos de cada linha, define-se o índice de ligação de Hirschman-Rasmussen para frente:

$$
F L_{i}=\left(G_{i^{*}} / n\right) / G^{*}
$$

\footnotetext{
${ }^{15}$ No caso da produção, multiplicador e gerador se equivalem.

${ }^{16}$ Esta parte do trabalho sobre os índices de ligação segue Miller e Blair (2009), Guilhoto (2009), Guilhoto e Sesso Filho (2005) e Liu, Polenske e Guilhoto (2010).
} 
Com o cálculo destes índices, é possível classificar os setores como: (a) independentes de (ou pouco relacionados a) outros setores, caso ambos os índices de ligação sejam inferiores a 1; (b) dependentes de (ou fortemente relacionados a) outros setores, caso ambos os índices de ligação sejam superiores a 1, o que também denota setores chave para o crescimento da economia; (c) dependentes da oferta interindustrial, se apenas o índice de ligação para trás for maior do que 1; (d) dependentes da demanda interindustrial, se apenas o índice de ligação para frente for superior a 1. (Miller e Blair, 2009)

Entretanto, estes índices não consideram os distintos níveis de produção em cada setor, ou seja, o tamanho do setor na economia. Guilhoto, Hewings e Sonis (1997) utiliza dois métodos para tal consideração: o enfoque dos setores chave e o enfoque de ligações puras. Este modelo (GHS) resulta de uma série de decomposições da matriz inversa de Leontief, conforme descrito a seguir.

Define-se uma matriz bloco de coeficientes técnicos $(A)$, composta por matrizes quadradas de coeficientes técnicos diretos do setor $\mathrm{j}\left(A_{j j}\right)$ e do resto da economia $\left(A_{r r}\right)$, e matrizes retangulares dos insumos diretos comprados pelo setor $\mathrm{j}$ do restante da economia $\left(A_{r j}\right)$ e dos insumos diretos comprados pelo restante da economia do setor $\mathrm{j}\left(A_{j r}\right)$.

$$
A=\left[\begin{array}{ll}
A_{j j} & A_{j r} \\
A_{r j} & A_{r r}
\end{array}\right]
$$

Por esta matriz $A$ subdividida, obtém-se a inversa da matriz de Leontief:

$$
L=(I-A)^{-1}=\left[\begin{array}{ll}
L_{j j} & L_{j r} \\
L_{r j} & L_{r r}
\end{array}\right]=\left[\begin{array}{cc}
\Delta_{j j} & 0 \\
0 & \Delta_{r r}
\end{array}\right]\left[\begin{array}{cc}
\Delta_{j} & 0 \\
0 & \Delta_{r}
\end{array}\right]\left[\begin{array}{cc}
I & A_{j r} \Delta_{r} \\
A_{r j} \Delta_{j} & I
\end{array}\right]
$$

Onde:

$\Delta_{j}=\left(I-A_{j j}\right)^{-1}$

$\Delta_{r}=\left(I-A_{r r}\right)^{-1}$

$\Delta_{j j}=\left(I-\Delta_{j} A_{j r} \Delta_{r} A_{r j}\right)^{-1}$

$\Delta_{r r}=\left(I-\Delta_{r} A_{r j} \Delta_{j} A_{j r}\right)^{-1}$ 
Desenvolvendo-se algebricamente a equação original do modelo de Leontief (equação 2.27) com a matriz inversa de Leontief apresentada acima, tem-se:

$$
\left(\begin{array}{l}
X_{j} \\
X_{r}
\end{array}\right)=\left(\begin{array}{cc}
\Delta_{j j} & 0 \\
0 & \Delta_{r r}
\end{array}\right)\left(\begin{array}{c}
\Delta_{j} Y_{j}+\Delta_{j} A_{j r} \Delta_{r} Y_{r} \\
\Delta_{r} A_{r j} \Delta_{j} Y_{j}+\Delta_{r} Y_{r}
\end{array}\right)
$$

Com isso, deduzem-se os índices puros de ligação para trás (PBL) e para frente (PFL), dados por:

$$
P B L=\Delta_{r} A_{r j} \Delta_{j} Y_{j}
$$

$$
P F L=\Delta_{j} A_{j r} \Delta_{r} Y_{r}
$$

Dada esta dedução, o índice puro de ligação para trás (PBL) indica o impacto do valor da produção total do setor $\mathrm{j}$ sobre o resto da economia, livre da demanda de insumos que o setor j produz para ele mesmo e dos retornos do resto da economia para o setor j e vice-versa. Já o PFL indica o impacto do valor da produção total do resto da economia sobre o setor j. Somando-se estes dois índices, obtém-se o índice puro total das ligações (PTL):

$$
P T L=P B L+P F L
$$

Como estes índices estão em valores correntes, para a comparação com os índices de Hirschman-Rasmussen, calculam-se os índices puros normalizados, dividindo-se os índices puros de cada setor pelo valor médio dos índices puros da economia como um todo. Assim, os índices puros normalizados para trás (PBLN), para frente (PFLN) e total (PTLN) são dados por:

$$
\begin{aligned}
& P B L N_{i}=P B L_{i} /\left(\sum_{i=1}^{n} P B L_{i} / n\right) \\
& P F L N_{i}=P F L_{i} /\left(\sum_{i=1}^{n} P F L_{i} / n\right) \\
& P T L N_{i}=P T L_{i} /\left(\sum_{i=1}^{n} P T L_{i} / n\right)
\end{aligned}
$$




\subsection{5- Metodologia de Cálculo}

A análise do impacto econômicos da expansão das universidades federais ocorridas na última década envolve o estudo da relação do subsetor Educação de Ensino Superior Federal com o resto da economia. Entretanto, tal subsetor não é apresentado separadamente nas contas nacionais e, consequentemente, na matriz de insumo-produto. Desta forma, usa-se o setor Educação Pública.

É utilizada a matriz de insumo-produto do ano de 2004, que possui 55 setores e 558 microrregiões. Com base nos gastos da União com universidades públicas federais por município, descritos no item referente à base de dados, agregou-se no nível microrregional, e calculou-se a variação entre cada ano (t) e o ano anterior (t-1), tomando-se 2004 como ano inicial. Desta forma, para cada um dos 6 anos (de 2005 a 2010), tem-se uma matriz de choques, com 558 microrregiões e 59 universidades (32.922 pares microrregiõesuniversidades). Foram consideradas apenas as variações positivas de gastos federais para o cálculo dos choques anuais. Desta forma, totaliza-se um total de choques de R \$ 5,3 bilhões quando consideradas as variações abertas pelos 32.922 pares de microrregião e universidades, apesar do orçamento observado ser em torno de $\mathrm{R} \$ 10$ bilhões em 2004 e R $\$ 14$ bilhões em 2010.

Aplicando-se o choque anual de cada universidade na microrregião sobre o setor Educação Pública, podem-se mensurar os efeitos diretos, indiretos e induzidos sobre as microrregiões e setores da economia para o período 2004-2010.

Desta forma, neste capítulo, serão considerados três efeitos descritos a seguir. Inicialmente, o Efeito Direto, que é constituído pelo choque de gastos de uma universidade federal aplicado à microrregião no setor Educação Pública, ou seja, aumento na demanda do governo através do aumento dos gastos públicos com esta universidade em questão. Aplicado este choque, dois outros efeitos podem ser mensurados também: o Efeito Indireto, e o Induzido. $\mathrm{O}$ primeiro efeito mede o impacto que este choque gera nos demais setores e microrregiões da economia, uma vez que a implantação e manutenção aumenta indiretamente a demanda por bens e serviços da economia. Por fim, há o Efeito Induzido (efeito renda), em que o choque, ao provocar aumento na demanda por mão de obra, consequentemente acarreta um aumento no poder aquisitivo das famílias, que por sua vez impulsiona a demanda por 
produtos finais. Tal demanda impacta sobre os diversos insumos da economia, inclusive mãode-obra, aumentando novamente o poder aquisitivo das famílias. Este processo sucessivo ocorre até que o sistema produtivo encontre um equilíbrio. Assim, o Efeito Induzido é o efeito causado pelo aumento do consumo das famílias, dado o choque inicial.

\section{3- $\quad$ Resultados}

A análise dos resultados do modelo Insumo-Produto, dados os choques anuais por universidade sobre as microrregiões no setor Educação Pública, será apresentada considerando diferentes níveis de agregação, que envolvem: região, estado, setor econômico, universidade, universidade nova, microrregião e ano. É importante ressaltar que todas as variáveis monetárias se encontram em valores de Reais de 2010.

Vale enfatizar que os efeitos locais são o resultado de todos os efeitos provenientes de todas as universidades sobre cada região. Assim, uma região é relacionada com as demais regiões não apenas pelos efeitos direto e indireto de suas próprias universidades, mas também pelo efeito indireto proveniente das universidades de outras regiões. Além disso, há também o efeito induzido pelo consumo das famílias. Portanto, uma universidade localizada numa certa região apresenta efeitos indiretamente sobre as demais regiões do País, dependendo das relações econômicas do setor Educação Pública com os demais setores e microrregiões.

É importante lembrar que, dada a recente expansão de gastos públicos com educação superior federal, os resultados aqui apresentados buscam mostrar os efeitos de curto prazo.

\subsection{1- Impacto Regional}

Considerando o efeito conjunto das 59 universidades federais sobre a economia, incialmente analisam-se os impactos sobre as cinco regiões brasileiras, buscando uma análise macrorregional da questão. 
Pelo gráfico a seguir, observa-se que a região Sudeste apresenta o maior impacto econômico. Ainda que tenha recebido os maiores choques microrregionais, como se pode verificar pelo maior efeito direto, esta região se destaca pelo maior efeito induzido, que representa pouco mais de $70 \%$ do efeito total. Isto evidencia o forte efeito renda do consumo das famílias, dado um certo acréscimo no gasto público com educação. $\mathrm{O}$ efeito indireto em valor absoluto é o maior do País, mas relativamente a sua participação sobre o efeito total da região, é apenas o terceiro maior, representando 7,8\% do total, ficando atrás das regiões Centro-Oeste e Sul, cujos efeitos indiretos representam 11,4\% e 9,3\% dos respectivos efeitos regionais totais. Assim, a região Sudeste significa 46,2\% do efeito total no Brasil, que é de R\$ 19,9 bilhões.

\section{Gráfico 2.3 - Efeitos Regionais da Expansão sobre Valor Bruto da Produção no Período} 2004-2010

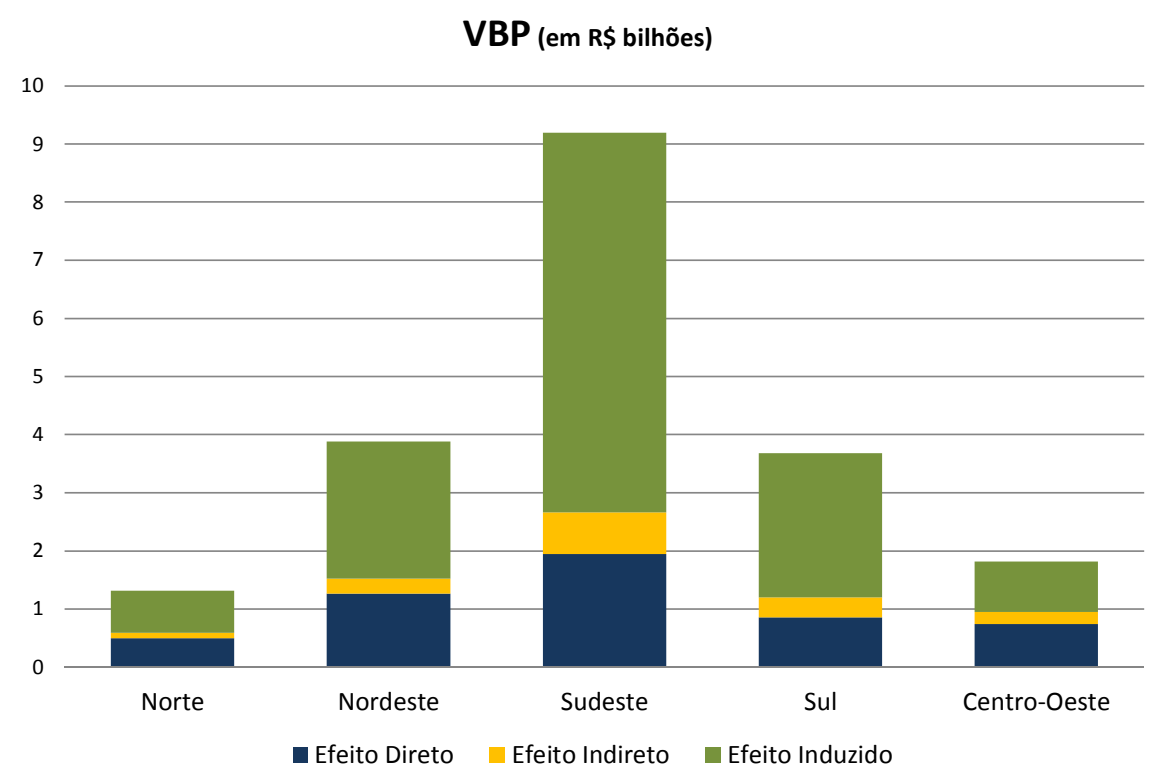

Fonte: Elaboração própria a partir da Matriz Insumo-Produto 
As regiões Nordeste e Sul apresentam respectivamente o segundo e terceiro maiores efeitos totais, acima dos R\$ 3 bilhões cada. Ainda que a região Nordeste tenha maior efeito direto, a Sul se destaca sobre ela pelos efeitos indireto e induzido.

A região Centro-Oeste apresenta a maior participação dos efeitos direto e indireto sobre o seu total, e consequentemente a menor proporção de efeito induzido. Assim, relativamente às demais regiões, esta região tem o maior potencial de difundir um choque sobre os setores e microrregiões adjacentes, sem considerar o efeito do consumo das famílias. Difunde mais de $50 \%$ do impacto sobre a economia através dos efeitos direto e indireto. Enquanto que a Sudeste difunde mais de $70 \%$ pelo induzido. Por fim, a região Norte apresenta os menores efeitos sobre a economia.

Com relação ao valor adicionado, a região Sudeste apresenta um efeito de $\mathrm{R} \$ 5,0$ bilhões, seguida pela Nordeste com R \$ 2,5 bilhões e Sul com R \$ 2,0 bilhões. Vale destacar o efeito renda do consumo das famílias na região Sudeste de $\mathrm{R} \$ 3,1$ bilhões, representando $62 \%$ do efeito total nesta região. A região Sudeste participa com $37 \%$ do efeito direto e $44 \%$ do resultado total do Brasil.

É importante lembrar que estes efeitos regionais são o resultado de todos os efeitos provenientes de todas as universidades sobre cada região. Uma vez que a região Sudeste é a mais relacionada com as demais regiões, naturalmente recebe também o maior efeito indireto proveniente das universidades de outras regiões, além do efeito indireto de suas próprias universidades.

Por fim, as regiões Centro-Oeste e Norte apresentam um efeito por volta de R\$ 1 bilhão, representando 9,6\% e 7,6\% dos R\$ 11,5 bilhões sobre valor adicionado no Brasil. 


\section{Gráfico 2.4 - Efeitos Regionais da Expansão sobre Valor Adicionado no Período 2004- 2010}

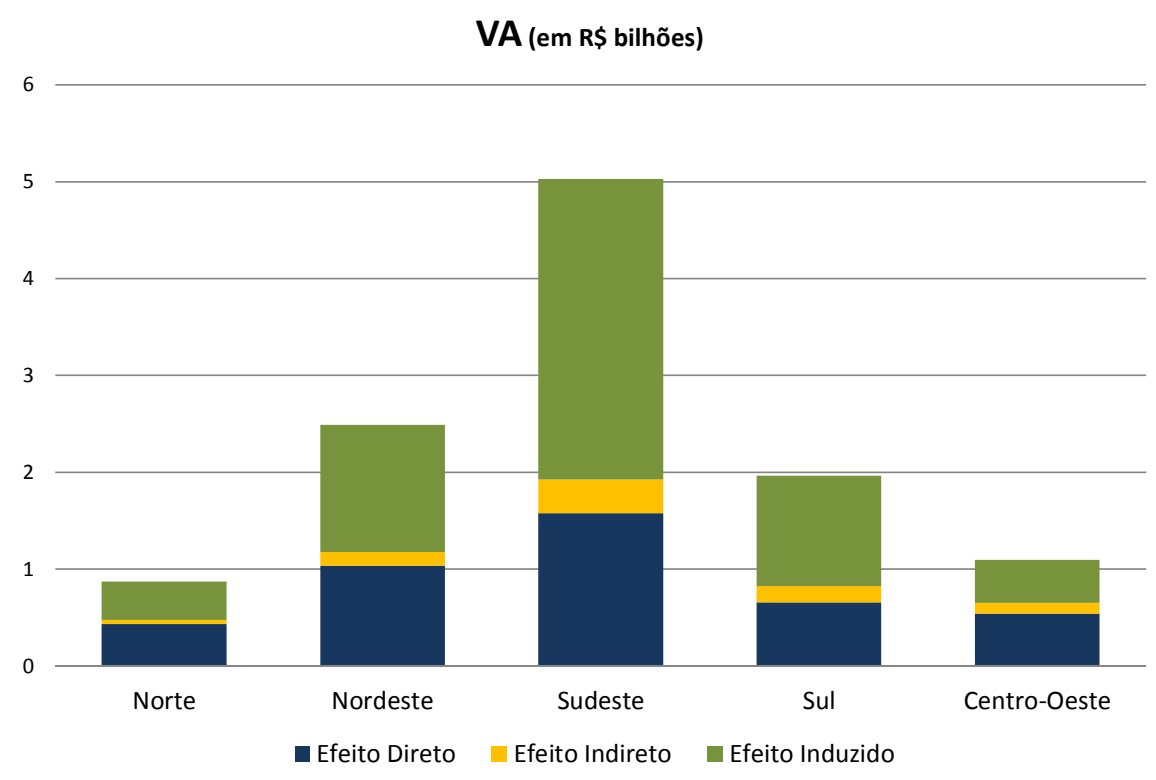

Fonte: Elaboração própria a partir da Matriz Insumo-Produto

Os efeitos aqui mensurados são acumulados no período analisado. Uma vez que está sendo analisado o valor adicionado, é relevante comparar tais resultados com os PIB's regionais e nacional. Assim, tem-se uma melhor sensibilidade sobre a magnitude do efeito. Considerando o PIB de $2004{ }^{17}$ como referência, por ser o ano base da Matriz Insumo-Produto, o impacto da expansão dos gastos públicos federais com universidades é de $0,39 \%$ sobre o PIB nacional, sendo de $0,06 \%$ em média por ano. A região com maior impacto acumulado sobre o PIB regional é a Nordeste com 0,67\%, seguida pelas regiões Norte e Centro-Oeste, com impactos de $0,60 \%$ e $0,41 \%$, respectivamente. As regiões mais ricas do País, Sudeste e Sul, apresentam impacto de $0,31 \%$ e $0,38 \%$, respectivamente. Vale mencionar que se for considerado como referência o PIB de 2010, então o impacto nacional cai para $0,30 \%$.

Do ponto de vista do impacto nacional da expansão universitária sobre pessoal ocupado, constata-se um aumento de 467 mil no número de pessoas ocupadas no período, sendo em média 7,9 mil por universidade e 77,8 mil por ano.

\footnotetext{
${ }^{17}$ Em valores do ano de 2010.
} 


\section{Gráfico 2.5 - Efeitos Regionais da Expansão sobre Pessoal Ocupado no Período 2004-} 2010

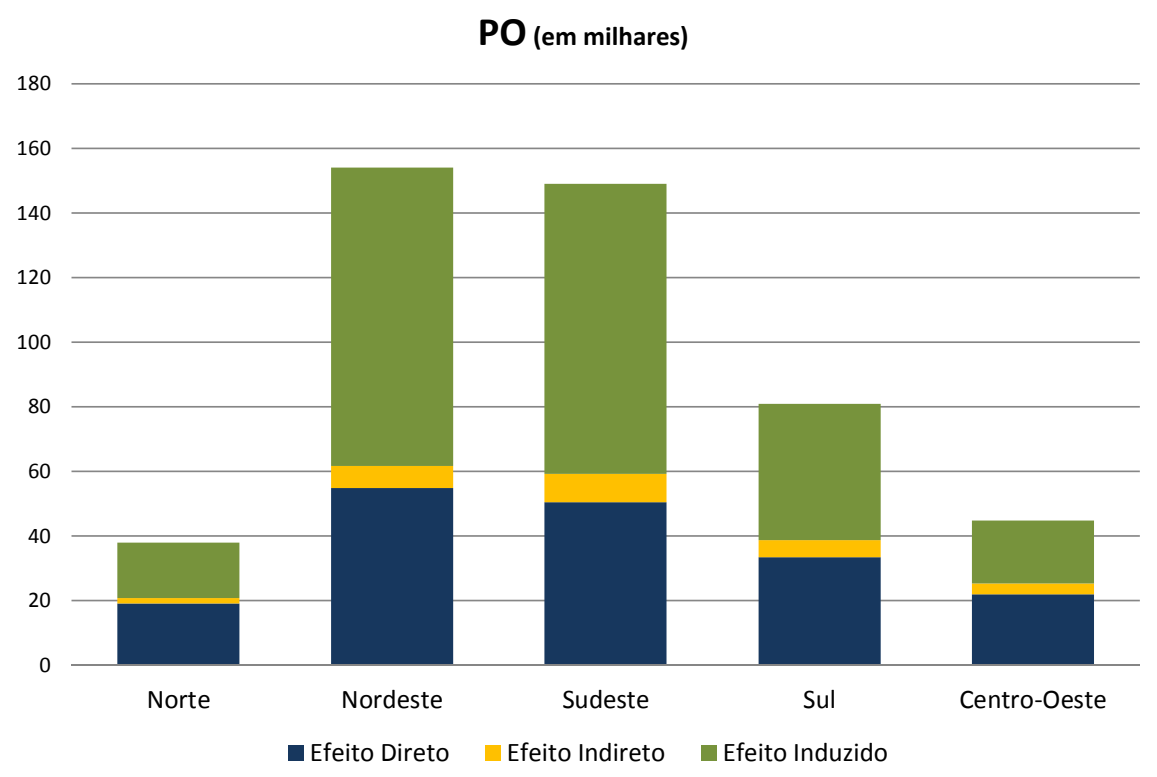

Fonte: Elaboração própria a partir da Matriz Insumo-Produto

Regionalmente, os resultados com relação a pessoal ocupado destacam-se, pois a região Sudeste, que têm um choque monetário 53\% maior do que a Nordeste, não apresenta o maior impacto sobre pessoal ocupado. Na verdade, a região Nordeste mostra o maior efeito total no Brasil, sendo da ordem de 154 mil pessoas ocupadas, contra 149 mil da região Sudeste. Considerando os efeitos direto, indireto e induzido, a região Nordeste apresenta uma diferença sobre a Sudeste de 4,4 mil, -2,0 mil e 2,6 mil, respectivamente. Assim, apesar de um choque 53\% menor, a região Nordeste tem um efeito direto de $8,8 \%$ maior sobre pessoal ocupado quando comparada com a Sudeste. As demais regiões juntas recebem um aumento de 163,5 mil pessoas ocupadas.

Enfim, consta-se que a região Sudeste recebe $36,6 \%$ do choque nacional e apresenta a maior participação no resultado nacional, com 46,2\% e 43,9\%, respectivamente, sobre valor bruto da produção e valor adicionado. Já sobre pessoal ocupado, destaca-se a região Nordeste com 33,0\% do efeito total. Para valor bruto da produção e valor adicionado, esta região tem o segundo maior resultado. As regiões Sul, Centro-Oeste e Norte apresentam em média uma participação de $17,7 \%, 9,4 \%$ e 7,5\%, respectivamente, sobre as três variáveis consideradas. 


\subsection{2- Impacto Estadual}

Detalhando-se o impacto regional, pode-se analisar o impacto da expansão dos gastos públicos com universidades federais no nível estadual. Em consonância com o nível regional, três dos quatro estados da região Sudeste apresentam os maiores efeitos totais sobre valor bruto da produção. Em primeiro lugar está São Paulo, seguido por Minas Gerais e Rio de Janeiro. Pelo efeito direto, que no caso é o próprio choque, Minas Gerais recebe o maior montante, seguido por Rio de Janeiro e São Paulo. Além de receber o terceiro maior efeito direto, o estado de São Paulo se destaca por apresentar o maior efeito total, da ordem de R\$ 4,3 bilhões, com os efeitos indireto e, principalmente, induzido, sendo aproximadamente o dobro dos efeitos em Minas Gerais, que é o estado com o segundo maior efeito total.

\section{Gráfico 2.6 - Efeitos Estaduais da Expansão sobre Valor Bruto da Produção no Período} 2004-2010

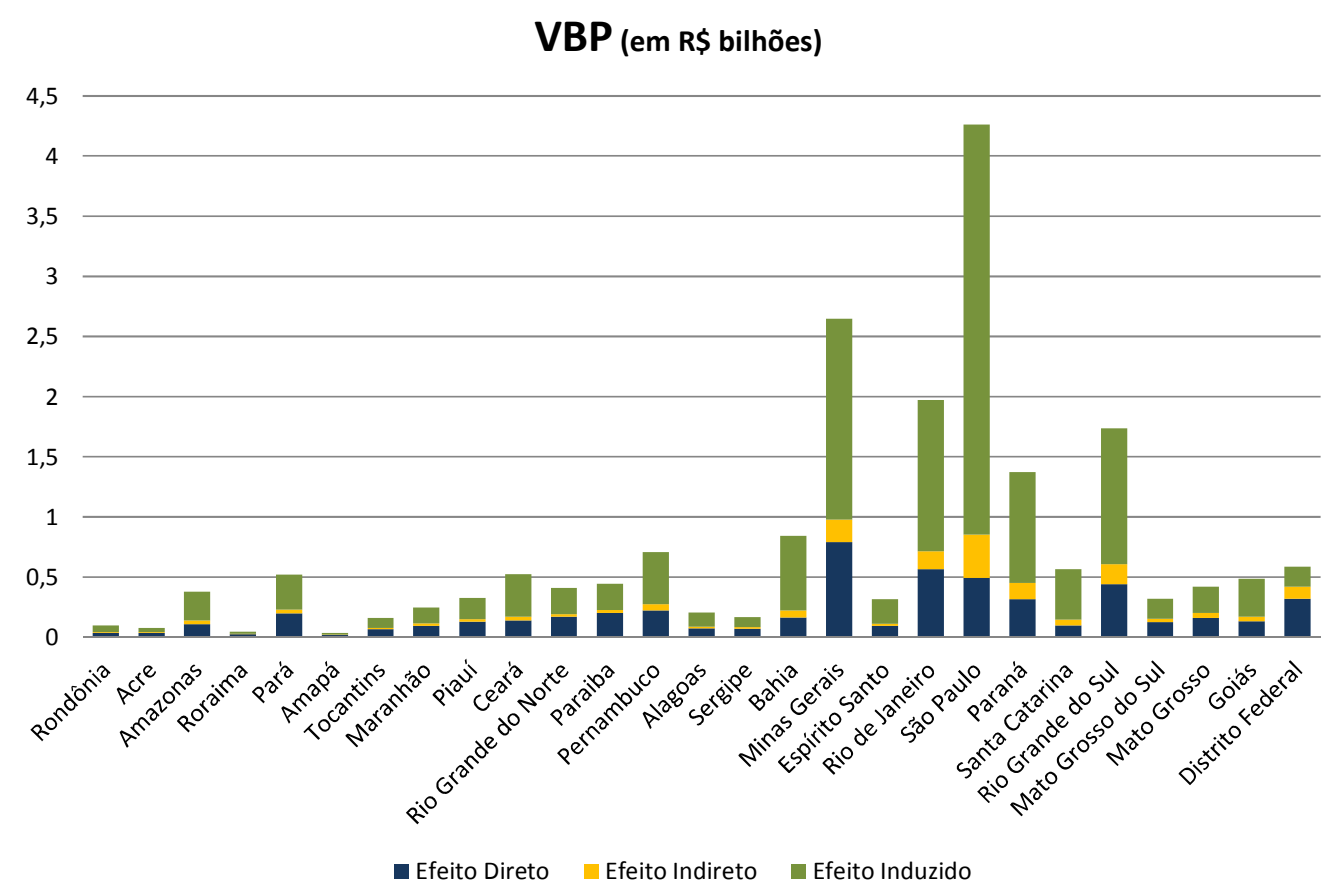

Fonte: Elaboração própria a partir da Matriz Insumo-Produto 
Fora da região Sudeste, destacam-se o Rio Grande do Sul, com o quarto maior efeito total ( $\mathrm{R}$ \$ 1,7 bilhões), seguido pelo Paraná com R \$ 1,4 bilhões, a Bahia e Pernambuco, com efeitos acima de R 700 milhões.

Com relação à participação dos efeitos direto, indireto e induzido sobre o total de cada unidade da federação; destacam-se São Paulo com uma proporção do efeito induzido da ordem de 80\%, Distrito Federal com 17\% de efeito indireto, e Roraima com 55\% de efeito direto (apenas $0,25 \%$ do efeito direto total no País).

Analisando o aumento em valor adicionado em cada estado, novamente São Paulo apresenta o maior valor, acima de $\mathrm{R} \$ 2$ bilhões (17,6\% do efeito total nacional), onde se destaca o efeito induzido, que corresponde a $23 \%$ deste efeito no País.

Gráfico 2.7 - Efeitos Estaduais da Expansão sobre Valor Adicionado no Período 20042010

VA (em R\$̣ bilhões)

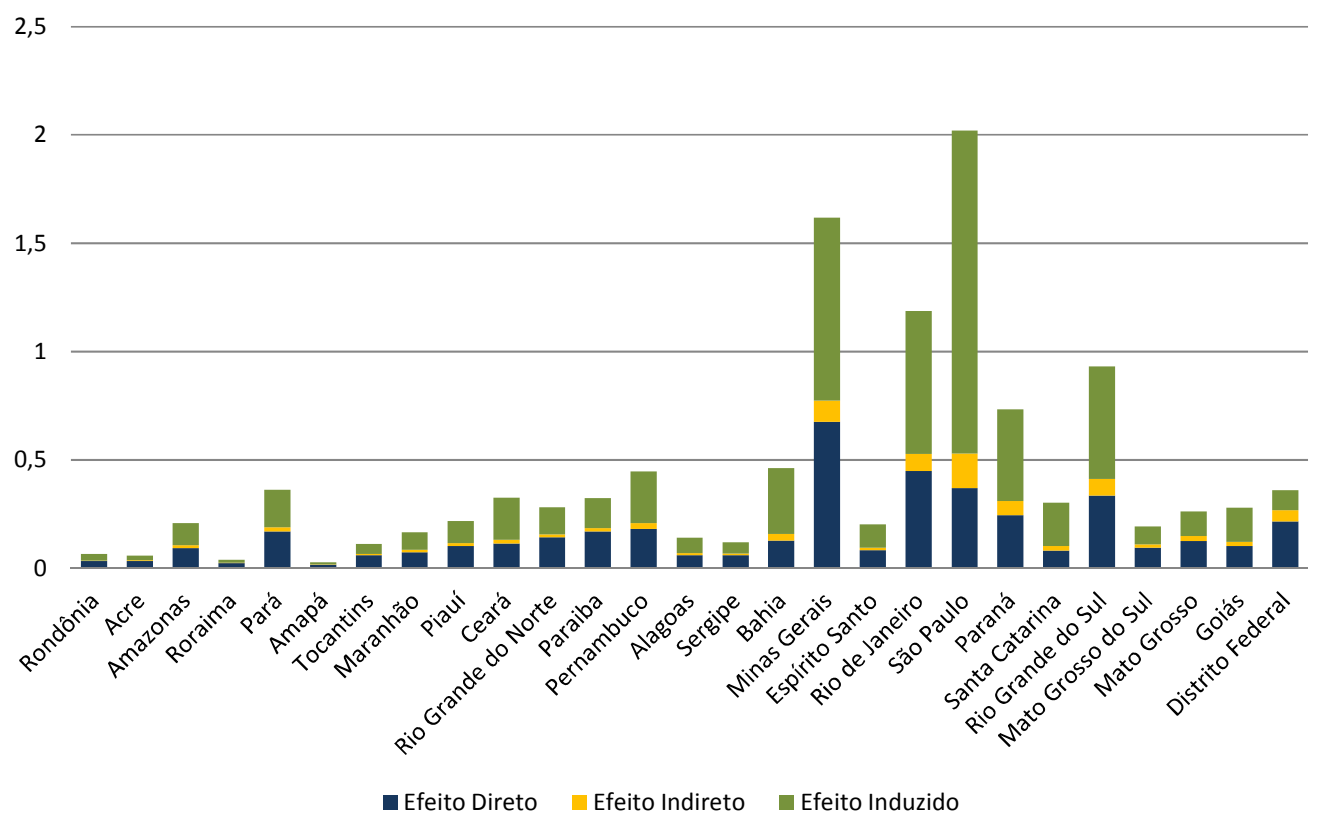

Fonte: Elaboração própria a partir da Matriz Insumo-Produto 
Apesar de Minas Gerais e Rio de Janeiro terem os maiores efeitos diretos sobre o valor adicionado, seus efeitos totais são menores do que em São Paulo. Em geral, os resultados acompanham os de valor bruto da produção, inclusive com relação à participação de cada efeito sobre o total de cada estado.

Do ponto de vista do efeito sobre pessoal ocupado, os resultados não seguem o mesmo padrão de valor bruto da produção e valor adicionado, especialmente devido aos efeitos sobre a região Nordeste. O estado com o maior efeito total novamente é São Paulo, com aumento de 53,8 mil pessoas ocupadas (11,5\% do total Brasil), continuando sendo o primeiro em efeito induzido (38 mil pessoas ocupadas), devido à sua economia ser mais desenvolvida e relacionada com as demais regiões. Este último fato faz deste estado o com maior efeito indireto também (aumento de quase 4 mil pessoas ocupadas).

Gráfico 2.8 - Efeitos Estaduais da Expansão sobre Pessoal Ocupado no Período 20042010

PO (em milhares)

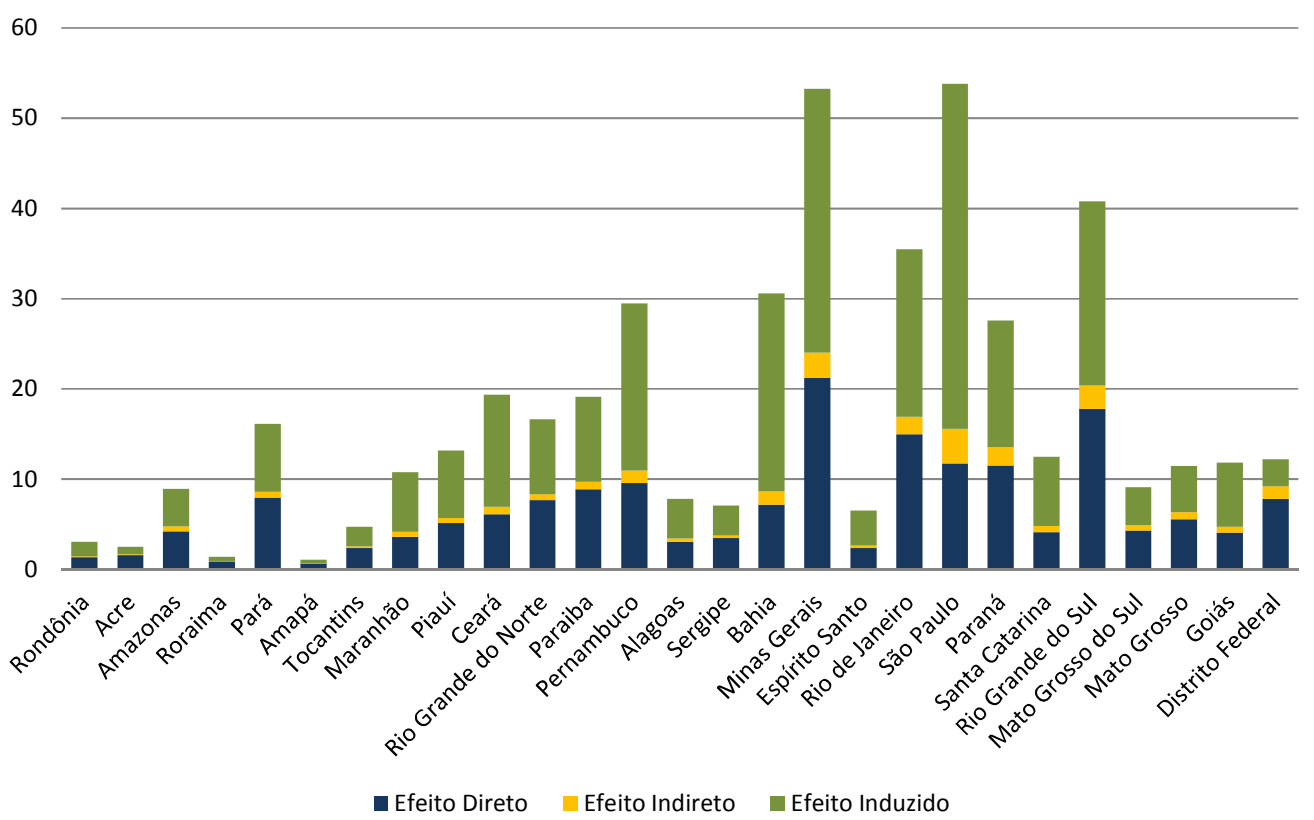

Fonte: Elaboração própria a partir da Matriz Insumo-Produto 
O estado de Minas Gerais recebe efeito total muito próximo ao de São Paulo, com expansão de 53,2 mil ao número de pessoas ocupadas.

Vale destacar o Rio Grande do Sul, que assume a terceira posição em efeito sobre pessoal ocupado, com aumento de quase 41 mil pessoas ocupadas. Fora das regiões Sudeste e Sul, destacam-se Pernambuco e Bahia, com valores acima de 29 mil pessoas ocupadas. No caso deste último, apresenta o terceiro maior efeito induzido do País, próximo de 22 mil pessoas ocupadas, sendo o de maior participação interna $(71,7 \%)$ sobre o seu efeito total em todas as unidades da federação.

É importante observar que o significativo efeito sobre pessoal ocupado nos estados da região Nordeste não vem acompanhado por resultados sobre valor bruto da produção e valor adicionado. Tal fato provavelmente está relacionado com a menor produtividade da mão-deobra nesta região em comparação às regiões Sudeste e Sul. Isto se deve também ao fato da região Nordeste apresentar uma maior presença de empresas tradicionais e mais intensivas em mão-de-obra.

Portanto, em geral, São Paulo apresenta os maiores efeitos sobre a economia nacional, seguido pelo estado de Minas Gerais se destaca. Vale ainda mencionar que o Rio Grande do Sul, que tem efeitos sobre valor bruto da produção e valor adicionado abaixo do Rio de Janeiro, apresenta o terceiro maior efeito para pessoal ocupado.

\subsection{3- Impacto Setorial}

Como descrito no item Metodologia de Cálculo, o choque de cada universidade na microrregião é aplicado integralmente no setor Educação Pública. Desta forma todo efeito direto, independente da variável analisada (valor bruto da produção, valor adicionado e pessoal ocupado), está neste setor. Para a análise setorial, os gráficos não apresentarão este setor, buscando destacar os demais; porém, para cada variável, os efeitos do setor Educação Pública serão mencionados e quantificados. Tal efeito é mostrado na tabela abaixo. 
Tabela 2.4 - Efeitos da Expansão sobre o Setor Educação Pública no Período 2004-2010

\begin{tabular}{lrrr}
\hline \multicolumn{1}{c}{ Efeito } & VPB & VA & PO \\
\hline Direto & $5.311,83$ & $4.250,36$ & 179.663 \\
Indireto & 0,36 & 0,28 & 12 \\
Induzido & 1,85 & 1,46 & 59 \\
\hline Total & $5.314,04$ & $4.252,11$ & 179.733 \\
\hline
\end{tabular}

Obs.: VBP = Valor Bruto da Produção (em R \$ milhões);

$\mathrm{VA}=$ Valor Adicionado (em R $\$$ milhões); $\mathrm{PO}=$ Pessoal Ocupado.

Fonte: Elaboração própria a partir da Matriz Insumo-Produto

Observa-se que o efeito direto é predominante no setor Educação Pública, representando $99,96 \%{ }^{18}$, independente da variável analisada. Isto mostra que tal setor apresenta baixo efeito feedback ${ }^{19}$. Entretanto apresenta significativo efeito spillover, ao provocar o aumento da demanda dos demais setores e microrregiões, como vem sendo estudado neste capítulo. É importante lembrar que, como os choques são concentrados no setor Educação Pública, todos os efeitos diretos registrados neste modelo, em qualquer nível de agregação, estão neste setor, não existindo tais efeitos em quaisquer outros setores em uma determinada microrregião.

Ao se analisar o efeito sobre a produção, a partir de um choque de $\mathrm{R} \$ 5,3$ bilhões no setor Educação Pública, constata-se que o setor que tem o maior efeito total é o de Alimentos e Bebidas, com R\$ 1,5 bilhões sobre valor bruto da produção. Este setor não tem um efeito indireto elevado (apenas 5\% de seu efeito total), mas sim um alto efeito induzido. Isto indica que é um setor em que o consumo das famílias é o grande responsável pelo seu desempenho, dado um choque de demanda no setor Educação Pública.

\footnotetext{
${ }^{18}$ Como pode ser também observado nos gráficos do Apêndice C.

${ }^{19}$ Efeito feedback ocorre quando um setor $\mathrm{i}$, que provoca o choque, aumenta a demanda dos demais setores $\mathrm{j}$ $(\mathrm{j} \neq \mathrm{i})$ e estes, por conseguinte, demandam bens e serviços do setor $\mathrm{i}$.
} 


\section{Gráfico 2.9 - Efeitos Setoriais da Expansão sobre Valor Bruto da Produção no Período 2004-2010}

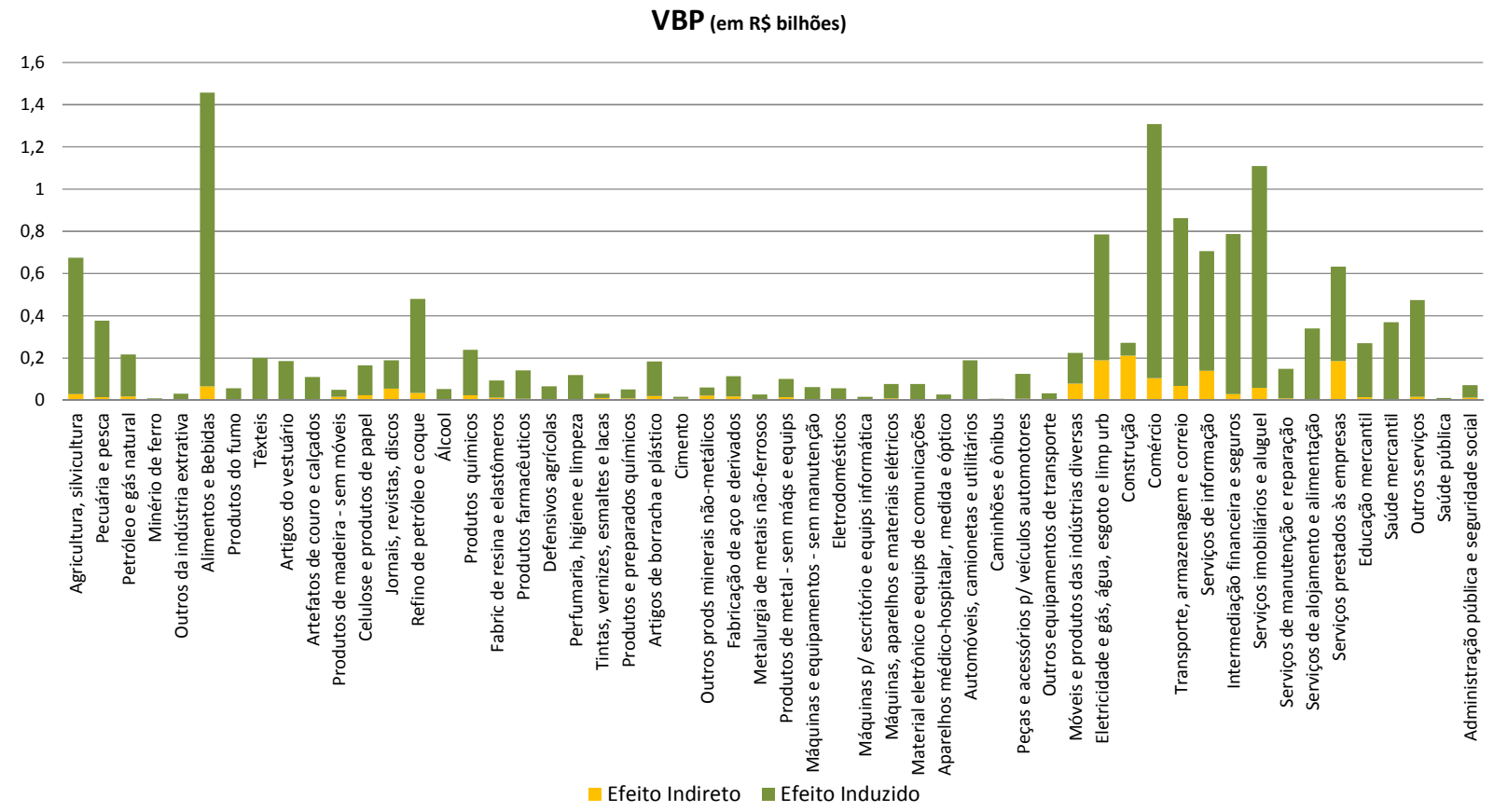

Obs.: O setor Educação Pública (omitido neste gráfico, mas representado na Tabela 2.4) concentra o efeito direto, sendo os demais efeitos muito pequenos.

Fonte: Elaboração própria a partir da Matriz Insumo-Produto

Como já constatado neste capítulo, a maior parte dos efeitos sobre as microrregiões e setores se deve ao efeito induzido, visto que o choque no setor Educação Pública se espalha pela economia principalmente via consumo das famílias. Este setor não se caracteriza pela oferta de bens, mas sim de serviços e renda para às famílias através da remuneração do trabalho. É sempre importante enfatizar que, dado o fenômeno estudado aqui, os modelos apresentados buscam medir os efeitos de curto prazo. Assim, este choque em Educação Pública não gera aumento do capital humano, apenas o remunera. 
Cabe destacar ainda os setores de Comércio (R $\$ 1,3$ bilhão) e Serviços Imobiliários e Aluguel (R\$ 1,1 bilhão). No caso do primeiro setor, fica evidenciado o efeito de uma universidade sobre o comércio local, através principalmente do consumo das famílias. O seu efeito indireto se deve ao próprio consumo da universidade como empresa pública, que pressiona a produção. Já o segundo setor, mostra um fato bastante comentado pela literatura, mídia e agentes políticos: aumento da demanda por produtos do setor imobiliário. A instalação/existência de uma universidade em determinado local aumenta a demanda por moradia, por farte das famílias, justificando um forte efeito induzido pela renda ${ }^{20}$.

O setor de Construção tem efeito indireto de R 211 milhões sobre valor bruto da produção, que é próximo dos $80 \%$ de seu efeito total. Tal predominância do efeito indireto é consequência principal da demanda da universidade por construção de campi, prédios e moradias. Outros setores que apresentam impacto total relevante, da ordem de R $\$ 700$ milhões, são Agricultura, Silvicultura e Exploração Florestal, Eletricidade e Gás, Água, Esgoto e Limpeza Urbana, Transporte, Armazenagem e Correio, Serviços de Informação, e Intermediação Financeira e Seguros, e Serviços Prestados às Empresas. Com exceção do primeiro, que é bastante correlacionado com os demais setores da economia, todos os demais se caracterizam por serem setores de serviços.

Quando se observa o efeito do choque de Educação Pública nos demais setores e consequente efeito sobre o valor adicionado destes setores, constata-se que o setor que gera o maior valor adicionado é Serviços Imobiliários e Aluguel (quase R \$ 1,1 bilhão), representado $9,2 \%$ do efeito total sobre valor adicionado e $0,036 \%$ do PIB nacional de 2004 (e 0,028\% do PIB nacional de 2010).

\footnotetext{
${ }^{20}$ Apesar do aumento da demanda poder provocar pressões sobre o preço dos aluguéis, isto não é considerado no modelo aplicado neste trabalho.
} 


\section{Gráfico 2.10 - Efeitos Setoriais da Expansão sobre Valor Adicionado no Período 2004-} 2010

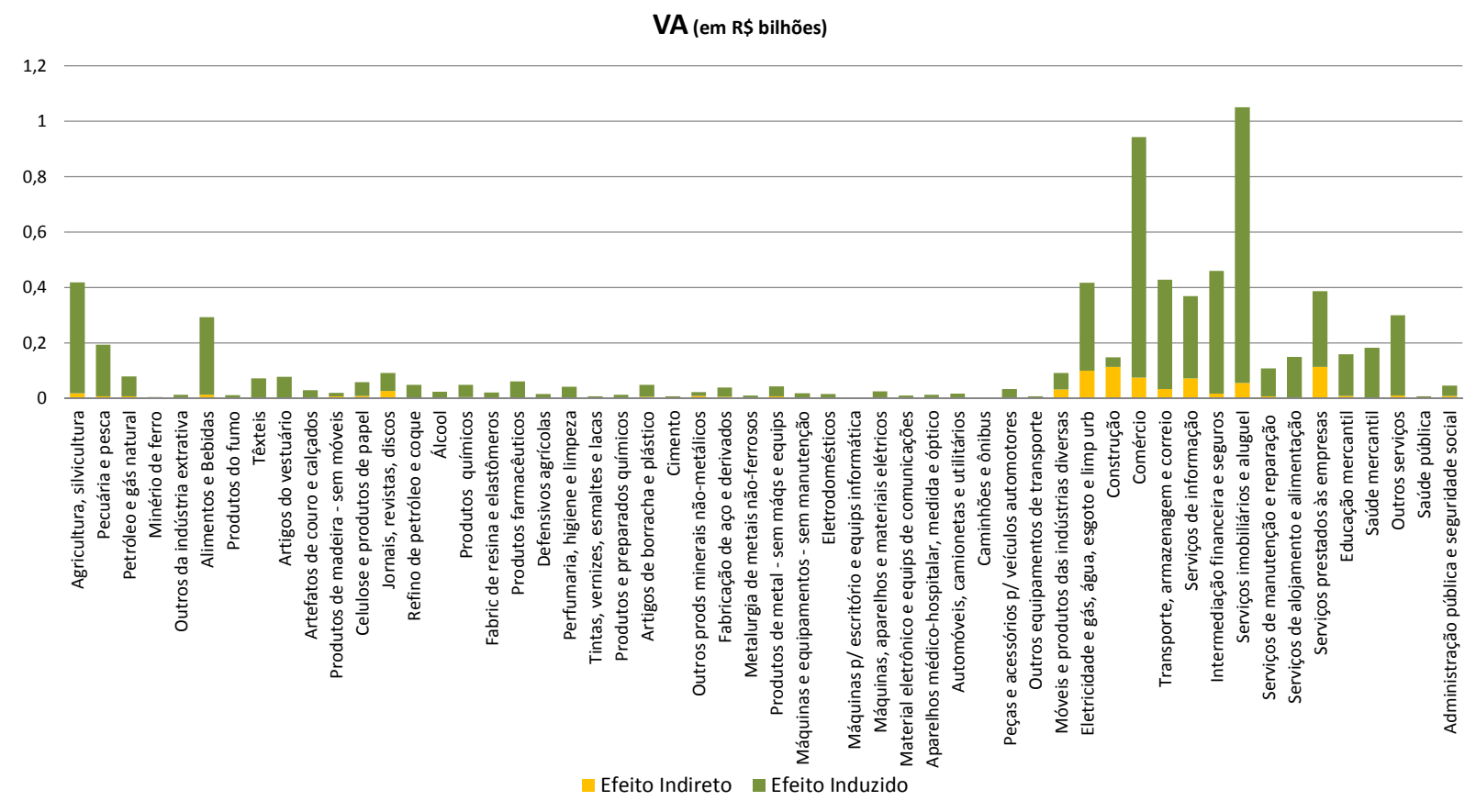

Fonte: Elaboração própria a partir da Matriz Insumo-Produto

Além do setor Serviços Imobiliários e Aluguel, o setor de Comércio também apresenta forte efeito sobre o valor adicionado (R 942 milhões), que é 0,032\% do PIB do País em 2004 e $8,2 \%$ do efeito total sobre valor adicionado. Novamente o setor de Construção apresenta o maior efeito indireto, mas apenas um efeito de $\mathrm{R} \$ 148$ milhões sobre o valor adicionado. Os demais setores que se destacam aqui são os mesmos apresentados para valor bruto da produção, mas o setor de Alimentos e Bebidas tem participação pequena sobre o efeito total, correspondendo a apenas $\mathrm{R} \$ 293$ milhões, que é 2,6\% do efeito total sobre valor adicionado.

Considerando o efeito sobre pessoal ocupado, os setores que mais se destacam são Comércio e Agricultura, Silvicultura e Exploração Florestal, com efeito de 52,2 mil e 48,2 mil sobre o número de pessoas ocupadas. Ao todo, o efeito total é de 467 mil pessoas ocupadas. Estes dois setores juntos correspondem a $21,5 \%$ do efeito total sobre pessoal ocupado. 
Gráfico 2.11 - Efeitos Setoriais da Expansão sobre Pessoal Ocupado no Período 20042010

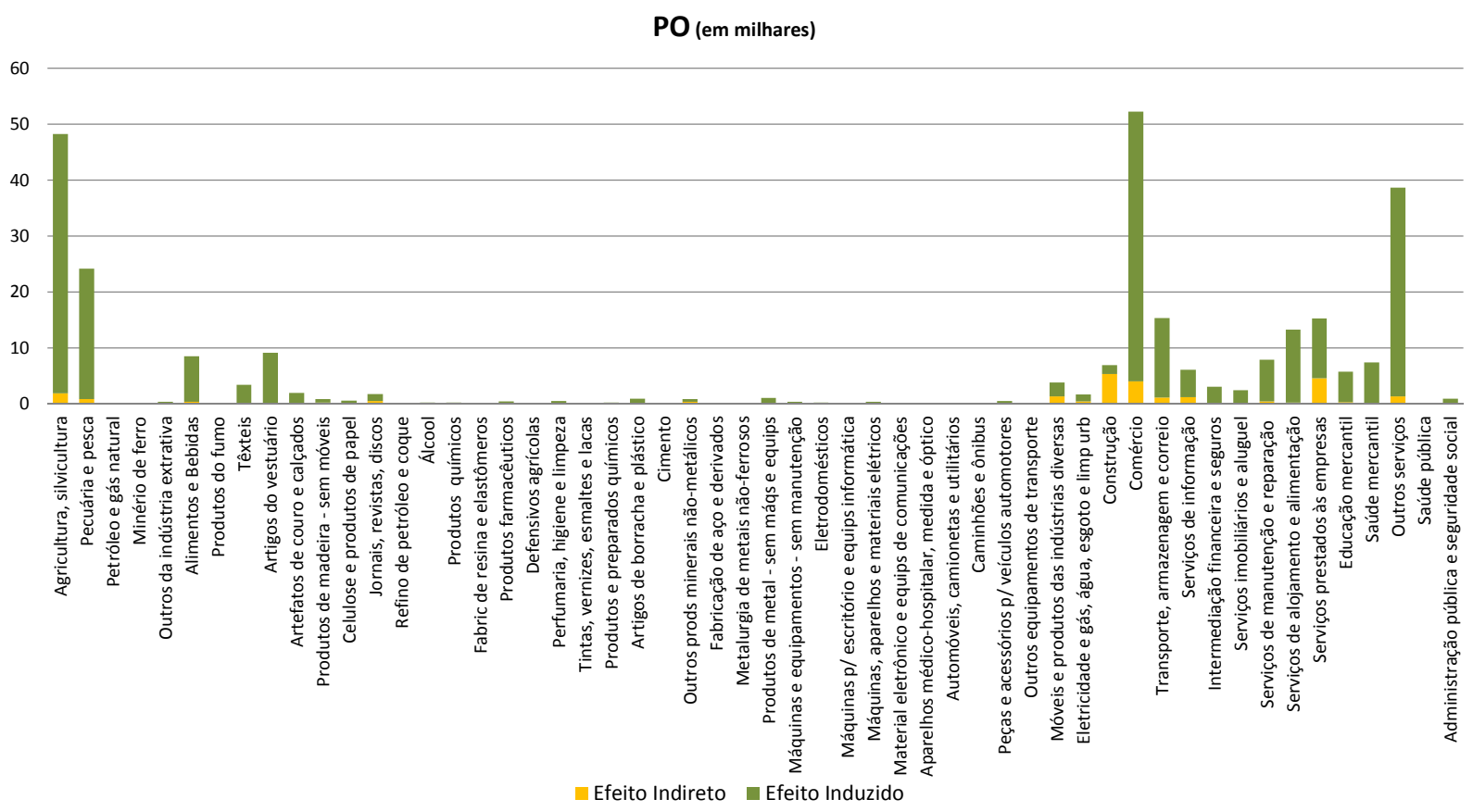

Fonte: Elaboração própria a partir da Matriz Insumo-Produto

Outros dois setores que merecem menção são Outros Serviços, com efeito de 38,7 mil (8,3\% do total), e Pecuária e Pesca, com efeito de 24,2 mil (5,2\%). Vale ressaltar que o setor de Construção, apesar de apresentar efeito baixo (6,9 mil) sobre pessoal ocupado, tem o maior efeito indireto, recebendo um impacto positivo de 5,3 mil sobre o número de pessoas ocupadas.

Enfim, com relação à produção, o setor Alimentos e Bebidas gera o maior efeito na economia, mas pouco representa sobre valor adicionado e pessoal ocupado. Já o setor de Comércio apresenta grandes efeitos sobre as três variáveis, sendo o segundo maior efeito sobre valor bruto da produção e valor adicionado, e o primeiro maior efeito sobre pessoal ocupado, resultando em mais de 50 mil pessoas ocupadas.

O setor de Agricultura, Silvicultura e Exploração Florestal, que tem uma razoável significância em valores monetários, é o segundo maior produtor de empregos, chegando a pouco mais de 48 mil pessoas ocupadas. Tal conclusão retrata a situação agregada nacional. Abrindo-se o setor de Agricultura, Silvicultura e Exploração Florestal pelas regiões 
geográficas, constata-se que a região Nordeste representa $38,6 \%$ do efeito indireto sobre o pessoal ocupado e apenas $12,6 \%$ e $15,2 \%$ do efeito indireto sobre valor bruto da produção e valor adicionado, respectivamente. O mesmo ocorre com esta região pelo efeito induzido, representando $49,7 \%$ do efeito sobre pessoal ocupado e somente $18,5 \%$ e $21,9 \%$ sobre valor bruto da produção e valor adicionado, respectivamente. Assim, apesar da grande participação sobre o número de pessoas ocupadas, o impacto sobre valor bruto da produção e valor adicionado é proporcionalmente menor. Isto provavelmente é um reflexo do setor ser mais intensivo em mão-de-obra na região Nordeste em comparação à média nacional.

\subsection{4- Impacto Nacional por Universidade}

Considerando os choques anuais de gastos públicos sobre as 59 universidades federais brasileiras, podem-se calcular os impactos de cada universidade sobre a economia. Aplicando tais choques individualmente para cada universidade é possível isolar o efeito de cada uma. Tal efeito, como já descrito, se subdivide em efeito direto, indireto e induzido.

O gráfico a seguir apresenta estes efeitos originados por cada universidade sobre o valor bruto da produção. Pode-se observar que a UNIFESP ${ }^{21}$ recebe o segundo maior choque (efeito direto), porém tem o maior efeito total, destacando-se o efeito induzido devido ao consumo das famílias. Tal efeito renda expressivo provavelmente provem da localização da universidade, uma vez que sua estrutura abrange áreas com grandes economias, com destaque para a sua sede no município de São Paulo ${ }^{22}$. Mesmo fenômeno ocorre com a UFRJ e a UFF, que apresentam os terceiro e quarto maiores choques, respectivamente. Contudo, a UFRJ tem o segundo maior efeito total e a UFF tem o quarto maior efeito total.

\footnotetext{
${ }^{21}$ No Apêndice C, a tabela A1 mostra o significado de cada sigla, apresentando o nome de cada universidade. Tal significado também pode ser encontrado na Lista de Abreviaturas e Siglas.

${ }^{22}$ A UNIFESP está presente nas microrregiões São Paulo, Santos, Guarulhos e São José dos Campos, todas no Estado de São Paulo.
} 


\section{Gráfico 2.12 - Efeitos da Expansão sobre Valor Bruto da Produção por Universidade no} Período 2004-2010

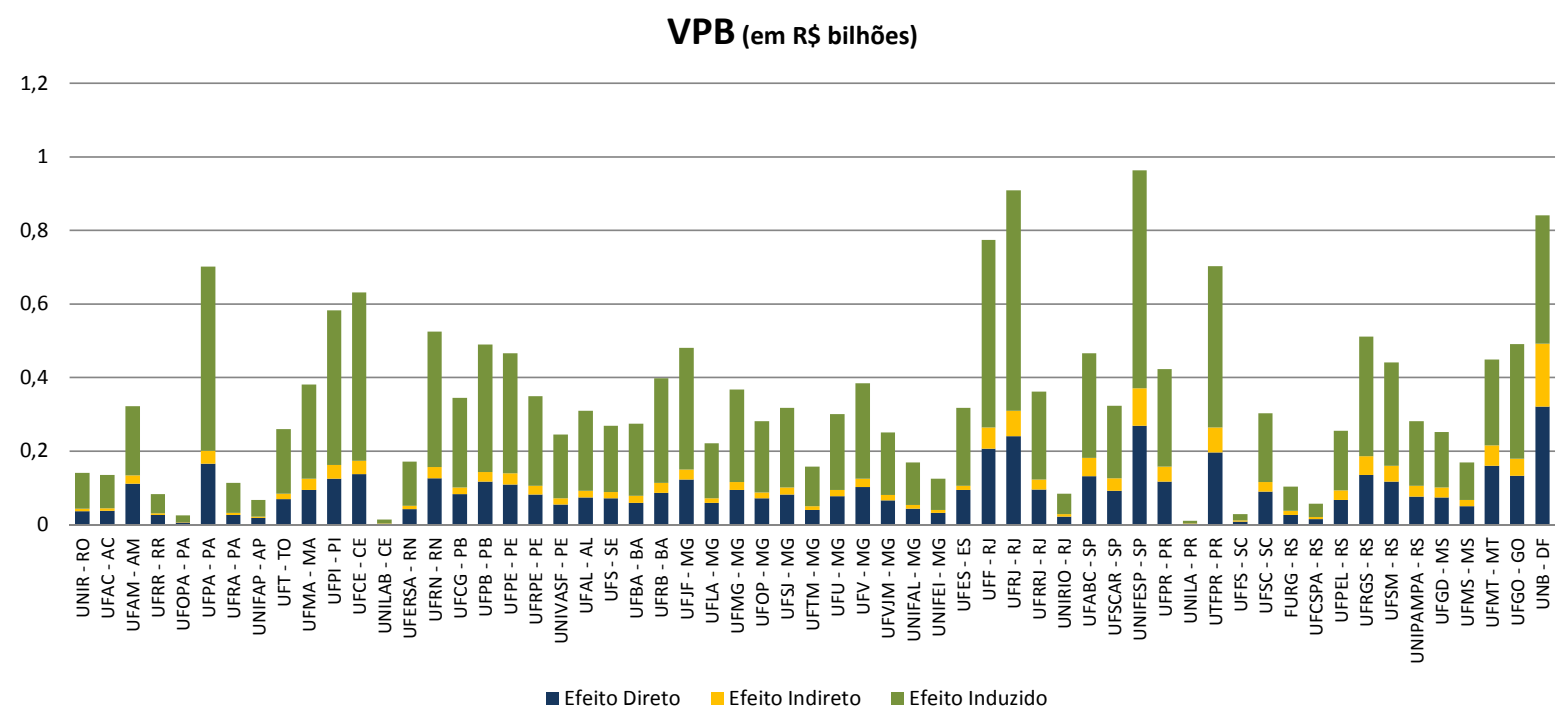

Obs.: A sigla de unidade da federação apresentada após a sigla da universidade é referente ao estado onde se localiza a sede da universidade.

Fonte: Elaboração própria a partir da Matriz Insumo-Produto

A UNB é a universidade que recebe no período a maior variação positiva de gastos públicos federais; porém, devido à economia do Distrito Federal apresentar um efeito renda baixo, quando comparado com Rio de Janeiro e São Paulo, o efeito induzido desta universidade não é tão expressivo. Entretanto, o efeito indireto da UNB é bastante significativo, sendo a universidade que provoca o maior efeito indireto sobre a economia regional, tanto do ponto de vista absoluto, quanto do relativo, representando aproximadamente $20 \%$ do efeito total, enquanto que nas demais universidades do País o efeito indireto representa menos de $10 \%$ do total. ${ }^{23}$

Vale mencionar ainda a UFPA que recebe o maior choque das regiões Norte e Nordeste e figura com o sexto maior efeito total sobre valor bruto da produção no País.

Com relação ao valor adicionado, as quatro universidades com maiores efeitos seguem o resultado anterior sobre valor bruto da produção. Observa-se que a UNIFESP e a UFRJ apresentam um efeito acima de $\mathrm{R} \$ 500$ milhões, recebendo choques ao redor de $\mathrm{R} \$ 200$

\footnotetext{
${ }^{23}$ No Apêndice C, são apresentadas as tabelas com os valores relativos (\%) dos efeitos sobre Valor Bruto da Produção.
} 
milhões. Assim, para estas duas universidades, constata-se um efeito multiplicativo próximo de 2,5 .

\section{Gráfico 2.13 - Efeitos da Expansão sobre Valor Adicionado por Universidade no} Período 2004-2010

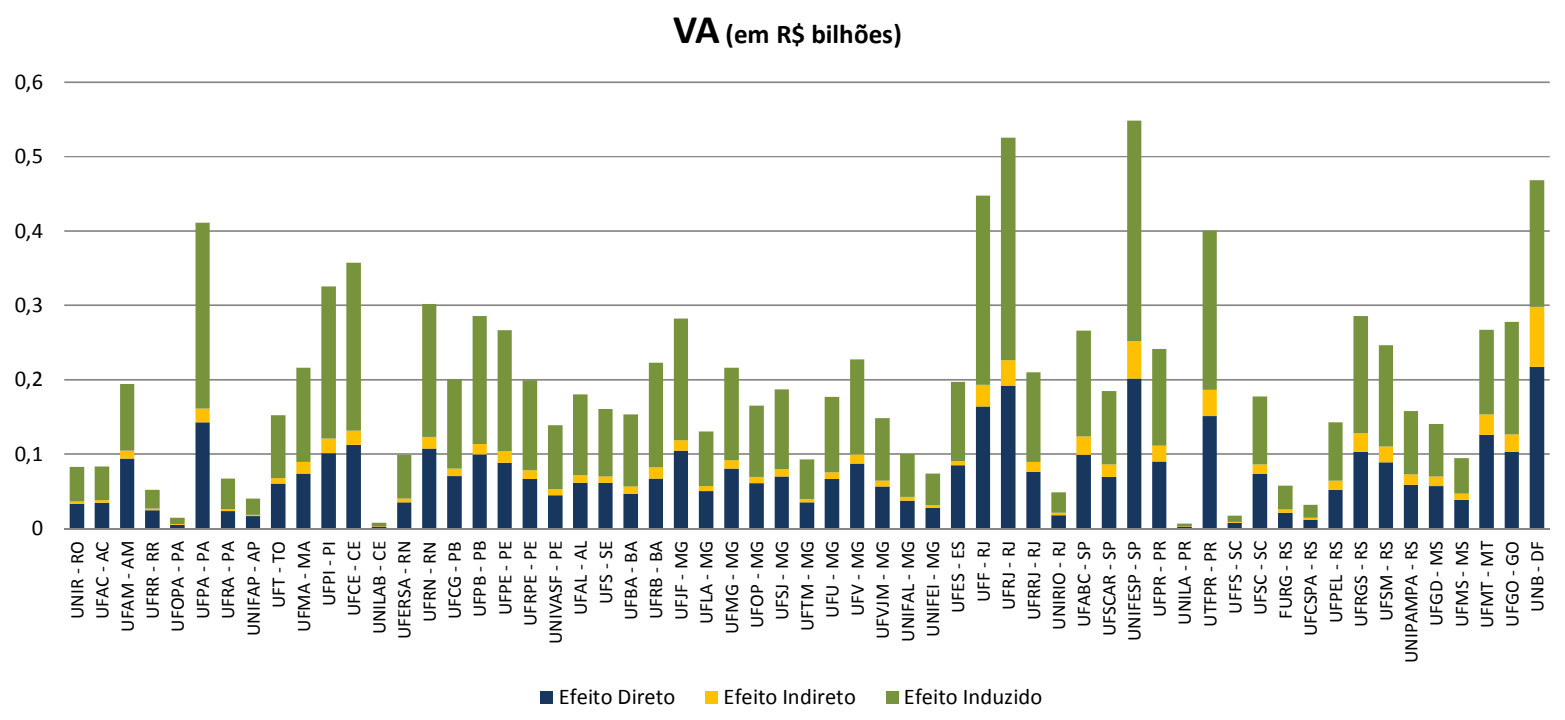

Obs.: A sigla de unidade da federação apresentada após a sigla da universidade é referente ao estado onde se localiza a sede da universidade.

Fonte: Elaboração própria a partir da Matriz Insumo-Produto

Além das quatro universidades mencionadas, destaca-se a UFPA que apresenta o quinto maior efeito total sobre a economia. Entretanto, esta universidade está longe dos pólos Rio de Janeiro, São Paulo e Brasília. A UFCE apresenta o maior efeito total na região Nordeste e o sétimo maior efeito no Brasil. Apesar de ter um efeito direto semelhante a outras universidades (UFPI, UFRN, UFPB, UFJF, UFABC, UFRGS, UFMT E UFGO), a UFCE se destaca com relação ao efeito induzido sobre o valor adicionado na economia regional.

Ainda que os resultados de valor bruto sobre a produção e valor adicionado sejam proporcionalmente semelhantes, os efeitos sobre pessoal ocupado mostram outra dinâmica, como pode ser observado na tabela abaixo. 
Gráfico 2.14 - Efeitos da Expansão sobre Pessoal Ocupado por Universidade no Período 2004-2010

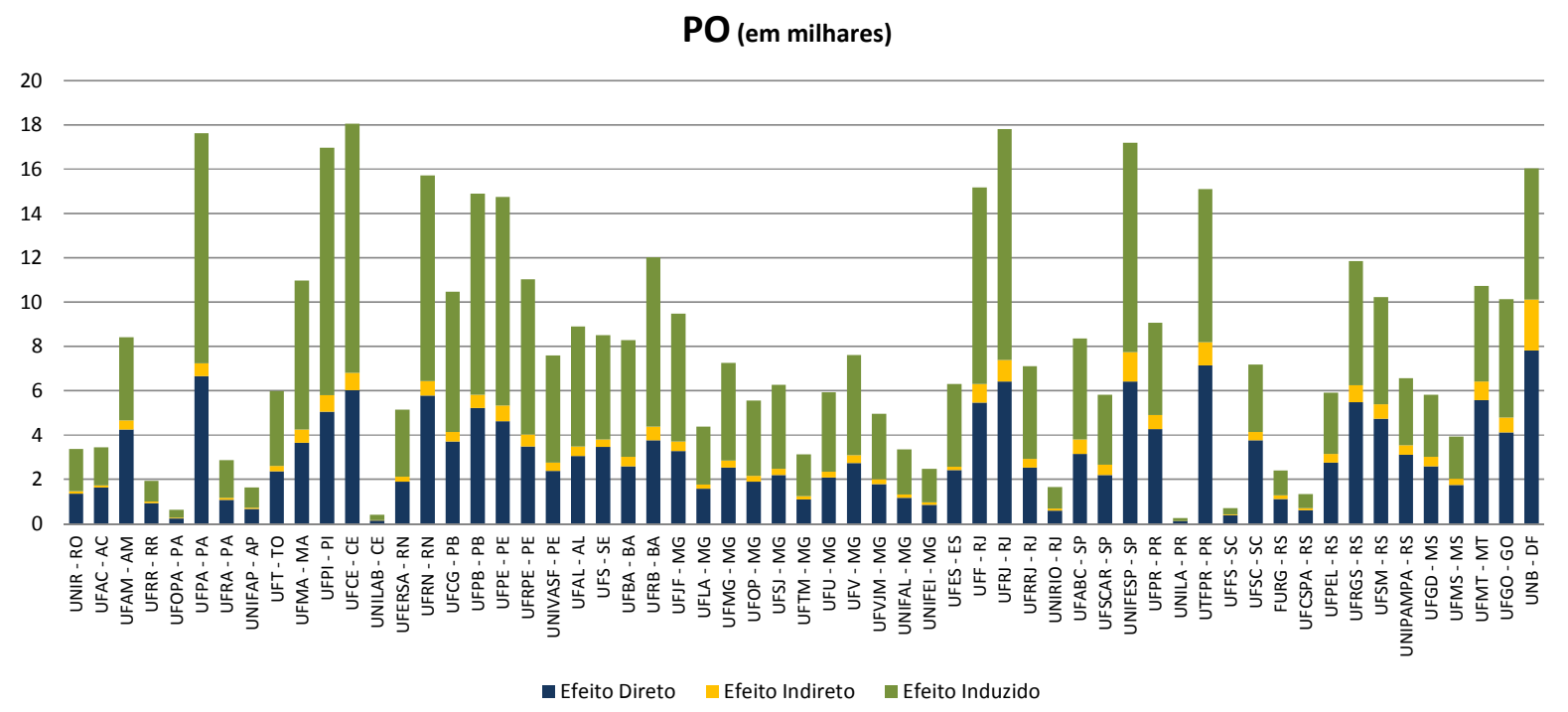

Obs.: A sigla de unidade da federação apresentada após a sigla da universidade é referente ao estado onde se localiza a sede da universidade.

Fonte: Elaboração própria a partir da Matriz Insumo-Produto

A UFCE apresenta o maior efeito sobre pessoal ocupado, provocando um acréscimo de 18 mil no quadro de pessoas ocupadas no País. Seu efeito direto é de 6,7 mil pessoas ocupadas, ficando atrás apenas da UNB com quase 8 mil e da UTFPR com 7,1 mil pessoas ocupadas. A UNB tem um impacto total de 16 mil pessoas ocupadas, e o maior efeito indireto com pouco mais de 2 mil pessoas ocupadas. Com valor próximo ao da UFCE, a UFRJ tem o segundo maior efeito total sobre o número de pessoas ocupadas. A universidade com terceiro maior efeito é a UFPA.

Em geral, 12 das 15 universidades federais do Nordeste apresentam efeito total sobre pessoal ocupado acima da média nacional de 7,9 mil pessoas ocupadas por universidade.

\subsubsection{1- Impacto das Novas Universidades}

Como já mencionado anteriormente, das dezessete universidades criadas após 2000, sete já existiam como faculdades, centros universitários ou escolas técnicas. Assim, efetivamente foram criadas dez universidades. Acrescenta-se a este grupo a Universidade 
Federal do Tocantins (UFT), que foi credenciada no final do ano de 2000, mas iniciou suas atividades apenas em 2003. Este grupo de universidades é apresentado a seguir com respectivos anos de credenciamento:

- Universidade Federal do Tocantins (UFT), credenciamento em 2000;

- Universidade Federal do Vale do São Francisco (UNIVASF), credenciamento em 2002;

- Universidade Federal de Campina Grande (UFCG), credenciamento em 2002;

- Universidade Federal da Grande Dourados (UFGD), credenciamento em 2005;

- Universidade Federal do Recôncavo da Bahia (UFRB), credenciamento em 2005;

- Universidade Federal do ABC (UFABC), credenciamento em 2005;

- Universidade Federal do Pampa (UNIPAMPA), credenciamento em 2008;

- Universidade Federal do Oeste do Pará (UFOPA), credenciamento em 2009;

- Universidade Federal da Integração Latino Americana (UNILA), credenciamento em 2010;

- Universidade Federal da Fronteira Sul (UFFS), credenciamento em 2010;

- Universidade Federal da Integração Luso-Afro Brasileira (UNILAB), credenciamento em $2010^{24}$.

Vale lembrar que este trabalho se propõe a estudar o efeito econômico da expansão das universidades federais no Brasil, ocorrida nos anos 2000. Assim, ainda que o modelo deste capítulo utilize a matriz Insumo-Produto de 2004, aplicando os choques a partir de 2005, serão consideradas na análise das universidades novas todas as criadas a partir de 2000, ou seja, incluindo as universidades UFT, UNIVASF e UFGD.

As onze universidades novas juntas apresentam um efeito total de $\mathrm{R} \$ 2,3$ bilhões sobre valor bruto da produção, $\mathrm{R} \$ 1,3$ bilhão sobre valor adicionado e 58,8 mil pessoas ocupadas. Quando comparadas com o efeito de todas as universidades federais brasileiras, representam um efeito por volta de $12 \%$ sobre efeito total na economia.

\footnotetext{
${ }^{24}$ A UFFS e a UNILAB foram criadas por legislação federal em 2009, mas somente credenciadas pelo MEC em 2010 .
} 
Tabela 2.5 - Efeitos da Expansão das Universidades Novas no Período 2004-2010

\begin{tabular}{lrrr}
\hline \multicolumn{1}{c}{ Efeito } & VPB & VA & PO \\
\hline Direto & 599,48 & 473,98 & 21.920 \\
Indireto & 189,52 & 95,41 & 3.271 \\
Induzido & $1.540,64$ & 755,63 & 33.593 \\
\hline Total Universidades Novas & $2.329,64$ & $1.325,02$ & 58.784 \\
\hline Total Todas as Universidades & $19.881,70$ & $11.452,04$ & 466.628 \\
\hline
\end{tabular}

Obs.: VBP = Valor Bruto da Produção (em R \$ milhões);

$\mathrm{VA}=$ Valor Adicionado (em R $\$$ milhões); $\mathrm{PO}=$ Pessoal Ocupado.

Fonte: Elaboração própria a partir da Matriz Insumo-Produto

Pelo gráfico abaixo, analisando o efeito destas novas universidades sobre o valor bruto da produção, observa-se que a UFABC apresenta o maior efeito total, de R\$ 467 milhões. Além disso, possui os maiores efeitos direto, indireto e induzido. Isto se deve não apenas pelo fato de ter recebido o maior choque de gastos públicos, mas também devido à sua localização no estado de São Paulo, que tem os maiores efeitos indiretos e induzidos pela renda das famílias, entre os estados brasileiros.

\section{Gráfico 2.15 - Efeitos da Expansão das Universidades Novas sobre Valor Bruto da Produção no Período 2004-2010}

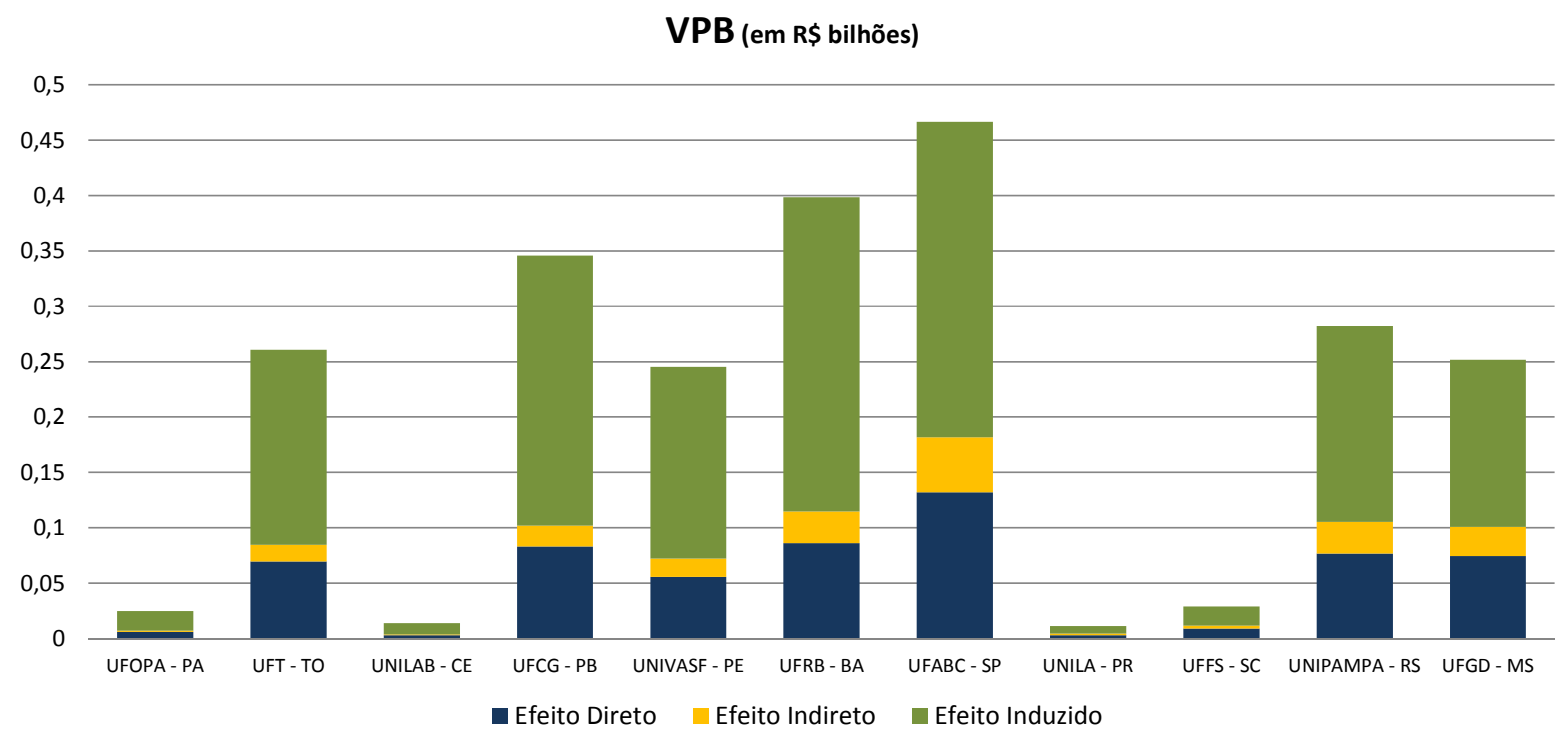

Obs.: A sigla de unidade da federação apresentada após a sigla da universidade é referente ao estado onde se localiza a sede da universidade.

Fonte: Elaboração própria a partir da Matriz Insumo-Produto 
A UFRB apresenta o segundo maior impacto total sobre a economia, e a UFCG o terceiro maior. Fato que chama a atenção é que universidades criadas no início dos anos 2000, como a UFT, UNIVASF e UFCG, apresentam resultados abaixo de outras criadas mais recentemente, como UFABC, UFRB e UNIPAMPA. Esta última, ainda que criada apenas em 2008, destaca-se por ter um efeito total acima de universidades como UNIVASF e UFGD, que foram criadas anteriormente. A UFOPA, a UNILA, a UNILAB e a UFFS apresentam efeito muito pequeno, uma vez que são muito recentes.

Com relação ao efeito sobre valor adicionado, a ordem dos efeitos se mantem semelhante aos resultados sobre valor bruto da produção. A UFABC tem impacto total de R\$ 266 milhões, seguida pela UFRB com impacto de R \$ 223 milhões. Novamente, os efeitos totais seguem a ordem dos efeitos diretos, provenientes diretamente do choque.

\section{Gráfico 2.16 - Efeitos da Expansão das Universidades Novas sobre Valor Adicionado no Período 2004-2010}

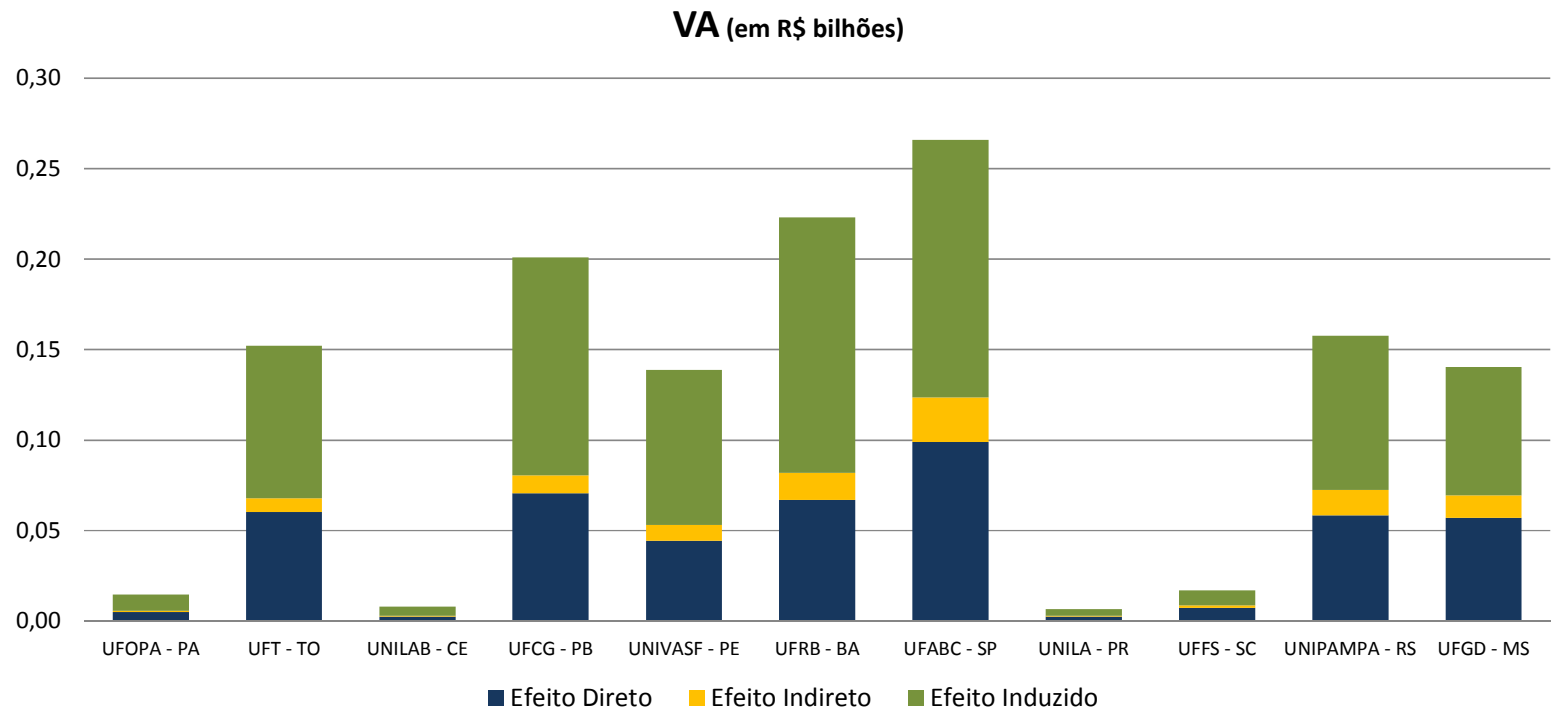

Obs.: A sigla de unidade da federação apresentada após a sigla da universidade é referente ao estado onde se localiza a sede da universidade. Fonte: Elaboração própria a partir da Matriz Insumo-Produto 
Considerando pessoal ocupado, a universidade que gera o maior impacto sobre o número de pessoas ocupadas é a UFRB, com aumento de 12 mil pessoas ocupadas, seguida pela UFCG, com 10,5 mil, e UFABC, com 8,4 mil pessoas ocupadas. A UNIVASF assume a quarta posição, com efeito de 7,6 mil, seguida pela UNIPAMPA, UFT e UFGD, com impacto por volta de 6 mil pessoas ocupadas. Vale destacar que estas universidades geram efeito total médio de aproximadamente 5,3 mil pessoas ocupadas. A UNIVASF, apesar de receber um menor choque, com menor efeito direto, apresenta efeito induzido significativo pela renda das famílias.

\section{Gráfico 2.17 - Efeitos da Expansão das Universidades Novas sobre Pessoal Ocupado no Período 2004-2010}

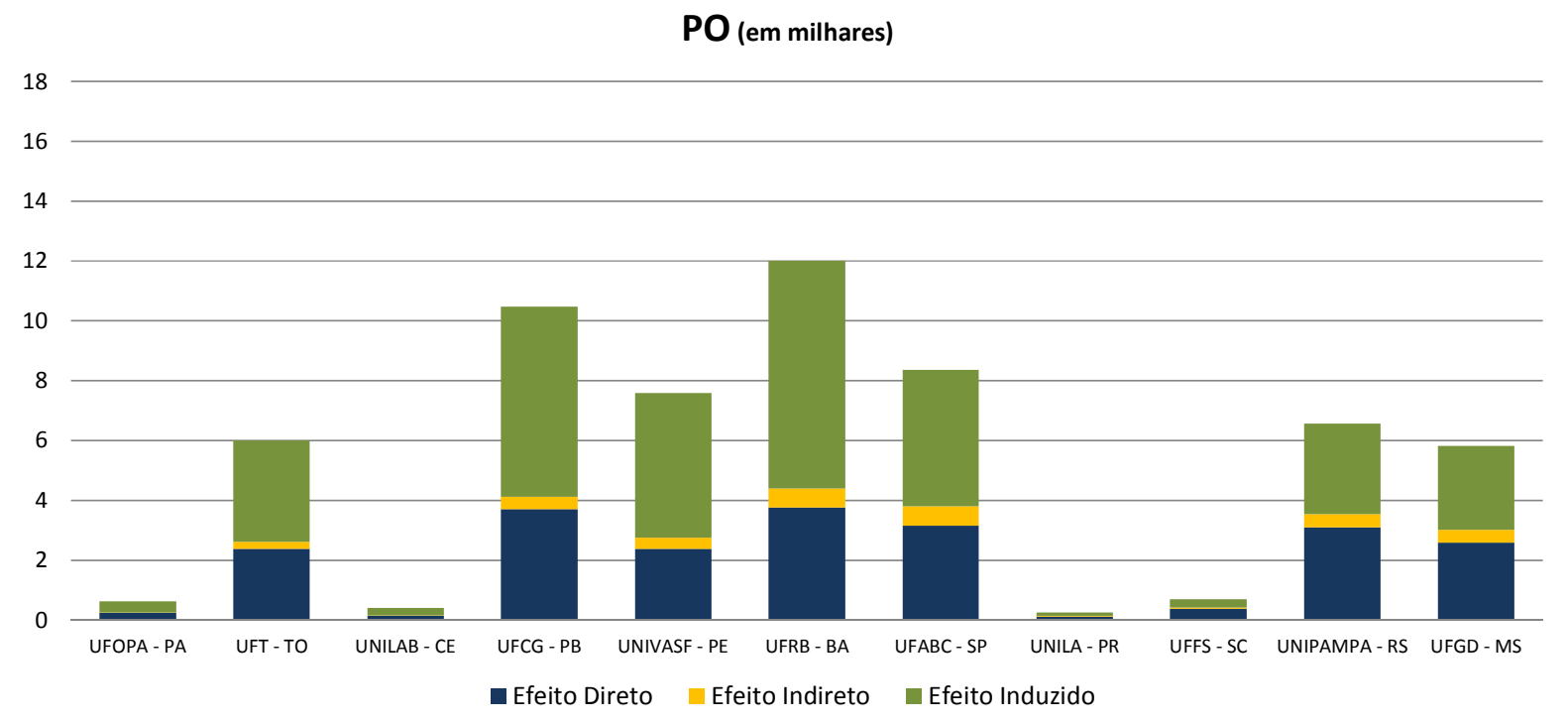

Obs.: A sigla de unidade da federação apresentada após a sigla da universidade é referente ao estado onde se localiza a sede da universidade.

Fonte: Elaboração própria a partir da Matriz Insumo-Produto

Este impacto sobre pessoal ocupado está mais relacionado com o tempo no qual a universidade atua, quando comparado com as outras variáveis, visto que as universidades criadas até 2005 assumem as primeiras posições. A exceção está com a UFT, criada em 2000, e a UFGD, criada em 2005, mas com efeito menor do que a UNIPAMPA, criada em 2008. Entretanto vale ressaltar que tal diferença se deve ao efeito direto do choque. 
De modo geral, a UFABC apresenta o maior impacto monetário sobre a economia, mas ao se considerar o número de pessoas ocupadas, as universidades UFRB e UFCG da região Nordeste, se destacam, corroborando para o resultado mostrado sobre efeitos regionais.

\subsection{5- Impacto Microrregional}

\subsubsection{1- Impacto Microrregional de cada Universidade}

Ao se analisar o efeito de cada universidade sobre as microrregiões brasileiras, buscase observar o impacto sobre as microrregiões mais afetadas com relação ao PIB, para as três variáveis econômicas analisadas (Valor Bruto da Produção, Valor Adicionado e Pessoal Ocupado). Para a análise deste item serão considerados os 20 maiores aumentos percentuais sobre PIB microrregional.

Constata-se que a microrregião de Diamantina - MG, devido à expansão de gastos públicos com a UFVJM, apresenta o maior impacto sobre o seu respectivo PIB microrregional e tem um impacto sobre valor bruto da produção de $\mathrm{R} \$ 52,6$ milhões. Vale ressaltar que esta universidade, apesar de credenciada em 2005, já existia desde 1953. Ainda assim, dada a sua transformação em universidade em 2005, passou a ser contemplada com elevado aumento de gastos públicos federais, saindo de um patamar de orçamento executado e pago de $\mathrm{R} \$ 15,2$ milhões para R\$ 81,5 milhões. Em segundo e terceiro lugares, estão as microrregiões de Litoral Norte - PB, com a UFPB, e de Curimatau Ocidental - PB, com a UFCG, apresentando impacto de $\mathrm{R} \$ 48,0$ milhões e $\mathrm{R} \$ 23,2$ milhões sobre o valor bruto da produção, respectivamente. 


\section{Gráfico 2.18 - Efeitos da Expansão sobre Valor Bruto da Produção por Universidade} para as Microrregiões com Maiores Efeitos Relativos sobre PIB no Período 2004-2010

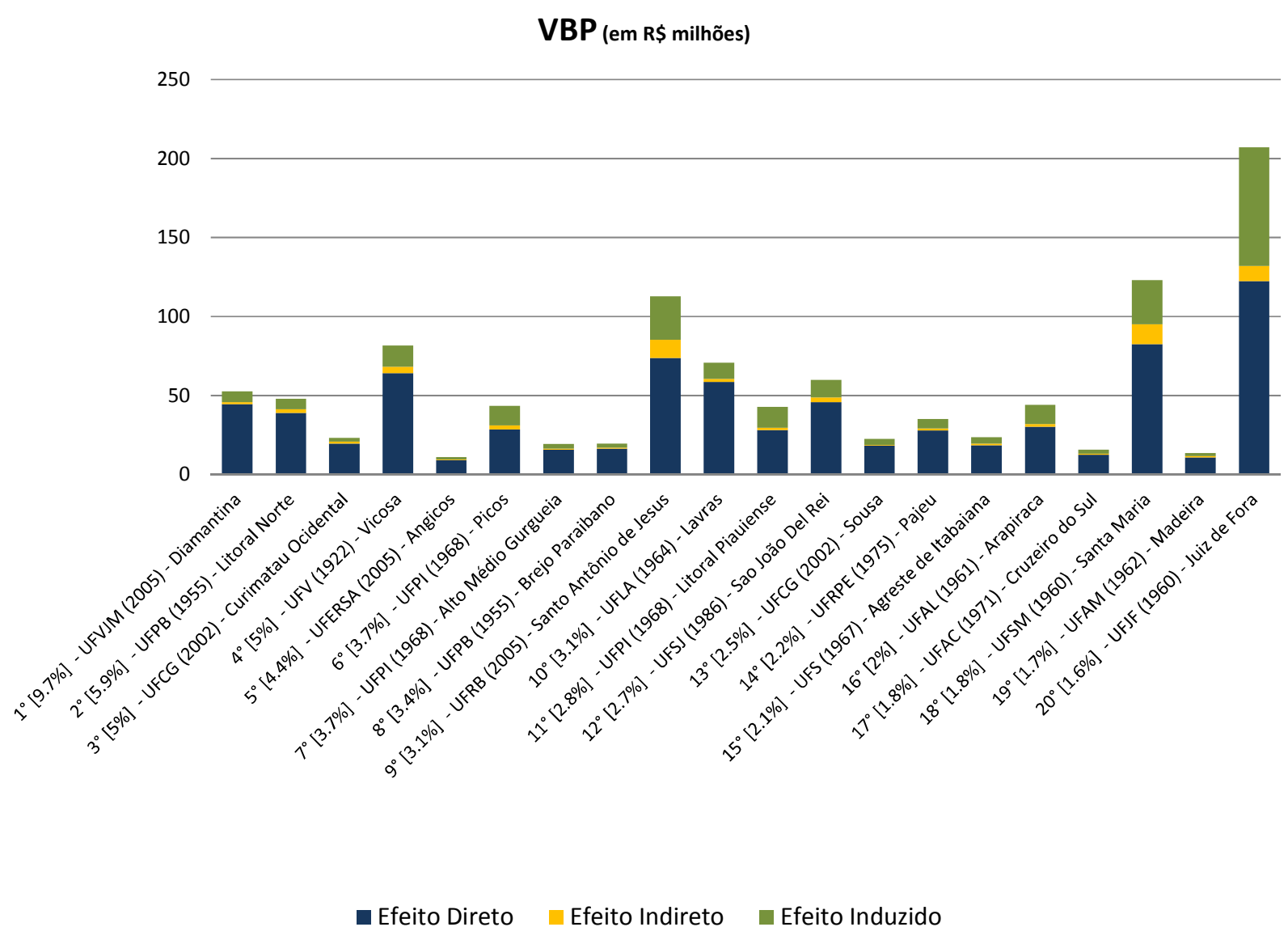

Obs.: O valor entre colchetes representa o efeito relativo sobre o PIB da microrregião em análise. Fonte: Elaboração própria a partir da Matriz Insumo-Produto

Dentre estas microrregiões com os vinte maiores efeitos relativos sobre PIB, Juiz de Fora - MG se destaca pelo volume de impacto sobre valor bruto da produção, com mais de R\$ 200 milhões, seguida pelas microrregiões de Santa Maria - RS e Santo Antônio de Jesus - BA, com impactos de $\mathrm{R} \$ 123,0$ milhões e $\mathrm{R} \$ 113,0$ milhões, respectivamente.

Considerando o efeito sobre valor adicionado, as microrregiões de Diamantina - MG, Litoral Norte - PB e Curimatau Ocidental - PB apresentam os maiores efeitos relativos, com variação de 9,7\%, 5,9\% e 5\%, respectivamente, sobre o PIB microrregional. 


\section{Gráfico 2.19 - Efeitos da Expansão sobre Valor Adicionado por Universidade para as} Microrregiões com Maiores Efeitos Relativos sobre PIB no Período 2004-2010

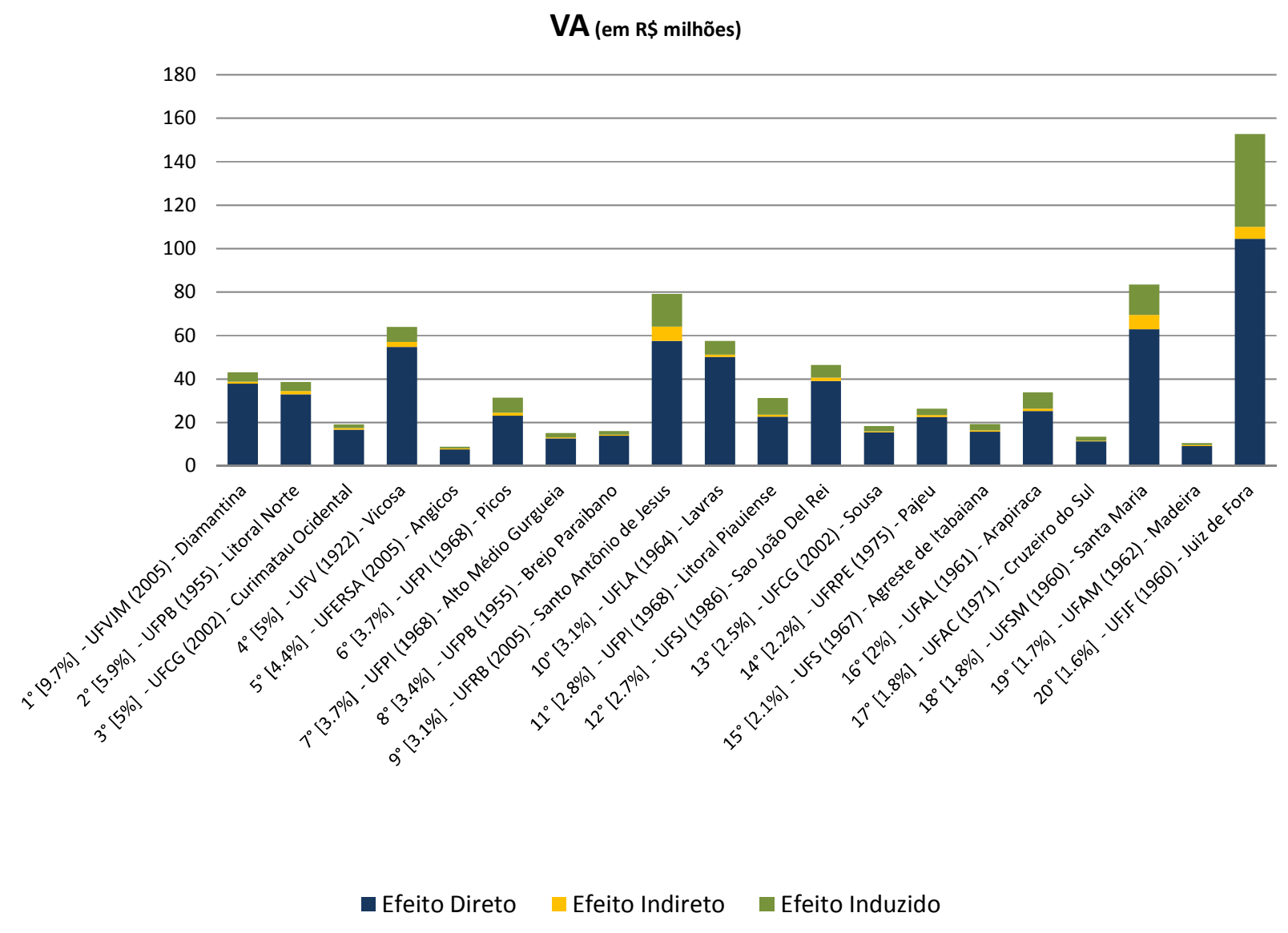

Obs.: O valor entre colchetes representa o efeito relativo sobre o PIB da microrregião em análise.

Fonte: Elaboração própria a partir da Matriz Insumo-Produto

Dentre as 20 microrregiões de maiores impactos relativos, considerando os valores absolutos, o maior impacto está na microrregião de Juiz de Fora - MG, com quase R\$160 milhões de valor adicionado (1,6\% do PIB microrregional), devido à UFJF, seguida por Santa Maria - RS, em que a UFSM provoca um impacto de pouco mais de R\$ 80 milhões $(1,8 \%$ do PIB microrregional).

Analisando-se a variável pessoal ocupado, as três microrregiões (Diamantina - MG, Litoral Norte - PB e Curimatau Ocidental - PB) com maiores efeitos relativos sobre PIB, totalizam um impacto sobre a economia de quase 5 mil pessoas ocupadas. 


\section{Gráfico 2.20 - Efeitos da Expansão sobre Pessoal Ocupado por Universidade para as Microrregiões com Maiores Efeitos Relativos sobre PIB no Período 2004-2010}

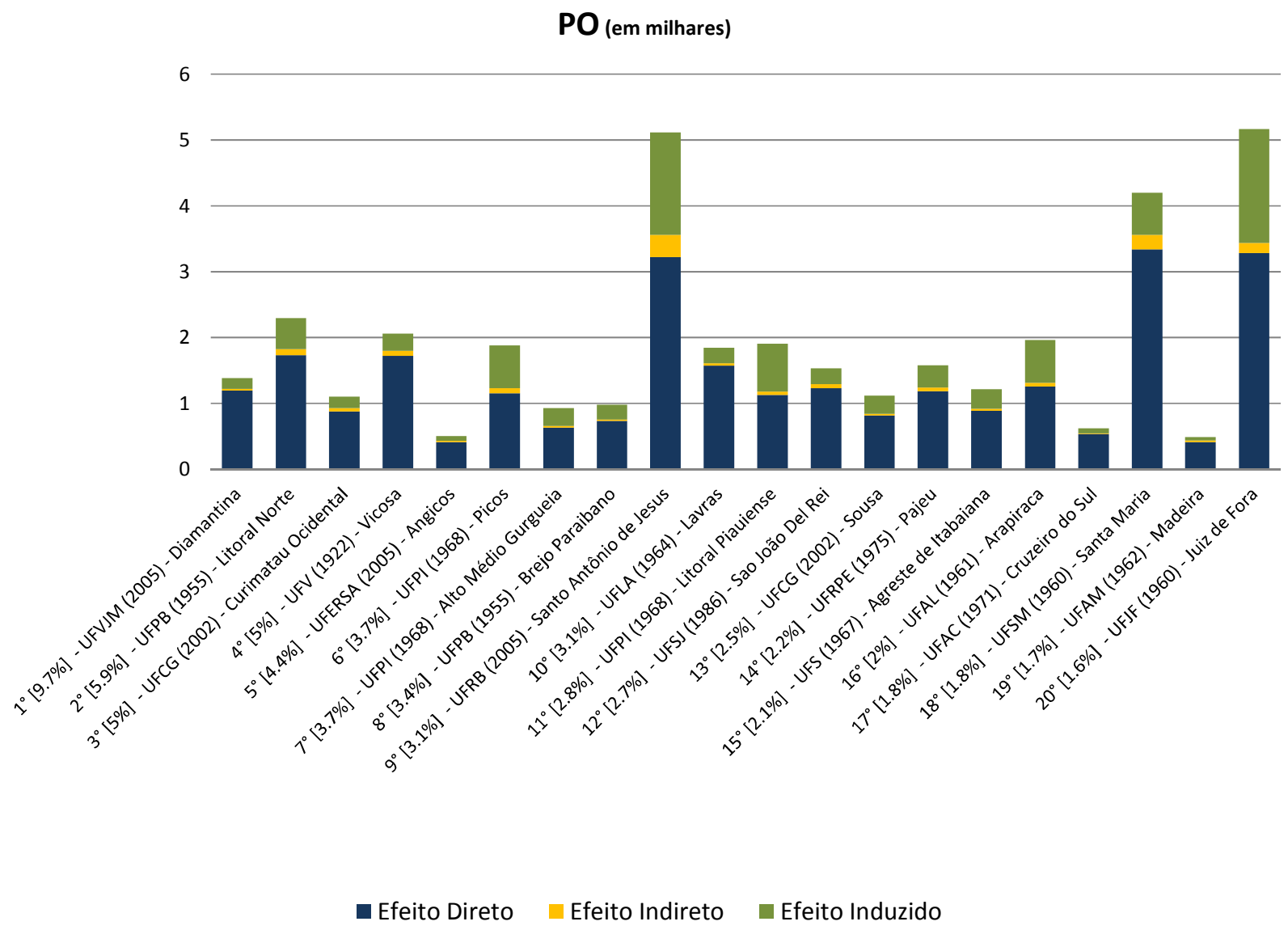

Obs.: O valor entre colchetes representa o efeito relativo sobre o PIB da microrregião em análise. Fonte: Elaboração própria a partir da Matriz Insumo-Produto

Neste grupo das 20 microrregiões de maiores impactos relativos sobre PIB, considerando os valores absolutos, os maiores impactos estão novamente nas microrregiões de Juiz de Fora - MG (com a UFJF), Santo Antônio de Jesus - BA (com a UFRB) e Santa Maria - RS (com a UFSM), que totalizam um aumento de 14,5 mil pessoas ocupadas.

A microrregião de Brasília - DF, com a UNB, tem o maior efeito direto $(7,8$ mil pessoas ocupadas) em valores absolutos, com efeito total da ordem de 11,4 mil pessoas ocupadas, porém apresenta efeito relativo sobre seu PIB microrregional de apenas $0,3 \%$, ocupando a $139^{\mathrm{a}}$ posição entre as variações percentuais sobre PIB. É importante destacar a microrregião do Rio de Janeiro - RJ (com a UFRJ), que apresenta o maior efeito absoluto sobre PIB (R \$ 355 milhões - 0,1\% do PIB microrregional). 
Tabela 2.6 - Maiores Efeitos Absolutos Microrregionais por Universidade da Expansão no Período 2004-2010

\begin{tabular}{|c|c|c|c|c|c|}
\hline \multirow{2}{*}{$\begin{array}{l}\text { Universidade e } \\
\text { Microrregião }\end{array}$} & \multirow{2}{*}{$\begin{array}{c}\text { VBP } \\
\text { (em R\$ milhões) } \\
\text { absoluto } \\
\end{array}$} & \multicolumn{3}{|c|}{$\begin{array}{c}\text { VA } \\
\text { (em R\$ milhões) } \\
\end{array}$} & \multirow{2}{*}{$\begin{array}{c}\text { PO } \\
\text { a bsoluto } \\
\end{array}$} \\
\hline & & absoluto & re la tivo & posiçã o & \\
\hline UFRJ (1920) - Rio de Janeiro & 534,27 & 355,04 & $0,15 \%$ & $195^{\circ}$ & 11.198 \\
\hline UNB (1962) - Brasilia & 539,65 & 337,64 & $0,32 \%$ & $139^{\circ}$ & 11.436 \\
\hline UFF (1960) - Rio de Janeiro & 364,10 & 233,49 & $0,10 \%$ & $225^{\circ}$ & 7.227 \\
\hline UNIFESP (1938) - Sao Paulo & 360,33 & 205,09 & $0,05 \%$ & $269^{\circ}$ & 5.208 \\
\hline UFABC (2005) - Sao Paulo & 324,93 & 203,68 & $0,05 \%$ & $271^{\circ}$ & 5.711 \\
\hline UFRGS (1950) - Porto Alegre & 298,16 & 191,63 & $0,24 \%$ & $157^{\circ}$ & 8.238 \\
\hline UFPA (1957) - Belem & 255,39 & 184,21 & $0,78 \%$ & $68^{\circ}$ & 7.172 \\
\hline UTFPR (2005) - Curitiba & 284,04 & 179,04 & $0,26 \%$ & $147^{\circ}$ & 6.376 \\
\hline UFCE (1954) - Fortaleza & 262,69 & 175,26 & $0,52 \%$ & $101^{\circ}$ & 9.002 \\
\hline UFJF (1960) - Juiz de Fora & 207,19 & 152,77 & $1,62 \%$ & $20^{\circ}$ & 5.167 \\
\hline
\end{tabular}

Obs.: (1) VBP - Valor Bruto da Produção; VA - Valor Adicionado; PO - Pessoal Ocupado;

(2) Microrregiões ordenadas pelo impacto absoluto sobre o PIB (coluna VA "absoluto");

(3) Coluna "absoluto" é o efeito em valores absolutos; coluna "relativo" é o efeito relativamente ao respectivo PIB microrregional; e coluna "posição" se refere à posição do par microrregiãouniversidade entre as 32.922 (558x59) microrregiões-universidades, considerando a coluna "relativo".

Fonte: Elaboração própria a partir da Matriz Insumo-Produto

$\mathrm{Na}$ tabela acima, vale mencionar que, com exceção da UFABC, todas as demais universidades já existiam antes da expansão de gastos públicos federais com universidades. ${ }^{25}$ Esta universidade nova representa o quinto maior impacto absoluto sobre PIB, porém tem impacto relativo de apenas $0,05 \%$ sobre o PIB da microrregião de São Paulo - SP.

Estes 10 pares de universidade e microrregião representam juntos 17,3\%, 19,4\% e $16,4 \%$ dos impactos totais no Brasil com relação a valor bruto da produção, valor adicionado e pessoal ocupado, respectivamente. Vale lembrar que neste item estuda-se o efeito de cada universidade de forma individualizada, ou seja, estuda-se o efeito de cada universidade desconsiderando os efeitos das demais. Assim, apesar de se considerar que uma universidade tem efeito sobre diversas microrregiões, os resultados refletem o fato do maior efeito da universidade estar sobre a microrregião onde ela se localiza.

\footnotetext{
${ }^{25}$ A UTFPR foi credenciada como universidade em 2005, mas já existia como Escola Técnica desde 1943.
} 


\subsubsection{2- Impacto Microrregional Conjunto}

Os itens anteriores sobre o impacto por universidade consideram o efeito individualizado de cada universidade, sem considerar os efeitos conjuntos das demais universidades. Assim, os resultados mostravam o efeito de cada universidade individualmente, desconsiderando o efeito das outras. Neste sub-item, considera-se o efeito conjunto de todas as universidades em cada microrregião, buscando contemplar casos em que os efeitos individualizados são pequenos, mas conjuntamente são significativos.

Desta forma, iniciando pela análise do impacto sobre valor bruto da produção, constata-se que grande parte do efeito sobre determinada microrregião é devido à própria universidade, que em geral é responsável por pelo menos $90 \%$ do efeito sobre a microrregião. Os resultados pouco se alteram, apresentando entre os 20 maiores aumentos percentuais sobre PIB microrregional, as mesmas microrregiões, em relação ao item anterior, com a manutenção das duas primeiras posições para as microrregiões de Diamantina - MG e Litoral Norte - PB.

\section{Gráfico 2.21 - Efeitos da Expansão sobre Valor Bruto da Produção para as} Microrregiões com Maiores Efeitos Relativos sobre PIB no Período 2004-2010

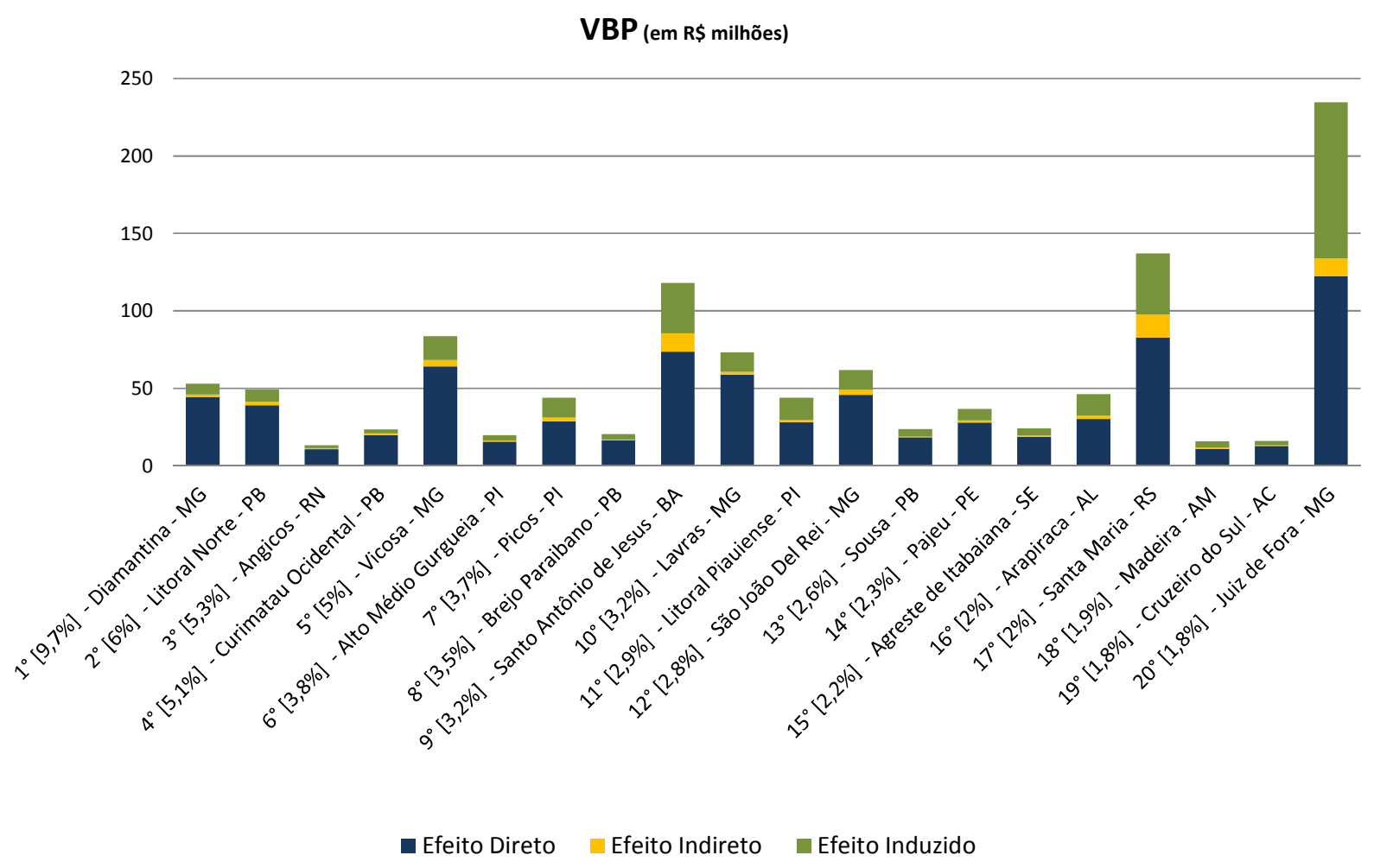

Obs.: O valor entre colchetes representa o efeito relativo sobre o PIB da microrregião em análise. Fonte: Elaboração própria a partir da Matriz Insumo-Produto 
Considerando o efeito sobre valor bruto da produção, Juiz de Fora - MG apresenta a maior variação absoluta no subgrupo considerado, com aumento de R 235 milhões, seguida pela microrregião de Santa Maria - RS, com R\$ 137 milhões sobre valor bruto da produção microrregional.

Observa-se que com relação ao impacto sobre PIB na microrregião de Diamantina MG, a UFVJM é responsável praticamente pela totalidade do efeito, que é de 9,7\% sobre o PIB microrregional, sendo o efeito das outras universidades de apenas 0,04\%. Dentre as 20 microrregiões consideradas, Angicos - $\mathrm{RN}$ apresenta a maior diferença entre o efeito total de todas as universidades $(5,3 \%)$ e o efeito local da universidade (UFERSA) estabelecida nesta microrregião $(4,4 \%)$, ou seja, as demais universidades são responsáveis por $0,9 \%$ do aumento do PIB. É importante lembrar que estas diferenças se devem aos efeitos indiretos e induzidos pela renda das famílias, pois os efeitos diretos são os correspondentes a própria universidade da microrregião.

\section{Gráfico 2.22 - Efeitos da Expansão sobre Valor Adicionado para as Microrregiões com Maiores Efeitos Relativos sobre PIB no Período 2004-2010}

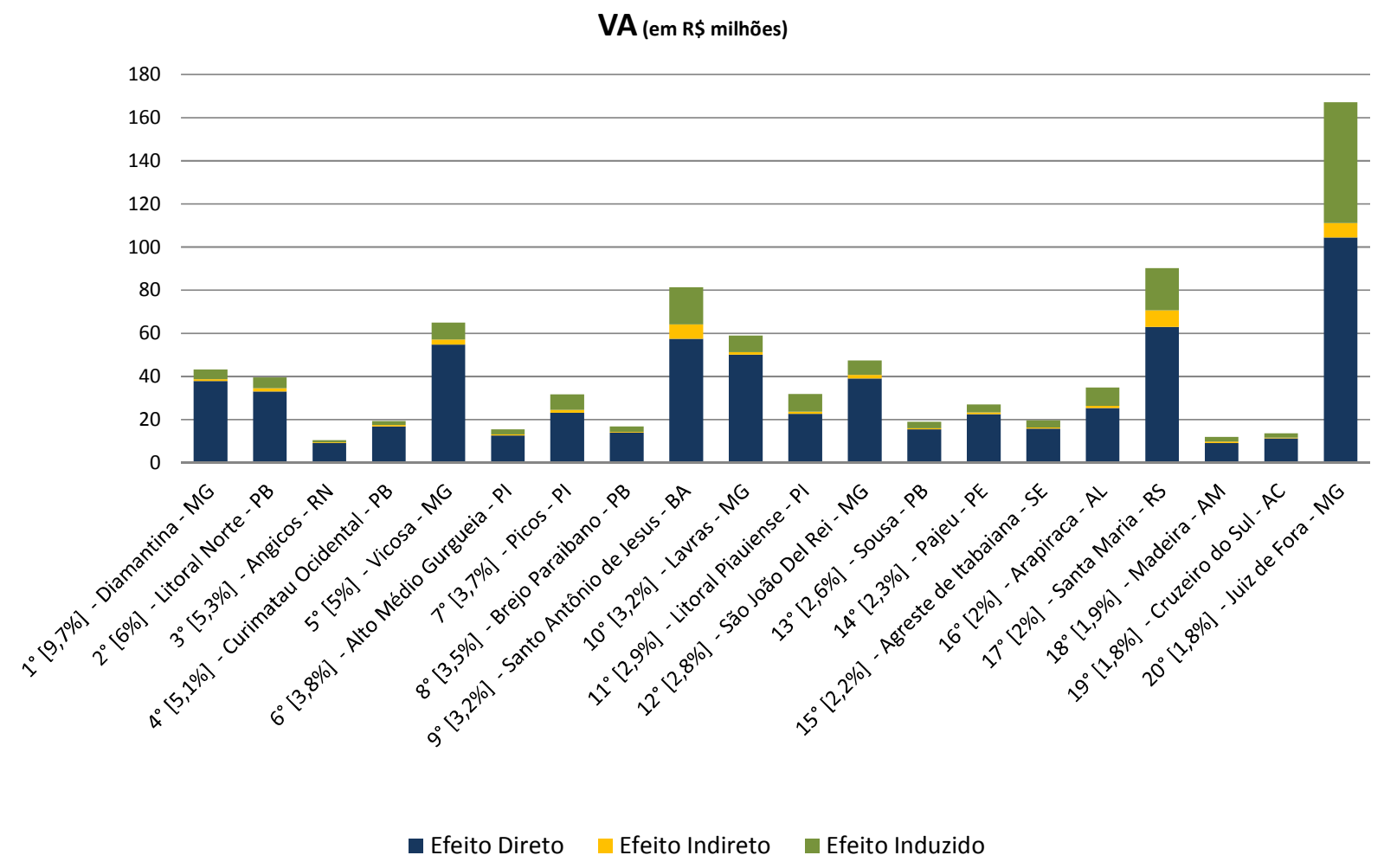

Obs.: O valor entre colchetes representa o efeito relativo sobre o PIB da microrregião em análise. Fonte: Elaboração própria a partir da Matriz Insumo-Produto 
Dentre as 20 microrregiões com maiores efeitos percentuais sobre valor adicionado, a microrregião de Angicos - RN apresenta o maior impacto de outras universidades, atingindo 0,85\%, com a UFERSA sendo responsável por um impacto de 4,4\% sobre PIB microrregional, como já mencionado. Neste subgrupo analisado, Juiz de Fora - MG tem o maior impacto absoluto sobre o PIB, com variação do valor adicionado de R \$ 167,1 milhões, seguida por Santa Maria - RS, com R\$ 90,3 milhões.

Considerando o efeito sobre pessoal ocupado, constata-se que as 20 microrregiões com maiores impactos percentuais sobre o estoque de pessoas ocupadas são as mesmas, independente do efeito ser apenas da universidade local ou considerar as demais universidades.

\section{Gráfico 2.23 - Efeitos da Expansão sobre Pessoal Ocupado para as Microrregiões com} Maiores Efeitos Relativos sobre PIB no Período 2004-2010

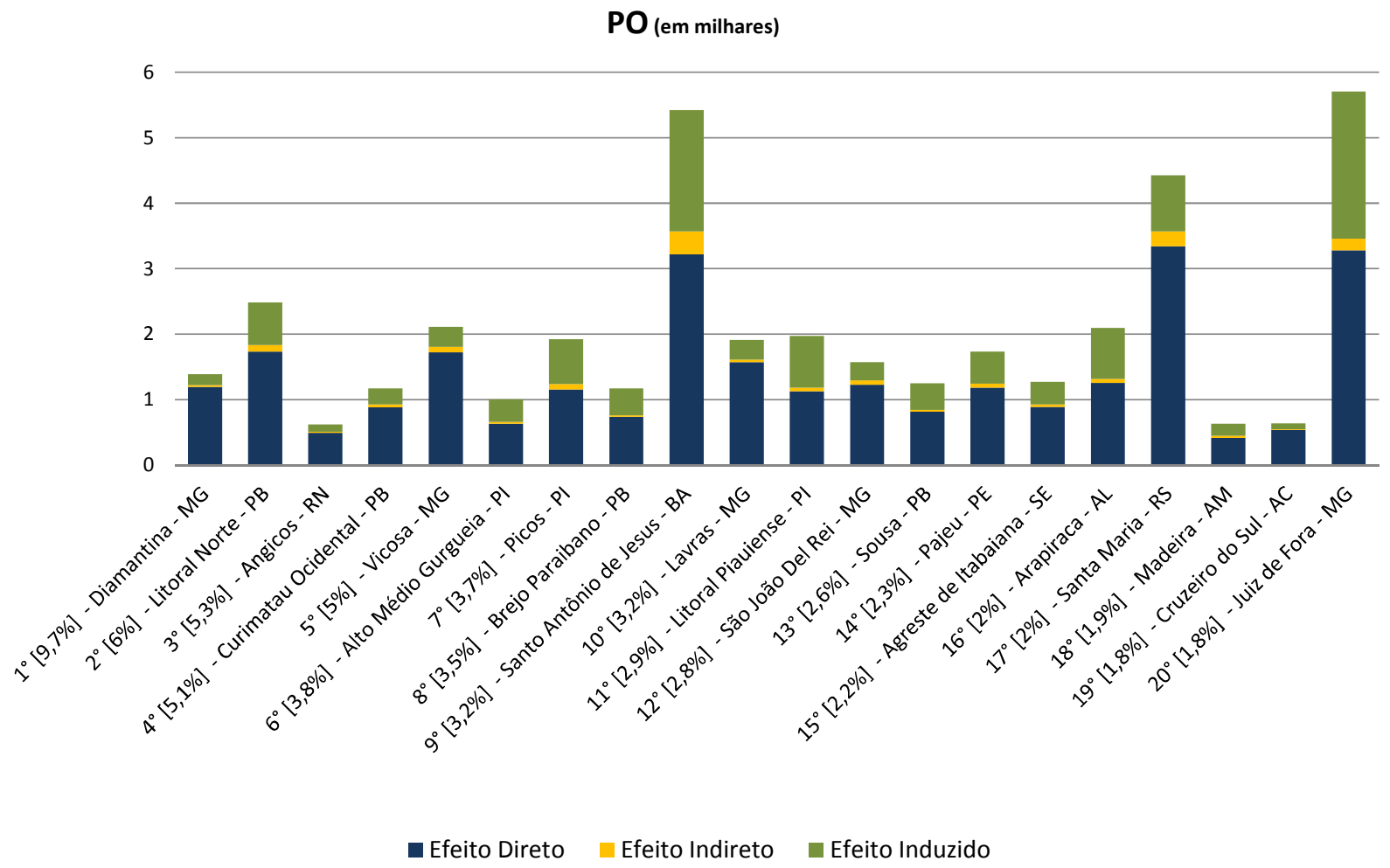

Obs.: O valor entre colchetes representa o efeito relativo sobre o PIB da microrregião em análise. Fonte: Elaboração própria a partir da Matriz Insumo-Produto 
Com relação a valores absolutos, neste subgrupo, Juiz de Fora - MG tem o maior impacto, com aumento de 5,7 mil pessoas ocupadas, seguida por Santo Antônio de Jesus BA, com 5,4 mil sobre o número de pessoas ocupadas da microrregião.

Analisando-se os maiores efeitos absolutos, pela tabela abaixo, observa-se que as 10 microrregiões com maiores valores absolutos são as que possuem a capital de cada estado. São Paulo tem o maior impacto (34,1 mil pessoas ocupadas), mas apresenta impacto sobre PIB microrregional de apenas $0,3 \%$. Com isso, ocupa a $161^{\mathrm{a}}$ posição entre os maiores impactos relativos sobre PIB microrregional.

Tabela 2.7 - Maiores Efeitos Absolutos Microrregionais Conjuntos da Expansão no Período 2004-2010

\begin{tabular}{|c|c|c|c|c|c|}
\hline \multirow[t]{2}{*}{ Microrregião } & \multirow{2}{*}{$\begin{array}{c}\text { VBP } \\
\text { (em R\$ milhões) } \\
\text { absoluto }\end{array}$} & \multicolumn{3}{|c|}{$\begin{array}{c}\text { VA } \\
\text { (em R } \$ \text { milhões) }\end{array}$} & \multirow{2}{*}{$\frac{\text { PO }}{\text { a bsoluto }}$} \\
\hline & & a bsoluto & re la tivo & posiç ã o & \\
\hline São Paulo - SP & $2.779,73$ & $1.381,57$ & $0,3 \%$ & $161^{\circ}$ & 34.084 \\
\hline Rio de Janeiro - RJ & $1.670,51$ & 987,63 & $0,4 \%$ & $141^{\circ}$ & 28.999 \\
\hline Belo Horizonte - MG & $1.163,12$ & 640,71 & $0,7 \%$ & $88^{\circ}$ & 20.202 \\
\hline Porto Alegre - RS & 918,17 & 497,93 & $0,6 \%$ & $104^{\circ}$ & 17.754 \\
\hline Curitiba - PR & 836,46 & 461,95 & $0,7 \%$ & $101^{\circ}$ & 14.933 \\
\hline Brasîlia - DF & 586,67 & 361,58 & $0,3 \%$ & $158^{\circ}$ & 12.245 \\
\hline Recife - PE & 448,41 & 276,93 & $0,8 \%$ & $75^{\circ}$ & 16.361 \\
\hline Salvador - BA & 513,02 & 257,69 & $0,4 \%$ & $135^{\circ}$ & 11.448 \\
\hline Fortaleza - CE & 401,13 & 244,81 & $0,7 \%$ & $92^{\circ}$ & 12.705 \\
\hline Belém - PA & 334,58 & 236,27 & $1,0 \%$ & $60^{\circ}$ & 9.040 \\
\hline
\end{tabular}

Obs.: (1) VBP - Valor Bruto da Produção; VA - Valor Adicionado; PO - Pessoal Ocupado;

(2) Microrregiões ordenadas pelo impacto absoluto sobre o PIB (coluna VA "absoluto");

(3) Coluna "absoluto" é o efeito em valores absolutos; coluna "relativo" é o efeito relativamente ao respectivo PIB microrregional; e coluna "posição" se refere à posição da microrregião entre as 558 microrregiões, considerando a coluna "relativo".

Fonte: Elaboração própria a partir da Matriz Insumo-Produto

As maiores economias do Brasil ocupam as primeiras posições entre os maiores efeitos absolutos, com exceção de Brasília que tem o terceiro maior PIB e está na $6^{\text {a }}$ posição. Estas 10 microrregiões são responsáveis por 48,5\%, 46,7\% e 38,1\% dos impactos totais sobre valor bruto da produção, valor adicionado e pessoal ocupado, respectivamente, no Brasil. 
Constata-se uma grande variação entre a participação destas 10 microrregiões na economia brasileiras e a participação das maiores microrregiões no item anterior, que desconsidera o efeito conjunto. Isto mostra claramente que as maiores economias do Brasil recebem efeito de diversas universidades conjuntamente.

Constata-se que as microrregiões que possuem capitais de unidades da federação apresentam os maiores efeitos em valores absolutos, e as menores microrregiões do ponto de vista econômico recebem os maiores impactos relativos da expansão de gastos públicos federais com universidades. Isto pode também ser evidenciado considerando o tamanho populacional das microrregiões que possuem campi universitários federais. Deste grupo de 194 microrregiões, o subgrupo com as 19 microrregiões de menor população (ou seja, representando $10 \%$ do grupo) apresentam efeito médio de 1,5\% sobre o PIB microrregional, enquanto que o restante, com $90 \%$ das microrregiões, tem impacto médio de $0,9 \%$. Dentre as 364 microrregiões que não possuem campus de universidade federal, o efeito médio é de apenas $0,1 \%$ sobre o PIB microrregional.

\subsubsection{3- Distribuição Territorial do Impacto Microrregional Conjunto}

Analisando-se territorialmente a distribuição dos impactos microrregionais conjuntos do sub-item anterior, optou-se por distribuir as microrregiões em quantidades iguais entre os sete coortes apresentados nos mapas a seguir (por volta de 80 microrregiões por coorte).

Inicialmente observa-se que há um efeito distributivo da expansão de gastos da União com universidades federais no período analisado neste trabalho, uma vez que não há significativas concentrações regionais dos efeitos. 
Figura 2.2 - Distribuição Territorial dos Efeitos da Expansão sobre Valor Bruto da Produção no Período 2004-2010

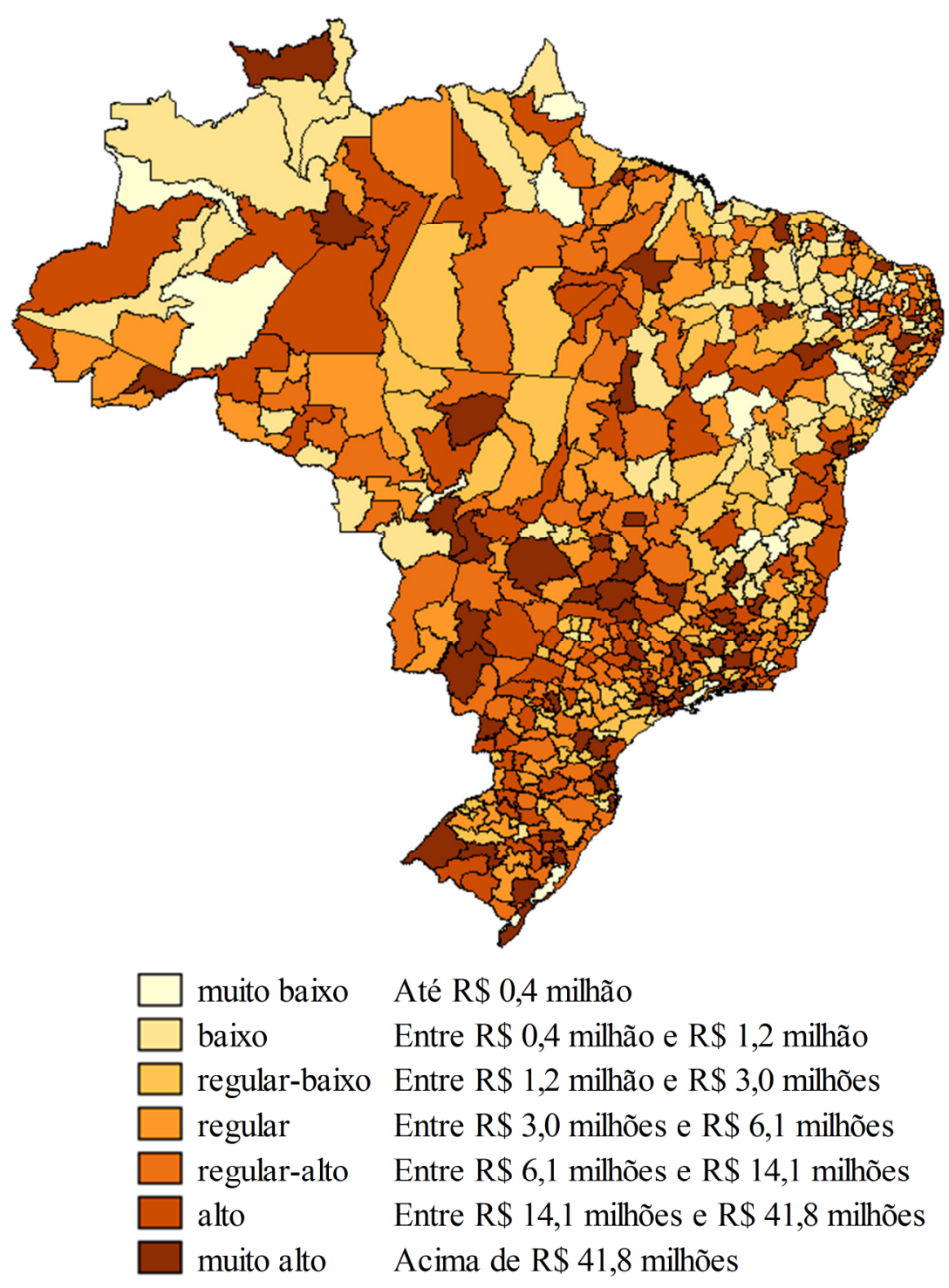

Fonte: Elaboração própria a partir da Matriz Insumo-Produto

Comparando-se os resultados expostos neste mapa acima com os da tabela que mostra os efeitos da expansão sobre valor bruto da produção para as 20 microrregiões com maiores efeitos relativos sobre PIB microrregional, constata-se que apenas 11 microrregiões apresentam efeitos acima de $\mathrm{R} \$ 41,8$ milhões.

Ao se analisar o efeito sobre valor adicionado e valendo-se desta mesma comparação, observa-se que 12 microrregiões possuem impactos superior a $\mathrm{R} \$ 25,7$ milhões. 
Figura 2.3 - Distribuição Territorial dos Efeitos da Expansão sobre Valor Adicionado no Período 2004-2010

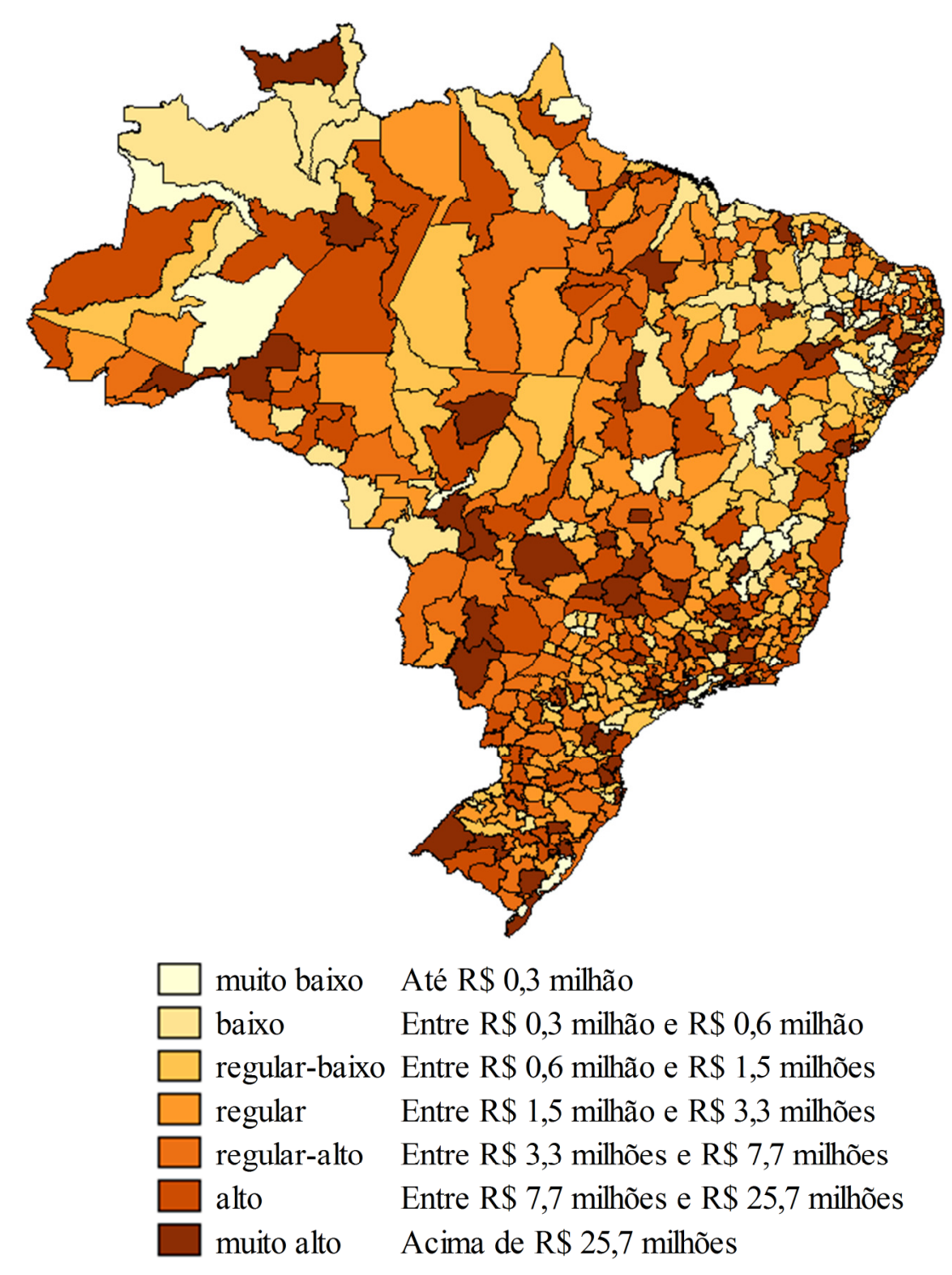

Fonte: Elaboração própria a partir da Matriz Insumo-Produto

Também se constata que as distribuições dos efeitos sobre valor bruto da produção e valor adicionado são bastante semelhantes. Tal semelhança na distribuição dos resultados entre as microrregiões já foi mencionado ao longo deste capítulo.

Com relação aos resultados de valor bruto da produção e valor adicionado, o efeito sobre pessoal ocupado apresenta um padrão similar, porém é possível constatar, pelo mapa a seguir, que há um pequeno aumento de concentração na região Nordeste, com redução na região Sudeste. 
Figura 2.4 - Distribuição Territorial dos Efeitos da Expansão sobre Pessoal Ocupado no Período 2004-2010

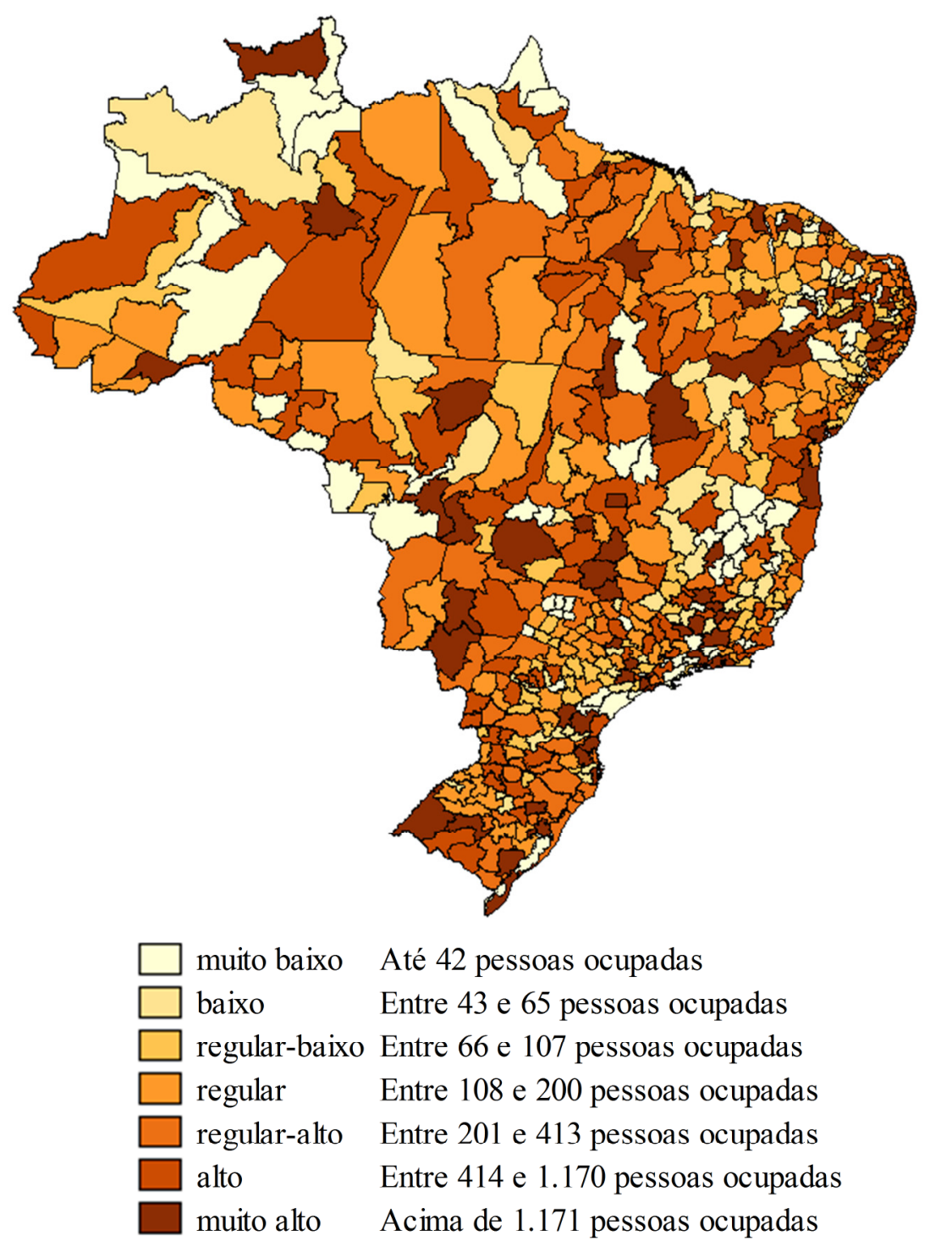

Fonte: Elaboração própria a partir da Matriz Insumo-Produto

Vale destacar que o foco da expansão na interiorização da rede de universidades federais, com destaque para municípios menores, promoveu um efeito distributivo nos impactos do aumento de gastos da União. Por este motivo, o efeito da expansão é mais distribuído pelas microrregiões brasileiras do que o efeito do sistema pré-existente em 2000 (anterior à expansão). De modo geral, pelos mapas, observa-se nas três variáveis econômicas consideradas que não há concentração do efeito desta expansão, ainda que haja uma concentração do sistema na região Sudeste. 


\subsection{6- Impacto Anual}

Este item complementa os demais apresentando a distribuição dos choques e resultados do modelo Insumo-Produto por ano. Em cada ano, o choque é a variação de gastos públicos da União com as universidades federais entre o ano em questão e o ano anterior. A série histórica de gastos públicos com universidades federais nos anos 2000 oscila em torno de $\mathrm{R} \$ 10$ bilhões até 2005, crescendo constantemente até 2010, quando atinge o patamar de $\mathrm{R} \$ 14$ bilhões.

A tabela a seguir mostra que os choques no primeiro período são relativamente baixos, da ordem de R $\$ 150$ milhões, repercutindo o pequeno aumento dos gastos federais com as universidades em 2005. A partir deste ano, os choques crescem, atingindo o patamar de R\$ 1,7 bilhão em 2010.

Tabela 2.8 - Choques e Impactos Econômicos Anuais da Expansão no Período 20042010

\begin{tabular}{rrrrrrrrr}
\hline Ano & Choque & \% Choque & \multicolumn{1}{c}{ VBP } & \% VBP & \multicolumn{1}{c}{ VA } & \% VA & PO & $\%$ PO \\
\hline $\mathbf{2 0 0 5}$ & 149,64 & $2,8 \%$ & 531,04 & $2,7 \%$ & 305,08 & $2,7 \%$ & 12.324 & $2,6 \%$ \\
$\mathbf{2 0 0 6}$ & 879,78 & $16,6 \%$ & $3.359,72$ & $16,9 \%$ & $1.935,67$ & $16,9 \%$ & 80.031 & $17,2 \%$ \\
$\mathbf{2 0 0 7}$ & 704,41 & $13,3 \%$ & $2.542,96$ & $12,8 \%$ & $1.463,80$ & $12,8 \%$ & 59.957 & $12,8 \%$ \\
$\mathbf{2 0 0 8}$ & 920,81 & $17,3 \%$ & $3.455,44$ & $17,4 \%$ & $1.988,56$ & $17,4 \%$ & 81.937 & $17,6 \%$ \\
$\mathbf{2 0 0 9}$ & 966,14 & $18,2 \%$ & $3.667,43$ & $18,4 \%$ & $2.112,62$ & $18,4 \%$ & 86.134 & $18,5 \%$ \\
$\mathbf{2 0 1 0}$ & $1.691,05$ & $31,8 \%$ & $6.325,12$ & $31,8 \%$ & $3.646,31$ & $31,8 \%$ & 146.245 & $31,3 \%$ \\
\hline Total & $5.311,83$ & $100,0 \%$ & $19.881,70$ & $100,0 \%$ & $11.452,04$ & $100,0 \%$ & 466.628 & $100,0 \%$ \\
\hline
\end{tabular}

Obs.: As colunas "Choque", "VBP” e "VA" estão em R\$ milhões.

VBP - Valor Bruto da Produção; VA - Valor Adicionado; PO - Pessoal Ocupado. Ano inicial é 2004, cujo choque é zero.

Fonte: Elaboração própria a partir da Matriz Insumo-Produto

Em média, o choque anual é de R \$ 885 milhões, com resultados da ordem de R\$ 3,3 bilhões para valor bruto da produção, $\mathrm{R}$ \$ 1,9 bilhões para valor adicionado e aumento de 77,8 mil em pessoas ocupadas.

Entretanto a tabela acima, pouco informa sobre o efeito regional da expansão temporal dos gastos públicos com universidades federais. O gráfico a seguir mostra estes efeitos para cada uma das cinco regiões brasileiras. Inicialmente, nota-se que os resultados acompanham a 
grandeza dos choques, com a região Sudeste destacando-se pelos maiores impactos nas variáveis monetárias. O segundo maior efeito está na região Nordeste, seguida pela Sul.

\section{Gráfico 2.24 - Evolução Anual dos Choques e Impactos Econômicos por Região}

\section{Geográfica no Período 2004-2010}

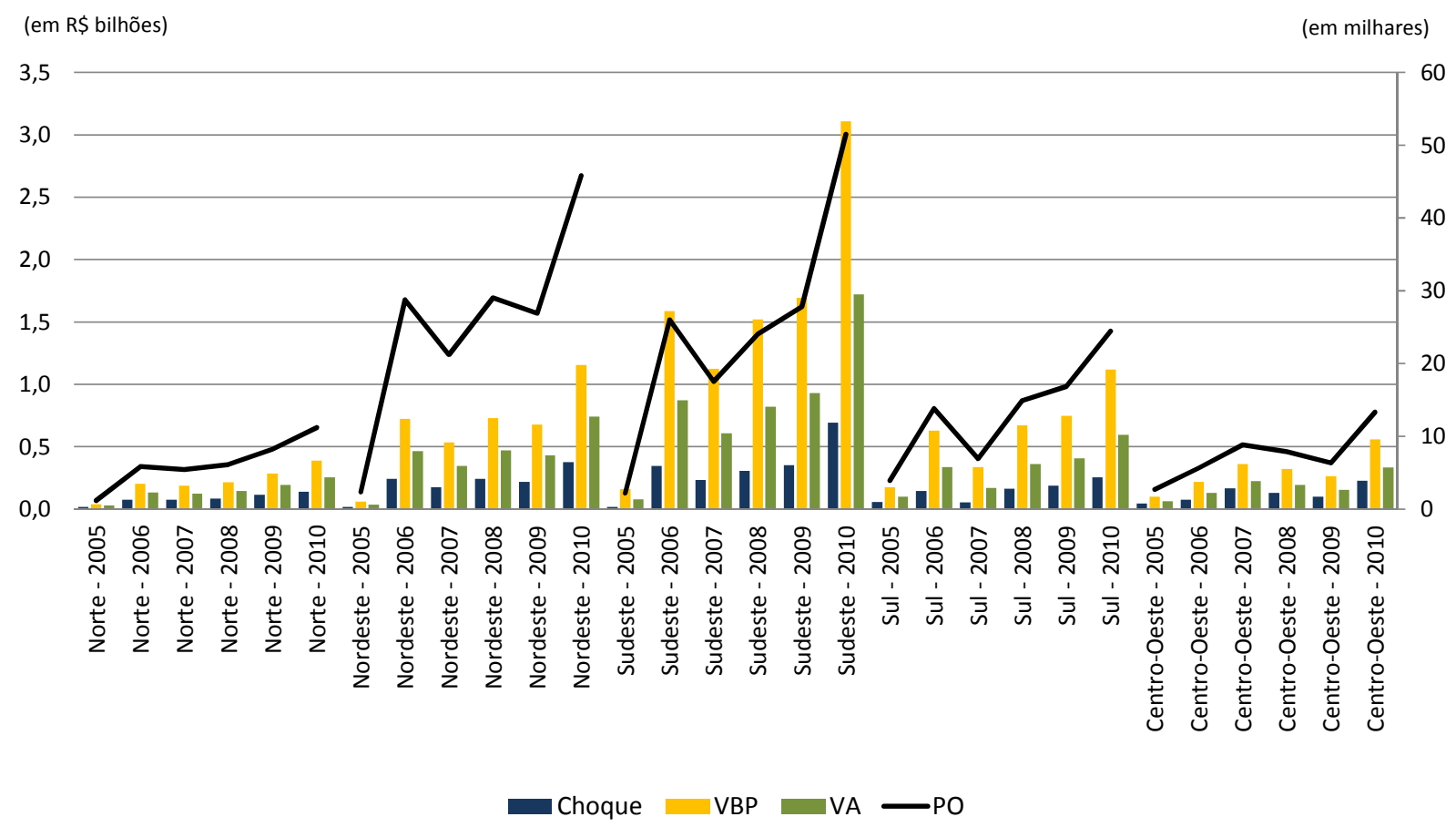

Obs.: O eixo vertical da esquerda se refere às variáveis "Choque", "VBP" e "VA", e o eixo vertical da direita se refere à variável "PO",

VBP - Valor Bruto da Produção; VA - Valor Adicionado; PO - Pessoal Ocupado.

Ano inicial é 2004, cujo choque é zero.

Fonte: Elaboração própria a partir da Matriz Insumo-Produto

Com relação ao valor bruto da produção, na região Sudeste, os efeitos oscilam por volta de R \$ 1,5 bilhão, até 2009. Em 2010, tal efeito chega a R 33 bilhões, dada a forte expansão de gasto neste ano. Para valor adicionado, neste ano, o efeito chega a R \$ 1,7 bilhão. Este forte impacto no último ano ocorre em todas as regiões e para todas as variáveis, visto que é um ano de forte expansão de gastos.

Os impactos na região Nordeste apresentam magnitudes por volta da metade da dos impactos da região Sudeste. Entretanto, chama a atenção o impacto sobre pessoal ocupado. Como já constatado anteriormente, no item sobre impactos regionais, o efeito total do período da região Nordeste é maior do que o da Sudeste. Isto também ocorre, quando a análise é 
aberta pelos anos. Até 2008, os efeitos sobre pessoal ocupado na região Nordeste são maiores do que os da Sudeste. Para os anos de 2009 e 2010, este comportamento se inverte. Todavia, no acumulado o resultado da região Nordeste é o maior do País, chegando em 2010 a quase 46 mil pessoas ocupadas e no acumulado a 154 mil.

\subsection{7- Análise Estrutural}

No contexto de estudo de impacto de um choque resultante de política pública na economia; neste item, busca-se entender o funcionamento da economia em relação ao setor Educação Pública e como este se relaciona com os demais setores e microrregiões.

Para tanto, analisa-se os geradores, multiplicadores e índices de ligação da economia brasileira, com base na metodologia apresentada no item do modelo de Insumo-Produto. Desta forma, a análise é apresentada na seguinte ordem: multiplicadores de produção e emprego, gerador de emprego, índices de ligação de Rasmussen/Hirschman, e índice Puro de ligação. Além disso, comparam-se estes índices entre os anos de 2004 e 2009, com base nas respectivas matrizes de insumo-produto, investigando se a estrutura produtiva da economia sofreu alteração significativa neste período. Tal investigação é extremamente importante, visto que uma das hipóteses no modelo calculado neste capítulo é que estrutura produtiva da economia brasileira sofreu pouca alteração no período de análise entre 2004 e 2010.

O multiplicador de produção indica quanto se produz para cada unidade monetária gasta no consumo final. Observa-se pelo gráfico abaixo que os valores de multiplicadores do tipo II (que também considera a demanda das famílias no sistema) quase não se alteram entre 2004 e 2009. Dentre os maiores multiplicadores calculados para a economia, destacam-se os seguintes em três setores: Alimentos e bebidas; Pecuária e pesca; e Automóveis, camionetas e utilitários. O setor com a maior variação é o de Cimento que apresentou um pequeno aumento, ganhando relativamente capacidade de gerar estímulo à produção, quando há um aumento no consumo da demanda final. 


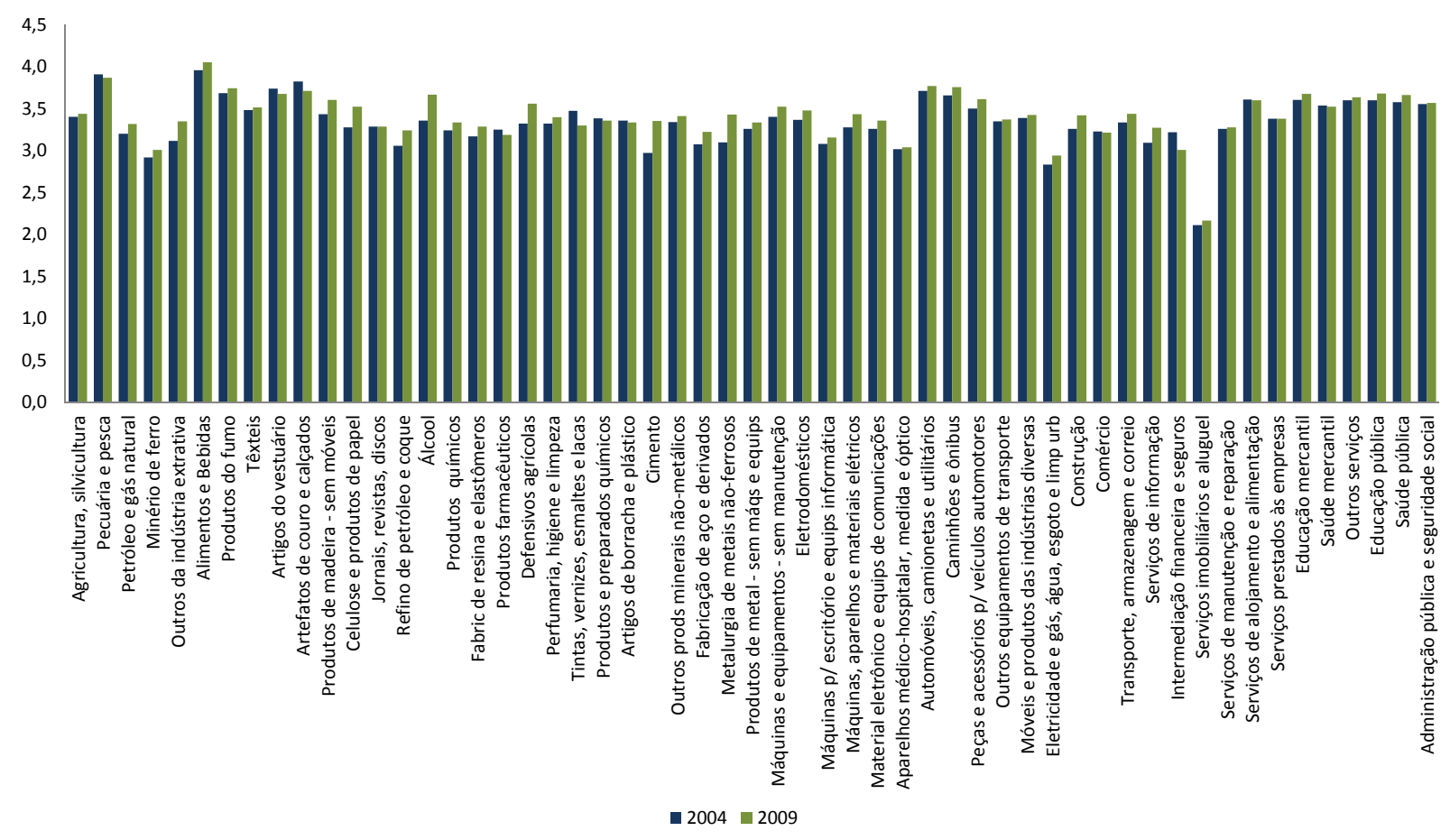

Fonte: Calculada a partir da matriz de insumo-produto

O setor de Educação Pública apresenta multiplicador de produção do tipo II praticamente inalterado no período, indo de 3,60 para 3,68, sendo acima da média nacional, próxima de 3,40. O setor com menor capacidade de estímulo à produção é o de Serviços imobiliários e aluguel. Vale lembrar que este é o setor que recebe o terceiro maior impacto da expansão da rede de universidades federais. Já o setor de Alimentos e Bebidas, que apresenta a maior capacidade de estímulo à produção na economia, também é o setor mais impactado pela expansão de gastos federais com universidades.

Enquanto que os multiplicadores de produção estão praticamente todos no mesmo patamar, gerando por volta de $\mathrm{R}$ \$,50 em produção para cada $\mathrm{R} \$ 1,00$ gasto no consumo final, o mesmo não se observa com relação aos multiplicadores de emprego. Vale lembrar que o multiplicador de emprego apresenta quanto de cada emprego que é ofertado em um dado setor é gerado de emprego na economia como um todo. 
Gráfico 2.26 - Multiplicadores de Emprego da Economia Brasileira (2004 e 2009)

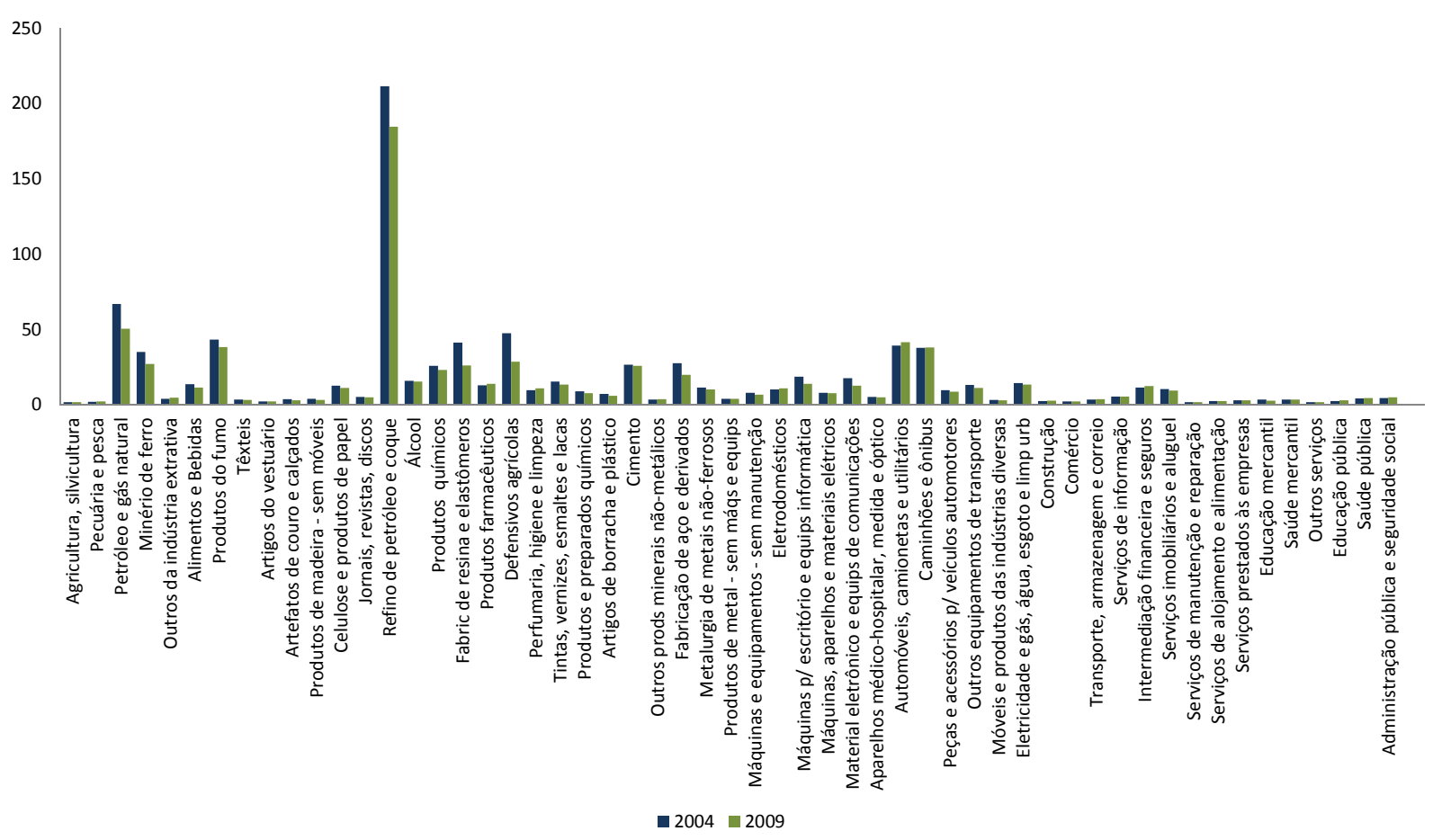

Fonte: Calculada a partir da matriz de insumo-produto

De acordo com os valores apresentados no gráfico acima, o setor que mais gera emprego na economia ao ofertar um emprego é o setor de Refino de petróleo e coque. Os setores com menores multiplicadores de emprego são os setores referentes a serviços.

O setor Educação Pública apresenta multiplicador de emprego de 2,50 em 2004 e 2,89 em 2010, ou seja, para cada emprego ofertado no setor, foram gerados 2,89 empregos na economia em 2010. Como apresentado anteriormente, este setor apresenta significativa parte do seu impacto sobre os setores referentes a serviços, com destaque para Comércio e Serviços imobiliários e aluguel, mas os setores de serviços são os que menos geram empregos, dada a oferta de emprego deles.

Entretanto, quando se analisa os geradores de emprego, observa-se um padrão diferente dos multiplicadores, pois os setores relacionados a serviços se destacam, pela tabela abaixo. O gerador de emprego diz respeito a quanto cada setor gera de emprego para cada unidade monetária produzida para a demanda final. A diferença observada entre os multiplicadores de emprego e os geradores de emprego mostra que, quando a geração de 
emprego é referenciada pela produção que cada setor destina à demanda final, o setor de serviços tem um maior poder na geração de empregos.

\section{Gráfico 2.27 - Geradores de Emprego da Economia Brasileira (2004 e 2009)}

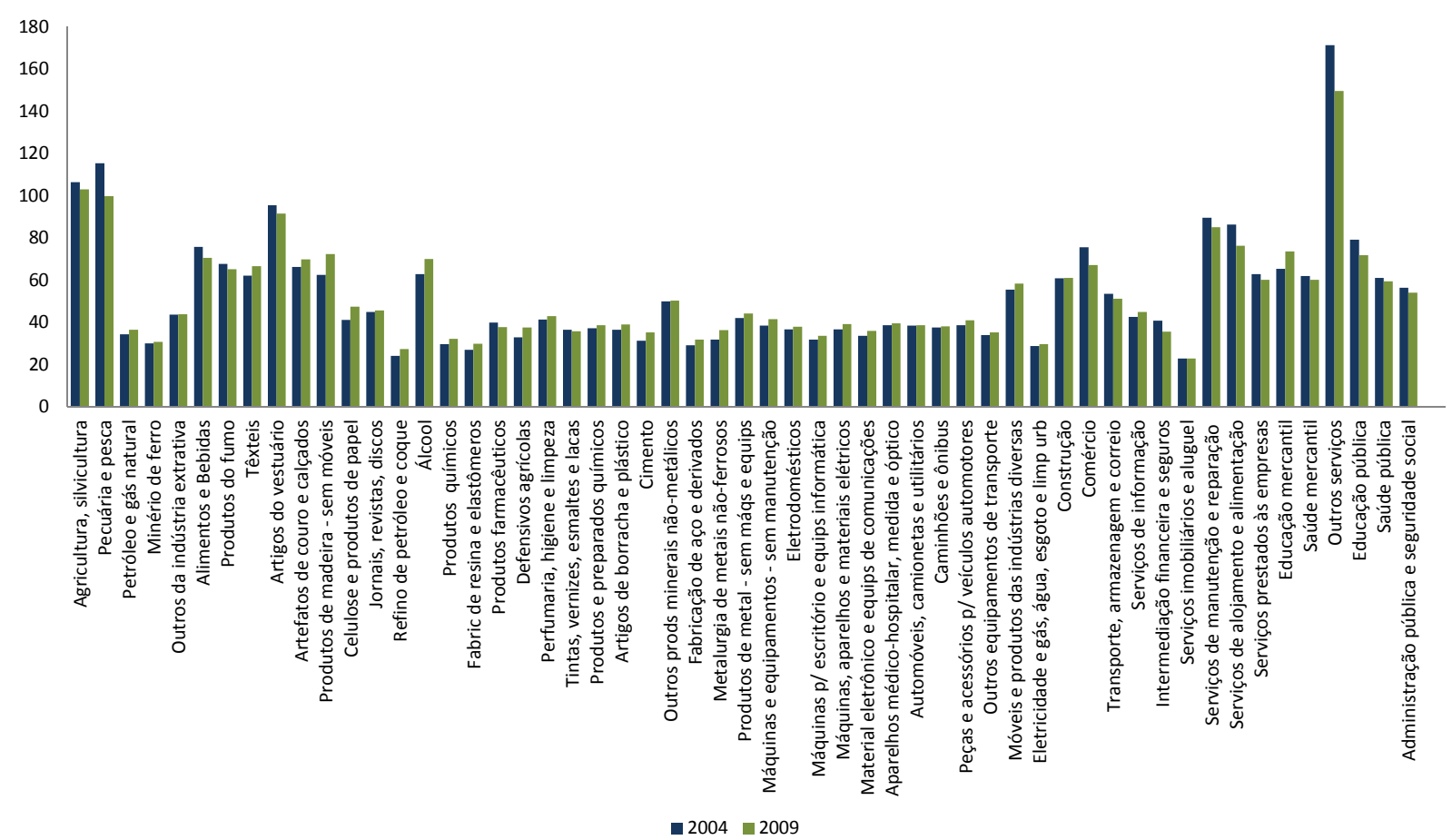

Obs.: Valores dos geradores têm como ano de referência 2010.

Fonte: Calculada a partir da matriz de insumo-produto

Constata-se que houve pouca alteração nos valores dos geradores de emprego entre 2004 e 2009, com praticamente a mesma participação de cada setor na geração de emprego na economia. Vale lembrar que os valores dos geradores têm como ano de referência 2010, sendo deflacionados pelo deflator implícito do PIB.

Com relação ao setor Educação Pública, o gerador de emprego cai de 79,32 para 71,82 no período. Em 2009, este setor gerava 72 empregos em toda a economia para cada $\mathrm{R} \$$ 1 produzido para a demanda final, considerando efeitos direto, indireto e induzido. Especificamente, a geração de emprego é de aproximadamente: 25 diretamente; 5 indiretamente; e 42 através do efeito renda das famílias. Observa-se a grande participação das famílias no resultado do setor com relação ao emprego. 
A seguir são apresentados os índices de ligação de Hirschman-Rasmussen para frente e para trás em dois gráficos, um para cada ano, uma vez que a análise envolve a comparação direta entre os índices para trás e para frente. Conforme mencionado anteriormente, Miller e Blair (2009) apresenta uma classificação de setores, de acordo com os valores dos índices para trás e para frente: (a) setores independentes de (ou pouco relacionados a) outros setores, caso ambos os índices de ligação sejam inferiores a 1; (b) setores dependentes de (ou fortemente relacionados a) outros setores, caso ambos os índices de ligação sejam superiores a 1, o que também denota setores-chave para o crescimento da economia; (c) setores dependentes da oferta interindustrial, se apenas o índice de ligação para trás for maior do que 1; (d) setores dependentes da demanda interindustrial, se apenas o índice de ligação para frente for superior a 1 .

\section{Gráfico 2.28 - Índices de Ligação de Hirschman-Rasmussen para Trás e para Frente} (2004)

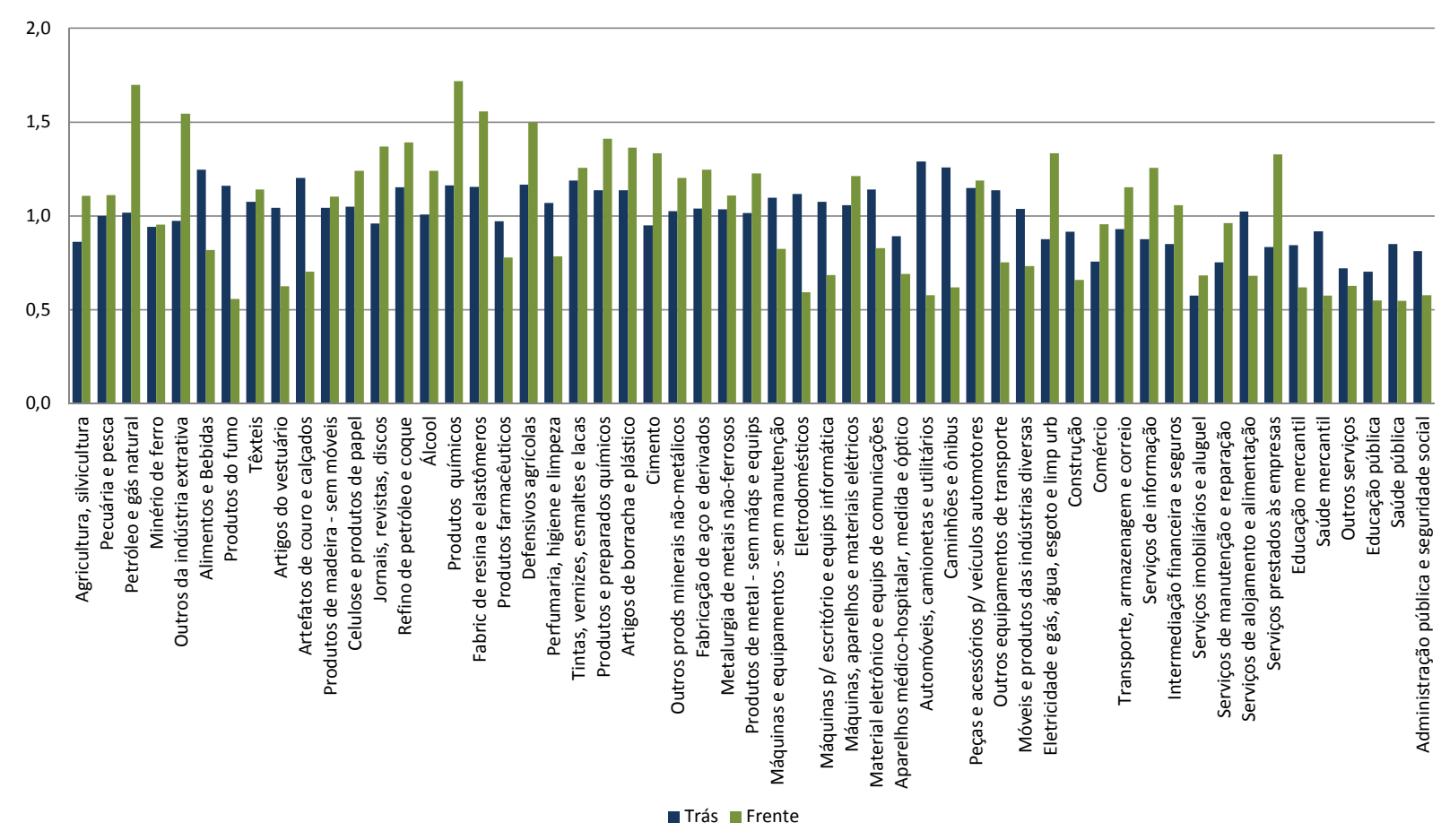

Fonte: Calculada a partir da matriz de insumo-produto 


\section{Gráfico 2.29 - Índices de Ligação de Hirschman-Rasmussen para Trás e para Frente} (2009)

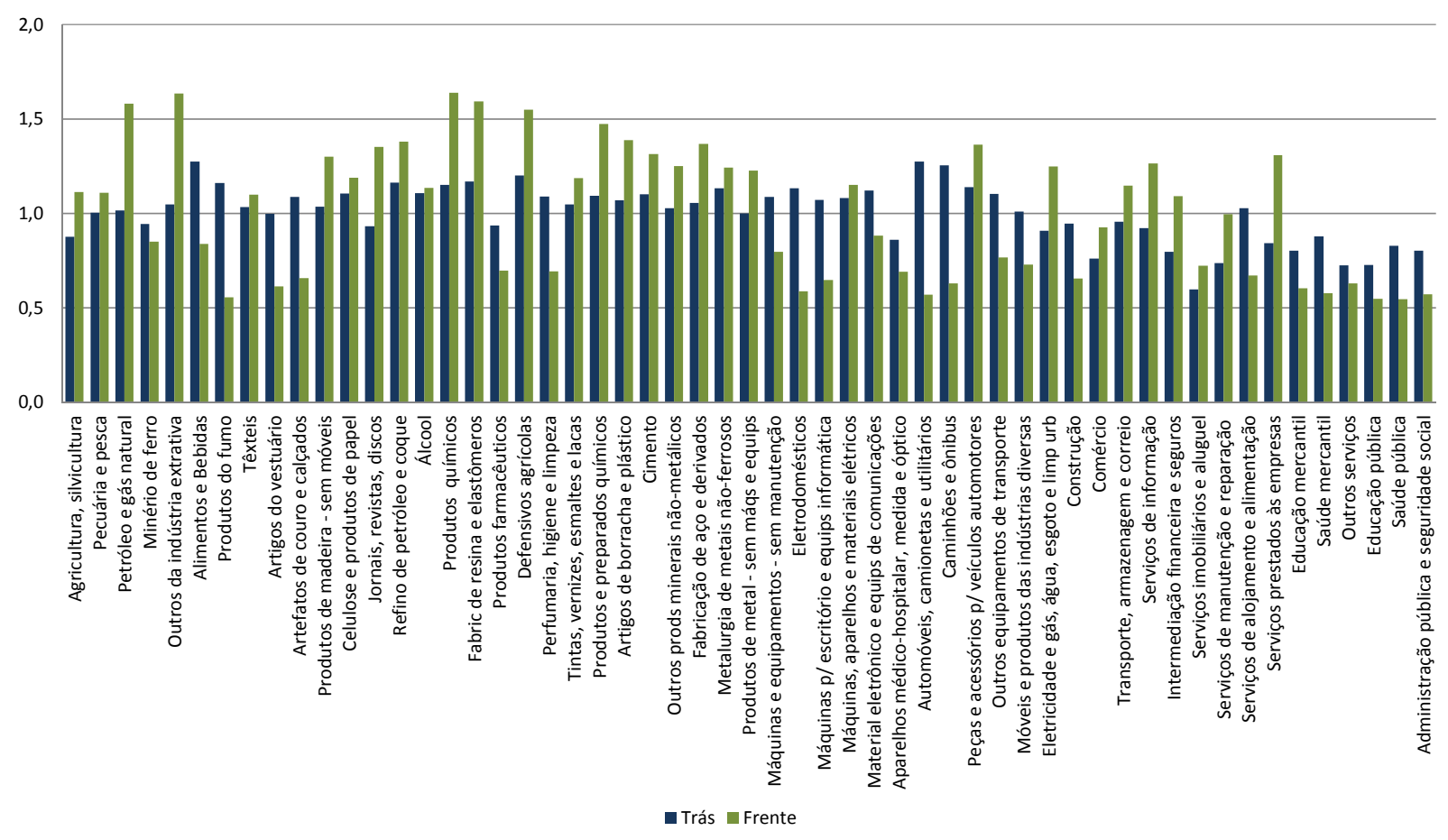

Fonte: Calculada a partir da matriz de insumo-produto

Podem ser identificados como setores-chave da economia brasileira em ambos os anos os seguintes 17 setores: Petróleo e gás natural; Têxteis; Produtos de madeira - sem móveis; Celulose e produtos de papel; Refino de petróleo e coque; Álcool; Produtos químicos; Fabricação de resina e elastômeros; Defensivos agrícolas; Tintas, vernizes, esmaltes e lacas; Produtos e preparados químicos; Artigos de borracha e plástico; Outros produtos minerais não-metálicos; Fabricação de aço e derivados; Metalurgia de metais não-ferrosos; Máquinas, aparelhos e materiais elétricos; Peças e acessórios para veículos automotores.

Dentre estes setores-chave, destacam-se os setores relacionados com a indústria química: Produtos químicos; Fabricação de resina e elastômeros; Defensivos agrícolas. Tais setores apresentam os maiores índices de ligação para trás e para frente conjuntamente.

Dos setores relativamente independentes dos demais, a maior parte concentra-se no setor de serviços. Estes setores com ambos os índices inferiores a 1 em ambos os anos são: Minério de ferro; Produtos farmacêuticos; Aparelhos médico-hospitalar, medida e óptico; Construção; Comércio; Serviços imobiliários e aluguel; Serviços de manutenção e reparação; 
Educação mercantil; Saúde mercantil; Outros serviços; Educação pública; Saúde pública; Administração pública e seguridade social.

Os setores caracterizados apenas por forte dependência da oferta interindustrial foram os setores de: Alimentos e Bebidas; Produtos do fumo; Artefatos de couro e calçados; Perfumaria, higiene e limpeza; Máquinas e equipamentos - sem manutenção; Eletrodomésticos; Máquinas para escritório e equipamentos informática; Material eletrônico e equipamentos de comunicações; Automóveis, camionetas e utilitários; Caminhões e ônibus; Outros equipamentos de transporte; Móveis e produtos das indústrias diversas; Serviços de alojamento e alimentação.

Já os setores somente dependentes da demanda interindustrial foram: Agricultura, silvicultura; Jornais, revistas, discos; Eletricidade e gás, água, esgoto e limpeza urbana; Transporte, armazenagem e correio; Serviços de informação; Intermediação financeira e seguros; Serviços prestados às empresas.

Os resultados obtidos com os índices de Hirschman-Rasmussen são reflexos da estrutura intersetorial. Todavia, não consideram o tamanho dos setores na economia, que é um fator relevante na identificação dos setores-chave. Buscando levar em consideração o nível de produção em cada setor, pode-se utilizar o índice Puro de ligação que é usado para analisar a estrutura produtiva, considerando os diferentes níveis de produção em cada setor. Com isso, é possível determinar quais seriam os principais setores responsáveis por variações nos níveis do PIB e de outras variáveis macroeconômicas importantes.

Os índices de ligação puros normalizados consideram o peso de cada setor como demandante ou ofertante na economia e o seu respectivo tamanho relativo, permitindo assim analisar a importância do setor. Nestes índices, é possível observar o impacto puro de um setor sobre o resto da economia, e devido à normalização, podemos fazer uma análise comparativa com os índices de Hirschman-Rasmussen apresentados anteriormente.

Pela tabela abaixo, analisando o Índice puro de ligação normalizado para trás, destacam-se os seguintes dez setores: Alimentos e Bebidas; Máquinas e equipamentos - sem manutenção; Automóveis, camionetas e utilitários; Construção; Comércio; Transporte, armazenagem e correio; Serviços de alojamento e alimentação; Saúde mercantil; Outros serviços; Administração pública e seguridade social. Estes setores apresentam elevado impacto puro do valor de sua produção, demandando os demais setores da economia. Isto 
significa que este índice mostra o impacto do valor da produção total de um setor sobre o resto da economia, livre da demanda de insumos que este setor produz para ele mesmo e dos retornos do resto da economia para este setor e vice-versa. Vale destacar o aumento de importância do setor de Construção como demandante na economia.

\section{Gráfico 2.30 - Índices Puros de Ligação Normalizados para Trás (2004 e 2009)}

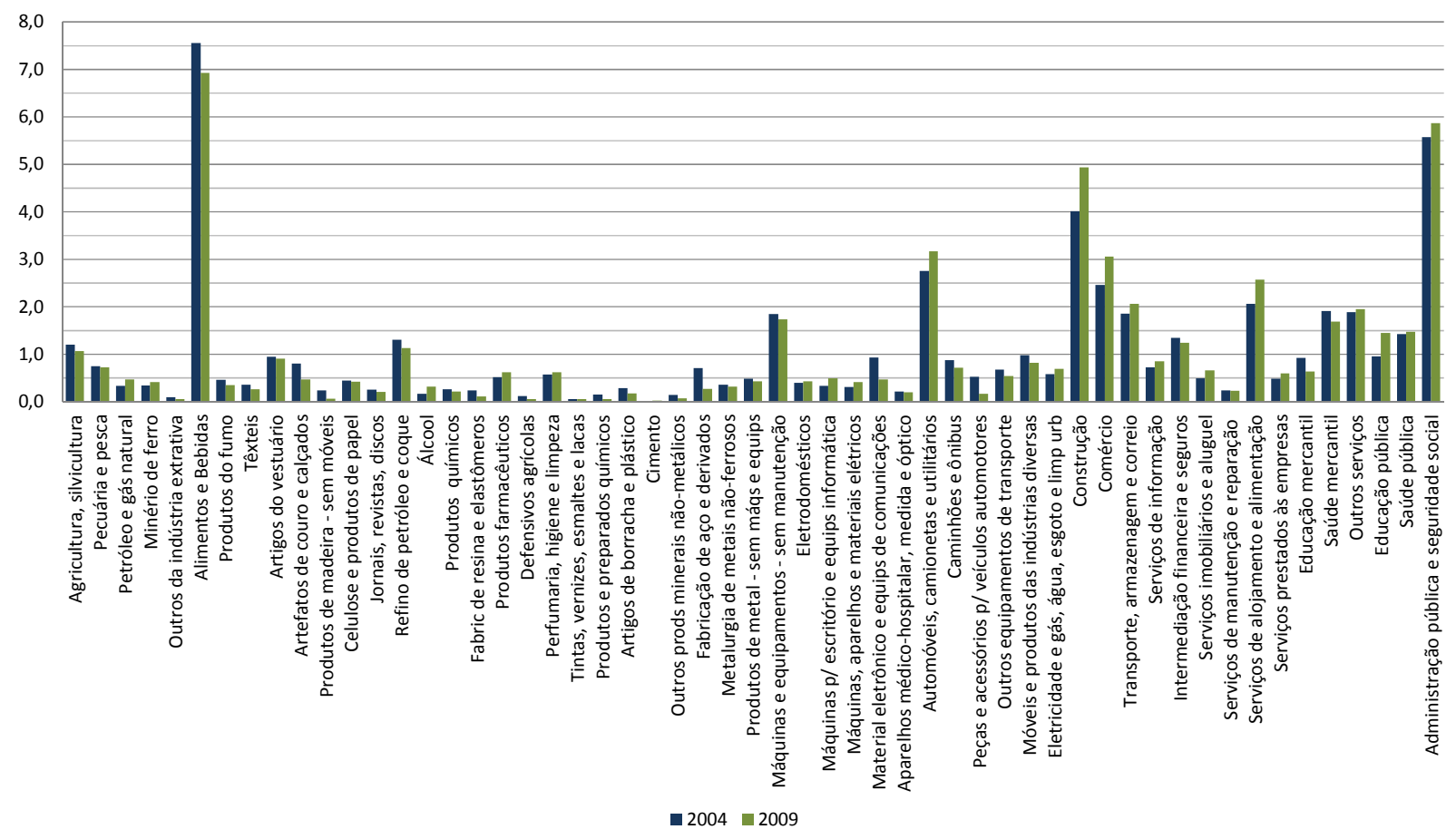

Fonte: Calculada a partir da matriz de insumo-produto

Com relação ao Índice puro normalizado para frente, de acordo com a tabela a seguir, destacam-se oito setores: Agricultura, silvicultura; Refino de petróleo e coque; Eletricidade e gás, água, esgoto e limpeza urbana; Comércio; Transporte, armazenagem e correio; Serviços de informação; Intermediação financeira e seguros; Serviços prestados às empresas. Tais setores têm maior impacto do valor da produção total do resto da economia sobre si. Isto significa que são ofertantes na economia, ou seja, geram produção para os demais setores da economia. Vale mencionar o setor de Intermediação financeira e seguros que apresenta aumento de sua relevância na economia. 
Gráfico 2.31 - Índices Puros de Ligação Normalizados para Frente (2004 e 2009)

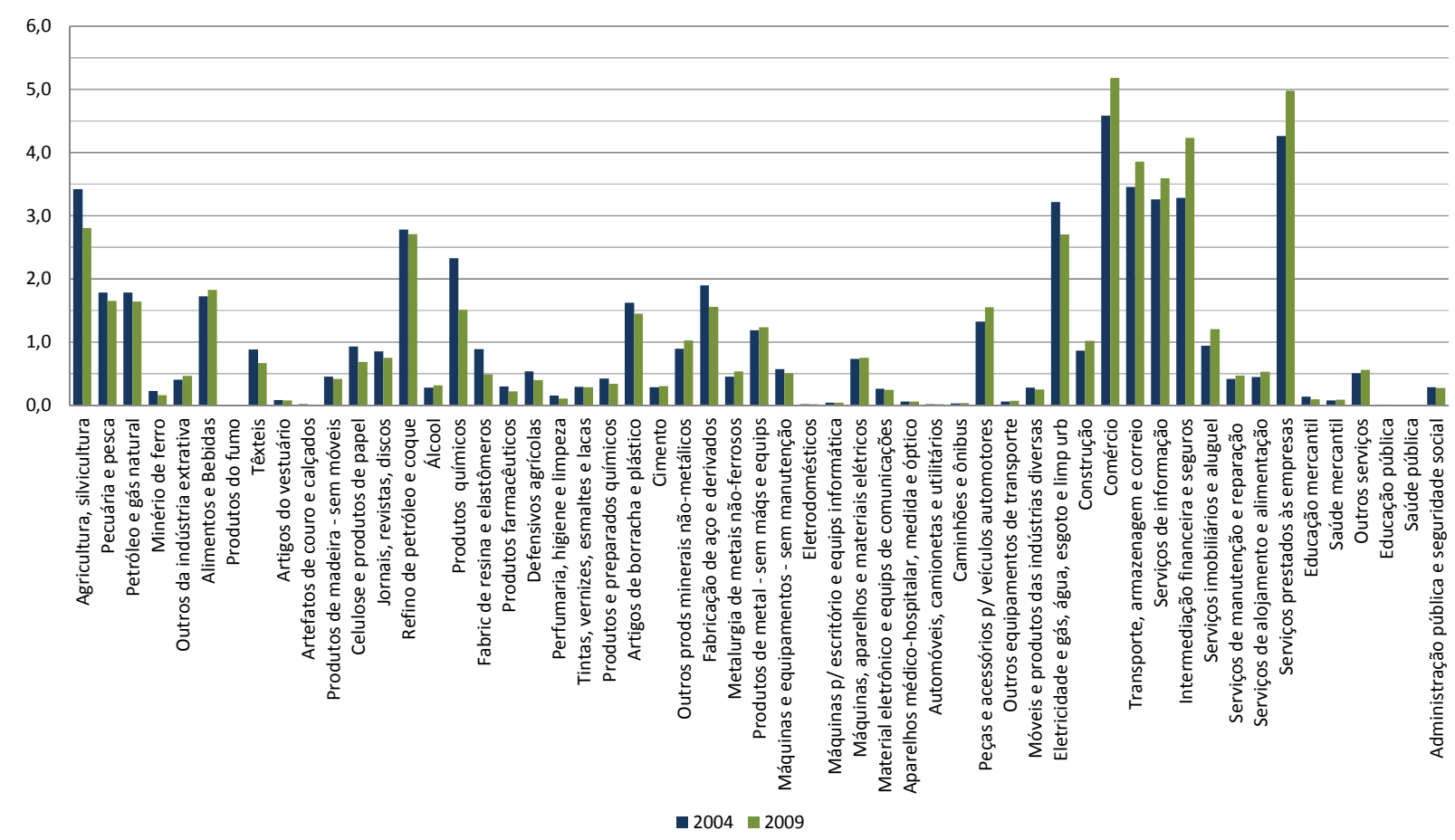

Fonte: Calculada a partir da matriz de insumo-produto

Considerando-se a média dos índices puros normalizados para trás e para frente, podemos analisar o impacto conjunto na economia de cada setor como demandante e ofertante. O gráfico abaixo mostra que existem sete setores com esta característica. Estes setores são: Alimentos e Bebidas; Construção; Comércio; Transporte, armazenagem e correio; Intermediação financeira e seguros; Serviços prestados às empresas; Administração pública e seguridade social. Vale ressaltar que o setor de Construção vem perdendo importância na economia, e os setores de Serviços de finanças e de Serviços profissionais e de negócios mostram tendência contrária. Além disso, fica evidenciado o aumento de importância do setor de Serviços de governo, com forte aumento do índice puro total na última década. 
Gráfico 2.32 - Índices Puros de Ligação Normalizados Totais (2004 e 2009)

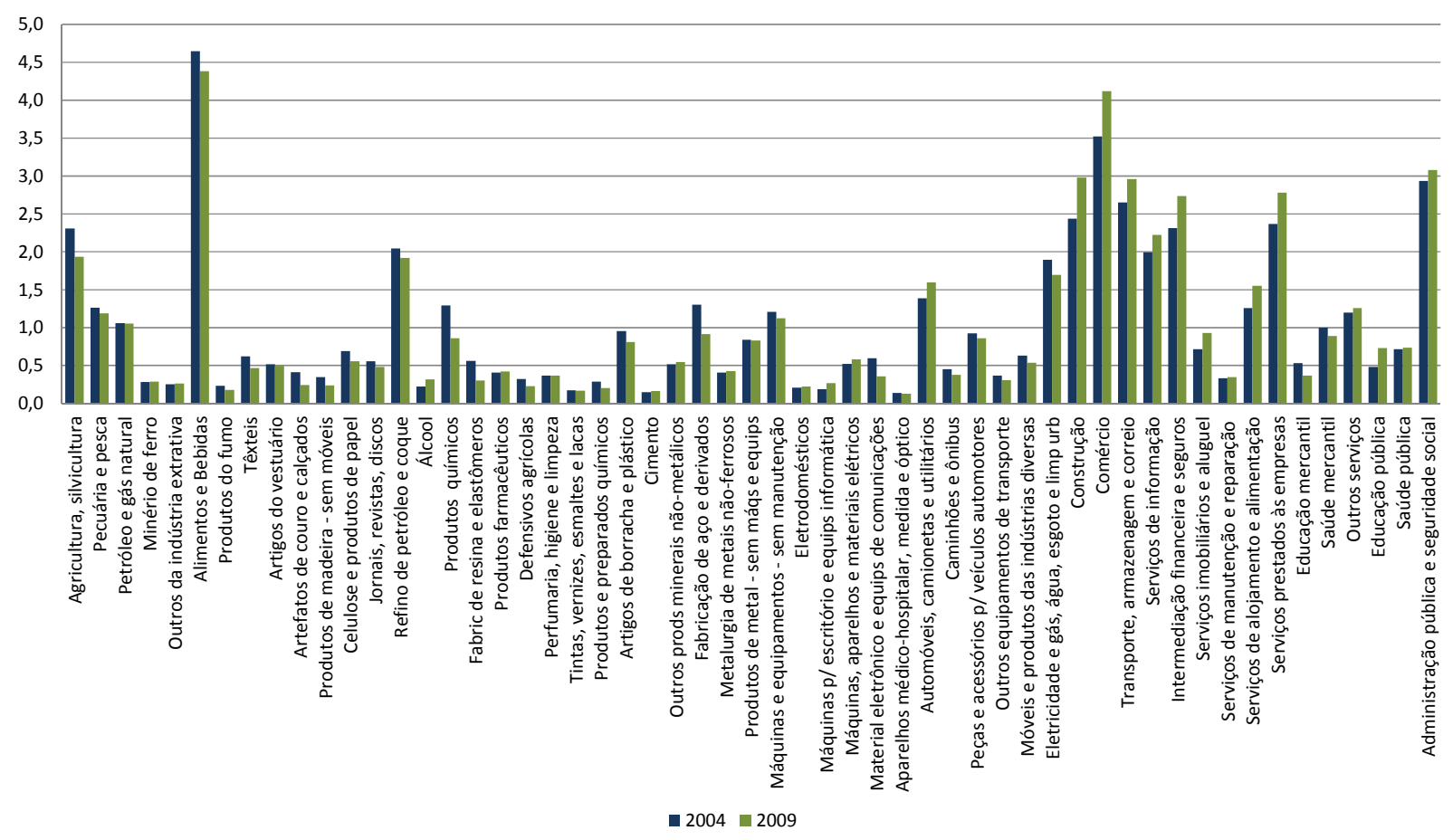

Fonte: Calculada a partir da matriz de insumo-produto

Os índices puros de ligação normalizados apresentam resultados semelhantes aos mostrados pelos índices de ligação de Hirschman-Rasmussen. Em geral, verifica-se que, entre 2004 e 2009, não houve alterações significativas nas inter-relações entre os setores e seus encadeamentos, seja enquanto ofertantes, seja enquanto demandantes de insumos, com poucas exceções. Isto corrobora para a hipótese de que a estrutura produtiva brasileira sofreu pouca alteração no período analisado, justificando a utilização da matriz de insumo-produto microrregionalizada de 2004 para a análise de todo o período.

Buscando evidenciar as alterações dos índices puros de ligação normalizados totais entre 2004 e 2009, pode-se calcular a razão dos valores de 2009 sobre 2004, de forma a destacar os crescimentos e reduções dos índices. Assim, pelo gráfico abaixo, pode-se verificar quais setores ganharam ou perderam importância como demandantes e ofertantes na economia brasileira entre 2004 e 2009. 


\section{Gráfico 2.33 - Razão dos Índices Puros de Ligação Normalizados Totais (2009/2004)}

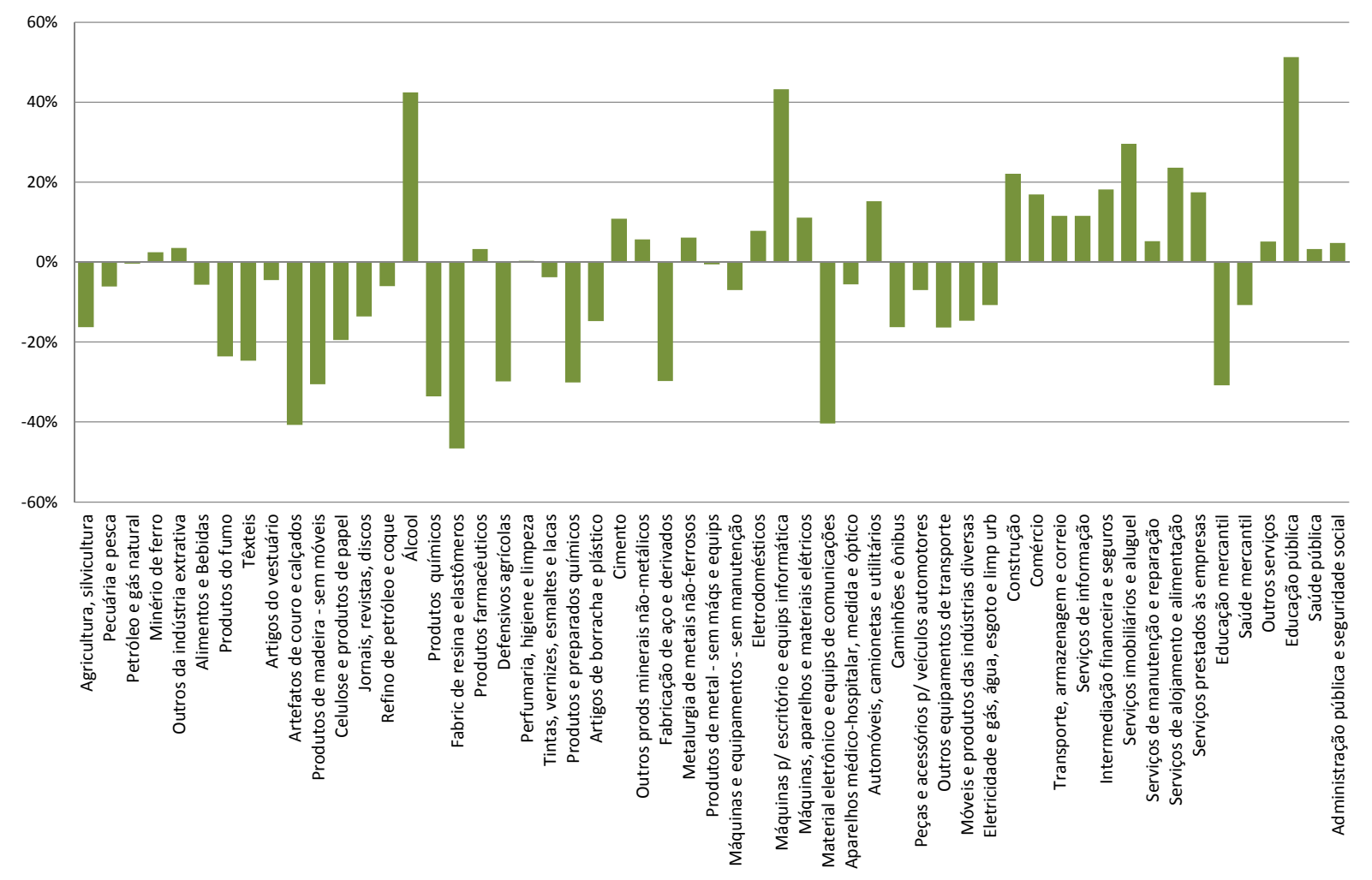

Fonte: Calculada a partir da matriz de insumo-produto

Os setores que perderam importância na economia, com queda acima de $40 \%$ são: Fabricação de resinas e elastômeros; Artefatos de couro e calçados; e Material eletrônico e equipamentos de comunicações. Dentre aqueles com ganho de importância, os que apresentaram crescimento do índice puro de ligação normalizado total acima de $40 \%$ são: Educação pública; Máquinas para escritório e equipamentos de informática; e Álcool.

No enfoque deste trabalho, o resultado que se destaca é o referente ao setor Educação Pública, que apresenta a maior razão do índice puro de ligação normalizado total, ou seja, o maior crescimento. Apesar deste setor ter baixo valor absoluto neste índice, relativamente no tempo, apresenta o maior aumento de participação na economia brasileira. Tal resultado devese ao índice puro de ligação normalizado para trás, o que significa que o setor Educação Pública ganhou importância como demandante dos demais setores da economia, ou seja, apresenta aumento do seu impacto do valor da produção total sobre o resto da economia. 
Vale mencionar que o modelo utilizado neste capítulo não considera eventuais restrições à oferta de mão-de-obra em alguns setores ao longo do tempo. As restrições contempladas pela matriz insumo-produto são as intrínsecas à estrutura produtiva da economia brasileira. Tem-se por hipótese neste capítulo de que estas restrições na oferta de mão-de-obra no período apresentam pouco impacto nos resultados setoriais e consequentemente nos demais resultados. Tal hipótese se fundamenta na observação de dois índices econômicos. O primeiro diz respeito a uma tendência suave de queda da taxa anual de desemprego nacional ao longo da década 2000-2010 (taxas de desemprego de 10,0, 9,7 e 9,1, em 2001, 2004 e 2009, respectivamente). Analisando a taxa mensal de desemprego nas regiões metropolitanas de Recife, Salvador, Belo Horizonte, Rio de Janeiro, São Paulo e Porto Alegre, observa-se pela Pesquisa Mensal de Emprego do IBGE que a média anual da taxa de desemprego apresenta uma tendência de queda ainda maior, sendo de 11,7\% em 2002, 11,5\% em 2004 e 6,7\% em 2010. O segundo índice econômico em defesa da hipótese apresentada é que a taxa de utilização da capacidade instalada da indústria (dessazonalizada), calculada pela Confederação Nacional da Indústria (CNI). Constata-se que durante a década, há um suave aumento da utilização da capacidade instalada da indústria, sendo de 80,7\% em 2000, 81,8\% em 2004 e 83,2\% em 2010. Assim, um cenário de queda da taxa de desemprego e aumento da utilização da capacidade instalada da indústria indica que a restrição na oferta de mão-de-obra não apresentaria alterações significativas nos resultados apresentados neste capítulo, pelo menos no nível nacional.

O fato do setor Educação Pública não se destacar como um setor-chave da economia, pelos índices calculados, e não ser considerado um forte demandante ou ofertante entre os setores, não significa que investimentos neste setor tenham efeitos insignificantes sobre a economia. No longo prazo, tais investimentos tem forte potencial de alteração das condições de oferta regional com relação ao capital humano e à tecnologia. Além disso, é importante lembrar que Educação Pública é um setor de serviços e seu maior impacto está naturalmente no efeito induzido sobre a renda das famílias, que corresponde a mais de $50 \%$ do efeito total. Os índices de ligação puros normalizados apontam para um aumento da importância do setor de serviços na economia, enquanto que, quando a geração de emprego é referenciada pela produção que cada setor destina à demanda final, o setor de serviços tem um maior poder na geração de empregos. 


\section{4- Conclusão}

Dada a questão do impacto regional da expansão do ensino superior público federal, neste capítulo utilizou-se o modelo de Insumo-Produto, com o intuito de estudar o impacto econômico de curto prazo das universidades federais sobre as variáveis econômicas Valor Bruto da Produção, Valor Adicionado, e Pessoal Ocupado. Desta forma, buscou-se usar o aumento de gastos do governo federal com suas universidades no período entre 2004 e 2010 . Para tanto, foi utilizada a Matriz de Insumo-Produto do ano de 2004, aplicando-se choques anuais microrregionais na demanda sobre o setor Educação Pública.

Além da matriz Insumo-Produto, vale destacar a base de dados do SIAFI, que possibilitou calcular os gastos públicos dos órgãos-universidade por município e ano, agregando-se posteriormente em microrregiões. A forte expansão destes gastos públicos se dá claramente a partir de 2005, justificando a utilização da Matriz Insumo-Produto de 2004 como base para o modelo.

Dado um choque total de $\mathrm{R} \$ 5,3$ bilhões no período, o impacto mensurado sobre o Brasil foi de $\mathrm{R}$ \$ 19,9 bilhões sobre valor bruto da produção, $\mathrm{R}$ \$ 11,5 bilhões sobre o PIB, que representa um efeito de $0,39 \%$ sobre o PIB de 2004, e aumento de 466,6 mil pessoas ocupadas.

Ao se analisar o âmbito regional, observa-se que a região Sudeste recebe 36,6\% do choque nacional e apresenta a maior participação no resultado do País, com 46,2\% e 43,9\%, respectivamente, sobre valor bruto da produção e valor adicionado. Já sobre pessoal ocupado, destaca-se a região Nordeste com $33,0 \%$ do efeito total.

Do ponto de vista estadual, São Paulo tem os maiores efeitos sobre a economia brasileira, com exceção do efeito sobre pessoal ocupado, onde Minas Gerais se destaca. Vale ainda mencionar que o Rio Grande do Sul, que tem efeitos sobre valor bruto da produção e valor adicionado abaixo do Rio de Janeiro, que apresenta o terceiro maior efeito para pessoal ocupado, ficando abaixo apenas de Minas Gerais e São Paulo. Ao se analisar as microrregiões dos estados, constata-se que as microrregiões menores do ponto de vista econômico recebem os maiores impactos relativos da expansão de gastos públicos federais com universidades, e as que possuem capitais de unidades da federação apresentam os maiores efeitos em valores absolutos. 
Observando-se o impacto de cada universidade individualmente sobre sua respectiva microrregião, sem considerar o efeito das demais universidades, é evidenciado que as microrregiões com os 10 maiores impactos absolutos tem participação de aproximadamente $17,7 \%$ nos impactos totais nacionais com relação a valor bruto da produção, valor adicionado e pessoal ocupado. Considerando todas as universidades conjuntamente, os efeitos totais acumulados sobre as microrregiões, são expressivos. As 10 microrregiões com maior efeito absoluto sobre PIB detêm 48,5\%, 46,7\% e 38,1\% dos impactos totais sobre valor bruto da produção, valor adicionado e pessoal ocupado, respectivamente, no Brasil.

Setorialmente, considerando o impacto sobre produção, percebe-se que o setor Alimentos e Bebidas gera o maior efeito na economia. Entretanto, sua participação sobre valor adicionado e pessoal ocupado não é tão expressiva. Já o setor de Comércio apresenta grandes efeitos sobre as três variáveis, sendo o segundo maior efeito sobre valor bruto da produção e valor adicionado, e o primeiro maior efeito sobre pessoal ocupado. O setor de Agricultura, Silvicultura e Exploração Florestal, que tem uma razoável significância em valores monetários, é o segundo maior produtor de empregos, tendo um impacto econômico de quase 48 mil pessoas ocupadas.

Dentre as universidades novas, merece destaque a UFABC com os maiores efeitos sobre valor bruto da produção e valor adicionado. Já sobre pessoal ocupado, apresenta-se em terceiro lugar, abaixo da UFRB e UFCG.

Analisando-se os impactos anuais, constata-se que a região Nordeste apresenta efeitos de magnitudes por volta da metade dos efeitos da região Sudeste. Todavia, destaca-se com relação a pessoal ocupado ao longo do período entre 2004 e 2010. Até 2008, os efeitos sobre pessoal ocupado na região Nordeste são maiores do que os da Sudeste. Para os anos de 2009 e 2010, este comportamento se inverte. Todavia, no acumulado o resultado da região Nordeste é o maior do País, chegando em 2010 a quase 50 mil pessoas ocupadas e no acumulado a 142 mil, representando quase $42 \%$ do efeito.

Por fim, buscando entender a estrutura produtiva da economia brasileira e sua relação com o setor Educação Pública, são analisados os multiplicadores, geradores e índices de ligação da economia. Independente do índice considerado, podem-se apontar como setores demandantes na economia brasileira, os setores de: Alimentos e Bebidas; Máquinas e equipamentos - sem manutenção; Automóveis, camionetas e utilitários. Já como ofertantes, tem-se os setores de: Agricultura, silvicultura; Eletricidade e gás, água, esgoto e limpeza 
urbana; Transporte, armazenagem e correio; Serviços de informação; Intermediação financeira e seguros; Serviços prestados às empresas.

O setor Educação Pública não apresenta elevada relevância como ofertante ou demandante na economia brasileira no curto prazo, sendo classificado como um setor pouco relacionado com os demais setores da economia. Entretanto, uma destinação das despesas públicas, focada apenas no curto prazo e nos setores-chaves, não levaria em conta a questão do bem-estar social e os impactos de longo prazo que um setor pode ter sobre a economia brasileira.

Vale destacar que o setor Educação Pública apresenta o maior aumento de índice puro de ligação normalizado total. Apesar deste setor ter baixo valor absoluto neste índice, apresenta no período 2004-2010 o maior aumento de participação na economia brasileira. Isto se deve principalmente pelo fato deste setor ter ganhado importância como demandante dos demais setores da economia.

Portanto, ainda que o setor Educação Pública não se destaque como setor-chave, ofertante ou demandante, na economia brasileira, isto não significa que investimentos no setor Educação Pública tenham efeitos insignificantes. No longo prazo, tais investimentos tem forte potencial de alteração das condições de oferta regional com relação ao capital humano e à tecnologia. Além disso, é importante lembrar que Educação Pública é um setor de serviços e seu maior impacto está naturalmente no efeito induzido sobre a renda das famílias, que corresponde a mais de $50 \%$ do efeito total. Os resultados apontam também para um aumento da importância do setor de serviços na economia, apresentando um maior potencial de geração de empregos na economia brasileira. 


\section{3- MODELO ECONOMÉTRICO DE EFEITO ECONÔMICO DO TRATAMENTO}

\section{1- Introdução}

Tendo por objetivo a estimação do impacto econômico de curto prazo devido à expansão da estrutura universitária brasileira, busca-se estudar o impacto da presença de uma nova universidade sobre a atividade econômica local. Basicamente, pretende-se comparar indicadores econômicos básicos entre o cenário com a presença da universidade e o cenário sem esta no local (consequentemente hipotético). Entretanto, dado que este último é hipotético, tal estimação não é trivial, envolvendo o uso de técnicas econométricas que buscam tratar tal questão.

Como já apresentado, é importante frisar que uma universidade apresenta diversas influências sobre a economia regional no curto e longo prazo. No curto prazo, podem-se destacar os impactos com relação a gastos, como por exemplo, despesas e investimentos diretos da universidade (implantação e manutenção de estabelecimentos); salários dos funcionários, incluindo os professores, e consequentes impactos diretos sobre a demanda de bens e serviços; além disso, há os gastos dos estudantes na região. Já no longo prazo, os impactos estão relacionados com o lado da oferta, especificamente com relação aos efeitos sobre capital humano.

Neste trabalho, dada a recente expansão das universidades federais no Brasil, busca-se estimar os efeitos de curto prazo, uma vez que estes são os únicos possíveis de mensuração no período analisado.

A abordagem seguida neste capítulo compreende em tratar a questão da expansão como a implantação de uma política pública, mais especificamente, como um tratamento sobre as regiões afetadas num contexto de inferência causal com base em técnicas econométricas. Desta forma, pode-se estimar o efeito deste tratamento sobre os municípios que o receberam. 
Até onde se pôde pesquisar, não foi encontrado nenhum trabalho que abordasse a questão da expansão de universidades sob a ótica econométrica de tratamento sobre os tratados. A maioria dos trabalhos da literatura sobre impacto de universidades aborda a questão sob a ótica de Insumo-Produto. Para a abordagem econométrica deste capítulo, vale destacar alguns trabalhos que servem de base para o estudo proposto, podendo-se destacar Duflo (2001), que num cenário de expansão da rede de ensino fundamental na Indonésia, estima o efeito da construção de escolas sobre a escolaridade e renda. Adicionalmente, na literatura de efeito do tratamento sobre os tratados, mostram-se relevantes os artigos Galiani, Gertler e Schargrodsky (2005) e Duflo e Pande (2007). Este capítulo utiliza o método de Diferenças-em-Diferenças com Pareamento por Escore de Propensão (Matching por Propensity Score) com base em Meghir e Palme (2003) e Blundell et al (2004), que implementam tal método a partir do trabalho de Heckman, Ichimura e Todd (1997).

Este capítulo está estruturado da forma a seguir. Primeiramente, apresenta-se o modelo econômico. Na seção seguinte, detalha-se o modelo econométrico, bem como a estratégia de identificação para a estimação. Na quarta seção, é descrita a base de dados utilizada, sendo seguida pela seção onde os resultados do método de Diferenças-em-Diferenças com Pareamento por Escore de Propensão são apresentados. Por fim, mostram-se as conclusões do estudo feito neste capítulo.

\section{2- Modelo Econômico}

O arcabouço teórico, que envolve o efeito do gasto público em infraestrutura universitária sobre o desempenho da economia regional, está inserido na literatura de crescimento econômico endógeno em que os gastos públicos influenciam as taxas de crescimento de longo prazo. Neste contexto, estes gastos exercem um efeito de externalidade sobre o crescimento da economia (Heo, 2010).

Na determinação do crescimento econômico, tanto no curto quanto no longo prazo, a literatura sobre modelos neoclássicos de crescimento enfatiza a importância de fatores, como acumulação de capital físico, mudanças na quantidade de mão-de-obra disponível e progresso 
tecnológico exógeno. Nas últimas décadas, outras variáveis passaram a ser consideradas como relevantes no aumento da renda e do padrão de vida, podendo-se destacar: acumulação de capital humano, dinâmicas populacionais, instituições, e gastos governamentais. Com relação a esta última variável, vale mencionar os trabalhos pioneiros de Barro (1990) e Barro e Sala-iMartin (1992), que evidenciam que tais gastos públicos com bens e serviços podem afetar o crescimento econômico.

\subsection{1- Modelo de Crescimento Endógeno}

O modelo econômico usado tem como base num modelo de economia fechada, em que existem $L$ agentes representativos que vivem infinitamente e têm preferências representadas pela função de utilidade $u(c)$, onde $c$ é o consumo individual. O planejador central maximiza uma função de utilidade intertemporal da sociedade $(U)$, de forma que $L$ é suficientemente grande e cada indivíduo é atomístico dentro da sociedade.

$$
U=\int_{0}^{\infty} u(c) L e^{-\rho . t} d t
$$

Onde $\rho>0$ é a taxa constante de preferência temporal. A função de utilidade é dada por:

$u(c)=\frac{c^{1-\sigma}-1}{1-\sigma}, \sigma>0$

$u^{\prime}(c)>0, u^{\prime \prime}(c)<0$, de forma que a utilidade marginal tem elasticidade constante $-\sigma$.

\subsubsection{1- Função de Produção}

Com base em Ram (1986) e Cândido (2001), a economia representada neste modelo tem 2 setores (privado e público). Cada agente representativo se depara com uma função de produção $Y$ com 2 tipos de bens, um de natureza privada $P$ e outro pública $G$. Assim, o conjunto de bens da economia vem de:

$Y=P+G$, 
em que $P=p\left(A, K_{P}, L_{P}, G\right)$,

e $G=g\left(K_{G}, L_{G}\right)$

Onde $p($.$) e g($.$) são funções com as seguintes características:$

$p(0)=0, p^{\prime}()>0,. p^{\prime \prime}()<0$,

$g(0)=0, g^{\prime}()>0,. g^{\prime}()<$.

$K_{i}, L_{i}>O(i=P, G)$

$K_{i}$ é o estoque de capital utilizado pelo setor $i ; L_{i}$ é o nível de mão-de-obra empregado pelo setor $i$; $A$ é um indicador de progresso tecnológico; e $G$ é o produto do setor público e também insumo do setor privado, apresentando assim um efeito externalidade.

\subsubsection{2- Modelo Simplificado}

Dado o modelo descrito de crescimento endógeno com externalidade do setor público, para a análise de impacto da expansão da estrutura universitária brasileira sobre a economia regional são necessárias algumas simplificações. Assume-se que os gastos públicos são exógenos, ou seja, o produto da função $g($.) é pré-definido e não determinado pelo modelo.

Tomando-se a diferenciação total da função de produção, tem-se:

$d Y=d P+d G$

Com relação ao termo $d P$, tem-se:

$d P=\frac{\partial p\left(A, K_{P}, L_{P}, G\right)}{\partial A} d A+\frac{\partial p\left(A, K_{P}, L_{P}, G\right)}{\partial K_{P}} d K_{P}+\frac{\partial p\left(A, K_{P}, L_{P}, G\right)}{\partial L_{P}} d L_{P}+\frac{\partial p\left(A, K_{P}, L_{P}, G\right)}{\partial G} d G$

Sabendo-se que $d K_{P}=I_{P}$ (investimento privado) e substituindo (3.7) em (3.6), chegase a:

$d Y=\frac{\partial p\left(A, K_{P}, L_{P}, G\right)}{\partial A} d A+\frac{\partial p\left(A, K_{P}, L_{P}, G\right)}{\partial K_{P}} I_{P}+\frac{\partial p\left(A, K_{P}, L_{P}, G\right)}{\partial L_{P}} d L_{P}+\left(1+\frac{\partial p\left(A, K_{P}, L_{P}, G\right)}{\partial G}\right) d G$ 
Definindo a elasticidade do produto do setor privado com relação aos gastos públicos $\theta=\frac{\partial p\left(A, K_{P}, L_{P}, G\right)}{\partial G} \frac{G}{P}$, e a elasticidade (do setor privado) do produto com relação ao trabalho $\delta=\frac{\partial p\left(A, K_{P}, L_{P}, G\right)}{\partial L_{P}} \frac{L_{P}}{P}$. Dividindo (3.8) por $Y$ e aplicando estas definições de elasticidade, temse:

$$
\frac{d Y}{Y}=\frac{\partial p\left(A, K_{P}, L_{P}, G\right)}{\partial A} \frac{d A}{Y}+\frac{\partial p\left(A, K_{P}, L_{P}, G\right)}{\partial K_{P}} \frac{I_{P}}{Y}+\delta \frac{P}{Y} \frac{d L_{P}}{L_{P}}+\left(\frac{G}{P}+\theta\right) \frac{P}{Y} \frac{d G}{G}
$$

Visando simplificar a equação (3.9), pode-se definir:

$$
\frac{\partial p\left(A, K_{P}, L_{P}, G\right)}{\partial A} \frac{d A}{Y}=\alpha, \frac{\partial p\left(A, K_{P}, L_{P}, G\right)}{\partial K_{P}}=\beta, \delta \frac{P}{Y}=\gamma,\left(\frac{G}{P}+\theta\right) \frac{P}{Y}=\varphi
$$

Vale ressaltar que o modelo de crescimento econômico endógeno é inicialmente para o longo prazo. Para um cenário de curto prazo, como o aqui representado pela recente expansão da estrutura universitária brasileira, propõe-se uma simplificação, de forma que o indicador de progresso tecnológico se mantenha inalterado. Assim, $d A=\overline{d A}$, ou seja, $d A$ é constante e compõe o intercepto da seguinte equação:

$$
\frac{d Y}{Y}=\alpha+\beta \frac{I_{P}}{Y}+\gamma \frac{d L_{P}}{L_{P}}+\varphi \frac{d G}{G}
$$

Esta equação indica que a variação no produto total da economia é função da mudança tecnológica, da participação do investimento privado no produto, da variação de mão-de-obra ocupada e da variação dos gastos públicos.

Parte desta variação de gastos públicos é devida à construção de novos campi universitários. Reorganizando os termos e passando para a forma matricial, introduzem-se alguns termos: $G_{c}$ (gastos com construção de novos campi de universidades federais) e $X_{e}$ (conjunto de variáveis que engloba características econômicas - tecnologia, investimento privado, mão-de-obra ocupada - e demais gastos governamentais). Desta forma, a equação anterior muda para:

$$
\frac{d Y}{Y}=X_{e} \psi+g_{G c} \rho
$$

Onde $g_{G c}$ é a variação do gasto público com construção de novos campi de universidades federais, $\psi$ e $\rho$ são parâmetros do modelo. 


\section{3- Modelo Econométrico}

Com base na equação (3.11), constrói-se um modelo básico econométrico, em que as variáveis $d Y / Y, X_{e}$ e $g_{G c}$ são representadas por covariadas observadas de crescimento da renda per capita $\left(g_{y}\right)$, características socioeconômicas $(X)$ e implantação de campus de universidade federal no municípios i $(D)$, respectivamente, que servem de proxies para as variáveis teóricas. Desta forma, o modelo básico econométrico é:

$g_{y_{i}}=X_{i} \delta+D_{i} \eta+\varepsilon_{i}$

Onde $\delta$ é o coeficiente do efeito das características socioeconômicas sobre o crescimento da renda per capita, $\eta$ é o coeficiente que mostra o efeito da variável indicadora da construção de novo campus de universidade federal no município i, e $\varepsilon_{i}$ é o resíduo. Para este capítulo, o coeficiente $\eta$ se destaca por ser indicativo do impacto econômico de curto prazo do programa de expansão de universidades federais no que tange a implantação de novos campi.

Com este modelo introdutório, objetiva-se estimar o impacto econômico de curto prazo da expansão da estrutura universitária brasileira, buscando-se estudar o impacto da presença de um novo campus universitário sobre a atividade econômica local.

Neste item, apresenta-se primeiramente a metodologia econométrica de efeito médio do tratamento sobre os tratados, utilizada neste trabalho. Em seguida, mostra-se seu método de implementação.

\subsection{1- Efeito Médio do Tratamento nos Tratados}

No trabalho seminal de Rosenbaum e Rubin (1983), apresenta-se uma técnica para avaliar tais impactos, controlando pelas informações observáveis. É proposto então o método de Pareamento por Escore de Propensão, visando reduzir o viés na estimação dos efeitos do tratamento com base nos dados observados. Este método se tornou a base de diversos experimentos médicos e de avaliação de intervenções de política econômica. 
Este capítulo se fundamenta na interpretação da expansão como implantação de uma política pública, ou seja, como um tratamento sobre os municípios que recebem novos campi. Desta forma, baseia-se na metodologia econométrica de efeito do tratamento sobre os tratados, através do método de Pareamento por Escore de Propensão aplicado sobre a variação temporal da renda domiciliar per capita municipal.

Como já mencionado, é importante frisar que, até onde se pôde pesquisar, não foi encontrado nenhum estudo na literatura que trata o efeito de uma universidade sobre a atividade de uma região com base nesta metodologia. Tal fato faz com que este trabalho seja inédito não somente no Brasil, mas também no mundo. A maioria dos trabalhos na literatura sobre impacto de curto prazo de universidades aborda a questão sob a ótica de InsumoProduto.

Alguns trabalhos que servem de base para o estudo proposto merecem menção. $\mathrm{O}$ principal artigo, que guarda certa relação com a questão aqui estudada, é Duflo (2001), que num cenário de expansão da rede de ensino fundamental na Indonésia, estima o efeito da construção de escolas sobre a escolaridade e renda. Além deste, na literatura de efeito do tratamento sobre os tratados, mostram-se relevantes os artigos Galiani, Gertler e Schargrodsky (2005) e Duflo e Pande (2007). O primeiro estima o impacto da privatização da provisão de água em diversos municípios argentinos sobre a mortalidade infantil. Já o segundo, estuda o efeito sobre resultados econômicos, como produção agrícola e pobreza, devido à construção de represas na Índia.

Sobre a metodologia econométrica, especificamente, este trabalho utiliza o método de Diferenças-em-Diferenças com Pareamento por Escore de Propensão com base em Meghir e Palme (2003) e Blundell et al (2004). O primeiro avalia o efeito do impacto de uma reforma no sistema educacional sueco sobre a renda dos indivíduos com elevada habilidade e pais com baixa escolaridade. Já Blundell et al (2004) estima o efeito de um programa obrigatório para procura de emprego sobre a transição da situação de desempregado para a de empregado. Vale citar ainda, no Brasil, o trabalho de Peixoto, Andrade e Azevedo (2008) que também implementa esta metodologia, estimando o impacto de um programa de prevenção e controle de criminalidade sobre a taxa de homicídios.

Para se estimar o efeito do tratamento sobre os tratados, ou seja, o efeito da construção e manutenção de novos campi de universidades públicas federais sobre os resultados econômicos regionais; utiliza-se fundamentalmente o método de Diferenças-em-Diferenças, 
tendo como hipótese básica de identificação que o grupo tratado evoluiria, caso não fosse tratado, da mesma forma como é observado na evolução do grupo controle; isto é, na ausência da política pública de expansão do ensino superior público federal, os locais tratados evoluem no tempo semelhantemente aos locais não-tratados. Isto não significa que, na ausência do tratamento, ambos os grupos precisam ter o mesmo nível de resultados econômicos entre si, mas sim que apresentam a mesma evolução.

Desta forma, pode-se identificar o efeito do tratamento sobre os tratados. Com relação à validade externa, seria necessária alguma hipótese adicional que este efeito é comum a todos os grupos, o que significaria que o efeito do tratamento sobre os tratados é, na verdade, o efeito médio do tratamento.

Dada a hipótese de identificação, pode-se construir a amostra de tratados e controles de forma a simular um experimento aleatório, ou seja, buscando garantir a aleatoriedade do tratamento. Uma vez que o evento ocorreu no passado, sendo caracterizado como um experimento não-aleatório, busca-se aproximá-lo de um experimento aleatório, inicialmente através da compreensão do processo decisório de alocação do tratamento. Como a base de dados dos tratados é fixa, uma vez que abrange todos os locais que receberam novos estabelecimentos universitários, a principal questão passa a ser como escolher os municípios que serão considerados contrafactuais destes tratados. Portanto, é preciso restringir a população com todos os municípios que não receberam o tratamento em uma amostra com os que apresentam características observáveis semelhantes aos municípios tratados, ou seja, amostrar na população os municípios controles.

Esta metodologia com base nas características observáveis, segundo Heckman, Ichimura e Todd (1997), pode gerar duas fontes de viés no método de Diferenças-emDiferenças. Um primeiro viés é com relação à eventual falta de contrafactual ao local tratado, o que parece ser pouco provável uma vez que no território nacional há um grande número e variedade de municípios que, em sua maioria, não receberam investimentos provenientes da expansão do ensino superior público, frente aos poucos que receberam o tratamento. Assim, dificilmente haveria um município-tratado sem algum município-controle com características semelhantes. Uma segunda fonte de viés surge das diferenças nas distribuições das variáveis observáveis que afetam o resultado econômico dentro dos grupos tratado e controle. Tal viés apresenta uma maior probabilidade de ocorrência dada a amostra considerada. Por isso, é fundamental a escolha de um critério adequado para a construção do grupo controle. 
Estas duas fontes de viés podem ser minimizadas com a utilização do método de pareamento, em que se constrói pares de municípios tratados com municípios não-tratados que possuem atributos observados similares.

\subsubsection{1- Método de Diferenças-em-Diferenças com Pareamento por Escore de Propensão}

O método de Diferenças-em-Diferenças com Pareamento por Escore de Propensão combina o método de Pareamento por Escore de Propensão com o de Diferenças-emDiferenças. Com este método, o efeito do tratamento é estimado reduzindo o viés, pois o Pareamento por Escore de Propensão minimiza o viés proveniente da distribuição de atributos observáveis e de ausência de suporte comum, enquanto que o Diferenças-em-Diferenças reduz o viés de seleção (Peixoto, Andrade e Azevedo, 2008).

Inicialmente, o estimador causal de interesse é em geral o efeito médio do tratamento (Average Treatment Effect - ATE) sobre toda a população ou sobre uma determinada subpopulação. O parâmetro a ser estimado depende do contexto específico de avaliação. Considerando $\mathrm{Y}(1)$ e $\mathrm{Y}(0)$ como os resultados potenciais nas duas situações contrafactuais de tratamento e não-tratamento, respectivamente, o ATE = E[Y(1)-Y(0)] avalia qual é o efeito esperado no resultado se os indivíduos na população fossem escolhidos para o tratamento aleatoriamente. Entretanto, não há como observar $\mathrm{Y}(1)$ e $\mathrm{Y}(0)$ simultaneamente, o que caracteriza o problema fundamental da inferência causal. Além disso, vale destacar que o ATE pode não ser relevante para os tomadores de decisão porque inclui o efeito sobre pessoas para quem o programa nunca teve o objetivo de contemplar.

Neste sentido, define-se o efeito médio do tratamento sobre os tratados (Average Treatment Effect on the Treated - ATT) como ATT $=\mathrm{E}[\mathrm{Y}(1)-\mathrm{Y}(0) \mid \mathrm{D}=1]$, que avalia explicitamente os efeitos sobre aqueles para quem o programa foi elaborado, ou seja, os efetivamente tratados ${ }^{26}$. Neste trabalho, busca-se estimar o ATT.

$\mathrm{Na}$ busca por identificar o ATT, é importante observar que $\mathrm{E}[\mathrm{Y}(0) \mid \mathrm{D}=1]$, a média contrafactual dos tratados, não é observada. Assim, é preciso escolher um substituto apropriado para esta média, de forma a estimar o ATT. Devido ao viés de seleção, não é possível utilizar a média dos resultados dos indivíduos não-tratados, $\mathrm{E}[\mathrm{Y}(0) \mid \mathrm{D}=0]$, como substituto apropriado. Em experimentos onde a alocação do tratamento é aleatória, pode-se

\footnotetext{
${ }^{26}$ Considerando que o conjunto dos tratados está contido no conjunto do público-alvo do programa.
} 
considerar que os resultados dos indivíduos dos grupos de tratamento e de comparação não diferem na ausência do tratamento, justificando o uso de $\mathrm{E}[\mathrm{Y}(0) \mid \mathrm{D}=0]$, como substituto. Entretanto, em estudos em que a aleatoriedade do tratamento não é garantida, são necessárias algumas hipóteses para resolver o problema de seleção.

Enfim, os procedimentos de pareamento baseados no balanceamento do escore são conhecidos como Pareamento por Escore de Propensão, que ao introduzir a estimação inicial do escore acrescenta um fator não-paramétrico ao modelo. Desta forma, busca-se evitar erros potenciais de especificação do $\mathrm{E}[\mathrm{Y}(0) \mid \mathrm{X}]$.

\section{Hipóteses de Identificação}

Para que um estimador de pareamento do efeito do tratamento seja identificado e estimado consistentemente, é preciso assumir:

(a) Ignorabilidade (Unconfoundedness) - a alocação ao tratamento é independente dos resultados potenciais, quando condicional nas covariadas.

$(Y(0) ; Y(1)) \perp D \mid X$;

(b) Suporte Comum - a probabilidade de alocação do tratamento está entre 0 e 1 , exclusive.

$0<\operatorname{Pr}(D=1 \mid X)<1$.

Rosenbaum e Rubin (1983) define Ignorabilidade Forte ao contemplar ambas as hipóteses supracitadas.

Sob Ignorabilidade, a ideia básica é encontrar, num grupo numeroso de unidades nãotratadas, unidades similares às tratadas sob todas as características relevantes $\mathrm{X}$ prétratamento observadas. Uma vez que condicionar nas covariadas é limitado devido ao fato de $\mathrm{X}$ ser uma matriz de alta dimensão, propõe-se o uso do escore de propensão, ou seja, probabilidade do tratamento, dadas as características observadas X. Rosenbaum e Rubin (1983) apresenta o uso do escore de propensão para reduzir a dimensionalidade no problema de alta dimensão de $\mathrm{X}$ no pareamento, permitindo condicionar em uma variável unidimensional $\mathrm{p}(\mathrm{X})=\operatorname{Pr}(\mathrm{D}=1 \mid \mathrm{X})$ ao invés de uma multidimensional $\mathrm{X}$. Abadie e Imbens (2006) desenvolveram teoria assintótica sobre o assunto. 
Especificamente, Rosenbaum e Rubin (1983) sugere o uso de uma função b(X), chamada balancing score, de tal forma que a distribuição condicional de $\mathrm{X}$ dado $\mathrm{b}(\mathrm{X})$ é independente da alocação do tratamento: $\mathrm{X}_{\mathrm{i}} \perp \mathrm{D}_{\mathrm{i}} \mathrm{lb}\left(\mathrm{X}_{\mathrm{i}}\right)$. Vale ressaltar que esta função $\mathrm{b}(\mathrm{X})$ não é única. Uma função possível de $b(X)$ é o escore de propensão $p(X)=\operatorname{Pr}(D=1 \mid X=x)=$ $\mathrm{E}(\mathrm{D} \mid \mathrm{X}=\mathrm{x})$.

Se Ignorabilidade é válida, todo viés devido às covariadas observadas pode ser removido simplesmente ao condicionar no escore de propensão: $(Y(0) ; Y(1)) \perp D$ I p (X).

O principal ponto na estimação por pareamento com escore de propensão é que, se a hipótese $\mathrm{D} \perp \mathrm{X} \mid \mathrm{p}(\mathrm{X})$ é válida, então observações com o mesmo escore de propensão devem ter a mesma distribuição de características observáveis independentemente do status do tratamento. Assim, para um dado escore de propensão, a exposição ao tratamento é aleatória e, portanto, as unidades tratadas e controles deveriam ser observacionalmente idênticas em média.

\section{Modelo de Escolha do Tratamento}

A literatura sobre expansão do ensino superior pouco aborda sobre a escolha dos municípios brasileiros que receberam campi universitários federais, destacando que a escolha envolve critérios técnicos e estratégicos. Quando há expansão com novas filiais, esta escolha tem como principal agente decisório a respectiva universidade federal. Já nos casos de criação de uma nova universidade pública, envolve decisão do Ministério da Educação. Todavia, esta mesma literatura explicita diversos fatores de ordem política na expansão da estrutura universitária brasileira. Assim, poder-se-ia supor a possibilidade de influências políticas sobre esta escolha.

Neste contexto, suponhamos um planejador central escolhendo entre dois municípios (denominados por A e B), qual receberá os investimentos para construção de um novo estabelecimento universitário. Definem-se as utilidades resultantes da escolha, como $U_{A}$ para o município A e $U_{B}$ para o município B. Estas utilidades são funções de critérios técnicos e estratégicos, segundo características socioeconômicas $(X)$ e políticas $(P)$.

Assim, num modelo de utilidade linear, a utilidade com o município j é:

$U_{j}(X, P)=X \beta_{j 1}+P \beta_{j 2}+u_{j}$ 
Onde $\mathrm{j}=\mathrm{A}, \mathrm{B} ; \beta_{j 1}$ e $\beta_{j 2}$ são coeficientes referentes à $X$ e $P$, respectivamente, para o município $\mathrm{j}$; e $\mathrm{u}_{\mathrm{j}}$ é o termo aleatório para o município j.

Para tanto, assume-se preferências contínuas e racionais, e função utilidade estritamente crescente e estritamente côncava.

A escolha observada de um município apenas revela que este provém maior utilidade do que o outro, mas não revela as utilidades específicas para cada um dos municípios. Considerando um indicador observado D igual a 1 (um) se $U_{A} \geq U_{B}$, e igual a 0 (zero) se $U_{A}<$ $U_{B}$; a escolha do município A para receber o tratamento em detrimento do município B envolve:

$\operatorname{Prob}[D=1 \mid X, P]=\operatorname{Prob}\left[U_{A} \geq U_{B}\right]$

$$
\begin{aligned}
& =\operatorname{Prob}\left[X \beta_{A 1}+P \beta_{A 2}+u_{A}-X \beta_{B 1}-P \beta_{B 2}-u_{B} \geq 0 \mid X, P\right] \\
& =\operatorname{Prob}\left[X\left(\beta_{A 1}-\beta_{B 1}\right)+P\left(\beta_{A 2}-\beta_{B 2}\right)+u_{A}-u_{B} \geq 0 \mid X, P\right] \\
& =\operatorname{Prob}\left[X \beta_{1}+P \beta_{2}+u \geq 0 \mid X, P\right]
\end{aligned}
$$

Assim, a probabilidade de um município ser escolhido para o programa de expansão do ensino superior público federal depende de variáveis socioeconômicas e políticas.

\section{Modelo de Diferenças em Diferenças}

Uma vez estimado o escore de propensão e feito o pareamento, estima-se o modelo econométrico de estimador em diferenças. Este compreende uma estratégia empírica de identificação do efeito médio do tratamento entre os tratados (ATT) num arcabouço nãoexperimental.

O método de Diferenças-em-Diferenças utiliza a estrutura de painel dos dados para estimar o efeito do tratamento sobre os tratados. Assim, com base na equação abaixo, estimase o ATT, controlando-se pelas características individuais não observadas e constantes no tempo $\left(c_{i}\right)$.

$y_{i t}=\left(D_{i t}\right) \cdot \delta+c_{i}+\varepsilon_{i t}$ 
Onde $\mathrm{y}_{i t}$ é o crescimento percentual da renda domiciliar per capita do município i no período entre $\mathrm{t}$ e $\mathrm{t}+1 ; D_{i t}$ é a variável indicadora da construção de novo campus de universidade federal no local i; $\varepsilon_{i t}$ é o resíduo.

Com relação à hipótese de identificação, além das hipóteses de Ignorabilidade e Suporte Comum, acrescenta-se a hipótese básica de que o grupo tratado, caso não recebesse o tratamento, evoluiria da mesma forma que a evolução observada no grupo controle.

\section{Variância do Estimador}

Com relação à variância do estimador de pareamento, Abadie e Imbens (2008) mostra que apesar de bastante comum na literatura de avaliação de programas ou tratamentos, o desvio-padrão estimado pelo método de Bootstrap é viesado, para o caso de pareamento com o escore de propensão mais próximo, devido ao fato deste pareamento ser extremamente nãosuavizado (extreme non-smoothness), ou seja, os estimadores por pareamento com o mais próximo são estrutura funcionais de dados bastante não-suavizadas. É destacado que este é o primeiro exemplo de estimador $\sqrt{N}$ - consistente e assintoticamente normal que apresenta viés através de Bootstrap.

Um estimador consistente para a variância assintótica do efeito do tratamento sobre os tratados é proposto por Abadie e Imbens (2006) e apresentado a seguir:

$$
\hat{V}^{t}=\frac{1}{N_{1}} \sum_{D_{i}=1}\left(Y_{i}-\hat{Y}_{i}(0)-\hat{\tau}_{M}^{t}\right)^{2}+\frac{1}{N_{1}} \sum_{i=1}^{N}\left(1-D_{i}\right) \cdot\left\{\frac{K_{M}(i)\left[K_{M}(i)-1\right]}{M^{2}}\right\} . \hat{\sigma}^{2}\left(X_{i}, D_{i}\right)
$$

Onde $N_{l}$ é o número de municípios tratados; $Y_{i}$ é a renda domiciliar per capita do município i; $\hat{\tau}_{M}^{\dagger}$ é o efeito médio estimado do tratamento sobre os tratados; $K_{M}(i)$ é o número de vezes que o município i é usado como par no pareamento, num universo de M pares por município.

Para o cálculo do estimador $\hat{\sigma}^{2}\left(X_{i}, D_{i}\right)$, Abadie e Imbens (2006) propõe um método de pareamento de tratados com tratados e controles com controles, ao invés do pareamento original de tratados com controles. Este estimador segue a fórmula:

$$
\hat{\sigma}^{2}\left(X_{i}, D_{i}\right)=\frac{1}{2}\left(Y_{i}-Y_{l(i)}\right)^{2}
$$


Onde $l(i)$ é a unidade mais próxima à unidade i entre os municípios com o mesmo valor de tratamento $(D=1$ ou $D=0)$.

Com este estimador $\hat{V}^{t}$ da variância, não há problemas de consistência para o método de pareamento.

Neste trabalho, utiliza-se este estimador para os casos de pareamento um-a-um simples (pareamento sem suavização da renda). Nas estimações com base em Heckman et al (1998); Blundell et al (2004); e Meghir e Palme (2003), devido há implementação do pareamento com suavização, que considera uma ponderação polinomial entre os escores de propensão, utilizase o método de bootstrap com clusterização por municípios, conforme Meghir e Palme (2003).

\subsubsection{2- Análise de Sensibilidade com base nos Limites de Rosenbaum}

Como já mencionado, segundo Peixoto, Andrade e Azevedo (2008), o método de Diferenças-em-Diferenças com Pareamento por Escore de Propensão possibilita a redução do viés na estimação do efeito do tratamento visto que o Pareamento por Escore de Propensão minimiza o viés proveniente da distribuição de atributos observáveis e de ausência de suporte comum, enquanto que o Diferenças-em-Diferenças reduz o viés de seleção. Entretanto, ainda assim, é possível que variáveis não-observadas variantes no tempo provoquem eventualmente um viés de seleção ao influenciarem significativamente tanto o escore de propensão quanto o efeito do tratamento.

Especificamente, a estimação do efeito médio do tratamento pela metodologia de pareamento é fundamentada na hipótese de Ignorabilidade, que defende que a seleção ao tratamento, é baseada apenas em características observáveis, que uma vez controladas garante-se a independência do tratamento aos resultados potenciais. No entanto, se houver variáveis não-observadas que afetam simultaneamente a escolha do tratamento e a variávelresultado, pode surgir um problema de viés de seleção por não-observáveis, comprometendo a robustez dos estimadores de pareamento. Logo, a endogeneidade na escolha do tratamento pode levar a inconsistência do estimador de efeito do tratamento na metodologia de pareamento por escore de propensão. 
Visando estimar em que extensão esta seleção por não-observáveis pode comprometer os resultados dos efeitos médios do tratamento sobre os tratados, utiliza-se o procedimento proposto por Rosenbaum (2002). O propósito desta análise de sensibilidade é verificar em que proporção os efeitos estimados podem sofrer alterações devido às variáveis não observadas, visto que não é possível estimar diretamente a magnitude de tal viés de seleção usando informações observadas.

Para tanto, o método de Limites de Rosenbaum (Rosenbaum Bounds) assume que existe uma variável não-observada $\left(\mathrm{u}_{\mathrm{i}}\right)$, que afeta a probabilidade do tratamento, conforme a equação abaixo:

$P_{i}=P\left(X_{i}, u_{i}\right)=P\left(d_{i}=1 \mid X_{i}, u_{i}\right)=F\left(\beta X_{i}+\gamma u_{i}\right)$

Onde $\gamma$ é o efeito de $u$ sobre a probabilidade de tratamento. Pode-se assumir de $\mathrm{F}($.$) segue$ uma distribuição logística, de forma que a razão de probabilidades (odds ratio) em receber o tratamento entre duas observações pareadas (m e n são as observações tratada e controle, respectivamente) é dada por:

$\left(\frac{P\left(X_{\mathrm{m}}, u_{\mathrm{m}}\right)}{P\left(X_{\mathrm{n}}, u_{\mathrm{n}}\right)} \cdot \frac{1-P\left(X_{\mathrm{n}}, u_{\mathrm{n}}\right)}{1-P\left(X_{\mathrm{m}}, u_{\mathrm{m}}\right)}\right)=\frac{e^{\beta X_{m}+u_{m}}}{e^{\beta X_{n}+u_{n}}}=e^{\left[\gamma\left(u_{m}-u_{n}\right)\right]}$

Se a variável não-observada não tem nenhuma influência sobre a probabilidade de tratamento $(\gamma=0)$, ou se esta variável é a mesma para os tratados e controles $\left(\mathrm{u}_{\mathrm{m}}=\mathrm{u}_{\mathrm{n}}\right)$, então a razão de probabilidades é igual a um, o que indica a ausência de viés omitido relacionado com variáveis não-observáveis. A análise de sensibilidade avalia o quanto o efeito do tratamento é modificado, alterando os valores de $\gamma$ e $u_{m}-u_{n}$. Considerando $\Gamma=\mathrm{e}^{\gamma}$, Rosenbaum (2002) identifica os seguintes limites para a razão de probabilidades:

$\frac{1}{\Gamma} \leq \frac{P_{m} /\left(1-P_{m}\right)}{P_{n} /\left(1-P_{n}\right)} \leq \Gamma$

$\Gamma=1(\gamma=0)$ significa que não existe viés de seleção não-observado (omitido), e aumentos nos valores de $\Gamma$ implicam numa influência cada vez maior de características nãoobservadas na escolha do tratamento. Assim, variações no valor de $\Gamma$ permitem avaliar a sensibilidade dos resultados em relação ao viés omitido e derivar os limites em relação aos níveis de significância e intervalos de confiança. A interpretação intuitiva das estatísticas para diferentes níveis de $\Gamma$ é que os pareamentos podem diferir nas suas probabilidades de serem 
tratados por um fator $\Gamma$, devido ao viés omitido. Basicamente, independente da distribuição de $\mathrm{F}($.), estes limites mostram a mudança na razão de probabilidades devido a variável omitida. Por exemplo, se $\Gamma=2$, então as duas observações pareadas, que parecem ser semelhantes no vetor $\mathrm{X}$, podem diferir em suas probabilidades de tratamento por um fator de dois, ou seja, uma das observações pareadas pode ser duas vezes mais propensas a ser tratada do que a outra. Portanto, $\Gamma$ pode ser interpretado como uma medida do grau de afastamento da situação sem viés omitido. Se os valores de $\Gamma$ forem próximos de um, então o efeito médio estimado do tratamento sobre os tratados é sensível a viés de seleção não-observável, enquanto que mostra-se insensível se sofrer alterações apenas com valores elevados de $\Gamma(\Gamma>1)$. Isto significa que quanto maior $\Gamma$, maior é a chance das estimações serem alteradas devido à magnitude do viés omitido.

\subsection{2- Estratégia de Identificação e Implementação do Método de Estimação}

Com relação ao método de estimação do efeito do tratamento sobre os tratados neste estudo sobre o impacto de curto prazo da expansão das universidades federais ocorrida na última década, é necessário considerar três pontos importantes para a identificação do efeito. Primeiramente, a estimação de tal impacto envolve uma análise da localização dos municípios brasileiros, ou seja, sua distribuição no território e as relações entre eles. Assim, a implantação de um campus universitário em um determinado município pode apresentar um efeito spillover sobre os demais municípios vizinhos.

Concomitantemente, do ponto de vista econométrico, a estimação direta pelo método de Diferenças-em-Diferenças apresenta o problema de tratados e não-tratados poderem possuir evoluções diferentes da variável explicada no período pré-tratamento, o que provoca viés da estimação do efeito do tratamento.

Além disso, o fato de aproximadamente apenas 5\% dos municípios receberem campus universitário no período analisado incorre em problemas de estimação do modelo de escolha do tratamento, o que compromete a utilização do método de estimação por pareamento com escore de propensão. 
Buscando contemplar estes três pontos; assim como Blundell et al (2004), este trabalho apresenta uma metodologia de avaliação do impacto, em que se destaca a escolha do grupo de comparação.

\subsubsection{1- Escolha do Grupo de Comparação}

A escolha do grupo de comparação dentro do universo dos municípios não-tratados visa encontrar os municípios mais apropriados para serem controles dos municípios tratados, de forma a resolver as questões associadas aos três pontos anteriormente mencionados.

Considerando a questão do efeito spillover sobre os municípios vizinhos, tem-se por hipótese que os municípios localizados na vizinhança dos municípios tratados recebem parte do efeito do tratamento. Assim, estes municípios não-tratados não são apropriados para serem classificados como controles, uma vez que receberam a influência do tratamento.

Para contemplar esta questão, utiliza-se a informação de vizinhança a partir das características topológicas de contiguidade, em que um município j é considerado vizinho do município $\mathrm{i}$, se estes tiverem fronteiras em comum. O efeito do tratamento pode abranger áreas maiores do que um município, como por exemplo, um município z vizinho do município j, mas sem fronteira com o município i. Desta forma, é utilizado o nível microrregional para contemplar a questão da vizinhança, ou seja, tem-se por hipótese de que o tratamento de um município i, pertencente à microrregião I, tem efeito não apenas sobre os municípios desta microrregião, mas também sobre os municípios das microrregiões vizinhas à microrregião I.

Com base nesta hipótese, para a escolha do grupo de controle, excluem-se todos os municípios que pertencem à microrregião I do município tratado i ou às demais microrregiões vizinhas de I. Poder-se-ia excluir apenas os municípios pertencentes à microrregião I, porém caso o município tratado i esteja localizado próximo à fronteira da microrregião I, haveria o risco de um município próximo ao i, de microrregião $\mathrm{J} \neq \mathrm{I}$, ser considerado como controle.

Levando-se em consideração a questão abordada no segundo ponto, fundamenta-se o método de diferenças-em-diferenças na hipótese de identificação que a evolução dos tratados, caso não fossem tratados, seria igual à evolução observada dos controles. Apesar de tal hipótese não ser testável diretamente, é possível observar se os dois grupos, tratados e 
controles, apresentam a mesma evolução da variável explicada num período anterior ao tratamento.

$\mathrm{E}\left[\Delta \mathrm{Y}_{\mathrm{t}-1} \mid \mathrm{D}=1, \mathrm{t}=0\right]=\mathrm{E}\left[\Delta \mathrm{Y}_{\mathrm{t}-1} \mid \mathrm{D}=0, \mathrm{t}=0\right]$

Onde $\Delta \mathrm{Y}_{\mathrm{t}-1}$ é a variação da variável explicada observada entre t-1 e t.

Com base neste conceito, pode-se construir o grupo de comparação garantindo a validade da hipótese de identificação. Assim, para os controles potenciais, escolhem-se os municípios não-tratados que possuem a mesma evolução no período pré-tratamento da variável explicada dos municípios tratados.

Portanto, a escolha do grupo de comparação envolve basicamente dois filtros: Municípios de microrregiões não-vizinhas à microrregião do município tratado, e municípios com a mesma evolução da variável explicada dos municípios tratados no período prétratamento.

Estes dois filtros reduzem significativamente o número de não-tratados na amostra, o que contribui para minimizar o problema apontado pelo terceiro ponto. Com isso, constrói-se um grupo de comparação com municípios potenciais de serem controles, viabilizando a estimação do escore de propensão, através do modelo de escolha do tratamento. Após o pareamento pelo escore de propensão, obtém-se o grupo de controle que será comparado com o grupo tratado através do método de Diferenças-em-Diferenças.

\subsubsection{2- Implementação do Método de Estimação}

Para a estimação do efeito do tratamento sobre os tratados, utiliza-se a combinação dos métodos de Diferenças-em-Diferenças e de Pareamento com Escore de Propensão. Especificamente, adapta-se o método de Pareamento com Escore de Propensão para o caso de Diferenças-em-Diferenças, de acordo com Heckman, Ichimura e Todd (1997), Meghir e Palme (2003) e Blundell et al (2004).

Com a redução da dimensionalidade do modelo, através do escore de propensão $\mathrm{p}(\mathrm{x})$, garante-se o balanceamento da distribuição das características $\mathrm{X}$ entre os grupos tratado e controle. A estimação deste escore de propensão, com base no modelo de escolha do tratamento, permite efetuar o pareamento. 


\section{Pareamento com Suavização}

O método de pareamento utilizado inicialmente suaviza os resultados dos municípios controles, conforme Blundell et al (2004), usando um polinômio de interpolação spline. Racine (2012) explica que o termo spline vem da ferramenta usada pelos construtores e projetistas navais para a construção de formas suaves com as propriedades desejadas na engenharia naval. Na prática, utilizava-se uma tira flexível fixada em certo número de pontos, formando uma curva suave com minimização da tensão naqueles pontos. Com isso, a maleabilidade do material de filamento combinada com a restrição dos pontos de controle levaria a tira a tomar a forma que minimizasse a energia necessária para dobrá-la nos pontos fixos, sendo esta a forma mais suave possível.

O estimador de pareamento com suavização por spline cúbico ${ }^{27}$ pertence ao grupo de estimadores com suavização aos quais também pertencem os estimadores com pareamento via Kernel. Heckman et al (1998) argumenta que os estimadores de pareamento por Kernel podem apresentar problemas de viés nos limites do suporte do escore de propensão, com o grau da suavização sendo maior no interior da distribuição. Já o estimador utilizado neste trabalho, por suavizar a variável-resultado por $\mathrm{p}(\mathrm{x})$ através de uma função polinomial spline cúbica, não apresenta este problema de viés ao longo da distribuição de $\mathrm{p}(\mathrm{x})$, sendo robusto para diferentes distribuições do escore de propensão.

Tal pareamento com suavização se apresenta num contexto em que a variávelresultado (renda) do tratado, para o caso em que ele não tenha recebido o tratamento, ser desconhecida. Heckman et al (1998) e Meghir e Palme (2003) argumentam que é necessário utilizar uma estimação desta variável, com base no escore de propensão do pareamento. Desta forma, utiliza-se o estimador $\mathrm{E}\left[\ln \left(\mathrm{renda}_{\mathrm{i}}\right) \mid \mathrm{p}\left(\mathrm{X}_{\mathrm{i}}\right), \mathrm{D}_{\mathrm{i}}=0\right]$ para este contrafactual.

Nesta linha, Meghir e Palme (2003) e Blundell et al (2004) implementam o estimador de pareamento com suavização, estimando primeiramente o escore de propensão através de um modelo de escolha do tratamento. Em seguida, estimam $E\left[\ln \left(\right.\right.$ renda $\left.\left._{i}\right) \mid p\left(X_{i}\right), D_{i}=0\right]$ na amostra de indivíduos não-tratados, usando suavização por função spline cúbica. Cada indivíduo tratado na amostra é pareado com um indivíduo não-tratado com base no valor mais próximo do escore de propensão estimado, impondo-se Suporte Comum no pareamento. Assim, através do método de Diferenças-em-Diferenças, tem-se a diferença entre o resultado

\footnotetext{
${ }^{27}$ No Apêndice B, é apresentada uma descrição mais detalhada da função Spline Cúbica.
} 
observado do indivíduo tratado e o resultado suavizado do indivíduo controle $\mathrm{E}\left[\ln \left(\mathrm{renda}_{\mathrm{i}}\right)\right.$ । $\left.\mathrm{p}\left(\mathrm{X}_{\mathrm{i}}\right), \mathrm{D}_{\mathrm{i}}=0\right]$.

Peixoto, Andrade e Azevedo (2008) estima o efeito do tratamento sobre os tratados, ignorando esta questão. Enquanto que Heckman et al (1998) e Blundell et al (2004) implementam o pareamento com suavização apenas da variável-resultado (renda) do tratado, para o caso em que ele não tenha recebido o tratamento, Meghir e Palme (2003) diz que a suavização também deve ser efetuada na variável-resultado observada dos tratados (caso em que o tratado recebe o tratamento), uma vez que isto permite uma melhor comparação entre tratados e controles e aumenta a precisão do estimador. Todavia, este argumento de defesa da suavização em ambos os grupos não é provado teoricamente no artigo e os resultados não são comparados com o método de suavização apenas dos contrafactuais.

\section{Heterogeneidade do Efeito}

Xie, Brand e Jann (2012) e Zhou e Xie (2011) argumentam que o pareamento com suavização tanto para tratados como para controles, possibilita analisar não somente o efeito do tratamento, mas também sua heterogeneidade, uma vez que os indivíduos numa amostra diferem em características observadas e na responda a um determinado tratamento.

Esta análise da heterogeneidade do efeito do tratamento tem importantes implicações sobre o estudo de políticas públicas, segundo Xie, Brand e Jann (2012). Por um lado, se um determinado tratamento é custoso e de difícil implantação, então poder-se-ia buscar disponibilizá-lo apenas para aqueles indivíduos que são mais susceptíveis a se beneficiarem por ele, uma vez que a implantação em todo o conjunto de indivíduos pode reduzir a eficácia média do tratamento. Por outro lado, se os indivíduos com acesso ao tratamento não são os indivíduos que podem se beneficiar mais pelo tratamento, então aumentar a disponibilidade do tratamento pode aumentar o efeito médio entre os receptores do tratamento. Assim, se os administradores públicos conseguirem compreender os padrões de heterogeneidade do efeitotratamento, então poderão mais eficazmente atribuir diferentes tratamentos para os indivíduos, de modo a equilibrarem os objetivos concorrentes, como a redução de custos de implantação, a maximização dos resultados médios, e a diminuição da variância nos resultados de uma dada população (Manski, 2007). O estudo da heterogeneidade do efeito-tratamento também 
pode contribuir para uma melhor compreensão sobre a forma como os recursos escassos são distribuídos em uma sociedade desigual.

Neste trabalho, uma vez que não existe disponível a informação sobre o ano de implantação de cada campus universitário, a heterogeneidade devida à intensidade do tratamento não será abordada. Contudo, pode-se analisar a heterogeneidade devido à resposta ao tratamento dadas as características que levam ao tratamento, conforme descrita por Xie, Brand e Jann (2012).

\section{Implementação}

A implementação do método de estimação de Diferenças-em-Diferenças combinado com Pareamento por Escore de Propensão se inicia pela escolha do grupo de comparação. Como já explicado, esta escolha envolve basicamente dois filtros: municípios de microrregiões não-vizinhas à microrregião do município tratado, e municípios com a mesma evolução da variável explicada dos municípios tratados no período pré-tratamento.

Com relação ao segundo filtro, é importante detalhar o procedimento de escolha do grupo controle, uma vez que anteriormente este assunto foi tratado de forma genérica, sem aplicação ao caso aqui estudado. Primeiramente, vale ressaltar que a variável explicada no modelo é a renda domiciliar per capita municipal.

Antes do procedimento de escolha do grupo de comparação, aproximadamente $95 \%$ dos municípios da amostra são não-tratados. Desta forma, é altamente provável que vários municípios com diferentes evoluções da atividade econômica no tempo tenham escores de propensão muito próximos entre si, ainda que isto venha a ser controlado na estimação do modelo de escolha. Assim, pareamentos baseados no escore de propensão mais próximo ou numa ponderação de escores de municípios resultarão em resultados viesados.

Objetivando-se resolver este problema, além do foco nos municípios de microrregiões não-vizinhas à microrregião do município tratado, busca-se impor uma estrutura de forma a garantir a validade da abordagem de Diferenças-em-Diferenças. Com isso, propõe-se um pareamento considerando a evolução pré-tratamento da renda per capita.

A hipótese básica de identificação do método apresentado é que o grupo tratado evoluiria, caso não fosse tratado, da mesma forma como é observado na evolução do grupo 
controle; isto é, na ausência da política pública de expansão do ensino superior público federal, os locais tratados evoluiriam no tempo semelhantemente aos locais não-tratados. Isto não significa que, na ausência do tratamento, ambos os grupos precisam ter o mesmo nível de resultados econômicos entre si, mas sim que apresentam a mesma evolução.

Como já mencionado, esta hipótese não é diretamente testável, entretanto podem-se utilizar períodos anteriores ao tratamento e fazer um exercício de como os grupos tratados e controles evoluíram anteriormente a este tratamento. Supõe-se que se a evolução dos grupos é similar até o momento do tratamento, então, após este, espera-se que qualquer diferença seja devida ao fato de um grupo ter sido tratado e outro não. Desta forma, pode-se identificar o efeito do tratamento sobre os tratados.

Considerando esta hipótese básica, constrói-se o grupo de comparação, partindo de uma restrição sobre o grupo não-tratado, de forma a conter apenas os municípios com evolução da renda per capita, anterior ao período de tratamento, semelhante à evolução dos tratados. Busca-se então parear os municípios de acordo com a variação anual percentual da renda per capita $\left(\Delta_{\% \mathrm{Y}}\right)$ em período anterior ao tratamento. Para tanto, utiliza-se a renda per capita de 1991, e a variação desta para a de 2000 como período pré-tratamento.

Inicialmente, calculam-se as variações anuais percentuais da renda per capita de todos os municípios brasileiros entre 1991 e 2000. Ao se identificar os municípios tratados, calculase uma banda de tolerância para a variação da renda per capita a partir de um certo percentual (R) de oscilação aceitável desta variação. Desta forma, para cada município tratado, tem-se a banda $\mathrm{B}_{\mathrm{Y}}=\left[\Delta_{\%} \mathrm{Y}^{\mathrm{T}} \cdot(1-\mathrm{R}), \Delta_{\%} \mathrm{Y}^{\mathrm{T}} \cdot(1+\mathrm{R})\right]$. Os municípios não tratados, que apresentam $\Delta_{\% \mathrm{Y}}{ }^{\mathrm{NT}} \in$ $\mathrm{B}_{\mathrm{Y}}$, são considerados potenciais controles de um dado município tratado. Os índices T e NT indicam se o município é tratado ou não tratado, respectivamente. Além disso, para ser candidato a controle, um município j não-tratado deve pertencer a alguma microrregião nãovizinha à microrregião do município tratado $i$.

Após a escolha do grupo de potenciais controles, pode-se estimar o modelo de escolha do tratamento, onde a variável explicada é uma variável indicadora da implantação de campus universitário no município no período analisado. Para tanto, propõe-se um modelo de escolha para a expansão do ensino superior federal brasileiro ocorrida nos últimos anos, seguindo a equação:

$D_{i}{ }^{*}=\alpha+\left(X_{i}\right) \cdot \beta_{1}+\left(P_{i}\right) \cdot \beta_{2}+u_{i}$ 
Onde $D_{i}{ }^{*}$ é a variável não observável latente, representada nos modelos probit pela variável observada $D_{i}$ que é uma variável indicadora da construção de novo campus de universidade federal no local i; $X_{i}$ é um vetor de variáveis socioeconômicas características do local i, tanto no âmbito municipal, quanto no âmbito microrregional onde o local i está inserido; $P_{i}$ é um vetor de variáveis indicadoras da coligação do partido político do prefeito do local i com o presidente da república; e $u_{\mathrm{i}}$ é o resíduo da regressão que segue distribuição normal padrão.

Nesta equação, a unidade de observação i é municipal. Por simplificação, neste trabalho será utilizado o termo município para se referir às agregações municipais com base na Área Mínima Comparável (AMC).

A variável $P_{i}$ visa captar a influência política na escolha do local do campus universitário. O fato de o prefeito pertencer a partido político da coligação do partido político do governo federal pode ter influência na decisão de implantação de novos campi na região. Como o orçamento federal para um determinado ano é aprovado pelo legislativo no ano anterior, esta variável apresenta a situação política de um período anterior ao credenciamento da universidade instalada no local i.

Com esta estimação do modelo probit, utiliza-se o valor previsto da variável explicada $\mathrm{p}(\mathrm{x})$ como o valor do escore de propensão que, por sua vez, é usado para fazer o pareamento entre tratados e controles.

Da mesma forma como descrito para a variação da renda domiciliar per capita, constrói-se também uma banda para escore de propensão $\left(\mathrm{B}_{\mathrm{PS}}\right)$ com base em um nível de tolerância $(\mathrm{P})$, para os tratados, ou seja, $\mathrm{B}_{\mathrm{PS}}=\left[\mathrm{PS}^{\mathrm{T}}-\mathrm{P}, \mathrm{PS}^{\mathrm{T}}+\mathrm{P}\right]$. Assim, adicionalmente, os municípios do grupo de comparação devem apresentar $\mathrm{PS}^{\mathrm{NT}} \in \mathrm{B}_{\mathrm{PS}}$. Portanto, um município j não-tratado está no grupo $\left(\mathrm{G}_{\mathrm{i}}\right)$ de potenciais controles de um dado município tratado $\mathrm{i}$, se $\Delta \% \mathrm{Yj}^{\mathrm{NT}} \in \mathrm{B}_{\mathrm{Yi}}$ e $\mathrm{PS}_{\mathrm{j}}^{\mathrm{NT}} \in \mathrm{B}_{\mathrm{PSi}}$.

É importante ressaltar que a hipótese de Suporte Comum é assumida no pareamento. Portanto, são considerados apenas os municípios tratados pareados com algum município controle. Este pareamento permite repetição do município controle para diferentes tratados. Com estes procedimentos, busca-se garantir as hipóteses de Ignorabilidade e Suporte Comum, no pareamento, e indiretamente a hipótese básica de mesma evolução dos grupos na ausência do tratamento. 
Com a amostra final de tratados e controles construída, utiliza-se o método de pareamento com suavização por spline, através da uma regressão do logaritmo da renda domiciliar per capita numa função spline cúbica do escore de propensão. Neste ponto, Heckman, Ichimura, Smith e Todd (1998) e Blundell et al (2004) aplicam a suavização pelo pareamento apenas para o grupo controle. Já Meghir e Palme (2003), além do controle, também suaviza a renda observada dos tratados pareados. A variável prevista pela regressão para cada município é usada para a estimação do efeito do tratamento sobre os tratados pelo método de Diferenças-em-Diferenças, quer seja com pareamento com suavização dos controles, quer seja com pareamento com suavização de tratados e controles, considerando dados em painel dos anos de 2000 e 2010.

\section{4- Base de Dados}

Este trabalho envolve uma grande gama de bases de dados, uma vez que as informações necessárias para desenvolver este estudo não estão disponíveis em uma única base de dados.

Um alicerce fundamental deste estudo é a pesquisa sobre o histórico das 59 universidades federais, buscando identificar as expansões e criações de novos estabelecimentos nos últimos anos, com especial atenção às novas universidades e novos campi de universidades já existentes. Além disso, é importante acompanhar este processo pelo aspecto geográfico, ou seja, identificando as cidades onde se localizam os campi universitários, e suas respectivas vizinhanças.

Com base nos dados coletados no SIMEC (Painel de Controle do Ministério da Educação) e do Sistema e-MEC (Instituições de Educação Superior e Cursos Cadastrados), foram obtidas as informações a respeito de cada universidade pública federal, com relação aos campi, municípios, ano de credenciamento no MEC, bem como a localização das sedes universitárias. Além disso, foi preciso estudar a história de cada universidade através das informações disponibilizadas pelas próprias universidades em seus respectivos endereços eletrônicos, pois apenas assim poder-se-ia identificar as universidades efetivamente novas, ou seja, aquelas implantadas durante a última década e que não provinham de nenhuma instituição de ensino superior anterior. 
Ainda com relação às informações provenientes do IBGE, utilizaram-se as informações municipais do Censo Demográfico dos anos de 1991, 2000 e 2010, obtendo-se: renda per capita domiciliar ${ }^{28}$ e população residente; população entre 18 e 24 anos de idade frequentando o ensino médio ou com o ensino médio completo, mas sem frequentar ensino superior; localização do domicílio no município relativo a estar em região urbana ou rural, e respectiva unidade da federação. Com relação ao Índice de Desenvolvimento Humano, utilizou-se o calculado e disponibilizado pelo IPEA (Instituto de Pesquisa Econômica Aplicada). A informação sobre a distância à capital estadual para os municípios da divisão político administrativa também foi obtida no IPEA, com base nas coordenadas geodésicas do cadastro de cidades e vilas do IBGE. Além destas informações, são necessárias a matriz de vizinhança espacial microrregional e as Áreas Mínimas Comparáveis (AMC's), que o IBGE disponibiliza.

A informação de renda per capita está convertida para o ano base 2010 através do INPC (Índice Nacional de Preços ao Consumidor do IBGE). Corseuil e Foguel (2002) sugere uma metodologia para a correção do INPC. Por esta metodologia, o INPC, para ser utilizado como deflator dos rendimentos do Censo, deve sofrer três ajustes: alteração da data de referência; alteração do valor referente a julho de 1994; expansão do índice para períodos anteriores à sua criação. Como estamos trabalhando basicamente com o período da década de 90, o último ajuste não nos é relevante, uma vez que o INPC existe desde 1979. O primeiro ajuste se refere ao fato que, em março de 1986, o IBGE alterou o período de coleta dos preços que entravam no cálculo do índice. Anteriormente era considerado o período entre os dias 15 e 15 de dois meses consecutivos, ou seja, os índices ficavam centralizados no dia primeiro de cada mês. Após março de 1986, o período de coleta passou a ser entre os dias primeiro e 30 de cada mês, com os índices centralizados, portanto, no dia 15 do mês. Uma vez que os rendimentos do trabalho, que são a principal fonte de renda, tendem a se concentrar no início do mês, Corseuil e Foguel (2002) sugere centrar novamente os índices no dia primeiro, mediante o cálculo de uma média geométrica entre os valores dos índices de dois meses consecutivos. Já o segundo ajuste se refere ao problema da medida de inflação no mês de adoção do Plano Real. Em junho de 1994 havia duas unidades monetárias correntes. Para o

\footnotetext{
${ }^{28}$ Para o cálculo da renda domiciliar per capita municipal com ano de referência 2010, consideram-se apenas os domicílios particulares permanentes para os anos de 1991 e 2000, e os domicílios particulares permanentes ocupados para 2010. Visando minimizar os problemas de erros de imputação de renda nos Censos, excluem-se os domicílios com renda acima de $\mathrm{R} \$ 80$ mil em 1991 e $\mathrm{R} \$ 100$ mil em 2000. Tais limites acompanham o crescimento da renda domiciliar por volta de $25 \%$ em cada uma das décadas consideradas. Por questões de consistência, em 2010, excluem-se os domicílios com renda acima de R\$ 125 mil.
} 
cálculo do INPC de julho, o IBGE contrastou a média dos preços nesse mês, em reais (R\$), com a média dos preços em Unidade Real de Valor (URV), em junho. Porém muitos preços de julho de 1994 estavam em cruzeiro real (CR\$) e as pessoas gastaram seus rendimentos nesse mês com base nessa moeda. Como a variação dos preços em URV foi menor do que a variação em CR\$, entende-se ser necessário incorporar à variação reportada pelo INPC um componente relacionado ao excesso da variação de preços em cruzeiro real em relação à variação em URV.

Pelo Censo do Ensino Superior, obtiveram-se os dados sobre o número de matrículas de graduação presencial, abertos por tipo de unidade administrativa.

Com relação às coligações políticas, utilizaram-se as informações disponibilizadas pelo Tribunal Superior Eleitoral, provenientes do repositório de dados eleitorais. Assim a dummy de coligação política informa se o prefeito (governador) do município j (estado J, com jСJ) pertencia a um dos partidos políticos da coligação que elegeu o presidente da república, tendo-se como referência o ano de 2005. A adoção deste ano de referência é devida ao fato que o ano de credenciamento da universidade no MEC coincide em muitos casos ao ano de início de construção do campus, e que a expansão da rede de universidades federais ocorreu efetivamente a partir de 2005. Desta forma, para a coligação prefeito-presidente, considera-se a situação de eleição para o ano de 2005, ou seja, a coligação no período 2005-2006, uma vez que o mandato de prefeito é do ano de 2005 a 2008 e o de presidente de 2003 a 2006. Para a coligação governador-presidente, a eleição de referência é a do ano de 2003, ou seja, a coligação no período 2003-2006, visto que os mandatos de governador e presidente coincidem, compreendendo no período o ano de referência 2005.

\section{5- Resultados}

Apresentam-se os resultados para as estimações dos modelos propostos em item anterior, buscando-se estimar o efeito médio do tratamento sobre os tratados. É importante salientar que estes resultados estimados neste trabalho se referem ao efeito de curto prazo uma 
vez que expansão da rede de universidades federais é recente. ${ }^{29}$ Para se valorar a universidade no contexto econômico regional, considerando a recente expansão da estrutura de universidades federais, busca-se estimar o efeito da universidade, pela sua implantação, no período entre os anos de 2000 e 2010. Assume-se que o ano inicial 2000 apresenta as variáveis pré-tratamento. As universidades efetivamente novas são consideradas a partir de 2001, totalizando um total de 121 municípios contemplados com campi universitários.

Com relação ao número de municípios não tratados, para se estimar o modelo de Diferenças em Diferenças com Pareamento por Escore de Propensão, primeiramente é apresentada a evolução do número de observações da amostra com a implementação da escolha do grupo de controle ${ }^{30}$.

Tabela 3.1 - Evolução do Número de Não-Tratados na Construção do Grupo de Controle

\begin{tabular}{lr}
\hline & Não-Tratados \\
\hline Número de Municípios* na base de dados inicial & 4123 \\
Número de Municípios* após filtro Evolução da renda no pré-tratamento & 3594 \\
Número de Municípios** após filtro Vizinhança & 1432 \\
Número de Municípios** para Diferenças-em-Diferenças & 119 \\
\hline
\end{tabular}

Obs.: * e ** indicam municípios nas agregações de AMC's nos períodos 1991-2000 e 20002010, respectivamente. Nos municípios para a estimação por Diferenças-em-Diferenças pode haver repetições, visto que o pareamento é com reposição.

Fonte: Elaboração própria

\footnotetext{
${ }^{29}$ Estimações de longo prazo que envolvem projeções fogem do escopo deste estudo.

${ }^{30}$ De acordo com o que foi apresentado no sub-item "Implementação do Método de Estimação", a escolha do grupo de controle envolve a escolha dos valores de $\mathrm{R}$ e $\mathrm{P}$. Os resultados apresentados ao longo do capítulo se referem aos valores $R=0,10$ e $P=0,10$. A escolha de $R=0,10$ se deve ao fato que valores de $R<0,10$ reduz o número de municípios tratados pareados, independente da imposição de suporte comum no pareamento pelo propensity score, ou seja, independente do valor de P. Com relação aos valores de $\mathrm{P}$, estimam-se os efeitos para: $\mathrm{P}=0,05 ; \mathrm{P}=0,10 ; \mathrm{e} \mathrm{P}=0,20$ (este valor de $\mathrm{P}$ não é restritivo, ou seja, quando $\mathrm{P}=0,20$ não há a imposição de suporte comum no escore de propensão). No Apêndice deste trabalho, são apresentados os resultados para $(R ; P)=(0,10 ; 0,05)$ e $(R ; P)=(0,10 ; 0,20)$. Vale ressaltar que as diferenças de bandas pouco alteram os resultados estimados.
} 


\subsection{1- Escore de Propensão}

Para a estimação do modelo de Diferenças em Diferenças com Pareamento por Escore de Propensão, estima-se primeiramente o modelo de Escolha do tratamento. Considerando o tratamento como sendo a implantação de uma nova universidade no município durante a década passada, inicialmente utilizam-se variáveis pré-tratamento, ou seja, variáveis num momento do tempo anterior ao tratamento (ano de 2000). Assim, busca-se assegurar que neste modelo haja apenas variáveis não afetadas pelo tratamento.

Com base num modelo probit cuja variável dependente é indicadora do tratamento, descrevem-se a seguir as variáveis independentes. A escolha destas variáveis se baseou no potencial impacto direto sobre o tratamento, de acordo com a literatura sobre a implantação de universidades federais nos municípios brasileiros. As variáveis pré-tratamento, do ano 2000, consideradas são: dummy que indica a pré-existência de campus de universidade federal no município; população entre 18 e 24 anos com ensino médio completo e sem estar frequentando ensino superior, número de matrículas em instituições, segundo nível administrativo; dummy de existência de curso oferecido por universidade federal no município (mesmo que o município não possua campus); dummies populacionais indicadoras do tamanho do município; dummy indicadora do caso de o prefeito do município pertencer a partido político que compõe a coligação que elegeu o presidente da república; dummy indicadora do caso de o governador do município pertencer a partido político que compõe a coligação que elegeu o presidente; proporção de domicílios em área urbana; índice de desenvolvimento humano; variável de localização que aponta a distância do município à capital de sua unidade federativa; dummies dos estados que receberam campi universitários no período analisado.

Com relação ao grau de acessibilidade do município, inicialmente buscou-se trabalhar com a dummy de existência de rodovia federal ligando o município aos demais e a dummy de rodovia não federal no mesmo contexto. Basicamente, esta última variável considera as rodovias estaduais que ligam o município aos outros municípios. ${ }^{31}$ Entretanto, estas duas variáveis se mostraram insignificantes na estimação. Tal resultado é um indício que o grau de acessibilidade do município, conforme utilizado neste trabalho, não foi relevante na escolha do local de instalação de um campus, apesar de mencionada sua importância nos relatório de

\footnotetext{
${ }^{31}$ Agradecimentos à DERSA-SP (Desenvolvimento Rodoviário S/A), na figura do Sr. Sílvio Ichihara, por ceder as informações referentes às rodovias federais e não-federais para este trabalho.
} 
implantação de algumas universidades ${ }^{32}$. O resultado desta estimação se encontra no Apêndice deste trabalho.

Com base nestas variáveis, busca-se identificar os municípios não-tratados mais apropriados a serem os contrafactuais dos municípios tratados, estimando-se o escore de propensão através de um modelo probit. A tabela abaixo apresenta o resultado deste modelo de escolha do tratamento.

Tabela 3.2 - Modelo Probit de Escolha do Tratamento

\begin{tabular}{lc}
\hline \multicolumn{1}{c}{ Variáveis } & Tratamento \\
\hline Constante & $-5,507^{* * *}$ \\
& $(1,429)$ \\
Dummy campus universitário já existente & $-3,137^{* * *}$ \\
& $(0,555)$ \\
Proporção de matrículas em instituições estaduais & $0,602^{* *}$ \\
& $(0,253)$ \\
Proporção de matrículas em instituições municipais & 0,392 \\
& $(0,650)$ \\
Proporção de matrículas em instituições particulares & $0,548^{* *}$ \\
& $(0,255)$ \\
Dummy existência de curso oferecido por universidade federal & $1,215^{* * *}$ \\
População entre 18 e 24 anos cursando ou com Ensino Médio Completo & $(0,320)$ \\
& $0,00006^{* *}$ \\
Proporção de domicílios em área urbana & $(0,00002)$ \\
Dummy capital de unidade federativa & $1,375^{* *}$ \\
Índice de Desenvolvimento Humano & $(0,603)$ \\
Distância à capital da unidade federativa & $-1,354^{*}$ \\
Dummy Coligação política prefeito-presidente & $(0,721)$ \\
Dummy Coligação política governador-presidente & 2,223 \\
\hline Número de Observações & $(2,111)$ \\
& 0,001 \\
& $(0,001)$ \\
& $0,296^{*}$ \\
& $(0,180)$ \\
& $2,329^{* * *}$ \\
& $(0,499)$ \\
\hline & 1553 \\
& 0,5135 \\
& $436,42^{* * *}$ \\
\hline
\end{tabular}

Obs.: (1) O desvio-padrão está entre parênteses. *** p-valor $<0,01, * *$ p-valor $<0,05, *$ p-valor $<0,1$;

(2) São consideradas também as seguintes covariadas não apresentadas nesta tabela: dummies populacionais e estaduais. A tabela com todas as covariadas se encontra no Apêndice;

Fonte: Elaboração própria

\footnotetext{
${ }^{32}$ É importante mencionar que existem diversos tipos de graus de acessibilidade na literatura. Assim, não se pode concluir, com o resultado apresentado neste trabalho, que o grau de acessibilidade do município é irrelevante para a escolha de localização de uma universidade federal.
} 
Pelo modelo probit estimado, observa-se que o fato do município já possuir uma universidade federal, reduz a probabilidade de um campus federal ser implantado no local. Com relação à proporção do número de matrículas no total por nível administrativo. Constatase que a participação de instituições estaduais e privadas no ensino superior no município são relevantes na escolha. Isto indica que os novos campi de universidades federais priorizaram os municípios com maior participação de universidades estaduais e privadas. Desta forma, o efeito substituição entre federais e estaduais não pode ser constatado no caso específico da expansão da rede universitária federal na década 2000-2010. Como exemplo, o argumento da falta de investimento nas universidades federais no Estado de São Paulo devido à existência de três universidades estaduais de grande porte em relação às demais não é constatado na década analisada, uma vez que houve expansão da rede federal também neste estado, com a Universidade Federal de São Paulo, Universidade Federal de São Carlos e Universidade Federal do ABC.

A inclusão da proporção de matrículas em universidades federais, que serviu de referência na análise, provocaria colinearidade perfeita. Assim, esta variável foi substituída pela variável indicadora de presença de algum curso proveniente de universidade federal no município em 2000, independente da existência de campus federal. Observa-se que a escolha do local de implantação dos novos campi está relacionada positivamente à pré-existência de presença da rede federal no município, a um nível de significância de $1 \%$.

Com relação à população entre 18 e 24 anos frequentando ou com ensino médio completo e não cursando o ensino superior, constata-se que quanto maior este público, maior é a probabilidade de implantação de um novo campus universitário no município.

A escolha do tratamento sofre efeito positivo do fato do município apresentar elevada proporção de domicílios em área urbana, indicando que distribuição dos novos campi focalizaram as regiões mais urbanizadas. Entretanto, pelas dummies populacionais, apresentadas da tabela completa presente no Apêndice, constata-se que a probabilidade de um município receber um campus é crescente na população com pico no grupo entre 200 e 500 mil habitantes e não significante para municípios com mais de 500 mil habitantes. Apesar deste resultado, a dummy populacional de microrregiões com mais de 500 mil habitantes apresenta sinal negativo, mostrando que o efeito é positivo para municípios com menos de 500 mil habitantes pertencentes a microrregiões também com menos de 500 mil habitantes. 
Considerando uma variável de localização (distância do município à capital de sua unidade federativa), não se observa efeito sobre a escolha do tratamento. Assim, não há evidência que o programa de expansão das universidades federais provocou um movimento para o interior dos estados. Isto se deve ao fato que houve abertura de diversos campus universitários em cidades próximas das capitais. Este argumento de focalização no interior se deve à implantação das universidades efetivamente novas que ficaram sediadas em centros distantes das capitais, como é o caso da Universidade Federal de Campina Grande. Vale lembrar que antes do período de tratamento, existia uma grande concentração de campi nas capitais. Este movimento para fora das capitais, porém sem correlação com a distância, é captado pelo valor negativo da variável capital. Portanto, a probabilidade de escolha do tratamento é crescente no nível de urbanização, focando em municípios de pequeno e médio porte localizados fora das capitais de estado.

Com relação ao efeito de coligações políticas sobre a escolha do tratamento, as coligações eleitorais entre prefeitos e presidente se mostram significantes sobre a escolha do município, à um nível de significância de 10\%, e as coligações entre governadores e presidente apresentam relevante efeito positivo sobre a probabilidade de o município ser tratado, a um nível de significância de $1 \%$.

Introduziu-se também no modelo uma variável socioeconômica do nível de desenvolvimento humano, buscando averiguar se a escolha do município aguardava relação com alguma variável de bem-estar que refletisse parte da complexidade das capacidades humanas (Sen, 1999). Entretanto, tal variável não mostra nenhum impacto sobre a probabilidade de escolha.

Com relação à distribuição do escore de propensão, pode-se observar a mudança na distribuição na amostra inicial dos tratados e não-tratados para a amostra final para a estimação do efeito do tratamento, após o pareamento, em que há os tratados e seus respectivos controles. Pelo gráfico abaixo, nota-se que, antes do pareamento, as distribuições dos tratados e não-tratados são completamente diferentes e que há uma grande concentração de não-tratados com baixo escore de propensão. 


\section{Gráfico 3.1 - Distribuições de Escores de Propensão Antes do Pareamento}

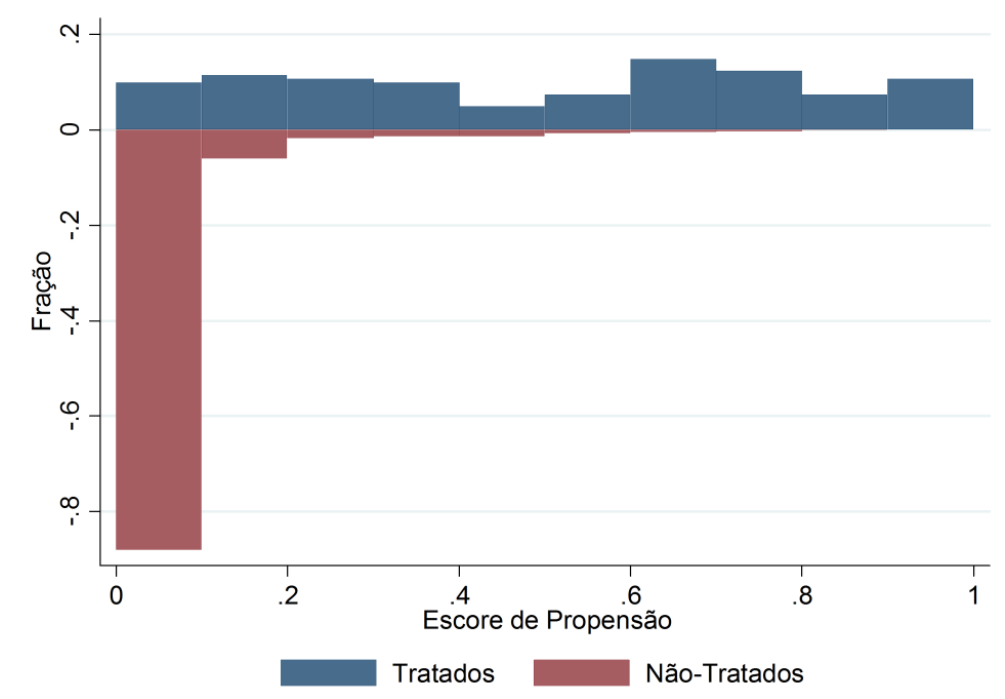

Obs.: Todos os valores de frequência são positivos, porém para efeito de apresentação do gráfico, o grupo Não-

Tratados é apresentado com valores negativos de fração, sendo assim diferenciado do grupo Tratados.

Fonte: Elaboração própria

Ao ser efetuado o pareamento pelo escore de propensão, as distribuições entre os tratados e os não-tratados contrafactuais (controles) são semelhantes, com os escores de propensão distribuídos por praticamente todo o seu suporte.

\section{Gráfico 3.2 - Distribuições de Escores de propensão Após o Pareamento}

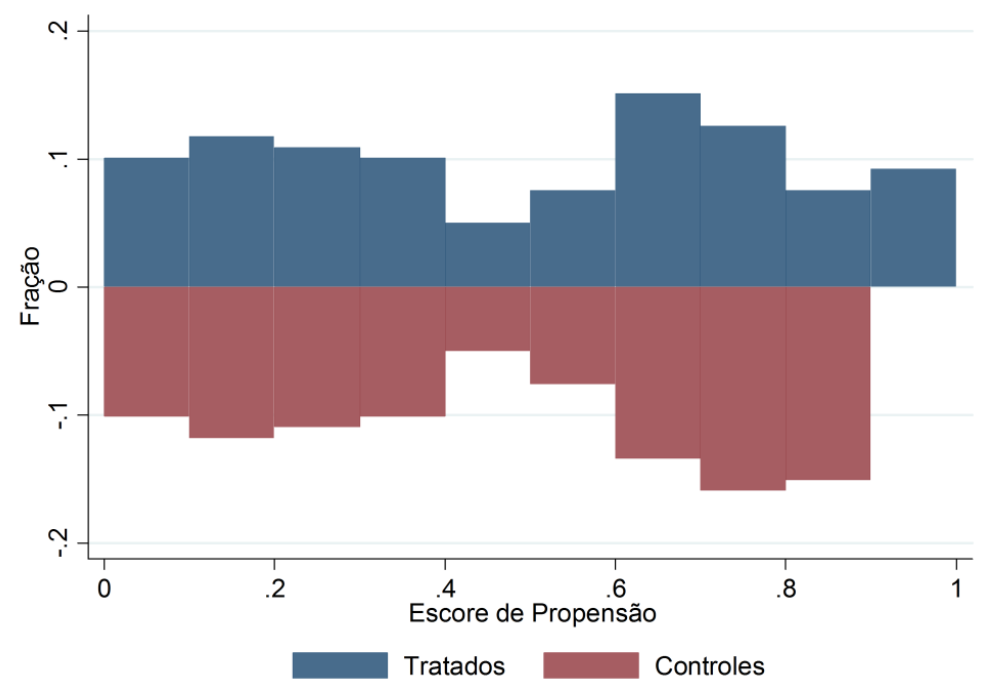

Obs.: Todos os valores de frequência são positivos, porém para efeito de apresentação do gráfico, o grupo Controles é apresentado com valores negativos de fração, sendo assim diferenciado do grupo Tratados.

Fonte: Elaboração própria 
Vale lembrar que para o pareamento pelo escore de propensão do mais próximo, permite-se a repetição de não-tratados como controles das unidades tratadas. Este pareamento com repetição é o usualmente feito na literatura de pareamento. Assim, altera-se a distribuição observada dos controles para ser próxima à distribuição dos tratados, podendo-se descartar várias unidades não-tratadas no procedimento de pareamento e possibilitando a estimação do efeito do tratamento sobre os tratados.

Neste trabalho, é utilizada a hipótese de suporte comum, de acordo com Heckman et al (1998) que argumenta que a não imposição de suporte comum pode provocar viés na estimação do efeito do tratamento, dependendo da base de dados usada. ${ }^{33}$

\subsection{2- Diferenças-em-Diferenças com Pareamento por Escore de Propensão}

Uma vez controlado pelo escore de propensão, pode-se finalmente fazer o pareamento entre tratados e não-tratados, encontrando o melhor controle para cada tratado. Como já explicado, este pareamento considera reposição, o que significa que um município não-tratado pode ser controle de mais de um município tratado. Com este pareamento, pode-se estimar o efeito médio do tratamento sobre os tratados com relação à renda domiciliar per capita, comparando-se esta renda entre tratados e controles.

Os resultados são apresentados de acordo com as três metodologias explicadas anteriormente: Estimação sem suavização da renda - modelo original (Peixoto, Andrade e Azevedo, 2008); Estimação com suavização da renda nos contrafactuais (Heckman, Ichimura, Smith e Todd, 1998; Blundell et al, 2004); Estimação com suavização da renda nos tratados e contrafactuais (Meghir e Palme, 2003).

\footnotetext{
${ }^{33}$ No Apêndice, apresentam-se os resultados para um pareamento mais restritivo quanto ao suporte comum, permitindo tolerância $\mathrm{P}=0,05$, e também para um pareamento sem a imposição de suporte comum $(\mathrm{P}=0,20)$. Conclui-se que, para a base de dados utilizada neste trabalho, a tolerância no pareamento com suporte comum pouco altera os resultados estimados.
} 
Tabela 3.3 - Efeito da Expansão de Campi Universitários Federais sobre Renda Per

\section{Capita}

\begin{tabular}{lccc}
\hline \multicolumn{4}{c}{ Estimação por Diferenças-em-Diferenças com Pareamento por Escore de Propensão } \\
\hline Método & $(1)$ & $(2)$ & $(3)$ \\
\hline Pareamento com suavização da renda dos controles & Não & Sim & Sim \\
\hline Pareamento com suavização da renda dos tratados & Não & Não & Sim \\
\hline \multirow{2}{*}{ Número de Observações $=238$} & $0,034^{* *}$ & $0,033^{* *}$ & $0,033^{* * *}$ \\
& $(0,015)$ & $(0,013)$ & $(0,008)$ \\
\hline
\end{tabular}

Obs.: $\quad 1$ - O desvio-padrão está entre parênteses;

*** p-valor $<0,01, * *$ p-valor $<0,05, *$ p-valor $<0,1$;

2- A suavização da variável ln(renda per capita) é feita usando função spline cúbica do escore de propensão;

3- A Coluna (1) faz o pareamento sem suavização da renda, a Coluna (2) segue a metodologia de Blundell et al (2004), e a Coluna (3) segue o proposto por Meghir e Palme (2003);

4- A estimação do desvio-padrão da Coluna (1) segue Abadie e Imbens (2006), e as estimações do desvio-padrão das Colunas (2) e (3) usam o método de bootstrap com 1000 replicações, com cluster por município.

Fonte: Elaboração própria

Pela tabela acima, percebe-se que o efeito médio do tratamento sobre os tratados é estatisticamente significante, independente da utilização da função spline cúbica do escore de propensão para suavizar a renda domiciliar per capita municipal. Observa-se que a variância do estimador é menor, quando a renda tanto dos contrafactuais quanto dos tratados. Como já mencionado, Meghir e Palme (2003) argumenta que este método com suavização tende a melhorar a precisão do efeito.

O efeito médio com suavização do tratamento é de 3,3\% sobre a renda domiciliar per capita municipal. Isto significa um efeito de 0,033 sobre o logaritmo da renda per capita. Considerando o modelo original, sabe-se a média da variável logaritmo da renda per capita é 6,6055 para o grupo contrafactual dos tratados ${ }^{34}$ em 2010. Um efeito médio de 0,033 indica um aumento de 0,033 sobre esta média, ou seja, o tratamento é responsável por uma mudança no logaritmo da renda per capita de 6,6055 para 6,6387. Aplicando-se a função exponencial, chega-se nos valores de $\mathrm{R} \$ 739,15$ e $\mathrm{R} \$ 764,10$, respectivamente, resultando num efeito médio de $\mathrm{R} \$ 24,95$. Tanto por este valor, como diretamente pelo coeficiente estimado, observa-se que o efeito médio do tratamento sobre os tratados é de 3,3\% sobre a renda domiciliar per capita municipal.

\footnotetext{
${ }^{34}$ Apesar do efeito estimado ser sobre os tratados, considera-se a variável média dos contrafactuais dos tratados, pois estes contrafactuais representam os tratados na ausência do tratamento.
} 
Constata-se que para a amostra utilizada neste trabalho, o efeito do tratamento pouco varia entre os métodos apresentados. Zhou e Xie (2011) argumenta que, na verdade, a grande vantagem do uso de suavização está na análise do comportamento de heterogeneidade do efeito do tratamento pela probabilidade de um indivíduo ser tratado. Xie, Brand e Jann (2012) também defende a suavização como meio de estudo deste tipo de heterogeneidade.

\section{Gráfico 3.3 - Distribuição do Efeito do Tratamento sobre o Escore de Propensão}

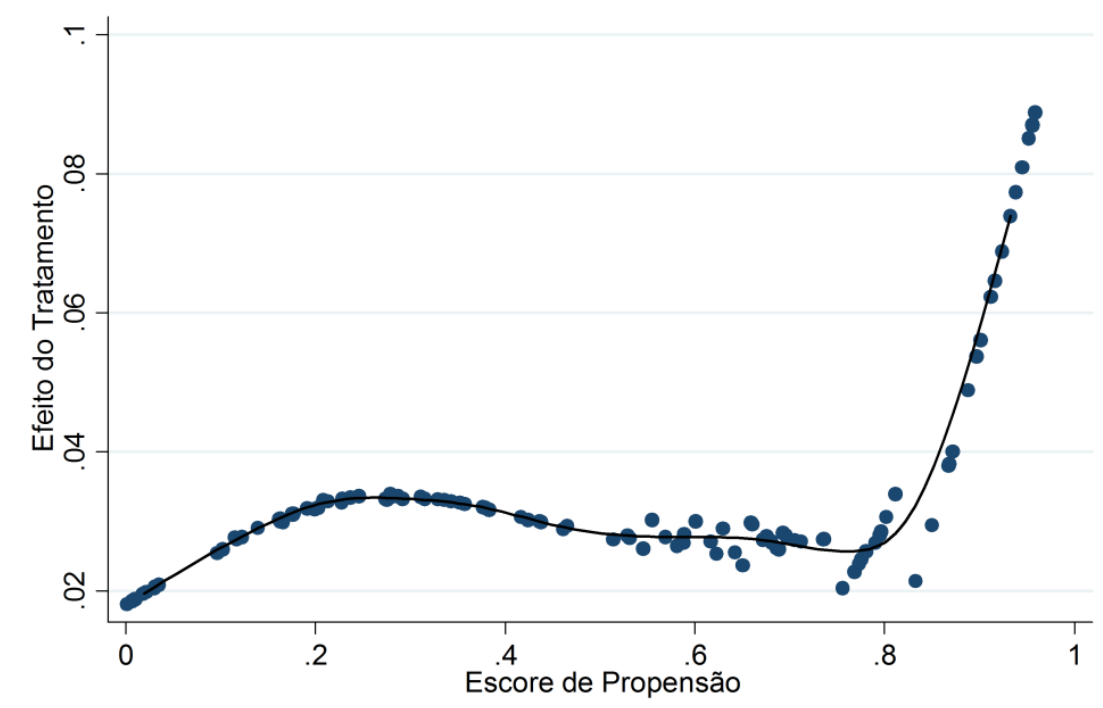

Obs.: Cada ponto no gráfico representa o efeito do tratamento de um determinado município. O efeito do tratamento sobre os tratados foi suavizado por uma função polinomial spline cúbica, representada pela curva, do escore de propensão, de acordo com Meghir e Palme (2003).

Fonte: Elaboração própria

É importante destacar que os efeitos estimados neste trabalho referem-se aos efeitos médios nos tratados, o que significa que uma análise pontual deve levar em consideração apenas a tendência evolutiva do efeito, e não o resultado pontual entre um determinado tratado e seu respectivo controle. Pelo gráfico acima, constata-se que o efeito do tratamento sobre os tratados não é homogêneo ao escore de propensão. Com esta heterogeneidade, o efeito é mais intenso dentre aqueles municípios que apresentam as maiores probabilidades de receberem campus universitário, ainda que o efeito não seja monotônico no escore de propensão. Assim, municípios que possuem variáveis que contribuem, no modelo de escolha 
do tratamento, para aumentar a probabilidade de tratamento são os que se destacam quanto ao efeito do tratamento.

Stokes e Coomes (1998) indica que o efeito econômico de curto prazo de uma universidade é mais intenso em comunidades pequenas. Nesta linha de raciocínio, pode-se dividir a amostra por níveis populacionais, buscando separar os menores municípios que receberam o tratamento e estimando o efeito do tratamento sobre os subgrupos da amostra. Intuitivamente, para os menores municípios, espera-se um efeito médio maior do que o estimado para toda a amostra dos tratados. Todavia, antes desta estimação por grupo, podemse acrescentar na estimação por Diferenças-em-Diferenças no modelo original as variáveis de população do município em 2000 e a interação desta com a variável-tratamento. Para se confirmar o argumento de Stokes e Coomes (1998), espera-se que esta variável de interação apresente coeficiente negativo.

\section{Tabela 3.4 - Efeito da Expansão de Campi Universitários Federais com Interação pelo}

Tamanho Populacional do Município

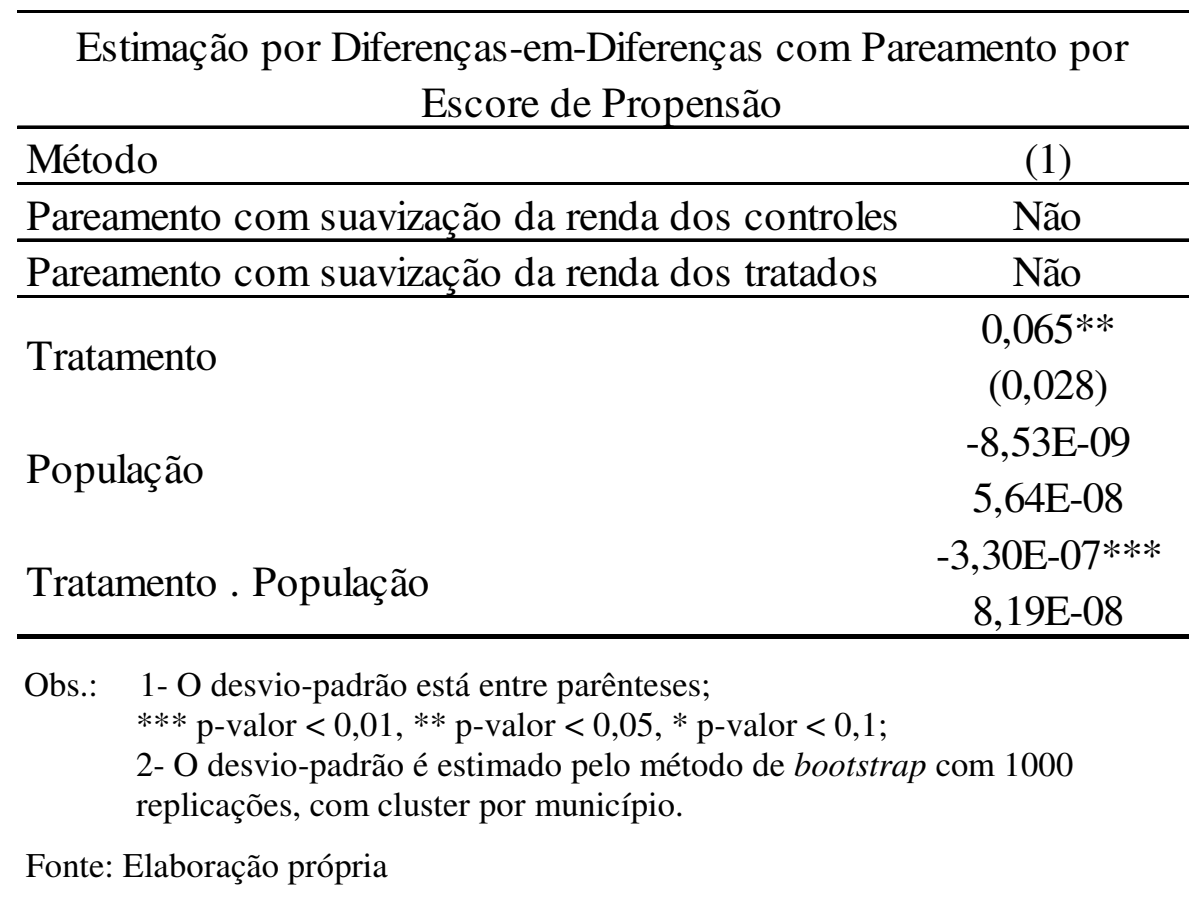

Pela tabela acima, percebe-se que o argumento de Stokes e Coomes (1998) é verificado uma vez que o mencionado coeficiente da interação tem valor negativo e é estatisticamente significativo a um nível de significância de 1\%. Este coeficiente indica que quanto maior for a população de um município tratado, menor será o efeito do tratamento 
sobre a renda domiciliar per capita municipal. Assim, os menores municípios apresentam os maiores efeitos do tratamento.

Seguindo Meghir e Palme (2003), para a estimação do efeito do tratamento nos grupos de tratados, é necessário impor a suavização dentro de cada grupo, uma vez que cada um tem distribuição distinta de escore de propensão, e a não suavização por grupo, suavizando-se por toda a amostra, implicaria na estimação do efeito em um grupo utilizando informações das distribuições do escore de propensão dos demais grupos. Tal necessidade de suavização por grupo e o número pequeno de tratados limita as possibilidades de separação da amostra em grupos, visto que quanto maior o número de grupos, menor o número de tratados e controles em cada grupo e consequentemente menos informação será utilizada para a suavização pelo escore de propensão.

Neste contexto, separa-se a amostra em dois grupos pela mediana, de acordo com a distribuição populacional dos municípios tratados. Assim, a amostra com os pares de municípios tratados e respectivos controles é dividida em dois grupos de acordo com a população dos tratados no ano 2000: Grupo 1, municípios com até 65 mil habitantes; Grupo 2, municípios com mais de 65 mil habitantes. A tabela abaixo mostra a quantidade de tratados e controles em cada grupo.

\section{Tabela 3.5 - Número de Municípios Tratados e Controles nos Subgrupos Amostrais}

\begin{tabular}{cccc}
\hline Grupo & Controles & Tratados & Total \\
\hline 1 & 59 & 59 & 118 \\
2 & 60 & 60 & 120 \\
\hline Total & 119 & 119 & 238 \\
\hline
\end{tabular}

Obs.: $\quad$ Grupo 1 - municípios com até 65 mil habitantes;

Grupo 2 - municípios com mais de 65 mil habitantes.

Fonte: Elaboração própria

A amostra utilizada é exatamente a mesma da estimação do efeito do tratamento entre todos os tratados. Assim, simplesmente se subdivide esta amostra em dois grupos, mantendo o pareamento por escore de propensão já efetuado, e estima-se o efeito médio do tratamento sobre os tratados de cada grupo através do método de Diferenças-em-Diferenças, aplicando-se a suavização dentro de cada grupo separadamente. 
Tabela 3.6 - Efeito da Expansão de Campi Universitários Federais sobre Renda Per Capita Por Grupo

\begin{tabular}{lccc}
\hline \multicolumn{4}{c}{ Estimação por Diferenças-em-Diferenças com Pareamento por Escore de Propensão } \\
\hline Método & $(1)$ & $(2)$ & $(3)$ \\
\hline Pareamento com suavização da renda dos controles & Não & Sim & Sim \\
\hline Pareamento com suavização da renda dos tratados & Não & Não & Sim \\
\hline Grupo 1 & $0,053^{* *}$ & $0,053^{* * *}$ & $0,053^{* * *}$ \\
Número de Observações $=118$ & $(0,021)$ & $(0,018)$ & $(0,009)$ \\
Grupo 2 & 0,016 & 0,013 & 0,013 \\
Número de Observações $=120$ & $(0,022)$ & $(0,019)$ & $(0,009)$ \\
\hline
\end{tabular}

Obs.: 1- O desvio-padrão está entre parênteses;

*** p-valor $<0,01, * *$ p-valor $<0,05, *$ p-valor $<0,1$;

2- A suavização da variável ln(renda per capita) é feita usando função spline cúbica do escore de propensão;

3- A Coluna (1) faz o pareamento sem suavização da renda, a Coluna (2) segue a metodologia de Blundell et al (2004), e a Coluna (3) segue o proposto por Meghir e Palme (2003);

4- A estimação do desvio-padrão da Coluna (1) segue Abadie e Imbens (2006), e as estimações do desvio-padrão das Colunas (2) e (3) usam o método de bootstrap com 1000 replicações, com cluster por município.

Fonte: Elaboração própria

Com a divisão da amostra em dois grupos, observa-se que as estimações são estatisticamente significantes apenas para o grupo de municípios com população até 65 mil habitantes, com efeito do tratamento de 5,3\% sobre a renda domiciliar per capita municipal. Tal resultado é preservado independente do método de estimação utilizado.

Isto evidencia que o efeito do tratamento não é homogêneo ao longo dos municípios, variando de acordo com o tamanho populacional. Assim, os municípios menores do ponto de vista populacional, com até 65 mil habitantes, apresentam efeito do tratamento acima da média dos tratados, enquanto que o grupo de municípios maiores não apresenta efeito estatisticamente significante.

Este resultado colabora com o argumento de Stokes e Coomes (1998) de que o efeito econômico de curto prazo de uma universidade é mais intenso em comunidades menores.

Com isso, conclui-se que enquanto o efeito do tratamento sobre toda a amostra é de $3,3 \%$ sobre a renda per capita; para os municípios menores em população, o efeito chega a $5,3 \%$. Isto indica que o efeito do tratamento nestes municípios é aproximadamente $60 \%$ maior do que o efeito sobre todo o grupo de tratados. 
Vale lembrar que este programa tem como foco, na implantação de novos campi universitários, os municípios menores e fora dos grandes centros econômicos, buscando aumentar o acesso à educação superior. Ainda assim, dentro do grupo destes municípios tratados, o efeito do tratamento se destaca no grupo dos menores municípios em população. Adicionalmente, ainda que o programa de expansão de universidades federais tenha ocorrido recentemente e seu foco não seja o aumento direto da renda domiciliar per capita municipal, este capítulo evidencia que há impacto sobre a renda no curto prazo, especialmente nos municípios menores.

\subsection{3- Análise de Sensibilidade}

Buscando-se estimar em que extensão a seleção em não-observáveis pode gerar viés nas inferências apresentadas neste capítulo, testa-se o efeito médio estimado do tratamento sobre os tratados para níveis de viés omitido capazes de afetar a sua significância estatística. Os resultados apresentados indicam em que medida a existência de heterogeneidade nãoobservada entre Tratados e Controles, devido à covariadas não-observadas, comprometem os efeitos estimados. Para tanto, utilizam-se a metodologia de limites de Rosenbaum, para estimar os valores críticos $\Gamma$ que tornam os resultados estimados sensíveis à presença de fatores não-observáveis.

Tabela 3.7 - Estimador da Análise de Sensibilidade $(\Gamma)$ para o Efeito do Tratamento sobre a Renda nos Municípios Tratados

\begin{tabular}{lccc}
\hline \multirow{2}{*}{ Sensibilidade para o Efeito sobre Renda } & \multicolumn{3}{c}{$\Gamma$} \\
\cline { 2 - 4 } & $\begin{array}{c}\text { Amostra } \\
\text { Inteira }\end{array}$ & Grupo 1 & Grupo 2 \\
\hline Renda Domiciliar Per Capita Municipal & 1,54 & 1,87 & 1,29 \\
\hline Obs.: Os valores críticos correspondem ao menor valor de $\Gamma$ que produz um intervalo entre os \\
estimadores mínimo e máximo de Hodges-Lehmann que contempla o valor zero. \\
Fonte: Elaboração própria
\end{tabular}


Constata-se que seria necessária uma influência das variáveis não-observadas de 54\% sobre a razão de probabilidade da escolha do tratamento para que o efeito sobre a renda dos tratados deixasse de ser estatisticamente significante. Vale lembrar que, segundo DiPrete e Gangl (2004), valores críticos de $\Gamma$ abaixo de 1,10 indicam forte influência de fatores nãoobserváveis sobre o efeito do tratamento. Logo, pode-se concluir que o efeito do tratamento sobre os tratados não apresenta elevada sensibilidade à heterogeneidade não-observada.

Considerando-se as sub-amostras populacionais, observa-se que ambos os grupos não apresentam grande influência das variáveis não-observadas sobre seus resultados estimados, destacando-se uma maior robustez dos resultados estimados para o grupo de municípios com população até 65 mil habitantes em comparação com o grupo com população acima de 65 mil habitantes. Para o primeiro grupo, apenas uma razão de probabilidades a partir de 1,87 seria capaz de tornar o efeito estimado estatisticamente não-significante, ou seja, as características não-observadas teriam que aumentar a razão de probabilidade em pelo menos $87 \%$ para que houvesse um viés omitido que comprometesse o efeito médio do tratamento sobre os municípios tratados com população até 65 mil habitantes. Enquanto que, para o segundo grupo de municípios, isto aconteceria se a razão de probabilidade fosse de pelo menos 1,29. No entanto, para este último grupo, tal análise de sensibilidade pouca relevância apresenta uma vez que o efeito estimado não é estatisticamente significante.

É importante destacar que, segundo DiPrete e Gangl (2004), esta análise de sensibilidade leva em consideração o pior cenário. Assim, um eventual valor baixo de $\Gamma$ não significa a inexistência de efeito positivo sobre a renda. Isto implica apenas que, se ocorrer viés de seleção capaz de levar a razão de probabilidades de escolha do tratamento a diferir entre os grupos de tratamento e controle pelo fator $\Gamma$, então o efeito estimado do tratamento sobre os tratados não será estatisticamente significante, ou seja, o intervalo de confiança para este efeito incluirá o valor zero. Caso uma variável omitida possua forte influência sobre a escolha do tratamento, mas somente uma pequena influência sobre a variável-resultado (renda), o intervalo de confiança não irá conter zero. Portanto, ainda que os limites de Rosenbaum representem o pior cenário, esta análise de sensibilidade indica quão elevada deve ser a influência de uma variável não-observada de modo a comprometer as conclusões obtidas através da metodologia de pareamento com escore de propensão. Neste contexto, conclui-se que a análise de sensibilidade apresentada corrobora para os efeitos estimados neste capítulo. 


\section{6- Conclusão}

Dado o contexto de expansão recente da rede de universidades federais no Brasil, este trabalho teve como objetivo estimar o impacto econômico de curto prazo da expansão desta rede. Tal expansão é caracterizada pela construção de novos campi universitários em diversos municípios brasileiros. Do ponto de vista metodológico, entende-se esta expansão como um tratamento de política pública, em que os municípios participantes recebem investimentos públicos que impactam sobre os resultados econômicos regionais. Assim, o tratamento compreende a implantação de campus de universidade federal no município no período entre 2000 e 2010.

Este capítulo estimou através de técnicas econométricas o efeito do tratamento sobre os tratados, com base no método de Diferenças-em-Diferenças com Pareamento por Escore de Propensão, conforme proposto por Meghir e Palme (2003).

Primeiramente, escolhem-se os municípios não-tratados mais apropriados para serem controles dos municípios tratados. Para tanto, visando garantir a hipótese de identificação do método de Diferenças-em-Diferenças, restringe-se o grupo de não-tratados aos municípios com evolução da renda domiciliar per capita semelhante à evolução da renda dos tratados, no período pré-tratamento. Em seguida, excluem-se os municípios não-tratados que pertencem ao conjunto de microrregiões que contemplam a microrregião de algum tratado e as respectivas microrregiões vizinhas.

Com isso, estima-se o escore de propensão e, com esta estimação, faz-se o pareamento entre tratados e não-tratados através do escore de propensão mais próximo, finalizando a construção do grupo de comparação. Especificamente sobre a estimação do escore de propensão, observa-se que a existência de campus universitário federal no município reduz a probabilidade deste receber um novo campus. As participações de instituições estaduais e federais contribuem para a escolha do tratamento. Além disso, a pré-existência de cursos de universidades federais, ainda que não haja campus no município, aumenta a probabilidade da implantação de campus. Esta probabilidade é crescente no nível de urbanização, e em municípios de pequeno e médio porte localizados fora das capitais de estado. Com relação à demanda por campus, constata-se que o número de pessoas entre 18 e 24 anos frequentando o ensino médio ou apenas com o ensino médio completo, sem estar cursando o ensino superior, 
contribui positivamente para a implantação de novo campus universitário. Com relação ao efeito de coligações políticas sobre a escolha do tratamento, as coligações eleitorais prefeitopresidente e governador-presidente apresentam efeito significativo sobre a probabilidade do município receber um campus universitário federal.

Este método permitiu fazer o pareamento dos tratados, totalizando 121 municípios que receberam campus de universidade federal. Com relação à estimação final pelo método de Diferenças em Diferenças, estima-se que o efeito médio do tratamento sobre os tratados é $3,3 \%$ sobre a renda domiciliar per capita municipal.

Com relação à heterogeneidade pelo escore de propensão, o efeito do tratamento é mais intenso dentre aqueles municípios tratados que apresentavam as maiores probabilidades de receberem campus universitário, ainda que este efeito não seja monotônico no escore de propensão.

Buscando contemplar a literatura e verificar o argumento mencionado em Stokes e Coomes (1998), que destaca um impacto de curto prazo maior sobre as comunidades pequenas, em comparação com as demais; dividiu-se a amostra em dois grupos (Grupo 1, municípios com até 65 mil habitantes; Grupo 2, municípios com mais de 65 mil habitantes). Estimando-se o efeito do tratamento para os grupos separadamente, constata-se que o Grupo 1, que possui os menores municípios tratados, apresenta o maior efeito do tratamento, com valor de 5,3\% sobre a renda domiciliar per capita. Já o Grupo 2, não apresenta indícios de efeito estatisticamente significante.

Os resultados estimados neste capítulo não apresentam elevada sensibilidade à heterogeneidade não-observada, relativa à influência de variáveis não-observadas conjuntamente sobre a escolha do tratamento e efeitos do tratamento sobre os tratados.

Por fim, para a comparação dos resultados no capítulo anterior com os deste capítulo, primeiramente vale ressaltar que esta comparação não é direta, uma vez que o capítulo do Método de Insumo-Produto utiliza a variável PIB enquanto que aqui se trabalha com a renda domiciliar per capita. Além disso, este primeiro calcula o efeito do tratamento via gastos públicos, que é uma variável contínua, sobre todo o Brasil. Já este capítulo, com base em técnicas econométricas, estima o efeito do tratamento apenas sobre os tratados através de uma variável dummy, indicadora do tratamento. 
Pelo capítulo anterior, dado um choque total de $\mathrm{R} \$ 5,3$ bilhões no período entre 2004 e 2010, o impacto mensurado sobre o Brasil foi de R \$ 11,5 bilhões sobre o PIB, que representa um efeito de 0,39\% sobre o PIB de 2004. Considerando apenas as 107 microrregiões que receberam campi universitários federais, tem-se um efeito total de $\mathrm{R} \$ 4,7$ bilhões sobre o PIB e um efeito médio de $\mathrm{R} \$ 90$ sobre o PIB per capita, que representa 0,93\% do PIB per capita médio destas microrregiões. Este efeito anualizado é de $0,16 \%$ sobre o PIB per capita microrregional, enquanto que o efeito anualizado estimado neste capítulo é de $0,33 \%$ sobre a renda domiciliar per capita municipal, ou seja, duas vezes maior. Buscando uniformizar o nível regional para microrregião, se considerarmos que a renda domiciliar per capita das microrregiões que receberam campi universitários federais é de $\mathrm{R} \$ 950,67$ e o efeito médio estimado no Capítulo 3 foi de $\mathrm{R} \$ 24,95$; isto representaria um efeito médio anualizado do tratamento de $0,27 \%$. Esta diferença entre $0,16 \%$ e $0,27 \%$, provavelmente se deve não apenas pela diferença de metodologias adotadas, mas também pelo tipo de variável de tratamento e especialmente pelo fato da variável-resultado ser diferente, uma vez que no Capítulo 2 trabalha-se com tratamento contínuo e resultado em valor adicionado e no Capítulo 3 com tratamento binário e resultado em renda domiciliar per capita. Entretanto, considerando que as metodologias e variáveis consideradas nos capítulos 2 e 3 são bastante diferentes, esta diferença nos resultados dos efeitos não é expressiva.

Vale lembrar que, pelo método econométrico, não é possível efetuar a expansão do resultado para outros municípios além dos tratados, uma vez que não há como garantir que o efeito do tratamento é comum para qualquer grupo de municípios, não há garantia de validade externa. Assim, não há como expandir o efeito de tratamento sobre os tratados para o efeito médio do tratamento. 


\section{4- MODELO ECONOMÉTRICO DE EFEITO POLÍTICO DO TRATAMENTO}

\section{1- Introdução}

A expansão da rede universitária federal envolve uma gama ampla de decisões tomadas não apenas pelo poder público federal, mas também pelos poderes locais. Como já mencionado, a literatura sobre expansão do ensino superior pouco detalha sobre os critérios técnicos e estratégicos para a escolha de determinada localidade como sede de um novo campus universitário. Com relação às universidades já existentes, a implantação de novos campi tem como principal agente decisório a própria universidade federal. Já para os casos de novas universidades, destaca-se como agente decisório o Ministério da Educação. Entretanto, além dos critérios técnicos e estratégicos, a literatura cita a influência de fatores políticos regionais sobre a expansão da rede universitária federal.

Esta influência política sobre a expansão das universidades nos municípios brasileiros surge na escolha do local de implantação de um novo campus, devendo-se principalmente à expectativa de benefícios políticos futuros que tal implantação pode trazer aos considerados responsáveis pelo processo decisório.

Assim, entende-se que a instalação de um novo campus não apenas pode ser efeito de influência política, mas também causa de resultados políticos futuros, uma vez que o administrador público busca maximizar sua função de utilidade que contempla a manutenção e expansão do poder político estabelecido.

O modelo clássico de escolha coletiva, em que um planejador central decide maximizando uma função de bem estar social, sofre mudanças num contexto democrático onde a possibilidade de perda de poder pode influenciar as decisões do administrador público. Com isso, na busca pela manutenção e expansão do poder estabelecido, este administrador toma uma série de decisões que terão impacto no resultado do processo eleitoral futuro.

A análise até aqui abordada se baseou no efeito econômico de curto prazo da expansão das universidades federais. Neste capítulo, altera-se o foco da análise, buscando-se estudar o 
impacto político desta expansão através do efeito da implantação de novo campus universitário federal no resultado das eleições municipais. A hipótese básica desta análise é que a implantação de um novo campus beneficia a coligação política, à qual pertence o prefeito do município, no processo eleitoral futuro.

Este capítulo é apresentado conforme a seguir. No próximo item, descreve-se brevemente a teoria dos ciclos político-econômicos. Em seguida, destaca-se o modelo de Rogoff (1990) que serve de base para a análise. Descreve-se então a implementação do método de estimação e a base de dados utilizada. Por fim, apresentam-se os resultados das estimações, finalizando-se com as conclusões.

\section{2- Revisão da Literatura de Teoria dos Ciclos Político-Econômicos}

A possibilidade futura de troca da coligação política detentora do poder em determinado local é fonte de influência sobre as decisões administrativas tomadas ao longo do mandato político do planejador central. Diversas decisões tomadas no período levam em consideração este ambiente de incerteza quanto à continuidade do poder estabelecido. Assim, qualquer decisão tomada pelo planejador central não apenas tem efeito socioeconômico, mas também efeito político sobre a localidade.

A teoria de ciclos político-econômicos (political business cycles theory) se baseia em modelos que buscam explicar os ciclos econômicos através de ciclos políticos. Downs (1957) argumenta que a análise do comportamento do planejador central (policymaker) vai além da maximização da função de bem estar social, devendo considerar também sua utilidade individual.

Alesina, Roubini e Cohen (1997) menciona que os modelos de ciclos políticoeconômicos começaram a serem formalizados efetivamente a partir dos anos 1970, podendo ser divididos em quatro grupos de acordo com as hipóteses consideradas para o comportamento dos partidos políticos e dos eleitores. Assim, os partidos podem ter comportamento oportunista ou ideológico, e os eleitores ter expectativas adaptativas ou racionais. Este item se baseia em estudo de Araújo Junior, Cançado e Shikita (2005). 


\subsection{1- Modelos com expectativas adaptativas}

\subsubsection{1- Teoria Oportunista}

Esta classe de modelos considera que os partidos políticos têm comportamento oportunista e os eleitores possuem expectativas adaptativas. Assume-se que todos os eleitores são idênticos e sumarizados num eleitor representativo que toma suas decisões com base nas variáveis econômicas observadas.

Vale destacar o trabalho seminal de Nordhaus (1975), em que o planejador central toma decisões buscando maximizar sua probabilidade de reeleição com base na curva de Philips de longo prazo, com uma baixa taxa de ajuste entre inflação e desemprego. Neste modelo, os eleitores consideram em suas preferências a taxa agregada de desemprego e a taxa de inflação, de forma que quanto maiores forem estas taxas, menor será o bem estar dos eleitores.

O fato da situação individual de cada eleitor estar correlacionada com o contexto agregado da economia justifica a incorporação da taxa agregada de desemprego na preferência do eleitor. Com relação à taxa de inflação, Nordhaus (1975) destaca três pontos. Primeiramente, argumenta que a inflação pode ocasionar uma perda da noção do valor da moeda. Além disso, por gerar uma distorção dos preços relativos, a inflação pode ocasionar uma alocação ineficiente do capital. Por fim, a inflação pode levar a uma redistribuição aleatória da renda, uma vez que afeta de formas diferentes as diversas parcelas de renda da população.

Quanto à questão das expectativas adaptativas, Nordhaus (1975) considera que há uma curta memória das condições macroeconômicas pelos eleitores, que formam suas expectativas de forma adaptativa. Com isso, estes valorizam o presente, descontando intensamente o passado, conforme a equação a seguir.

$\pi_{t}^{e}=\pi_{t-1}+\delta\left(\pi_{t-1}^{e}-\pi_{t-1}\right)$

Onde $\pi_{t}^{e}$ é a inflação esperada em t; $\pi_{t-1}$ é a inflação observada no período anterior; $\delta$ é a taxa de desconto temporal, com $0<\delta<1$; e $\delta\left(\pi_{t-1}^{e}-\pi_{t-1}\right)$ é um fator de ajuste do erro de previsão da inflação do período anterior. 
Os eleitores se baseiam nas experiências passadas para tomarem das decisões sobre política no presente. Nordhaus (1975) assume que, apesar dos eleitores serem racionais quanto às suas preferências, eles desconhecem o trade-off macroeconômico uma vez que não sabem como o planejador central está desempenhando sua função ex-ante. Assim, o administrador público pode escolher a cesta ótima de taxas de desemprego e inflação que maximize a sua probabilidade de reeleição. Neste modelo, o administrador público tem por objetivo maximizar a sua probabilidade de reeleição, não sofrendo influências partidárias.

Este administrador se comportar de acordo com o momento político. No período inicial de mandato, tem um comportamento mais responsável com relação à política monetária, entretanto às vésperas da eleição assume uma política expansionista de forma a reduzir as taxas de desemprego e inflação, maximizando sua probabilidade de reeleição, mas diminuindo a capacidade de crescimento de longo prazo.

\subsubsection{2- Teoria Partidária}

Estes modelos se baseiam o trabalho empírico de Hibbs (1977) que defende que a alternância de partidos políticos no poder com diferentes ideologias é a causa dos ciclos político-econômicos. Apesar de também se basear na curva de Philips e em eleitores com expectativas adaptativas, diferentemente de Nordhaus (1975), assume partidos e eleitores nãoidênticos, ou seja, com preferências diferentes de acordo com a situação econômica.

Os partidos políticos são classificados de acordo com suas ideologias em partidos de direita ou de esquerda, e tomam suas decisões com base em suas respectivas ideologias. Os eleitores com menores rendas são mais avessos à taxa de desemprego, preferindo partidos de esquerda. Já os eleitores com maiores rendas são mais avessos à taxa de inflação e preferem os partidos de direita. Basicamente, um partido de esquerda adotaria uma política monetária e fiscal expansionista, focando crescimento econômico e criação de empregos, sem preocupações inflacionárias. Enquanto que um partido de direita adotaria uma política monetária e fiscal restritiva, priorizando o combate à inflação. Desta forma, quanto maior for a alternância de tipos de partidos no poder, mais intensos seriam os ciclos políticoeconômicos.

Assim como Nordhaus (1975), Hibbs (1977) assume que o administrador público tem plenos poderes sobre as tomadas de decisão com relação à política monetária, com foco em 
sua probabilidade de reeleição ou sua ideologia partidária, o que é alvo de críticas na literatura uma vez que desconsidera instituições com caráter independente da situação políticas, como os bancos centrais independentes. Todavia, a principal crítica a estes modelos está relacionada à memória curta pelos eleitores, ou seja, o fundamento da expectativa adaptativa é questionado.

\subsection{2- Modelos com expectativas racionais}

Estes modelos buscam resolver a principal crítica dos apresentados anteriormente, baseando o comportamento dos eleitores em expectativas racionais. Ao invés de basear seu comportamento em uma memória curta de informações passadas, os eleitores passam a formar suas expectativas baseando-se na previsão dos valores futuros das variáveis econômicas. Estas expectativas são endógenas no modelo. Com relação aos erros de previsão, estes são imprevisíveis uma vez que possuem média zero.

Observa-se pela equação abaixo que as expectativas futuras dos eleitores são influenciadas pelas mudanças na política monetária ou fiscal.

$\pi_{t}^{e}=E\left(\pi_{t} / I_{t-1}\right)$

Onde $\pi_{t}^{e}$ é a inflação esperada em $\mathrm{t} ; I_{t-1}$ representa o conjunto de informações em t-1; $E\left(\pi_{t} / I_{t-1}\right)$ é a esperança matemática da inflação em $\mathrm{t}$, dadas as informações do período anterior.

Os modelos com expectativas racionais relacionam os ciclos político-econômicos não apenas com as mudanças de política monetária ou fiscal, mas também à assimetria de informações entre os eleitores e o administrador público, com relação à eficiência governamental. Assim, a probabilidade de reeleição de um administrador público está sujeita à percepção de sua eficiência pelos eleitores. Esta percepção depende de variáveis econômicas observadas e não necessariamente coincide com a realidade uma vez que o administrador tende a declarar ser eficiente, visando aumentar a sua probabilidade de reeleição. 


\subsubsection{1- Teoria Oportunista Racional}

Com base em Persson e Tabellini (1990), apresenta-se um modelo cujos eleitores possuem as mesmas preferências. Os administradores públicos também são racionais, com as mesmas preferências dos eleitores, mas não são idênticos, pois se diferenciam na habilidade de governar. Logo, na eleição, os eleitores votam no administrador mais eficiente, ou seja, naquele capaz de gerar o maior crescimento econômico, com menor taxa de desemprego, dado o nível de inflação.

O nível de eficiência ou competência do administrador público é dado pelo termo $\varepsilon_{t}$ da equação abaixo.

$y_{t}=\bar{y}+\left(\pi_{t}-\pi_{t}^{e}\right)+\varepsilon_{t}$

Onde $y_{t}$ é a taxa de crescimento em t; $\bar{y}$ é a taxa natural de crescimento; $\pi_{t}$ é a taxa de inflação em t; $\pi_{t}^{e}$ é a inflação esperada em $\mathrm{t}$; $\varepsilon_{t}$ é a medida de eficiência ou competência do administrador público em $\mathrm{t}$.

Assim, dados os resultados na economia em t-1, o administrador define em $\mathrm{t}$ a sua política monetária, e observa o consequente nível de produto e inflação em t. Os administradores públicos tenderão a buscar indicar aos eleitores que são eficientes, utilizandose de política monetária, através de uma administração com taxa de crescimento em $\mathrm{t}\left(y_{t}\right)$ maior do que a taxa natural $(\bar{y})$, para um dado nível de preços. Caso o administrador seja competente, ele obterá sucesso na busca de $y_{t}>\bar{y}$.

Os eleitores primeiramente observam a política monetária e a inflação em t-1, formando suas expectativas com relação à inflação e nível de salários em t. Após, observam os resultados da economia para nível de produto e inflação em t.

Vale lembrar que devido à informação assimétrica, os eleitores são limitados com relação à observação e interpretação dos efeitos da política monetária em t-1. Assim, não têm como preverem a política monetária e a inflação em t. Como destacam Persson e Tabellini (1990), ainda que os instrumentos de política monetária sejam observados imediatamente e sem custo, eles não são de grande utilidade aos eleitores, pois estes não observam outras informações relevantes que o administrador público tem sobre a situação da economia. Com isso, os eleitores tomam suas decisões com base na taxa de crescimento e na expectativa de taxa de inflação estimada por eles em t-1. É esperado pelo modelo que no ano de eleição, 
devido à política monetária expansionista, a taxa de inflação seja maior do que a esperada pelos eleitores.

É importante ressaltar o trabalho de Rogoff e Sibert (1988), que considera o efeito de política fiscal ao invés de política monetária, entendendo-se que as transferências governamentais e cortes de impostos têm maiores impactos sobre os ciclos políticoeconômicos do que as políticas monetárias. Ao considerar a política fiscal, a assimetria de informação entre os eleitores e os administradores públicos está relacionada com o alto custo de monitoramento das ações governamentais pelos eleitores. Então, neste modelo, o administrador público, para se mostrar competente e maximizar sua probabilidade de reeleição, utiliza política fiscal expansionista, provocando uma piora da situação econômica no período seguinte e gerando ciclos político-econômicos. Rogoff e Sibert (1988) argumenta que apenas um administrador competente seria capaz de gerar um ciclo político-econômico com redução de impostos e aumento dos gastos públicos.

\subsubsection{2- Teoria Partidária Racional}

Nesta teoria, o modelo partidário é apresentado com eleitores com expectativas racionais, como Alesina (1987). Apenas haverá efeito real sobre a economia se as políticas econômicas conseguirem surpreender os eleitores.

Alesina (1987) defende que os ciclos político-econômicos têm sua origem na incerteza sobre o resultado das eleições. Assim, os eleitores não têm como anteciparem os resultados eleitorais e o consequente comportamento das variáveis econômicas. A cada ano, os trabalhadores (eleitores) buscam reajustes nominais de salário visando mitigar os efeitos inflacionários. Em anos anteriores à eleição, os trabalhadores buscam reajustes que contemplem a probabilidade de vitória de cada partido político, observada pelas pesquisas eleitorais.

Neste modelo, os ciclos político-econômicos são causados pelas eleições e seus resultados inesperados. Quanto maiores as diferenças ideológicas entre os partidos, mais profundos serão os ciclos. Alesina e Tabellini (1990) adiciona a questão da discordância entre o administrador atual e futuro, destacando que quando o administrador percebe que não será reeleito, há uma forte expansão estratégica da dívida pública, reduzindo a liberdade 
administrativa e possibilidade de sucesso do administrador sucessor. Assim, o nível da dívida pública tende a ser maior do que o socialmente desejável.

\section{3- Modelo Teórico Básico}

Seguindo Bugarin e Ferreira (2007) e Meneguin, Bugarin e Carvalho (2005), considera-se como modelo teórico básico o apresentado por Rogoff (1990) que tem foco na política fiscal ao invés da política monetária e está relacionado com a Teoria Oportunista Racional. Segundo estes autores, o modelo de Rogoff (1990) é considerado adequado para o caso brasileiro, com municípios dentro de um estado federativo, e os prefeitos tendo alguns mecanismos para decidir sobre a política fiscal do município.

Rogoff (1990) estuda a influência da política fiscal sobre a reeleição, focalizando sobre a estratégia do governante com relação à política fiscal adotada por ele. Entende-se a política fiscal como decisões que envolvem a carga tributária, as transferências governamentais e as despesas correntes do governo. Neste estudo, os eleitores não conseguem observar diretamente a competência administrativa dos administradores públicos. A existência desta informação incompleta possibilita ao governante competente utilizar a política fiscal no período pré-eleições, visando aumentar sua probabilidade de reeleição.

Conforme este modelo, o governante de qualquer esfera da federação pode impor um viés na política fiscal, cortando tributos, aumentando transferências e promovendo gastos com projetos de curto prazo, ou seja, de viabilidade imediata.

O eleitor representativo no modelo apresenta a seguinte função de utilidade:

$U^{\text {eleitor }}=\sum_{s=t}^{T} \beta^{s-t}\left[U\left(c_{s}, g_{s}\right)+V\left(K_{s}\right)+\eta_{s}\right]$

Onde $\beta$ é o fator de desconto intertemporal $(0<\beta<1)$; T é o horizonte temporal, que pode ser finito ou infinito; $c_{s}$ é o consumo de bens privados per capita no tempo $s$, com $c_{s}=y-\tau_{s}$ (y é a renda inicial exógena, e $\tau_{t}$ representa os impostos lump sum); $g_{s}$ representa os bens públicos de consumo, per capita; $K_{s}$ é o consumo de bens públicos de capital, per capita, ou seja, corresponde ao investimento realizado em $s ; g_{s}$ e $K_{s}$ são produzidos pelo governo municipal; 
$\eta_{s}$ é um choque aleatório independente da política fiscal, observado pelo eleitor no final do período s-1 e com valor esperado zero. O termo $\eta_{s}$ pode ser considerado um choque de aparência que reflete a popularidade do governante atual no tempo s; de forma que, quando $\eta_{s}>0$, então, o choque de aparência beneficia o governante atual, enquanto que se $\eta_{s}<0$, o choque é favorável ao candidato do partido de oposição. Vale destacar que dentro da produção de bens públicos, os bens de capital somente existirão em $\mathrm{t}+1$ se o governo investiu em t. Além disso, o administrador público, por ser um cidadão, tem a mesma função de utilidade do eleitor representativo, porém é acrescida uma remuneração por estar exercendo o cargo político.

A função $U\left(c_{s}, g_{s}\right)$ é a utilidade do eleitor com o consumo dos bens privado $\left(c_{s}\right) \mathrm{e}$ público $\left(g_{s}\right)$. A função $V\left(K_{S}\right)$ é a utilidade do eleitor com o consumo do bem público de capital $\left(K_{s}\right)$. Assume-se que este tem utilidade aditivamente separável do consumo dos bens $c_{s}$ e $g_{s}$. Estas funções, U e V, são estritamente côncavas e estritamente crescentes em todos os argumentos, satisfazendo as seguintes condições: $\lim _{\mathrm{K} \rightarrow 0} \mathrm{~V}(K)=-\infty ; \forall c \geq 0, \lim _{\mathrm{g} \rightarrow 0} \mathrm{U}_{\mathrm{g}}(c, g)=$ $+\infty$ e $\lim _{\mathrm{g} \rightarrow \infty} \mathrm{U}_{\mathrm{g}}(c, g)=0 ; \forall g \geq 0, \lim _{\mathrm{c} \rightarrow 0} \mathrm{U}_{\mathrm{c}}(c, g)=+\infty$ e $\lim _{\mathrm{c} \rightarrow \infty} \mathrm{U}_{\mathrm{c}}(c, g)=0$. Assume-se que todos os bens são bens normais.

A provisão de bens públicos guarda relação direta com a competência $\left(\varepsilon_{t}\right)$ do administrador público, uma vez que aquele com elevador valor de competência conseguirá prover bens públicos cobrando menos impostos, conforme a seguir.

$g_{t}+K_{t+1}=\tau_{t}+\varepsilon_{t}$

Esta variável competência $\left(\varepsilon_{t}\right)$ é aleatória e persiste no tempo, ou seja, a informação sobre competência anterior à eleição persiste após o processo eleitoral. Entretanto, não é constante ao longo do tempo. Em cada momento, o administrador público se depara com um novo cenário que requer diferentes habilidades para ser resolvido. Assim, um administrador que se mostrou habilidoso para a solução de um determinado problema em t, pode não ter as habilidades suficientes para solucionar os problemas de $\mathrm{t}+1$. Isto é introduzido no modelo, em cada período, através de um choque que se caracteriza por uma média móvel de primeira ordem, MA(1), de forma $\varepsilon_{t}=\alpha_{t}+\alpha_{t-1}$, onde $\alpha_{t}$ é o choque de competência do administrador público em t.

Com relação à escolha do administrador público que controlará a produção de bens públicos, é importante destacar a diferença entre o governante e o candidato de partido 
político opositor. Uma vez que o eleitor pode aprender sobre a competência do governante atual, este administrador tem incentivos para utilizar a política fiscal de forma a aumentar a sua probabilidade de reeleição. Isto ocorre porque, em t, os eleitores apenas observam a produção de bens públicos de consumo $\left(g_{t}\right)$. A produção de bens públicos de capital $\left(K_{t+1}\right)$ será conhecida apenas em $t+1$. Exemplos de bens públicos de capital que os cidadãos só podem usufruir após um período são: escolas públicas, hospitais, bibliotecas e pontes. Uma importante propriedade relacionada a estes investimentos de longo prazo é que os eleitores somente conseguem averiguar a quantidade investida um período após o gasto efetivo. Assim, tal propriedade adiciona um elemento de assimetria de informação entre o representante eleito, que decide a política fiscal, e o eleitor, que precisa esperar um período para verificar esta componente de política fiscal.

Com relação ao processo eleitoral, a cada quatro anos ocorrem eleições municipais. A coligação política pode se candidatar infinitas vezes, independente do candidato. Isto significa que não há restrições quanto ao número de vezes que um partido político pode se reeleger. $\mathrm{O}$ candidato da oposição é escolhido de forma aleatória dentre os demais indivíduos da população. A escolha dos eleitores está entre reeleger a coligação política que governa atualmente ou eleger a coligação de oposição para ocupar a prefeitura nos quatro anos seguintes.

\section{4- Implementação do Método de Estimação}

Assim como no capítulo anterior, estima-se o efeito do tratamento sobre os tratados através do método de Diferenças-em-Diferenças com Pareamento por Escore de Propensão, com base em Heckman, Ichimura e Todd (1997), Meghir e Palme (2003) e Blundell et al (2004). O escore de propensão $\mathrm{p}(\mathrm{X})$ possibilita reduzir a dimensionalidade do modelo, balanceando tratados e controles, e fundamentando o pareamento. $\mathrm{O}$ método efetua um pareamento com suavização da variável-resultado, usando um polinômio de interpolação spline cúbico, de forma que a variável-resultado do município controle suavizada seja a estimação não-viesada da variável-resultado do contrafactual do tratado.

Meghir e Palme (2003) utiliza este método para avaliar o efeito do impacto de uma reforma no sistema educacional sueco sobre a renda dos indivíduos com elevada habilidade e 
pais com baixa escolaridade. Já Blundell et al (2004) estima o efeito de um programa obrigatório para procura de emprego sobre a transição da situação de desempregado para a de empregado.

Estes trabalhos estimam $\mathrm{E}\left[\mathrm{Y} \mid \mathrm{p}\left(\mathrm{X}_{\mathrm{i}}\right), \mathrm{D}_{\mathrm{i}}=0\right]$ com base numa função spline cúbica. Neste capítulo, a variável-resultado Y é a reeleição de partido ou coligação política; e p $\left(\mathrm{X}_{\mathrm{i}}\right)$ é o escore de propensão estimado. Enquanto que Heckman et al (1998) e Blundell et al (2004) efetuam o pareamento com suavização apenas da variável-resultado dos controles $(\mathrm{D}=0)$, Meghir e Palme (2003) propõe a mesma estimação para os tratados ( $D=1)$, argumentando que este procedimento enriquece a precisão do modelo e permite uma melhor comparação entre tratados e controles.

Xie, Brand e Jann (2012) e Zhou e Xie (2011) complementam Meghir e Palme (2003), dizendo que este pareamento com suavização dos tratados e controles possibilita analisar a heterogeneidade do efeito do tratamento em função da probabilidade do indivíduo receber o tratamento, uma vez que esta heterogeneidade ocorre devido às características observadas diferentes de cada indivíduo e as diferentes respostas de cada indivíduo ao tratamento. Num ambiente de restrição orçamentária, esta análise contribui para uma melhor compreensão sobre a forma de alocar os recursos e seus consequentes resultados numa população heterogênea.

Vale destacar que neste capítulo a variável-resultado reeleição é uma variável binária, semelhante ao caso apresentado em Blundell et al (2004). Para a estimação do efeito, no pareamento, é proposta uma transformação logística na aplicação da função spline cúbica. De forma prática, o procedimento envolve a substituição do método de mínimos quadrados sobre a função spline cúbica para uma estimação via logit sobre esta função, de forma a se obter resultados previstos mais coerentes com a característica binária da variável-resultado.

Para a estimação do efeito do tratamento, optou-se neste capítulo pela manutenção do termo "Diferenças-em-Diferenças", uma vez que o método utilizado é o mesmo do capítulo anterior. É importante ressaltar que neste capítulo a variável-resultado reeleição já representa, por construção, uma diferença (entre os resultados das eleições de 2004 e 2008, assumindo o valor 1, quando o ente político - partido do prefeito ou da coligação - se apresenta como vencedor em ambas as eleições, e 0 , caso contrário). Desta forma, para a estimação, a 
diferença no tempo desta variável não é necessária, pois já ocorre intrinsicamente em sua construção ${ }^{35}$.

A implantação do método de Diferenças-em-Diferenças com Pareamento por Escore de Propensão tem como fundamento a construção do grupo de comparação. Neste capítulo, utiliza-se apenas o filtro de municípios de microrregiões não-vizinhas à microrregião do município tratado. O filtro sobre a evolução da variável explicada no período pré-tratamento, aplicado no capítulo anterior, é entendido como desnecessário no contexto político brasileiro, em que há uma grande variedade de partidos políticos e as coligações políticas não apresentam um padrão homogêneo no tempo e no espaço, ou seja, as coligações locais não correspondem às coligações de outras esferas macrorregionais.

Com isso, pode-se escolher o grupo de potenciais controles e estimar o modelo de escolha do tratamento, de forma semelhante ao do capítulo anterior. Apesar de ser considerado o mesmo modelo, com as mesmas variáveis, isto não significa que os resultados estimados serão iguais aos do capítulo anterior, visto que o número de observações sofre um pequeno aumento, devido ao fato de se considerar apenas o filtro de vizinhança. $\mathrm{O}$ valor previsto da variável tratamento neste modelo de escolha é o valor do escore de propensão estimado, que é utilizado para se efetuar o pareamento entre tratados e controles, sob a hipótese de Suporte Comum. Assim, são considerados apenas os municípios tratados pareados com algum município controle. Este pareamento permite repetição do município controle para diferentes tratados.

Para o pareamento, utiliza-se o escore de propensão estimado dentro de uma banda $\left(\mathrm{B}_{\mathrm{PS}}\right)$ com base em um percentual de oscilação $(\mathrm{P})$, para os tratados, ou seja, $\mathrm{B}_{\mathrm{PS}}=\left[\mathrm{PS}^{\mathrm{T}}-\mathrm{P}\right.$, $\left.\mathrm{PS}^{\mathrm{T}}+\mathrm{P}\right]$, onde $\mathrm{PS}^{\mathrm{T}}$ é o escore de propensão dos tratados $(\mathrm{T})$. Os municípios do grupo de comparação devem apresentar $\mathrm{PS}^{\mathrm{NT}} \in \mathrm{B}_{\mathrm{PS}}$, onde $\mathrm{PS}^{\mathrm{NT}}$ é o escore de propensão dos nãotratados (NT). Assim, um município j não-tratado está no grupo $\left(\mathrm{G}_{\mathrm{i}}\right)$ de potenciais controles de um dado município tratado $\mathrm{i}$, se $\mathrm{PS}_{\mathrm{j}}^{\mathrm{NT}} \in \mathrm{B}_{\mathrm{PSi}}$.

Este pareamento de tratados e controles utiliza um método de suavização por spline, através da uma regressão logit da variável de reeleição de partido/coligação política numa função spline cúbica do escore de propensão para tratados e controles. A variável prevista por

\footnotetext{
${ }^{35}$ De certa forma, a variável-resultado reeleição representa uma variável transformada da variação do percentual de votos válidos entre as eleições de 2004 e 2008.
} 
esta regressão, representativa do contrafactual estimado, é usada para a estimação do efeito do tratamento sobre os tratados pelo método de Diferenças-em-Diferenças.

Buscando contemplar a possibilidade de influência de covariadas não-observadas simultaneamente sobre a escolha do tratamento e sobre a estimação do efeito sobre reeleição, conforme explicado no capítulo anterior, faz-se uma análise de sensibilidade com base nos limites de Rosenbaum, para o caso de variável-resultado binária. Com isso, estuda-se a influência de um eventual viés de seleção por não-observáveis sobre a robustez dos resultados estimados.

Por fim, assim como no capítulo anterior, vale mencionar a discussão relacionada com a variância do estimador de pareamento. Abadie e Imbens (2008) argumentam que os estimadores de pareamento cujo pareamento é extremamente não-suavizado, como é o caso do pareamento pelo escore de propensão mais próximo, apresentam viés na estimação da variância através de bootstrap. No desenvolvimento de teoria assintótica apropriada, Abadie e Imbens (2006) propõe um estimador consistente para os casos sem suavização da variávelresultado no pareamento, como já apresentado no capítulo anterior deste trabalho. Desta forma, para o modelo original, sem suavização, utiliza-se este estimador proposto e para os demais modelos segue-se Meghir e Palme (2003), com variância estimada através do método de bootstrap com cluster por município.

\section{5- Base de Dados}

A base de dados utilizada neste capítulo é a mesma já apresentada no capítulo anterior deste trabalho. Assim, a seguir serão descritas as variáveis de forma breve, detalhando-se apenas as variáveis que não constam no mencionado capítulo.

Os dados referentes às 59 universidades foram coletados das bases disponibilizadas pelo Ministério da Educação (MEC). No SIMEC (Painel de Controle do Ministério da Educação) e no Sistema e-MEC (Instituições de Educação Superior e Cursos Cadastrados), foram obtidas as informações a respeito de cada universidade pública federal, com relação aos 
campi, municípios, ano de credenciamento no MEC, bem como a localização das sedes universitárias.

Com relação às informações originárias do IBGE, utilizaram-se as informações municipais do Censo Demográfico do ano de 2000, obtendo-se: população residente; população entre 18 e 24 anos de idade frequentando o ensino médio ou com o ensino médio completo, mas sem frequentar ensino superior; localização do domicílio no município relativo a estar em região urbana ou rural, e respectiva unidade da federação. O Índice de Desenvolvimento Humano utilizado foi calculado e disponibilizado pelo IPEA (Instituto de Pesquisa Econômica Aplicada), que também é a fonte da informação sobre a distância à capital estadual para os municípios da divisão político administrativa, calculada a partir das coordenadas geodésicas do cadastro de cidades e vilas do IBGE. Também foram utilizadas as informações do IBGE sobre a matriz de vizinhança espacial microrregional e as Áreas Mínimas Comparáveis (AMC's).

Os dados sobre o número de matrículas de graduação presencial, abertos por tipo de unidade administrativa, foram obtidos no Censo do Ensino Superior, disponibilizado pelo INEP (Instituto Nacional de Estudos e Pesquisas Educacionais Anísio Teixeira).

A informação de maior destaque neste capítulo diz respeito às eleições obtida no Tribunal Superior Eleitoral, provenientes do repositório de dados eleitorais. A dummy de coligação política informa se o prefeito (governador) do município j (estado $\mathrm{J}$, com jCJ) pertencia a um dos partidos políticos da coligação que elegeu o presidente da república, tendo-se como referência o ano de 2005. A adoção deste ano de referência é devida ao fato que o ano de credenciamento da universidade no MEC coincide em muitos casos ao ano de início de construção do campus, e que a expansão da rede de universidades federais ocorreu efetivamente a partir de 2005. Desta forma, para a coligação prefeito-presidente, considera-se a situação de eleição para o ano de 2005, ou seja, a coligação no período 2005-2006, uma vez que o mandato de prefeito é do ano de 2005 a 2008 e o de presidente de 2003 a 2006. Para a coligação governador-presidente, a eleição de referência é a do ano de 2003, ou seja, a coligação no período 2003-2006, visto que os mandatos de governador e presidente coincidem e compreendem o ano de 2005.

Com relação à variável sobre reeleição, inicialmente considera-se como partido político reeleito aquele que se encontrava no poder no período anterior t-1 e venceu a eleição novamente em t. Dada a possibilidade de eleição em $\mathrm{t}$ de um dos partidos políticos da 
coligação política vencedora da eleição em t-1, utiliza-se isto também como variável sobre reeleição. Esta segunda variável-resultado incorpora em sua construção qualquer partido político eleito em $\mathrm{t}$ que tenha feito parte da coligação política que elegeu o prefeito em $\mathrm{t}-1$. Assim, esta variável contempla a primeira variável sobre reeleição, uma vez que o partido político vendedor em t-1 fazia parte de uma coligação política. Nos casos em que o partido político vencedor em t-1 não possuía coligação política, considera-se que a coligação política tinha apenas um partido, e naturalmente não havia outros partidos. Para este estudo, assumese $\mathrm{t}=2008$.

Entretanto, nesta análise, os campi universitários federais implantados em 2009 e 2010 fazem parte do tratamento, uma vez que a base de dados utilizada não especifica o ano de implantação de cada campus no País e esta informação não se encontra disponível publicamente. Pode-se argumentar que o fato da decisão de instalação de um campus universitário ser anterior ao seu ano de implantação mitigaria este problema, uma vez que, na eleição de 2008, a decisão pela implantação de um campus em 2009 ou 2010 já estaria tomada ou em fase avançada de negociação, assumindo-se a hipótese de que isto seria de conhecimento público em 2008.

\section{6- Resultados}

Neste item, apresentam-se os resultados da estimação do efeito médio do tratamento sobre os tratados, como no capítulo anterior. Entretanto, a variável explicada aqui é a reeleição do partido político ou coligação política. Como esta é uma variável indicadora (binária), pode-se considerar que o resultado é o impacto do tratamento sobre a probabilidade de reeleição. Dadas as características do cenário, como já explicado anteriormente, os resultados estimados neste trabalho se referem ao efeito de curto prazo. ${ }^{36}$ Como grande parte da expansão da rede de universidades federais ocorre no ano de 2005, utiliza-se a eleição municipal de 2008, observando-se se o partido ou coligação política no poder entre 2005 e 2008 conseguiu a reeleição para o mandato entre 2009 e 2012. Assim como no capítulo

\footnotetext{
${ }^{36}$ Estimações de longo prazo que envolvem projeções fogem do escopo deste estudo.
} 
anterior, assume-se que o ano inicial 2000 apresenta as variáveis pré-tratamento. Considera-se um total de 121 municípios contemplados com campi universitários no período analisado.

Apresenta-se a evolução do número de observações da amostra com a implementação da escolha do grupo de controle ${ }^{37}$, para a estimação do modelo de Diferenças em Diferenças com Pareamento por Escore de Propensão. Constata-se que o uso da hipótese de Suporte Comum reduz o número de tratados pareados para 120 municípios.

\section{Tabela 4.1 - Evolução do Número de Não-Tratados na Construção do Grupo de Controle}

\begin{tabular}{lr}
\hline & Não-Tratados \\
\hline Número de Municípios* na base de dados inicial & 4123 \\
Número de Municípios** após filtro Vizinhança & 1746 \\
Número de Municípios** para Diferenças-em-Diferenças & 120 \\
\hline
\end{tabular}

Obs.: * e ** indicam municípios nas agregações de AMC's nos períodos 1991-2000 e 20002010, respectivamente.

Fonte: Elaboração própria

\subsection{1- Escore de Propensão}

Para se estimar o efeito político médio do tratamento sobre os tratados, pelo método abordado neste capítulo, primeiramente é necessário estimar um modelo probabilístico do tratamento, lembrando que o tratamento é a implantação de uma nova universidade no município durante a década passada. Desta forma, para este modelo, utiliza-se a mesma base de dados do capítulo anterior, constituída de variáveis pré-tratamento do ano de 2000.

\footnotetext{
${ }^{37}$ De acordo com o que foi apresentado no sub-item "Implementação do Método de Estimação", a escolha do grupo de controle envolve a escolha dos valores de $\mathrm{R}$ e P. Os resultados apresentados ao longo do capítulo se referem aos valores $R=0,10$ e $P=0,10$. A escolha de $R=0,10$ se deve ao fato que valores de $R<0,10$ reduzem o número de municípios tratados pareados, independente da imposição de suporte comum no pareamento pelo propensity score, ou seja, independente do valor de $\mathrm{P}$. Com relação aos valores de $\mathrm{P}$, estimam-se os efeitos para: $\mathrm{P}=0,05 ; \mathrm{P}=0,10 ;$ e $\mathrm{P}=0,20$ (este valor de $\mathrm{P}$ não é restritivo, ou seja, quando $\mathrm{P}=0,20$ não há a imposição de suporte comum no escore de propensão). No Apêndice deste trabalho, são apresentados os resultados para $(\mathrm{R} ; \mathrm{P})=(0,10 ; 0,05)$ e $(\mathrm{R} ; \mathrm{P})=(0,10 ; 0,20)$. Vale ressaltar que as diferenças de bandas pouco alteram os resultados estimados.
} 
Para a estimação do modelo de Escolha do tratamento, utiliza-se um probit cuja variável dependente é indicadora do tratamento. Assim como no capítulo anterior, descrevemse a seguir as variáveis independentes. A escolha destas variáveis se baseou no potencial impacto direto sobre o tratamento, de acordo com a literatura sobre a implantação de universidades federais nos municípios brasileiros. As variáveis pré-tratamento, do ano 2000, consideradas são: dummy que indica a pré-existência de campus de universidade federal no município; população entre 18 e 24 anos com ensino médio completo e sem estar frequentando ensino superior, número de matrículas em instituições, segundo nível administrativo; dummy de existência de curso oferecido por universidade federal no município (mesmo que o município não possua campus); dummies populacionais indicadoras do tamanho do município; dummy indicadora do caso de o prefeito do município pertencer a partido político que compõe a coligação que elegeu o presidente da república; dummy indicadora do caso de o governador do município pertencer a partido político que compõe a coligação que elegeu o presidente; proporção de domicílios em área urbana; índice de desenvolvimento humano; variável de localização que aponta a distância do município à capital de sua unidade federativa; dummies dos estados que receberam campi universitários no período analisado.

Com isso, busca-se identificar os municípios não-tratados mais apropriados a serem os contrafactuais dos municípios tratados, ou seja, constrói-se o grupo de controle a partir do escore de propensão estimado. O resultado do modelo de escolha do tratamento é apresentado a seguir. 
Tabela 4.2 - Modelo Probit de Escolha do Tratamento

\begin{tabular}{|c|c|}
\hline Variáveis & Tratamento \\
\hline Constante & $\begin{array}{c}-6,091 * * * \\
(1,343)\end{array}$ \\
\hline Dummy campus universitário já existente & $\begin{array}{c}-3,026^{* * * *} \\
(0,542)\end{array}$ \\
\hline Proporção de matrículas em instituições estaduais & $\begin{array}{c}0,573 * * \\
(0,248)\end{array}$ \\
\hline Proporção de matrículas em instituições municipais & $\begin{array}{c}0,407 \\
(0,643)\end{array}$ \\
\hline Proporção de matrículas em instituições particulares & $\begin{array}{c}0,516 * * \\
(0,243)\end{array}$ \\
\hline Dummy existência de curso oferecido por universidade federal & $\begin{array}{c}1,159 * * * \\
(0,306)\end{array}$ \\
\hline População entre 18 e 24 anos cursando ou com Ensino Médio Completo & $\begin{array}{c}0,00006^{* *} \\
(0,00002)\end{array}$ \\
\hline Proporção de domicílios em área urbana & $\begin{array}{c}1,418 * * \\
(0,576)\end{array}$ \\
\hline Dummy capital de unidade federativa & $\begin{array}{c}-1,433 * * \\
(0,712)\end{array}$ \\
\hline Índice de Desenvolvimento Humano & $\begin{array}{c}2,93 \\
(2,000)\end{array}$ \\
\hline Distância à capital da unidade federativa & $\begin{array}{l}0,0005 \\
(0,000)\end{array}$ \\
\hline Dummy Coligação política prefeito-presidente & $\begin{array}{l}0,314 * \\
(0,177)\end{array}$ \\
\hline Dummy Coligação política governador-presidente & $\begin{array}{c}2,234 * * * \\
(0,470)\end{array}$ \\
\hline Número de Observações & 1867 \\
\hline Pseudo R-quadrado & 0,5216 \\
\hline LR Qui-Quadrado & $467,43 * * *$ \\
\hline
\end{tabular}

Obs.: (1) O desvio-padrão está entre parênteses. $* * *$ p-valor $<0,01, * *$ p-valor $<0,05, *$ p-valor $<0,1$;

(2) São consideradas também as seguintes covariadas não apresentadas nesta tabela: dummies populacionais e estaduais. A tabela com todas as covariadas se encontra no Apêndice;

Fonte: Elaboração própria

Obviamente, a estimação apresentada se destaca pelos resultados muito próximos dos apresentados no capítulo anterior. A diferença mais relevante entre as duas estimações se deve ao fato da estimação apresentada neste capítulo não considerar na construção da base de 
dados a evolução da renda domiciliar per capita em período anterior ao tratamento. Este filtro pela renda não se justifica, visto que a variável-resultado neste capítulo é a reeleição política.

Pelos resultados da tabela acima, observa-se o efeito negativo da pré-existência de campus de universidade federal sobre a probabilidade de implantação de um novo campus no município. Além disso, os municípios que são capitais de unidade federativa apresentam uma menor probabilidade de tratamento. As demais variáveis apresentam efeito positivo sobre esta probabilidade, valendo destacar: a participação de instituições estaduais e privadas no ensino superior; a pré-existência de presença da rede federal no município; a população entre 18 e 24 anos frequentando ou com ensino médio completo e não cursando o ensino superior; a proporção de domicílios em área urbana; as dummies de coligação política; as dummies populacionais; e as dummies de unidade da federação.

É importante destacar a conclusão de que a probabilidade de escolha do tratamento é crescente no nível de urbanização, focando em municípios de pequeno e médio porte localizados fora das capitais de estado. Além disso, com relação ao efeito de coligações políticas sobre a probabilidade de escolha do tratamento, constatam-se que as coligações eleitorais entre prefeito e presidente, e entre governador e presidente, se mostram significantes estatisticamente, em nível de significância de $10 \%$ e $1 \%$, respectivamente.

Assim, observa-se um efeito político sobre a probabilidade de escolha do tratamento. Tal conclusão introduz a questão sobre o efeito do tratamento sobre a probabilidade de reeleição da estrutura política no município, via partido político ou coligação de partidos.

Antes da implementação do pareamento e análise dos resultados, é importante observar a alteração na distribuição do escore de propensão nos tratados e não-tratados, antes e após o pareamento. Assim, como no capítulo anterior, os grupos de tratados e não-tratados apresentam distribuições bastante diferentes, conforme gráfico abaixo. 


\section{Gráfico 4.1 - Distribuições de Escores de Propensão Antes do Pareamento}

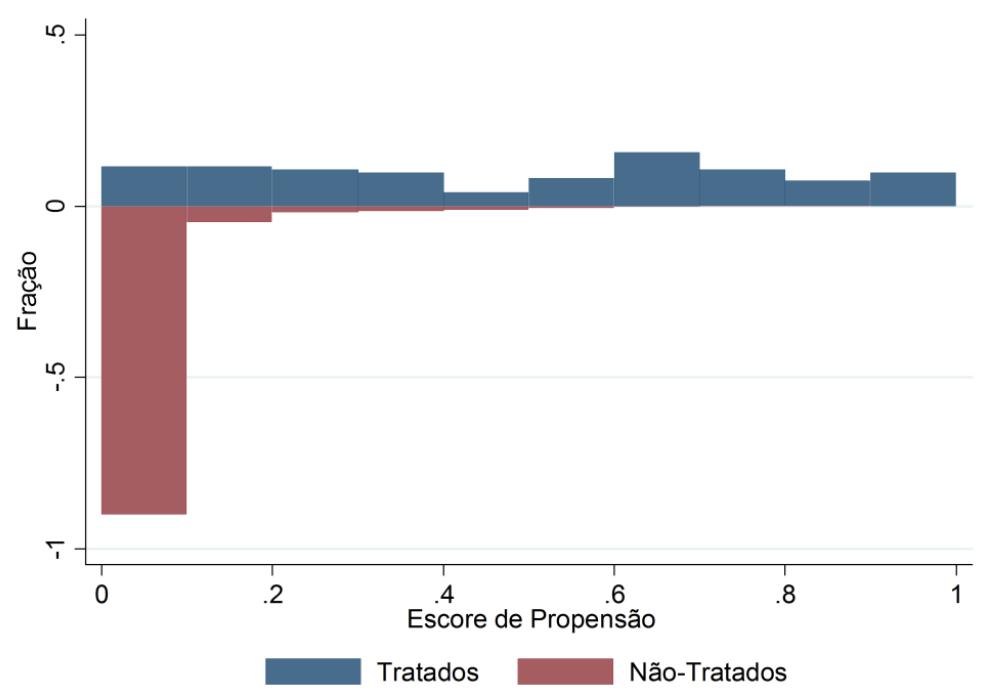

Obs.: Todos os valores de frequência são positivos, porém para efeito de apresentação do gráfico, o grupo NãoTratados é apresentado com valores negativos de fração, sendo assim diferenciado do grupo Tratados.

Fonte: Elaboração própria

Após o pareamento, há grande alteração na distribuição do grupo Não-Tratados, chamado agora de Controles, de forma que as distribuições de escores de propensão entre os Tratados e os Controles passam a ser semelhantes, como pode ser observado no gráfico abaixo.

\section{Gráfico 4.2 - Distribuições de Escores de Propensão Após o Pareamento}

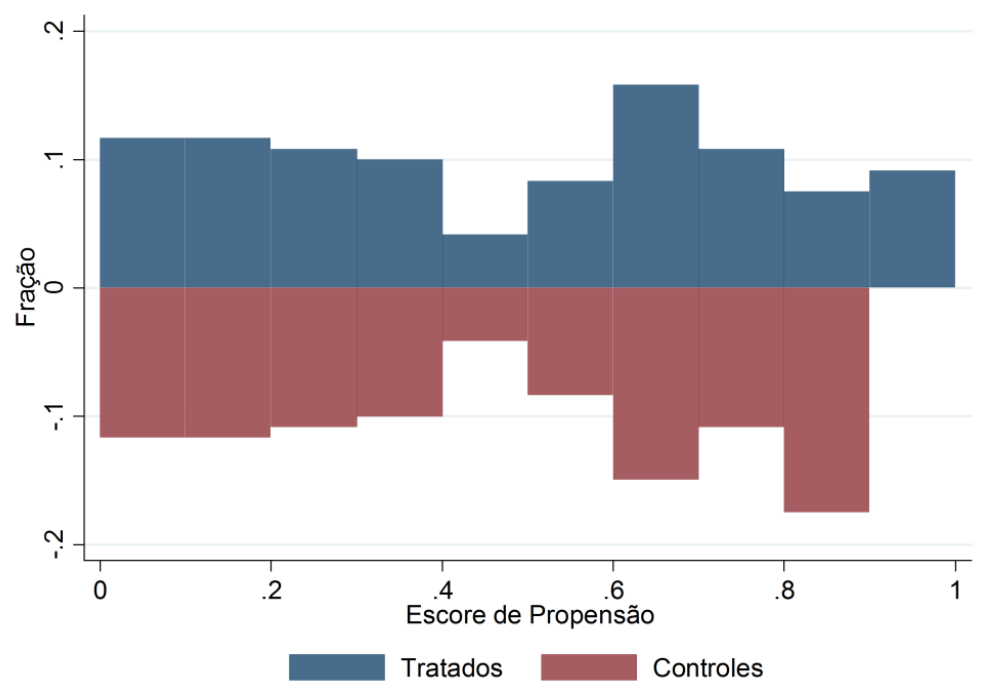

Obs.: Todos os valores de frequência são positivos, porém para efeito de apresentação do gráfico, o grupo Controles é apresentado com valores negativos de fração, sendo assim diferenciado do grupo Tratados.

Fonte: Elaboração própria 
O pareamento efetuado considera a possibilidade de repetição de não-tratados como controles das unidades tratadas, como é de uso comum na literatura de pareamento. Este pareamento permite a estimação do efeito do tratamento sobre os tratados, ao descartar diversas unidades não-tratadas no procedimento de pareamento e aproximar a amostra final de controles, após pareamento, com a amostra de tratados. Neste procedimento, usa-se a hipótese de suporte comum. Heckman et al (1998) defende que a não imposição de suporte comum pode provocar viés ao estimador de efeito do tratamento, dependendo da base de dados utilizada. $^{38}$

\subsection{2- Diferenças-em-Diferenças com Pareamento por Escore de Propensão}

Pela estimação do escore de propensão, constata-se a influência da variável política na escolha do tratamento. Com isso, busca-se entender se a implantação de novo campus universitário federal trouxe benefício político à administração pública municipal no período analisado.

Desta forma, controlando-se pelo escore de propensão, constrói-se o grupo de controle que representa o contrafactual dos tratados. Vale lembrar que o pareamento pelo escore de propensão estimado considera reposição, ou seja, um município não-tratado pode ser controle de mais de um município tratado. Uma vez feito este pareamento, estima-se pelo método de Diferenças-em-Diferenças, o efeito médio do tratamento sobre a reeleição nos municípios tratados, comparando-se o resultado de reeleição entre tratados e controles.

\footnotetext{
${ }^{38}$ No Apêndice, apresentam-se os resultados para um pareamento mais restritivo quanto ao suporte comum, permitindo tolerância $\mathrm{P}=0,05$ e também para um pareamento sem a imposição de suporte comum $(\mathrm{P}=0,20)$. Conclui-se que, para a base de dados utilizada neste trabalho, a tolerância no pareamento com suporte comum pouco altera os resultados estimados.
} 
Tabela 4.3 - Efeito da Expansão de Campi Universitários Federais sobre Reeleição Política em 2008

\begin{tabular}{lccc}
\hline \multicolumn{4}{c}{ Estimação por Diferenças-em-Diferenças com Pareamento por Escore de Propensão } \\
\hline Método & $(1)$ & $(2)$ & $(3)$ \\
\hline Pareamento com suavização de reeleição dos controles & Não & Sim & Sim \\
\hline Pareamento com suavização de reeleição dos tratados & Não & Não & Sim \\
\hline \multirow{2}{*}{ Partido Político Eleito em 2004 Vencedor em 2008 } & $0,101^{* *}$ & 0,1 & $0,1^{* *}$ \\
& $(0,049)$ & $(0,066)$ & $(0,046)$ \\
Partido Político da Coligação Eleita em 2004 Vencedor em 2008 & $0,271^{* * *}$ & $0,267^{* * *}$ & $0,267^{* * *}$ \\
& $(0,040)$ & $(0,082)$ & $(0,079)$ \\
\hline
\end{tabular}

Obs.: 1 - Número de observações $=240$

2- O desvio-padrão está entre parênteses;

$* * *$ p-valor $<0,01, * *$ p-valor $<0,05, *$ p-valor $<0,1$;

3- A suavização da variável binária reeleição é feita usando função spline cúbica do escore de propensão;

4- A Coluna (1) faz o pareamento sem suavização da variável reeleição, a Coluna (2) segue a metodologia de Blundell et al (2004), e a Coluna (3) segue o proposto por Meghir e Palme (2003); 5- A estimação do desvio-padrão da Coluna (1) segue Abadie e Imbens (2006), e as estimações do desvio-padrão das Colunas (2) e (3) usam o método de bootstrap com 1000 replicações, com cluster por município.

Fonte: Elaboração própria

Considerando o resultado para a variável dependente partido político eleito em 2004 e reeleito em 2008, tem-se que o efeito médio do tratamento sobre os tratados é estatisticamente significante dependendo do modelo de estimação utilizado. O valor do efeito, em si, é praticamente o mesmo, sendo da ordem de $10 \%$, ou seja, nos municípios tratados, o partido político no poder tem uma probabilidade $10 \%$ maior de se reeleger, quando comparado com um partido político no poder em um município que não recebeu o tratamento. ${ }^{39}$

Considerando-se a eleição em 2008 de qualquer partido político pertencente à coligação política vencedora da eleição de 2004, inclusive o partido do prefeito eleito, constata-se que o efeito do tratamento nos municípios tratados é de aproximadamente $27 \%$ (pontos percentuais), com nível de significância de $1 \%$ para qualquer um dos três métodos de estimação utilizados. Isto significa que a implantação de um novo campus universitário tem um efeito positivo de $27 \%$ sobre a probabilidade de reeleição para qualquer partido político que pertencia à coligação política vencedora da eleição de 2004.

Ainda que se entenda a implantação de um campus universitário federal de um município como um fator impulsionador do crescimento e desenvolvimento econômico, do ponto de vista político local, os resultados mostram indícios de que o administrador público

\footnotetext{
${ }^{39}$ Vale ressaltar que os resultados apresentados neste capítulo para os efeitos estimados sobre a variávelresultado reeleição são expressos em pontos percentuais.
} 
municipal angaria benefícios políticos com esta implantação através da sua manutenção no poder, quer seja pelo partido político ao qual pertence, quer seja pelo partido político constituinte da coligação política existente na eleição de 2004.

Do ponto de vista do administrador público, o efeito político é muito maior do que o efeito-renda. Política influência a decisão de implantação visando benefícios futuros.

Seguindo a linha de análise de Xie, Brand e Jann (2012) e Zhou e Xie (2011), pode-se observar como o efeito do tratamento é heterogêneo ao longo da distribuição dos valores de escore de propensão. Vale ressaltar que isto não se trata de uma análise pontual do efeito do tratamento para um determinado município, mas sim de uma análise da evolução do efeito ao longo da distribuição de probabilidades de tratamento.

\section{Gráfico 4.3 - Distribuição do Efeito do Tratamento sobre o Escore de Propensão}

Partido Político Eleito

em 2004 Vencedor em 2008

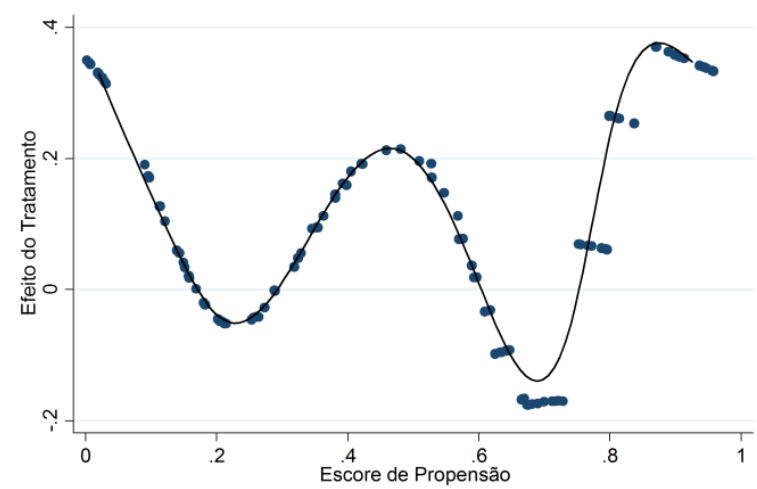

Partido Político da Coligação Eleita

em 2004 Vencedor em 2008

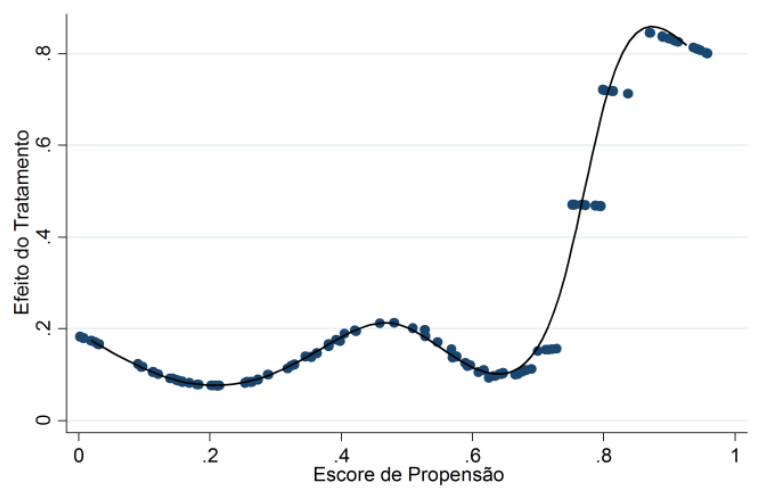

Obs.: Cada ponto no gráfico representa o efeito do tratamento de um determinado município. O efeito do tratamento sobre os tratados foi suavizado por uma função polinomial spline cúbica, representada pela curva, do escore de propensão, de acordo com Meghir e Palme (2003).

Fonte: Elaboração própria

Pelos gráficos acima, é evidente a diferença de padrão de heterogeneidade entre as duas variáveis de reeleição. Para a reeleição do partido político do prefeito, há um padrão oscilatório ao redor de $10 \%$ que é o efeito médio do tratamento sobre os tratados, e a ocorrência de efeitos negativos para municípios com probabilidades de receberem o tratamento próximas a $22 \%$ e $68 \%$. Este padrão está longe de ser monotônico, apresentando variação de $-20 \%$ a $40 \%$, aproximadamente. Os municípios com probabilidades de tratamento próximas a $0 \%, 50 \%$ e $100 \%$ apresentam os maiores efeitos-políticos do tratamento. 
Diferentemente, do caso anterior, analisando-se a variável de reeleição em 2008 relacionada a qualquer partido político da coligação eleita em 2004, observa-se um padrão mais claro de evolução do efeito do tratamento na distribuição do escore de propensão. Os municípios com probabilidade de tratamento até $65 \%$ apresentam um efeito-político sobre reeleição ao redor de $15 \%$. Já aqueles municípios com elevada probabilidade de tratamento, acima de 70\%, têm um efeito-político mais elevado e praticamente monotônico ao escore de propensão.

Os municípios que apresentam variáveis que contribuem para o aumento de suas respectivas probabilidades de tratamento são os que têm os maiores efeitos sobre a probabilidade de reeleição. Portanto, estes municípios apresentam não apenas os maiores efeitos políticos sobre reeleição, mas também os maiores efeitos econômicos sobre a renda per capita domiciliar municipal.

Assim como no capítulo anterior, pode-se analisar o efeito político de acordo com o tamanho populacional do município. Acrescentando-se no modelo original as variáveis de população do município em 2000 e a interação desta com a variável-tratamento, constata-se, pela tabela abaixo, que esta variável de interação não é estatisticamente significante para ambos os casos de reeleição. Isto mostra um indício de que, em média, o tamanho do município não guarda relação o efeito do tratamento sobre reeleição.

\section{Tabela 4.4 - Efeito da Expansão de Campi Universitários Federais com Interação pelo}

\section{Tamanho Populacional do Município}

\begin{tabular}{lcc}
\hline \multicolumn{3}{c}{ Estimação por Diferenças-em-Diferenças com Pareamento por Escore de Propensão } \\
\hline Variável Dependente: Reeleição & $\begin{array}{c}\text { Partido Político Eleito em } \\
\text { 2004 }\end{array}$ & $\begin{array}{c}\text { Partido Político da } \\
\text { Coligação Eleita em 2004 } \\
\text { Vencedor em 2008 }\end{array}$ \\
\hline Pareamento com suavização de reeleição dos controles & Não & Não \\
\hline Pareamento com suavização de reeleição dos tratados & Não & Não \\
\hline Tratamento & 0,048 & 0,142 \\
& $(0,104)$ & $(0,090)$ \\
População & $-3,24 \mathrm{E}-08$ & $-1,25 \mathrm{E}-07$ \\
& $1,42 \mathrm{E}-07$ & $1,38 \mathrm{E}-07$ \\
Tratamento . População & $1,90 \mathrm{E}-07$ & $1,14 \mathrm{E}-07$ \\
\end{tabular}

Obs.: 1- O desvio-padrão está entre parênteses; $* * *$ p-valor $<0,01, * *$ p-valor $<0,05, *$ p-valor $<0,1$; 2- O desvio-padrão é estimado pelo método de bootstrap com 1000 replicações, com cluster por município.

Fonte: Elaboração própria 
Sabe-se então que o efeito médio não guarda relação com o tamanho do município na amostra inteira, mas pode ocorrer que dentro de um determinado grupo de municípios, divididos de acordo com suas respectivas populações, este efeito seja significativo, ainda que não guarde relação direta com o tamanho populacional. Seguindo a divisão de grupos do capítulo anterior, pode-se analisar o efeito médio do tratamento para cada sub-amostra. Assim, estima-se o efeito médio do tratamento sobre os tratados para os dois grupos já apresentados: Grupo 1, municípios com até 65 mil habitantes; Grupo 2, municípios com mais de 65 mil habitantes. A distribuição de tratados e controles nos grupos é apresentada abaixo.

Tabela 4.5 - Número de Municípios Tratados e Controles nos Subgrupos Amostrais para Reeleição

\begin{tabular}{cccc}
\hline Grupo & Controles & Tratados & Total \\
\hline 1 & 59 & 59 & 118 \\
2 & 61 & 61 & 122 \\
\hline Total & 120 & 120 & 240 \\
\hline
\end{tabular}

Obs.: $\quad$ Grupo 1 - municípios com até 65 mil habitantes;

Grupo 2 - municípios com mais de 65 mil habitantes.

Fonte: Elaboração própria

Dada esta divisão de municípios, e mantendo-se o pareamento por escore de propensão feito, estima-se para cada grupo o efeito médio do tratamento sobre a probabilidade de reeleição para os tratados pelo método de Diferenças-em-Diferenças, conforme a tabela abaixo. 
Tabela 4.6 - Efeito da Expansão de Campi Universitários Federais sobre Reeleição

Política em 2008 por Grupo

\begin{tabular}{lccc}
\hline \multicolumn{4}{c}{ Estimação por Diferenças-em-Diferenças com Pareamento por Escore de Propensão } \\
\hline Método & $(1)$ & $(2)$ & $(3)$ \\
\hline Pareamento com suavização de reeleição dos controles & Não & Sim & Sim \\
\hline Pareamento com suavização de reeleição dos tratados & Não & Não & Sim \\
\hline Variável dependente: Partido Político Eleito em 2004 Vencedor em 2008 & & \\
Grupo 1 & 0,085 & 0,092 & $0,135^{* * *}$ \\
Número de Observações = 118 & $(0,079)$ & $(0,074)$ & $(0,036)$ \\
Grupo 2 & $0,118^{*}$ & 0,107 & 0,066 \\
Número de Observações = 122 & $(0,070)$ & $(0,096)$ & $(0,062)$ \\
\hline Variável dependente: Partido Político da Coligação Eleita em 2004 Vencedor em 2008 & \\
Grupo 1 & $0,24 * * *$ & $0,227 * * *$ & $0,202^{* * * *}$ \\
Número de Observações = 118 & $(0,070)$ & $(0,079)$ & $(0,065)$ \\
Grupo 2 & $0,304^{* * *}$ & $0,305 * * *$ & $0,329 * * *$ \\
Número de Observações = 122 & $(0,049)$ & $(0,111)$ & $(0,099)$ \\
\hline
\end{tabular}

Obs.: $\quad 1$ - Número de observações $=240$

2- O desvio-padrão está entre parênteses;

$* * * \mathrm{p}$-valor $<0,01, * * \mathrm{p}$-valor $<0,05, * \mathrm{p}$-valor $<0,1$;

3- A suavização da variável binária reeleição é feita usando função spline cúbica do escore de propensão;

4- A Coluna (1) faz o pareamento sem suavização da variável reeleição, a Coluna (2) segue a metodologia de Blundell et al (2004), e a Coluna (3) segue o proposto por Meghir e Palme (2003); 5- A estimação do desvio-padrão da Coluna (1) segue Abadie e Imbens (2006), e as estimações do desvio-padrão das Colunas (2) e (3) usam o método de bootstrap com 1000 replicações, com cluster por município.

Fonte: Elaboração própria

Pela tabela acima, percebe-se que os efeitos sobre reeleição do partido político do prefeito não são estatisticamente significantes para a maioria dos métodos de estimação. No modelo original, sem suavização, observa-se um efeito de $11,8 \%$ sobre a probabilidade de reeleição, a um nível de significância de 10\%, para os municípios com população acima de 65 mil habitantes. Considerando a aplicação de suavização sobre a variável reeleição, seguindo a metodologia de Blundell et at (2004), não é efeito estatisticamente significante. Já por Meghir e Palme (2003), constata-se efeito da implantação de campus universitário federal nos municípios sobre a probabilidade de reeleição de $13,5 \%$, a um nível de significância de $1 \%$, para o grupo com até 65 mil habitantes. 
Ao contrário do efeito da variável de reeleição do partido do prefeito, que se mostra dependente do método de estimação utilizado, ao se considerar o efeito da variável eleição em 2008 do partido pertencente à coligação vencedora na eleição de 2004, averígua-se que o efeito é robusto aos métodos de estimação. Para o grupo de municípios com até 65 mil habitantes, o efeito do tratamento sobre esta variável de reeleição está entre $20 \%$ e $24 \%$. Já para o grupo de municípios maiores, que receberam o tratamento, com tamanho populacional acima de 65 mil habitantes, o efeito da implantação de campus universitário federal sobe, sendo entre $30 \%$ e $33 \%$ sobre a probabilidade de eleição em 2008 do partido político constituinte da coligação da eleição anterior.

Ainda que estes municípios maiores, do ponto de vista econômico, não apresentem efeito do tratamento sobre a renda estatisticamente significante, como medido no capítulo anterior, os grupos políticos atuantes recebem benefícios políticos significativos. Neste grupo, o efeito-político do tratamento é mais expressivo do que o efeito econômico de curto prazo.

Conclui-se que, pelo modelo de escolha do tratamento, há indícios de influência política sobre a instalação de campus universitário federal em determinado município. Os grupos políticos responsáveis por esta influência exercem seu poder visando benefícios políticos futuros que se concretizam com a reeleição e sua manutenção no poder local.

\subsection{3- Análise de Sensibilidade}

Analisando-se a sensibilidade dos resultados estimados quanto a um eventual viés de seleção por não-observáveis, testam-se os efeitos médios estimados do tratamento sobre os tratados para diferentes níveis de viés omitido capazes de afetar as significâncias estatísticas. Com base na metodologia de limites de Rosenbaum, estimam-se os valores críticos $\Gamma$ que tornam os resultados estimados sensíveis à influência de fatores não-observáveis. 
Tabela 4.7 - Estimador da Análise de Sensibilidade ( $\Gamma$ ) para o Efeito do Tratamento sobre a Reeleição nos Municípios Tratados

\begin{tabular}{lccc}
\hline \multirow{2}{*}{ Sensibilidade para o Efeito sobre Reeleição } & \multicolumn{3}{c}{$\Gamma$} \\
\cline { 2 - 4 } & $\begin{array}{c}\text { Amostra } \\
\text { Inteira }\end{array}$ & Grupo 1 & Grupo 2 \\
\hline Partido Político Eleito em 2004 Vencedor em 2008 & 1,05 & 1,00 & 1,00 \\
Partido Político da Coligação Eleita em 2004 Vencedor em 2008 & 2,89 & 2,00 & 2,64 \\
\hline
\end{tabular}

Obs.: Os valores críticos correspondem ao valor de $\Gamma$ a um nível de significância de $10 \%$.

Fonte: Elaboração própria

Primeiramente, vale mencionar que a análise de sensibilidade dos efeitos médios do tratamento sobre a reeleição em 2008 do partido político eleito em 2004 nos municípios tratados, mostra elevada sensibilidade destes efeitos estimados quanto a eventual influência de variáveis não-observadas. Esta constatação vem ao encontro do que foi constatado nas estimações dos efeitos, que apresentaram grande sensibilidade na significância estatística quanto ao método de pareamento utilizado. De acordo com DiPrete e Gangl (2004), valores críticos de $\Gamma$ abaixo de 1,10 indicam forte influência de características não-observáveis sobre o efeito do tratamento. Portanto, conclui-se que os efeitos estimados sobre a reeleição de partido político eleito em 2004 não são robustos. Ainda assim é importante lembrar que a metodologia de limites de Rosenbaum representa o pior cenário quanto à influência de variáveis não-observáveis (DiPrete e Gangl, 2004).

Quanto ao efeito sobre a eleição em 2008 de partido político pertencente à coligação eleita em 2004, constata-se grande robustez dos resultados, uma vez que a influência das variáveis não-observadas deve ser acima de $100 \%$ sobre a razão de probabilidade da escolha do tratamento para que o efeito sobre a reeleição nos tratados deixe de ser estatisticamente significante. Especificamente, os resultados sobre a amostra inteira de municípios tratados estariam comprometidos apenas para influências de variáveis não-observadas a partir de $189 \%$ sobre a razão de probabilidade da escolha do tratamento, mostrando relevante robustez à heterogeneidade não-observada. Com relação aos resultados nas sub-amostras populacionais, o mesmo padrão de robustez é observado, destacando-se os resultados estimados para o grupo de municípios com população acima de 65 mil habitantes, nos quais, apenas uma razão de probabilidades a partir de 2,64 seria capaz de tornar o efeito estimado estatisticamente não-significante, ou seja, os fatores não-observados teriam que aumentar a razão de probabilidade em pelo menos $164 \%$ para que houvesse um viés omitido que 
comprometesse o efeito médio do tratamento sobre os municípios tratados. Já para o grupo de municípios tratados com população até 65 mil habitantes, a não-significância estatística do efeito estimado aconteceria se a razão de probabilidade fosse de pelo menos 2 .

Conclui-se então que a omissão de uma variável que influenciasse fortemente tanto a escolha do tratamento quanto a variável-resultado (reeleição de partido da coligação eleita em 2004) teria impacto sobre as conclusões apresentadas neste capítulo somente se tal influência alterasse a razão de probabilidade do tratamento em fatores acima de 2. Portanto, para esta variável-resultado, a análise de sensibilidade apresentada indica pouca influência de variáveis não-observadas sobre a robustez das resultados obtidos através da metodologia de pareamento com escore de propensão. 


\section{7- Conclusão}

A expansão das universidades federais nos municípios brasileiros envolveu não apenas critérios técnicos e estratégicos, mas também sofreu influência política. Esta influência na escolha do local de implantação de um novo campus, do ponto de vista político, deve-se principalmente à expectativa de benefícios políticos futuros que tal implantação poderia trazer aos considerados responsáveis pelo processo decisório.

Portanto, a instalação de um novo campus pode tanto ser efeito de influência política quanto causa de resultados políticos futuros, ou seja, um novo campus pode se transformar em benefício ao administrador público. Desta forma, este administrador busca maximizar sua função de utilidade que contempla a manutenção e expansão do poder político estabelecido, e toma uma série de decisões que terão impacto no resultado do processo eleitoral futuro.

Nos dois capítulos anteriores, a análise se norteou pelo foco no efeito econômico de curto prazo da expansão das universidades federais. Neste capítulo, busca-se estudar o impacto político desta expansão através do efeito da implantação de novo campus universitário federal no resultado eleitoral através da reeleição do partido ou coligação política que se encontra no poder.

A estimação do efeito do tratamento sobre a reeleição nos municípios tratados utiliza o método de Diferenças-em-Diferenças com Pareamento por Escore de Propensão, porém com a peculiaridade da variável-resultado (reeleição) ser binária. Esta aplicação do método é uma expansão do método apresentado no capítulo anterior e presente em Blundell et al (2004).

Para as eleições de 2008, as estimações indicam um efeito da implantação de um novo campus de $27 \%$ sobre a probabilidade de eleição de partido pertencente à coligação política vencedora das eleições de 2004. Este resultado cai para $10 \%$ se for considerado efeito sobre a probabilidade de reeleição do partido político do prefeito.

Analisando-se a heterogeneidade do efeito do tratamento sobre o escore de propensão, para a reeleição do partido político do prefeito, observa-se um padrão oscilatório ao redor de 10\%, com a ocorrência de efeitos negativos em alguns ranges de probabilidade de tratamento. Já para a reeleição em 2008 relacionada a qualquer partido político da coligação eleita em 2004, os municípios com probabilidade de tratamento até $65 \%$ apresentam um efeito-político 
sobre reeleição oscilatório ao redor de $15 \%$. Enquanto que, para municípios com elevada probabilidade de tratamento, acima de 70\%, há um efeito-político mais elevado, quase monotônico no escore de propensão.

Quando se analisa o efeito dentre os grupos populacionais (até 65 mil; e acima de 65 mil habitantes), observa-se que o efeito não é robusto considerando a reeleição do partido do prefeito, sendo dependente do método de estimação. Já para a eleição de partido político constituinte da coligação que venceu a eleição anterior, o efeito é por volta de $22 \%$ sobre a probabilidade de eleição em 2008 nos municípios menores, e de aproximadamente $31 \%$ nos municípios com população acima de 65 mil habitantes.

A análise de sensibilidade dos resultados quanto à eventual presença de viés de seleção por não-observáveis, mostra pouca robustez para o efeito sobre a probabilidade de reeleição em 2008 do partido político do prefeito, que também se mostra sensível à metodologia de pareamento. Já com relação à probabilidade de eleição em 2008 de partido pertencente à coligação política vencedora das eleições de 2004, aponta-se para significativa robustez dos resultados estimados.

Conclui-se, por fim, ainda que os maiores municípios tratados não apresentem efeitorenda significativo, seus agentes políticos recebem benefícios no que tange as eleições de 2008, justificando a influência política que venham a exercer sobre a decisão de implantação de um novo campus universitário federal nos locais onde possuem poder político. Assim, a implantação de um campus universitário em um município, além de ser influenciada politicamente, traz benefícios políticos aos partidos que se encontram no poder municipal no que tange a manutenção deste poder. 


\section{5- A EXPANSÃO E SEU IMPACTO REGIONAL}

No contexto em que o Plano de Desenvolvimento da Educação (PDE) se apresenta em reconhecimento da importância das universidades federais no desenvolvimento econômico e social do Brasil, este trabalho teve como principal objetivo estudar o impacto regional da expansão da rede de universidades federais ocorrida entre 2001 e 2010. Dado o fato desta expansão ser recente, o que é possível analisar de forma mais consistente é o seu impacto de curto prazo, que se apresenta de diversas formas. Em complemento à literatura de Educação, que analisa o impacto quantitativo e qualitativo da expansão sobre o sistema universitário, este trabalho analisou o impacto desta expansão do sistema universitário federal no nível microrregional e municipal, sob o âmbito econômico e político.

Com foco no curto prazo, este trabalho seguiu a literatura de impactos de universidades referentes às "relações para trás" (Backward linkages), ou seja, impactos de curto prazo devido a gastos como: despesas e investimentos diretos da universidade (implantação e manutenção de estabelecimentos); salários dos professores e funcionários universitários e respectivos impactos diretos sobre a demanda de bens e serviços; e os gastos dos estudantes (provenientes ou não da região).

Assim, abordou-se a questão da expansão recente da rede de universidades federais sob duas metodologias distintas. Na primeira, seguindo a literatura de impacto econômico de universidades, utilizou-se o método de Insumo-Produto, com base na informação de variação de gastos públicos federais anuais disponibilizados pelo SIAFI entre os anos de 2004 e 2010. $\mathrm{Na}$ segunda metodologia, entendendo-se a expansão do número de campi universitários federais como um tratamento de política pública sobre os municípios; utilizaram-se técnicas econométricas para estimar o efeito do tratamento sobre os municípios tratados. Dentro desta metodologia, estudou-se não apenas o efeito econômico sobre a renda domiciliar per capita municipal, mas também o efeito político sobre a probabilidade de eleição em 2008 do partido político do prefeito e de partidos pertencentes à coligação política deste partido na eleição anterior em 2004.

No Capítulo 2, teve-se como base a Matriz de Insumo-Produto microrregionalizada de 2004 com 558 microrregiões e 55 setores, num total de 30.690 microrregiões-setores de 
Insumo-Produto, resultando em uma matriz com 941.876.100 elementos. Baseando-se no modelo de Insumo-Produto, foram consideradas as variações positivas de gastos federais para o cálculo dos choques anuais, para cada um dos 6 anos (de 2005 a 2010). Desta forma, para cada ano e para cada uma das 59 universidades federais, aplicou-se uma matriz de choques microrregionais na demanda sobre o setor Educação Pública, totalizando um montante de choques de $\mathrm{R} \$ 5,3$ bilhões, abertos em 6 anos e 32.922 pares de microrregiões-universidades.

Do ponto de vista nacional, estimou-se um efeito da expansão universitária federal de $\mathrm{R}$ \$ 19,9 bilhões sobre valor bruto da produção, $\mathrm{R}$ \$ 11,5 bilhões sobre o PIB, (efeito de 0,4\% sobre o PIB de 2004), e aumento de 467 mil pessoas ocupadas. A região Sudeste, que recebeu o maior percentual do choque, apresentou os maiores impactos sobre produção e valor adicionado, mas foi a segunda com relação a pessoal ocupado, ficando atrás da região Nordeste.

Tal resultado é reflexo dos maiores efeitos econômicos do estado de São Paulo para produção e valor adicionado. Para pessoal ocupado, o estado com maior impacto foi Minas Gerais, seguido por São Paulo, mas com os estados da região Nordeste também se destacando. No nível microrregional, confirmou-se a evidência da literatura sobre impactos de universidades e destacada em Stokes e Coomes (1998) que no curto prazo as universidades localizadas em pequenas comunidades apresentam os maiores impactos econômicos. Assim, neste trabalho conclui-se que as microrregiões menores do ponto de vista econômico apresentaram os maiores efeitos relativos da expansão de gastos com universidades federais.

As universidades com maiores impactos sobre produção e valor adicionado foram a UNIFESP, a UFRJ e a UNB. Já sobre pessoal ocupado, vale destacar a UFCE e a UFPI na região Nordeste e a UFPA na região Norte. Com relação às universidades criadas no período analisado, destacou-se a UFABC na região Sudeste pelos maiores efeitos sobre produção e valor adicionado, e a UFRB e a UFCG, ambas na região Nordeste, pelos maiores efeitos sobre pessoal ocupado. Como no nível regional, vale ressaltar o significativo efeito sobre pessoal ocupado das universidades localizadas na região Nordeste, não vindo acompanhado por elevados resultados sobre valor bruto da produção e valor adicionado. Tal fato provavelmente guarda relação com a menor produtividade da mão-de-obra nesta região em comparação à região Sudeste. Além disso, também está relacionado com uma maior presença de empresas tradicionais e mais intensivas em mão-de-obra na região Nordeste. 
Analisando-se o efeito setorial, os setores de serviços, em especial o de Comércio, se destacam pelos maiores impactos nas variáveis econômicas, ressaltando-se o elevado efeito induzido sobre a renda das famílias. Vale também destacar, o setor de Alimentos e Bebidas, com o maior efeito sobre produção, e o setor de Agricultura, Silvicultura e Exploração Florestal, com o segundo maior efeito sobre pessoal ocupado.

Considerando-se a estrutura produtiva da economia brasileira e sua relação com o setor Educação Pública, constatou-se que este setor foi o que mais cresceu em importância, por ser demandante dos demais setores da economia. Apesar de não se destacar como um setor-chave, isto não significa que investimentos no setor Educação Pública tenham efeitos insignificantes, visto que no longo prazo possuem um forte potencial de alteração das condições de oferta regional sobre capital humano e tecnologia. Adicionalmente, vale ressaltar o potencial de geração de emprego deste setor, com significativo efeito sobre as rendas das famílias, além da constatação de aumento da importância dos setores de serviços na economia brasileira.

No Capítulo 3, utilizou-se uma nova metodologia para tratar a questão da expansão universitária federal no Brasil. Sob a literatura de econometria de efeito do tratamento sobre os tratados, considerou-se a expansão pela construção de novos campi universitários federais como um tratamento de política pública, em que os municípios participantes receberam investimentos públicos, através da implantação de um novo campus, que impactaram sobre os resultados econômicos regionais.

Vale ressaltar que, até onde se pôde verificar, nenhum estudo na literatura de impacto econômico de universidade utilizou esta metodologia econométrica de efeito do tratamento sobre os tratados. Destaca-se então o caráter inédito deste trabalho ao estimar o efeito médio de curto prazo da expansão de campi universitários federais sobre os municípios tratados, através de técnicas econométricas.

Especificamente, o mencionado capítulo estimou este efeito através do método de Diferenças-em-Diferenças com Pareamento por Escore de Propensão. Foram utilizadas três metodologias para a estimação deste efeito, por causa da não-suavização do pareamento utilizado. Primeiramente, estima-se o efeito desconsiderando esta questão, como em Peixoto, Andrade e Azevedo (2008). Na segunda metodologia, efetua-se o pareamento com suavização da renda dos municípios controles, seguindo Blundell et al (2004). Por fim, faz-se um 
pareamento com suavização das rendas dos tratados e controles, conforme Meghir e Palme (2003).

Dada a base de dados utilizada, estas três metodologias apresentam resultados muito próximos, apontando para um efeito médio do tratamento de 3,3\% sobre a renda domiciliar per capita dos municípios tratados. Com relação à heterogeneidade, seguindo Xie, Brand e Jann (2012), o efeito do tratamento é mais intenso nos municípios que apresentam as maiores probabilidades de receberem um campus universitário federal.

Assim como no Capítulo 2, também se confirmou a evidência da literatura sobre impactos de universidades no curto prazo que argumenta que as universidades localizadas em pequenas comunidades provocam os maiores impactos econômicos. Para tanto, os municípios tratados foram distribuídos em dois grupos de acordo com o tamanho da população, da seguinte forma: Grupo 1, municípios com até 65 mil habitantes; Grupo 2, municípios com mais de 65 mil habitantes. Os resultados estimados mostraram um efeito maior sobre o primeiro grupo, que tem os menores municípios, apresentando efeito médio do tratamento sobre os tratados de 5,3\% sobre a renda domiciliar per capita municipal. Já o Grupo 2 não apresentou efeito estatisticamente significante.

Com isso, constata-se que o programa de expansão de universidades federais, no que tange a construção de novos campi, teve impacto de curto prazo sobre a renda domiciliar per capita dos municípios que receberam estes campi, destacando-se os municípios com menor tamanho populacional que apresentam efeito $60 \%$ maior do que a média dos municípios tratados.

Analisando-se apenas as microrregiões que receberam novos campi no Capítulo 2, encontra-se um efeito médio anualizado de $0,16 \%$ sobre o PIB per capita microrregional. Agregando-se a renda municipal para microrregional no Capítulo 3, chega-se a um efeito médio anualizado de $0,27 \%$ sobre a renda domiciliar per capita microrregional. Tal diferença nos resultados se deve à utilização de diferentes metodologias, ao tipo de variável de tratamento utilizada e especialmente pelo fato da variável-resultado ser diferente, visto que no Capítulo 2 trabalha-se com tratamento contínuo e resultado em valor adicionado e no Capítulo 3 com tratamento binário e resultado em renda domiciliar per capita.

O Capítulo 4 deste trabalho trata de outro aspecto relacionado à implantação de um novo campus universitário em um município: a questão política. Observa-se que a expansão 
das universidades federais nos municípios envolveu não somente aspectos técnicos e estratégicos, mas também políticos. Isto ocorreu principalmente devido à expectativa de benefícios políticos futuros que a implantação de um novo campus poderia trazer aos considerados responsáveis pelo processo decisório no nível local. Desta forma, entende-se que o administrador político poderia influenciar a decisão de implantação, como também angariar benefícios em processos eleitorais futuros.

Com vista neste aspecto, desloca-se o foco do efeito econômico de curto prazo da expansão para o efeito político, através do estudo do impacto da implantação de um novo campus sobre o resultado eleitoral em 2008 relativo à reeleição do partido do prefeito ou eleição de algum partido pertencente à coligação política que elegeu o prefeito na última eleição. Para tanto, utilizaram-se as mesmas metodologias econométricas do Capítulo 3, mas com a especificidade da variável-resultado (reeleição) ser binária.

Neste contexto, os resultados apontaram para efeitos maiores sobre a variávelresultado do que os encontrados no Capítulo 3. Especificamente, estimou-se um efeito médio de $10 \%$ sobre a probabilidade de reeleição do partido político do prefeito. Considerando-se a eleição em 2008 de qualquer partido político pertencente à coligação vencedora na eleição de 2004, estima-se um efeito de $27 \%$ adicionalmente sobre a probabilidade de eleição.

No que diz respeito à heterogeneidade sobre a distribuição da probabilidade de receber campus universitário federal, para a reeleição do partido político do prefeito, constata-se um padrão oscilatório ao redor de $10 \%$ com a ocorrência de efeitos negativos em alguns pontos desta distribuição. Já considerando a reeleição relacionada à eleição de 2008 de qualquer partido político da coligação eleita em 2004, percebe-se uma evolução do efeito sobre a probabilidade do tratamento mais próxima à monotonicidade, destacando-se os municípios com esta probabilidade acima de $70 \%$, que apresentam maiores efeitos políticos.

Enquanto que o efeito econômico da expansão das universidades federais foi maior para os menores municípios, o efeito político não apresentou o mesmo comportamento. Aparentemente, este efeito se mostrou crescente no tamanho populacional dos municípios, quando foi considerada a eleição em 2008 de partido político da coligação eleita em 2004. Tal efeito é por volta de $22 \%$ para o grupo de municípios com até 65 mil habitantes, e de $31 \%$ para aqueles com população acima de 65 mil habitantes. Já para o caso da reeleição do partido político do prefeito, observa-se um efeito sensível à metodologia utilizada, pouco podendo se concluir a respeito. 
Assim, conclui-se que, para o caso dos municípios tratados maiores do ponto de vista populacional, os resultados não apresentam efeito de curto prazo do tratamento sobre a renda estatisticamente significativo. Entretanto, há indícios de que os partidos políticos da coligação eleita recebem benefícios políticos significantes nestes municípios, justificando suas influências políticas sobre o processo decisório de implantação de um campus universitário federal no município onde detêm o poder político.

Alguns pontos podem ser mencionados como potenciais para futuros estudos. Primeiramente, vale citar a abertura de um subsetor Educação Superior Federal na matriz de Insumo-Produto microrregionalizada, o que requereria, por exemplo, uma gama de informações detalhadas sobre a estrutura de custos das universidades federais. Tal informação no nível de detalhe necessário inexiste nas bases de dados disponibilizadas pelo IBGE, MEC e SIAFI. Além disso, vale mencionar os problemas de alocação de despesas nas contas públicas disponibilizadas pelo SIAFI, com predomínio de despesas centralizadas nas sedes das universidades federais, o que impossibilitou a utilização da informação do municípiodestino das despesas. Para solucionar esta questão, foi necessário distribuir as despesas com base nas matrículas anuais informadas pelo Censo do Ensino Superior. Entretanto, a alocação correta das despesas nos municípios destinatários resolveria a questão, aumentando a qualidade, confiabilidade e transparência das informações sobre despesas públicas federais.

Com relação aos capítulos com métodos econométricos, uma questão a ser levantada diz respeito à intensidade do tratamento, uma vez que os impactos estimados neste trabalho representaram os efeitos médios para o período, mas é conhecido que alguns campi foram criados no meio do período e outros no final. Para tanto, isto requereria a informação sobre o ano exato de implantação de cada campus. Esta informação atualmente não é disponibilizada ao público pelo Ministério da Educação, sabe-se apenas se o campus foi ou não implantado no período de expansão da rede de universidades federais. Todavia, é possível que haja problemas de consistência em eventuais estimações com esta abertura visto que o número de tratados no período é pequeno e consequentemente o número em cada ano seria ainda menor. Ainda assim, o ano de implantação apresentaria grande contribuição com relação ao efeito político, podendo-se retirar da amostra de tratados, os municípios que receberam campus universitário federal em 2009 e 2010, após as eleições municipais de 2008. Especificamente sobre o Capítulo 3, pode-se expandir a análise, estimando-se o impacto sobre somente os residentes que já se encontravam no município antes do período de expansão analisado, com base nos dados do Censo Demográfico do IBGE do ano de 2000. Desta forma, tem-se o 
impacto sobre os moradores já presentes antes da expansão, levando-se em conta questões relacionadas à migração. Outra contribuição relevante aos Capítulos 3 e 4 seria o acréscimo de outras variáveis explicativas nos modelos utilizados.

Além destes pontos, em conjunção com a literatura de Educação, podem-se mencionar como assuntos de potenciais futuros estudos: a comparação entre o efeito das universidades públicas e das privadas; a importância da expansão dos cursos diurnos para o período noturno; a discussão entre universidade de ensino e universidade de ensino e pesquisa; a questão da formação do corpo docente num cenário de expansão da rede de universidade federais; dentre outros.

Por fim, espera-se que este trabalho venha a contribuir à literatura de impacto de universidades. Primeiramente, por estudar o impacto da expansão universitária federal ocorrida recentemente no Brasil ao invés do impacto de todo o sistema. Com relação ao método de Insumo-Produto, este trabalho detalhou os efeitos ao distribuí-los por microrregião, setor, universidade e ano, indo além da análise nacional ou de uma universidade específica, como comumente encontrado da literatura de impacto de universidades. Considerando a metodologia econométrica, poucos estudos no mundo utilizam alguma técnica econométrica para estimar o impacto de curto prazo de universidades. Este trabalho apresenta uma nova forma de abordar o assunto, utilizando o método econométrico de efeito médio do tratamento sobre os tratados através do método de Diferenças-em-Diferenças com Pareamento por Escore de Propensão. Além destas contribuições, este trabalho complementa a literatura de Educação ao apresenta resultados empíricos sobre a questão da expansão das universidades públicas federais no Brasil. 


\section{REFERÊNCIAS}

ABADIE, A.; DRUKKER, D.; HERR. J.; IMBENS, G. Implementing Matching Estimators for Average Treatment Effects in Stata. The Stata Journal. v.4, Number 3, p. 290-311. 2004.

ABADIE, A.; IMBENS, G. On the Failure of the Bootstrap for Matching Estimators. Econometrica, vol. 76(6), p. 1537-1557. 2008.

Large Sample Properties of Matching Estimators for Average Treatment Effects.

Econometrica, vol. 74(1), p. 235-267. 2006.

AGÉNOR, P. Fiscal Policy and Endogenous Growth with Public Infrastructure. Discussion Paper Series. Centre for Growth and Business Cycle Research, Economic Studies, University of Manchester. 2005.

ALESINA, A. Macroeconomic Policy in a Two-Party System as a Repeated Game. The Quarterly Journal of Economics. The MIT Press, vol. 102(3), pages 651-78, August. 1987.

AlEsinA, A.; ROUBINI, N.; COHEN, G. Political Cycles and the Macroeconomy. The MIT Press. 302p., November. 1997.

AlESINA, A.; TABELlinI, G. A Positive Theory of Fiscal Deficits and Government Debt. Review of Economic Studies. Wiley Blackwell, vol. 57(3), p. 403-14, July. 1990.

ANDIFES - Associação Nacional dos Dirigentes das Instituições Federais de Ensino Superior. Disponível em: <http://www.andifes.org.br>. Acesso em: 01/12/2011.

ARAUJO, M.; PINHEIRO, H. Reforma Gerencial do Estado e Rebatimentos no Sistema Educacional: um exame do REUNI. Ensaio: Avaliação e Políticas Públicas em Educação. vol.18, n.69, p. 647-668. 2010.

ARAUJO JUNIOR, A.; CANÇADO, P.; SHIKIDA, C. Economics and Politics: o que determina as chances de reeleição em municípios? O caso das eleições municipais de Minas Gerais - 2000. Informe Gepec. Toledo-PR, v. 09, n.2. 2005.

ARIK, M. Higher Education Institutions in Middle Tennessee: An In-Depth Analysis of Their Impact on the Region from a Comparative Perspective. Studies 200705. Middle Tennessee State University, Business and Economic Research Center. 2007.

BARRO, R. Government Spending in a Simple Model of Endogenous Growth. Journal of Political Economy, Vol. 98, No. 5, Part 2: The Problem of Development: A Conference of the Institute for the Study of Free Enterprise Systems (Oct., 1990), p. S103-S125. 1990.

BARRO, R.; SALA-i-MARTIN, X. Public Finance in Models of Economic Growth. The Review of Economic Studies. V.59 issue 4, p. 645-661. 1992.

BAUMOL, W. Productivity Growth, Convergence, and Welfare: What the Long-run Data Show. American Economic Review, vol. 76(5), p. 1072-85, December. 1986. 
BECKER, S.; ICHINO, A. Estimation of Average Treatment Effects based on Propensity Scores. The Stata Journal. V.2, Number 4, p. 358-377. 2002.

BERNAT, A. Does Manufacturing Matter? A spatial econometric view of Kaldor's laws. Journal of Regional Science, vol. 36, p. 463-477. 1996.

BLUNDELL, R.; DIAS, M.; MEGHIR, C.; REENEN, J. Evaluating the Employment Impact of a Mandatory Job Search Program. Journal of the European Economic Association. MIT Press. Vol. 2 (4), p. 569-606. 2004.

BOOTH, G.; JARRETT, J. The Identification and Estimation of a University's Economic Impacts. The Journal of Higher Education. Vol. 47, number 5, p. 565-576. 1976.

BUCCI, A., FLORIO, M. e LA TORRE, D. Transitional Dynamics in a Growth Model with Government Spending, Technological Progress and Population Change. First Milan Workshop on Dynamics, Optimal Growth and Population Change: Theory and Applications. 2008.

BUGARIN, M.; FERREIRA, I. Transferências Voluntárias e Ciclo Político-Orçamentário no Federalismo Fiscal Brasileiro. Revista Brasileira de Economia, 61(3), 271-300. 2007.

CALIEDO, M. e KOPEINIG, S. Some Practical Guidance for the Implementation of Propensity Score Matching. IZA. Discussion Paper No. 1588. 2005.

CÂNDIDO, J. Os Gastos Públicos no Brasil São Produtivos? IPEA. Texto para Discussão no. 781. Brasília-DF. 2001.

CARVAlHO, C. A Política Pública para a Educação Superior no Brasil (1995-2008): Ruptura e/ou Continuidade? Campinas, 2011. Tese (Doutorado em Economia) - Instituto de Economia da Universidade Estadual de Campinas. 441 p.

CARVAlho, T. A Hipótese da Curva de Kuznets Ambiental Global e o Protocolo de Quioto. Juiz de Fora, 2008. Dissertação (Mestrado em Economia) - Universidade Federal de Juiz de Fora.

CHAGAS, A. Três Ensaios sobre o Setor Produtor de Cana-de-Açúcar no Brasil. São Paulo, 2009. Tese (Doutorado em Economia) - Programa de Pós-Graduação em Economia, Faculdade de Economia, Administração e Contabilidade da Universidade de São Paulo.

CHAVES, V.; ARAÚJO, R. Politica de Expansão das Universidades Federais via Contrato de Gestão - uma análise da implantação do REUNI na Universidade Federal do Pará. Revista Universidade e Sociedade. Ano XXI, n.48, p. 64-75. 2011.

CORSEUIL, C. H.; FOGUEL, M. N. Uma Sugestão de Deflatores para Rendas Obtidas a Partir de Algumas Pesquisas Domiciliares do IBGE. IPEA Texto para Discussão, no 897. Rio de Janeiro: Ipea. 2002. 
D'ALLEGRO, M.; PAFF, L. Estimating the Economic Impact of Higher Education: A Case Study of the Five Colleges in Berks County, Pennsylvania. Association for Institutional Research. Professional File. No. 117, 17p. 2010.

DIPRETE, T.; GANGL, M. Assessing Bias in the Estimation of Causal Effects: Rosenbaum Bounds on Matching Estimators and Instrumental Variables Estimation with Imperfect Instruments. Sociological Methodology. Vol. 34(1), p. 271-310, December. 2004.

DOWNS, A. An Economic Theory of Democracy. New York: Harper and Row. 310p. 1957.

DUFLO, E. Schooling and Labor Market Consequences of School Construction in Indonesia: Evidence from an Unusual Policy Experiment. American Economic Review, American Economic Association, vol. 91(4), p. 795-813, September. 2001.

DUFLO, E.; PANDE, R. DAMS. The Quarterly Journal of Economics, MIT Press, vol. 122(2), pages 601-646, 05. 2007.

ELLIOT, D.; LEVIN, S.; MEISEL, J. Measuring the Economic Impact of Institutions of Higher Education. Research in Higher Education. Vol. 28, number 1, p. 17-33. 1988.

FELSENSTEIN, D. The University in the Metropolitan Arena: Impacts and Public Policy Implications. Urban Studies, vol. 33, p. 1565-1580, November. 1996.

FINGLETON, LÓPEZ-BAZO, E. Empirical Growth Models with Spatial Effects. Papers in Regional Science, vol. 85 (2), p. 177-198, June. 2006.

FRANCO, M.; MOROSINI, M.; OLIVEN, A.; DEUS, M.; RIBEIRO, C. Expansão da Educação Superior e Arquiteturas Acadêmicas: tensões e conflitos. Série Estudos, UCDB, n.30, jul/dez, p.117-139. 2010.

FUJITA, M.; KRUGMAN, P.; VENABLES, A. The Spatial Economy: cities, regions, and international trade. The MIT Press, Cambridge MA. 1999.

GALIANI, S.; GERTLER, P.; SCHARGRODSKY, E. Water for Life: The Impact of the Privatization of Water Services on Child Mortality. Journal of Political Economy, University of Chicago Press, vol. 113(1), p. 83-120, February. 2005.

GANA, R. Econometric Estimation of the Economic Impact of a University. Association for Institutional Research. 1993 Annual Forum Paper. 1993.

GARRIDO-YSERTE, R.; GALLO-RIVERA, M. The Impact of the University upon Local Economy: Three Methods to Estimate Demand-Side Effects. The Annals of Regional Science, Springer, vol. 44(1), pages 39-67, February. 2010.

GODDARD, J.; KEMPTON, L. Connecting Universities to Regional Growth: A Practical Guide. Brussels: European Commission. 2011.

GOLDSTEIN, H.; DRUCKER, J. The Economic Development Impacts of Universities on Regions: Do Size and Distance Matter? Economic Development Quarterly, vol. 20, p. 2243, February. 2006. 
GONÇALVES, E. Estrutura Urbana e Atividade Tecnológica em Minas Gerais. Economia Aplicada, vol. 10(4), p. 481-502. 2006.

GOVERNO DO ESTADO DE SÃO PAULO. Orçamento do Estado 2010. Elaborado pela Secretaria de Economia e Planejamento do Estado de São Paulo. 688p. 2010.

GOVERNO FEDERAL. Site da Câmara dos Deputados. Banco de dados disponível em: $<$ http://www2.camara.gov.br/atividade-legislativa/orcamentobrasil/orcamentouniao/loa /execucao.html>. Acesso em: 15/04/2012.

GUILHOTO, J. Análise de Insumo-Produto: teoria, fundamentos e aplicações. Livro em elaboração. Departamento de Economia, FEA-USP. 2009.

GUILHOTO, J.; HEWINGS, G.; SONIS, M. Interdependence, Linkages and Multipliers in Asia: an international input-output analysis. Artigo Apresentado no V Summer Institute of the PRSCO of the RSAI, Nagoya, Japão. 1997.

GUILHOTO, J; SESSO FILHO, U. Estimação da Matriz Insumo-Produto Utilizando Dados Preliminares das Contas Nacionais: Aplicação e Análise de Indicadores Econômicos para o Brasil em 2005. Economia e Tecnologia. UFPR/TECPAR. Ano 6, Vol 23, p. 53-62. 2010.

Estimação da Matriz Insumo-Produto a partir de Dados Preliminares das Contas Nacionais. Economia Aplicada, vol. 9 (2), p. 277-299, abril-junho. 2005.

HARRIS, R. The Impact of the University of Portsmouth on the Local Economy. Urban Studies, vol. 34, p. 605-626, April. 1997.

HARVARD UNIVERSITY. Annual Fiscal Report of Harvard University. Fiscal Year 20102011. 47p. 2010.

HECKMAN, J.; ICHIMURA, H.; TODD, P. Matching as an Econometric Evaluation Estimator. Review of Economic Studies, vol. 65, p. 261-94, April. 1998.

Matching as an Econometric Evaluation Estimator: Evidence from Evaluating a Job Training Programme. Review of Economic Studies, vol. 64, pages 605-54, October. 1997.

HECKMAN, J.; ICHIMURA, H; SMITH, J.; TODD, P. Characterizing Selection Bias Using Experimental Data. Econometrica, vol. 66(5), p. 1017-1098, September. 1998.

HEO, U. The Relationship between Defense Spending and Economic Growth in the United States. Political Research Quarterly, Vol. 63, No. 4, p. 760-770. 2010.

HIBBS, D. Political Parties and Macroeconomic Policy. The American Political Science Review. Vol. 71, No. 4 (Dec., 1977), p. 1467-1487. 1977.

KELLY, U.; MCLELLAN, D.; MCNICOLL, I. The Impact of Universities on the UK Economy. Fourth Report. London: Universities UK. 2009. 
LÉDA, D.; MANCEBO, D. REUNI: heteronomia e precarização da universidade e do trabalho docente. Educação e Realidade, vol.34, n.1, p. 49-64. 2009.

LIMA, L.; AZEVEDO, M.; CATANI, A. O Processo de Bolonha, a Avaliação da Educação Superior e Algumas Considerações sobre a Universidade Nova. Avaliação (Campinas), vol.13, n.1, p. 7-36. 2008.

LIU, H.; POLENSKE, K.; GUILHOTO, J. China and Brazil Productive Structure and Economic Growth Compared: 1980's to 2000's. Paper presented at 57th Annual North American Meetings of the Regional Science Association International. Denver, USA, November. 2010.

LUGÃO, R.; ABRANTES, L.; BRUNOZI JR., A.; DA SILVA, F.; DE SOUZA, A. Reforma Universitária no Brasil: uma análise dos documentos oficiais e da produção científica sobre o REUNI - Programa de Apoio a Planos de Reestruturação e Expansão das Universidades Federais. X Coloquio Internacional sobre Gestión Universitaria en América del Sur. Dezembro. Mar del Plata, Argentina. Disponível em: <http://www.inpeau.ufsc.br/wp/v1 /detalhe-artigos.php?id=1386>. 2010. Acesso em 01/11/2012.

MANCEBO, D. Reforma da Educação Superior: o debate sobre a igualdade no acesso. In: BITTAR, Mariluci; OLIVEIRA, João Ferreira de; MOROSINI, Marília (Orgs.). Educação Superior no Brasil: 10 anos pós-LDB. Brasília-DF, Inep. p. 55-70. 2008.

MANKIW, N.; ROMER, D.; WEIL, D. A Contribution to the Empirics of Economic Growth. The Quarterly Journal of Economics, vol. 107(2), p. 407-37, May. 1992.

MANSKI, C. Identification for Prediction and Decision. Cambridge: Harvard University Press. 2007.

MEC - Ministério da Educação. Diretrizes Gerais: Documento Complementar. Diretoria de Desenvolvimento das instituições Federais de Ensino Superior. Brasília-DF. 14p. 2007.

O Plano de Desenvolvimento da Educação: Razões, Princípios e Programas. Brasília-DF. 43p. 2008.

Reuni 2008 - Relatório de Primeiro Ano. Diretoria de Desenvolvimento das instituições Federais de Ensino Superior. Brasília-DF. 17p. 2009.

MEGHIR, C.; PALME, M. Ability, Parental Background and Educational Policy: empirical evidence from a social experiment. IFS Working Papers W03/05, Institute for Fiscal Studies. 2003.

MENEGUIN, F.; BUGARIN, M.; CARVALHO, A. O que Leva um Governante à Reeleição? IPEA Textos para discussão $-\mathrm{n}^{\circ} 1135.2005$.

MILLER, R.; BLAIR, P. Input-Output Analysis: Foundations and Extensions. Second Edition. Cambridge: Cambridge University Press. 2009.

NADAL, R.; MARTINS, R. Efeitos de Mudanças Liberalizantes da Conta de Capital sobre o Crescimento: uma abordagem de avaliação de políticas públicas. Anais da ANPEC. 2010. 
NORDHAUS, W. The Political Business Cycle. Review of Economic Studies: no 42, p. 169190. 1975.

PARSONS, R.; GRIFFITHS, A. A Micro Economic Model to Assess the Economic Impact of Universities: A Case Example. Association for Institutional Research. Professional File. No. 87, 24p. 2003.

PEIXOTO, B., ANDRADE, M.; AZEVEDO, J. Prevenção e Controle de Homicídios: uma Avaliação de Impacto no Brasil, Textos para Discussão Cedeplar - UFMG, Cedeplar, Universidade Federal de Minas Gerais. 31p. 2008.

PERSSON, T.; TABELlinI, G. Macroeconomic Policy, Credibility and Politics. Harwood Academic Publishers. 187p. 1990.

RACINE, J. S. A Primer on Regression Splines. CRAN.R-Project. Disponível em: $<$ http://cran.r-project.org/web/packages/crs/vignettes/spline_primer.pdf>. 2012. Acesso em: 09/06/2013.

RAM , R. Government Size and Economic Growth: A New Framework and Some Evidence from Cross-Section and Time-Series Data. The American Economic Review, Vol. 76, No. 1 (Mar., 1986), p. 191-203. 1986.

RBEP - Revista Brasileira de Estudos Pedagógicos. Relatório do Grupo de Trabalho sobre Financiamento da Educação. Brasília-DF. 19p. 2001.

REY, S.; MONTOURI, B. US Regional Income Convergence: A Spatial Econometric Perspective. Regional Studies, vol. 33(2), p. 143-156. 1999.

ROGOFF, K. Equilibrium Political Budget Cycles. The American Economic Review, vol. 80 (1), p. 21-36. 1990.

ROGOFF, K.; SIBERT, A. Elections and Macroeconomic Policy Cycles. Review of Economic Studies, n. 55, p. 1-16. 1988.

ROLIM, C.; KURESKI, R. Impacto Econômico de Curto Prazo das Universidades Federais na Economia Brasileira. Artigo apresentado no XIII Encontro Regional de Economia. Anais da ANPEC Sul. Porto Alegre-RS, Agosto 11-13. 2010.

ROSENBAUM, P. Observational Studies. Second Edition. New York: Springer. 2002.

ROSENBAUM, P.; RUBIN, D. The Central Role of the Propensity Score in Observational Studies for Causal Effects. Biometrika, 70(1), p. 41-55. 1983.

ROYSTON, P.; SAUERBREI, W. Multivariable Modeling with Cubic Regression Splines: A Principled Approach. The Stata Journal, vol. 7 (1), p. 45-70. 2007.

SEN, A. Development as Freedom. New York: Alfred A. Knopf. 1999. 
SIEGFRIED, J.; SANDERSON, A.; MCHENRY, P. The Economic Impact of Colleges and Universities. Economics of Education Review, Elsevier, vol. 26(5), pages 546-558, October. 2007.

SMITH, R.; PRICE, J.; HOWSER, L. A Smooting Algorithm Using Cubic Spline Functions. Langley Research Center (NASA - National Aeronautics and Space Administration), February; 87p. 1974.

STOKES, K.; COOMES, P. The Local Economic Impact of Higher Education: an overview of methods and practice. Association for Institutional Research (AIR), Professional File, number 67, Spring; 16p. 1998.

VÝROSTOVÁ, E.; VÝROST, T. Measuring the Role of Universities in Regional Development. Technical University of Košice, Faculty of Economics - 2nd Central European Conference in Regional Science - CERS, 2007. p. 1141 - 1149. 2007.

WANG, H. Institutions of Higher Education and the Regional Economy: A Long-Term Spatial Analysis. Economics Research International. 19p. 2010.

XIE, Y.; BRAND, J., JANN, B. Estimating Heterogeneous Treatment Effects with Observational Data. Sociological Methodology, vol. 42(1), p. 314-347. 2012.

ZHOU, X.; XIE, Y. Propensity-Score-Based Methods versus MTE-Based Methods in Causal Inference. Population Studies Center Research Report no. 11-747. University of Michigan. December. Sociological Methods and Research (Forthcoming). 49p. 2011. 


\section{APÊNDICES}

APÊNDICE A - HISTÓRICO DAS UNIVERSIDADES CRIADAS NO PERÍODO 20012010

APÊNDICE B - MÉTODO DE MÍNIMOS QUADRADOS APLICADO À FUNÇÃO SPLINE CÚBICA

APÊNDICE C - APÊNDICE DO CAPÍTULO 1

APÊNDICE D - APÊNDICE DO CAPÍTULO 2

APÊNDICE E - APÊNDICE DO CAPÍTULO 3

APÊNDICE F - APÊNDICE DO CAPÍTULO 4 


\section{APÊNDICE A - HISTÓRICO DAS UNIVERSIDADES CRIADAS NO PERÍODO 2001-2010}

São descritas sucintamente aqui as universidades criadas no período de 2001 a $2010 .{ }^{40}$

\section{Universidade Federal do Tocantins $\left(\right.$ UFT) ${ }^{41}$}

A Universidade Federal do Tocantins, apesar de ter sido criada em 23 de outubro de 2000, sendo anterior ao período de 2001 a 2010, teve suas atividades efetivadas em maio de 2003, com a posse dos primeiros professores efetivos. A UFT nasceu com a missão de se tornar um diferencial na educação e no desenvolvimento de pesquisas e projetos inseridos no contexto socioeconômico e cultural do Estado do Tocantins.

A educação na UFT é desenvolvida, prioritariamente, por meio de seus cursos de graduação e licenciaturas. Além disso, vale destacar outras atividades como extensão e pesquisa. A UFT oferece oportunidade de formação nas áreas das Ciências Sociais Aplicadas, Humanas, Educação, Agrárias e Ciências Biológicas, com campi universitários nas seguintes cidades: Araguaína, Arraias, Gurupi, Miracema, Palmas (sede), Porto Nacional, e Tocantinópolis.

\section{Universidade Federal de Campina Grande (UFCG)}

A Universidade Federal de Campina Grande (UFCG) é uma instituição de ensino superior, pública e federal, criada pela Lei $\mathrm{n}^{\mathrm{o}} 10.419$ de 9 de abril de 2002. Sua criação ocorreu a partir do desmembramento da Universidade Federal da Paraíba (UFPB). Tem a sua sede em Campina Grande-PB. Compõem ainda o universo dessa instituição seis outros campi localizados nos seguintes municípios do Estado da Paraíba: Pombal, Patos, Sousa, Cajazeiras, Cuité, e Sumé.

\footnotetext{
${ }^{40}$ As informações apresentadas foram extraídas dos endereços eletrônicos oficiais de cada universidade.

${ }^{41}$ A Universidade Federal do Tocantins (UFT), que foi credenciada no final do ano de 2000, mas iniciou suas atividades apenas em 2003. Por isso, optou-se por acrescentá-la ao grupo de novas universidades, apresentandose então neste apêndice o seu histórico.
} 


\section{Universidade Federal Rural da Amazônia (UFRA)}

A Universidade Federal Rural da Amazônia (UFRA) é uma instituição pública federal de ensino superior com sede na cidade de Belém-PA, e campi nos municípios de Parauapebas e Capitão Poço, todos no Estado do Pará.

A Universidade é sucessora de uma série de instituições: a Escola de Agronomia do Pará iniciou suas atividades em 1918 (nome alterado em 1919 para Escola de Agronomia e Veterinária do Pará), sucedida pela Escola de Agronomia da Amazônia (EAA), criada em 1945, mas que iniciou suas atividades em 1951, transformada em 1971 na Faculdade de Ciências Agrárias do Pará (FCAP). Em 2002, pela Lei no 10.611, foi criada a Universidade Federal Rural da Amazônia-UFRA, substituindo a anterior. A UFRA foi desmembrada, tendo a unidade descentralizada de Tapajós para a Universidade Federal do Oeste do Pará.

\section{Universidade Federal do Vale do São Francisco (UNIVASF)}

É a única universidade federal com campi em três diferentes estados. A Fundação Universidade Federal do Vale do São Francisco é uma universidade pública situada nos estados de Pernambuco, Bahia e Piauí, com campi nas cidades de Petrolina-PE, Juazeiro-BA, São Raimundo Nonato-PI e Senhor do Bonfim-BA.

A Fundação Universidade Federal do Vale do São Francisco, criada pela Lei $n^{\circ} 10.473$ de 27 de junho de 2002, é uma instituição de ensino superior vinculada ao Ministério da Educação, de natureza fundacional, com sede na cidade de Petrolina-PE, que tem como objetivo ministrar ensino superior, desenvolver pesquisas nas diversas áreas do conhecimento e promover a extensão universitária, caracterizando sua inserção regional mediante atuação multicampi no Pólo Petrolina-PE e Juazeiro-BA, nos termos da Lei Complementar $n^{\circ} 113$, de 19 de setembro de 2001 e do seu estatuto e normas de funcionamento. A UNIVASF iniciou suas atividades acadêmicas em 2004.

A Fundação Universidade Federal do Vale do São Francisco foi criada com a finalidade de atuar no semiárido nordestino. O seu projeto é interestadual, sendo a primeira universidade regional dentro do Programa Especial de Desenvolvimento do Pólo PetrolinaPE/Juazeiro-BA. Com a edição do Decreto ${ }^{\circ}$ 4.465, de 13 de novembro de 2002 e do Decreto $n^{\circ} 4.935$ de 23 de dezembro de 2003, coube à Universidade Federal do Espírito Santo (UFES) 
o papel tutorial das atividades de implantação e execução de um projeto de estrutura institucional.

\section{Universidade Federal do ABC (UFABC)}

A Universidade Federal do ABC (UFABC) é uma instituição pública federal de ensino superior sediada em Santo André - SP, com campus também em São Bernardo do Campo -SP. A UFABC tem como objetivo a integração de vários campi na região do Grande $\mathrm{ABC}$.

No ano de 2004, o Ministério da Educação encaminhou ao Congresso Nacional o Projeto de Lei 3962/2004, que previa a criação da Fundação Universidade Federal do ABC. Essa lei foi sancionada pelo Presidente da República e publicada no Diário Oficial da União de 27 de julho de 2005, sob o no 11.145 e datada de 26 de julho de 2005 .

\section{Universidade Federal Rural do Semi-Árido (UFERSA)}

A Universidade Federal Rural do Semi-Árido (UFERSA) é uma instituição pública federal de ensino superior com sede na cidade de Mossoró-RN. Além deste campus-sede, possui campi nas cidades de Pau dos Ferros-RN, Caraúbas-RN e Angicos-RN.

A História desta universidade começa com a "ESAM" criada pela Prefeitura Municipal de Mossoró, através do Decreto $\mathrm{n}^{\mathrm{o}}$ 03/67 de 18 de abril de 1967 e inaugurada a 22 de dezembro do mesmo ano. Teve, na sua fase de implantação, como entidade mantenedora, o Instituto Nacional de Desenvolvimento Agrário (INDA). Foi incorporada à Rede Federal de Ensino Superior, como Autarquia em Regime Especial em 1969, dois anos após sua criação, através do Decreto-lei $\mathrm{n}^{\circ} 1036$, de 21 de outubro de 1969. A ESAM possuía quatro cursos de graduação (Agronomia, Medicina Veterinária, Zootecnia e Engenharia Agrícola). O Curso de Agronomia foi autorizado a funcionar em 1968. O reconhecimento viria em 28 de janeiro de 1972. O curso de Medicina veterinária foi aprovado pelo Ministério da Educação (MEC) em 26 de dezembro de 1994, através de despacho Ministerial publicado no D.O.U. de 28/12/1994, com ingresso da primeira turma em agosto de 1995, e reconhecido através de portaria ministerial $\mathrm{n}^{\circ} 376$, de 05 de março de 2001. Passa a ser federal pela a lei $\mathrm{n}^{\circ} 11.155$, de 29 de julho de 2005. 


\section{Universidade Federal da Fronteira Sul (UFFS)}

A Universidade Federal da Fronteira Sul (UFFS) é uma instituição de ensino superior pública sediada em Chapecó - SC. Criada pela lei no 12.029, de 15 de setembro de 2009, a UFFS abrange a Mesorregião Fronteira Mercosul - Sudoeste do Paraná, Oeste de Santa Catarina e Noroeste do Rio Grande do Sul.

Desde sua criação, a UFFS tem cinco campi: Chapecó - SC; Realeza - PR e Laranjeiras do Sul - PR e Cerro Largo - RS e Erechim - RS.

Com 33 cursos em 42 turmas ingressantes anualmente, a universidade prevê ter 10 mil alunos nos primeiros cinco anos.

\section{Universidade Federal da Grande Dourados (UFGD)}

A Universidade Federal da Grande Dourados (UFGD) é uma instituição pública que se localiza na cidade de Dourados-MS.

Inaugurado em 20 de dezembro de 1970, o então Centro Pedagógico de Dourados da UFMS, que inicialmente deveria abrigar o curso de Agronomia, começou a funcionar em fevereiro de 1971, promovendo o primeiro vestibular para os cursos de Letras e Estudos Sociais (licenciatura curta).

A UFGD é uma universidade com um único campus constituída em unidades. Em 2005, há a criação da UFGD pela Lei no 11.153, de 29 de Julho de 2005. Em 2006, a UFGD é implantada com tutoria de equipe da Universidade Federal de Goiás (UFG).

\section{Universidade Federal do Recôncavo da Bahia (UFRB)}

A Universidade Federal do Recôncavo da Bahia (UFRB) é uma universidade pública brasileira sediada na cidade de Cruz das Almas-BA, possuindo campi também nos municípios baianos de Amargosa-BA, Cachoeira-BA e Santo Antônio de Jesus-BA. Sua sede localiza-se no antigo campus da Escola de Agronomia da Universidade Federal da Bahia (UFBA), sendo a segunda universidade federal instituída no Estado da Bahia. É uma instituição pública autárquica vinculada ao Ministério da Educação (MEC) e influi atividades de ensino, pesquisa e extensão em várias áreas do conhecimento. 
É a segunda universidade federal com sede na Bahia, levando-se em consideração que a Universidade Federal do Vale do São Francisco (UNIVASF), não obstante tenha campus em Juazeiro, tem a sua sede na cidade de Petrolina-PE.

A Universidade Federal do Recôncavo da Bahia foi criada pela Lei 11.151 de 29 de julho de 2005, tendo sido inaugurada no ano posterior.

\section{Universidade Federal do Triângulo Mineiro (UFTM)}

A Universidade Federal do Triângulo Mineiro (UFTM) é uma instituição pública que se localiza na cidade de Uberaba-MG, antes sob o nome de FMTM (Faculdade de Medicina do Triângulo Mineiro) e transformada no ano de 2005 em Universidade em decreto do governo federal.

Tradicional no estudo da saúde, a Universidade Federal do Triângulo Mineiro, antiga Faculdade de Medicina do Triângulo Mineiro, foi fundada em 1953, obtendo autorização para o funcionamento do Curso de Medicina a partir de 1954. Em 1953, é fundada, com autorização para funcionar o Curso de Graduação em Medicina. Em 1960, há a federalização. Em 1982, é inaugurado do Hospital Escola. E finalmente em 2005, é transformada em Universidade Federal do Triângulo Mineiro.

\section{Universidade Federal dos Vales do Jequitinhonha e Mucuri (UFVJM)}

A Universidade Federal dos Vales do Jequitinhonha e Mucuri (UFVJM) tem sede no município de Diamantina-MG. Foi criada em 6 de setembro de 2005, pela Lei $n^{\circ} 11.173$, que transformou as Faculdades Federais Integradas de Diamantina em Universidade Federal dos Vales do Jequitinhonha e Mucuri. Em 2006, foi criado um campus em Teófilo Otoni. Está prevista a construção de dois novos campi nas cidades de Janaúba-MG e Unaí-MG.

A Faculdade de Odontologia de Diamantina foi criada em 1953, por Juscelino Kubitschek de Oliveira - então governador do Estado de Minas Gerais - através da Lei Estadual $\mathrm{n}^{\circ}$ 990, de 30 de setembro de 1953. No início de maio de 1954, entrou em funcionamento o curso de Odontologia. A escola foi federalizada em 17 de dezembro de 1960, se tornando Faculdade Federal de Odontologia de Diamantina (Fafeod). Em 4 de outubro de 2002, há a transformação da então Faculdade Federal de Odontologia de 
Diamantina (Fafeod) em Faculdades Federais Integradas de Diamantina (Fafeid). Em 6 de setembro de 2005, pela Lei $\mathrm{n}^{\mathrm{o}} 11.173$, a Fafeid foi transformada em universidade.

\section{Universidade Federal de Alfenas (UNIFAL)}

A Universidade Federal de Alfenas (UNIFAL) é uma instituição de ensino superior pública sediada na cidade de Alfenas-MG e com campi nas cidades de Poços de Caldas-MG e Varginha-MG, todas na região sul do Estado de Minas Gerais. A UNIFAL, originalmente Escola de Farmácia e Odontologia de Alfenas (EFOA), foi fundada no dia 3 de abril de 1914, com a implantação do Curso de Farmácia e, no ano seguinte, do Curso de Odontologia.

A EFOA foi reconhecida pela Lei Estadual $n^{\circ}$ 657, de 11 de setembro de 1915, do Governo do Estado de Minas Gerais. O reconhecimento, através do Ministro da Educação e Saúde, foi previsto no artigo 26 do Decreto 19.851 e, em 23 de março de 1932, foi aprovado o novo regulamento enquadrando-a nas disposições das leis federais. No dia 18 de dezembro de 1960, através da Lei no 3.854, a Escola foi federalizada.

A transformação em autarquia de regime especial efetivou-se através do Decreto $\mathrm{n}^{\circ}$ 70.686, de 7 de junho de 1972. Tal transformação favoreceu a implantação do curso de Enfermagem e Obstetrícia, autorizado pelo Parecer n. ${ }^{\circ}$ 3.246, de 5 de outubro de 1976 e Decreto n. ${ }^{\circ} 78.949$, de 15 de dezembro de 1976 e reconhecido pelo Parecer do CFE n. ${ }^{\circ}$ 1.484/79, Portaria MEC n. ${ }^{\circ} 1.224$, de 18 de dezembro de 1979. A mudança para centro universitário federal (EFOA/Ceufe) ocorreu em $1^{\circ}$ de outubro de 2001 pela Portaria/MEC n $^{\circ}$ 2.101. Em agosto de 2005 foi transformada em Universidade Federal de Alfenas pela Lei 11.154 .

\section{Universidade Tecnológica Federal do Paraná (UTFPR)}

A Universidade Tecnológica Federal do Paraná (UTFPR) é uma instituição federal brasileira que abrange Ensino Médio, com cursos técnicos integrados, e Ensino Superior. Em 7 de outubro de 2005, foi aprovado o projeto de transformação do CEFET-PR em universidade.

A UTFPR conta com treze campi no Estado do Paraná, nas cidades de: Apucarana, Campo Mourão, Cornélio Procópio, dois em Curitiba (campus Centro e campus Ecoville), 
Dois Vizinhos, Francisco Beltrão, Guarapuava, Londrina, Medianeira, Ponta Grossa, Pato Branco e Toledo.

\section{Universidade Federal de Ciências da Saúde de Porto Alegre (UFCSPA)}

A Universidade Federal de Ciências da Saúde de Porto Alegre (UFCSPA) é uma instituição federal brasileira de ensino superior especializada nas áreas das ciências da saúde. Está localizada em Porto Alegre-RS. Seu nome anterior Fundação Faculdade Federal de Ciências Médicas de Porto Alegre (FFFCMPA), foi alterado em 2008 com a transformação da faculdade em universidade. A UFCSPA possui dez cursos de graduação.

A construção do hospital universitário da UFRGS e a grande demanda por médicos no Estado do Rio Grande do Sul na década de 1950 determinaram a fundação da então Faculdade Católica de Medicina (FCM). No dia 7 de dezembro de 1953, propôs-se a criação da Faculdade Católica de Medicina (FCM). A proposta foi encaminhada ao Arcebispo Metropolitano de Porto Alegre, Dom Vicente Scherer, que acatou a proposta e decretou, no dia seguinte, a criação da faculdade.

A pedra fundamental foi lançada no dia 23 de junho de 1957. Iniciou-se então a construção do atual prédio central. Quatro anos depois a faculdade foi autorizada a funcionar pelo Decreto 50.165/61. A aula inaugural foi ministrada em 22 de março de 1961. Obteve o reconhecimento como instituição de ensino pelo Decreto 54.234/64.

Por ser importante para o Estado do Rio Grande do Sul e em razão de dificuldades financeiras, a faculdade foi federalizada, através da Lei 6.891/80. Passou então a denominarse Fundação Faculdade Federal de Ciências Médicas de Porto Alegre (FFFCMPA). Sete anos depois adquiriu a personalidade jurídica de fundação pública com o advento da Lei 7.596/87 (até então possuía personalidade jurídica de fundação privada).

Até o ano de 2003 a instituição ofereceu, na graduação, apenas o curso de medicina. Em 2004, a faculdade inicia seu projeto de expansão e passa a oferecer novos cursos de graduação. Durante a fase de expansão, em 2008, a FFFCMPA foi transformada em universidade especializada na área de ciências da saúde, através da Lei Federal n. 11.641/08, passando a ter a atual denominação, Universidade Federal de Ciências da Saúde de Porto Alegre. 


\section{Universidade Federal do Pampa (UNIPAMPA)}

A Universidade Federal do Pampa é uma universidade pública, fundada em 2006, sendo efetivamente criada pela Lei 11.640 de 11 de janeiro de 2008, como Fundação Universidade Federal do Pampa, de natureza pública, com sede e foro na cidade de Bagé-RS.

A UNIPAMPA é uma instituição federal de educação superior multicampi, com os campi localizados no Estado do Rio Grande do Sul nas seguintes cidades: Alegrete, Bagé, Caçapava do Sul, Dom Pedrito, Itaqui, Jaguarão, Santana do Livramento, São Borja, São Gabriel e Uruguaiana.

\section{Universidade Federal do Oeste do Pará (UFOPA)}

A Universidade Federal do Oeste do Pará (UFOPA) é uma instituição de ensino superior pública, multicampi, sediada na cidade de Santarém-PA, com campi em Itaituba-PA, Monte Alegre-PA, Oriximiná-PA, Óbidos-PA e Juruti-PA.

A UFOPA é resultado do desmembramento do campus de Santarém da Universidade Federal do Pará e da unidade descentralizada de Tapajós da Universidade Federal Rural da Amazônia. Foi instituída pela lei no 12085 de 5 de novembro de 2009.

\section{Universidade Federal da Integração Latino-Americana (UNILA)}

A Universidade Federal da Integração Latino-Americana (UNILA) é uma instituição pública de ensino superior sediada na cidade de Foz do Iguaçu-PR. Tendo sua proposta de criação em 2007, a Universidade foi criada somente no dia 12 de janeiro de 2010 na fronteira entre Brasil, Argentina e Paraguai. Teve sua primeira turma de 200 alunos entre brasileiros, paraguaios, uruguaios e argentinos em agosto de 2010.

\section{Universidade da Integração Internacional da Lusofonia Afro-Brasileira (UNILAB)}

A Universidade da Integração Internacional da Lusofonia Afro-Brasileira (UNILAB) é uma instituição de ensino superior pública sediada na cidade de Redenção - CE. A cidade de Redenção foi escolhida por ser a primeira cidade a abolir a escravidão no Brasil. 
O projeto de lei de sua criação foi enviado ao Congresso Nacional brasileiro em 20 de agosto de 2008. A Comissão de Educação e Cultura da Câmara dos Deputados aprovou em 13 de março de 2009 o Projeto de Lei 3891/08, do Executivo, criando a UNILAB, com o objetivo de formar recursos humanos para desenvolver a integração entre o Brasil e os demais países da Comunidade dos Países de Língua Portuguesa (CPLP), especialmente os africanos.

Os cursos da UNILAB serão ministrados preferencialmente em áreas de interesse mútuo do Brasil e dos demais países da CPLP, com ênfase em temas que envolvam formação de professores, desenvolvimento agrário, processos de gestão e saúde pública, entre outros.

A UNILAB será voltada aos países da África, sobretudo aos Países Africanos de Língua Oficial Portuguesa (PALOP), mas inclui também Timor-Leste e Macau. Seu projeto político-pedagógico visa à integração internacional.

Outro campus da UNILAB está em implantação em São Francisco do Conde - BA, que funcionará com convênios de cooperação técnica com os futuros campus de Camaçari da UFBA e de Feira de Santana da UFRB. 


\section{APÊNDICE B - MÉTODO DE MÍNIMOS QUADRADOS APLICADO À FUNÇÃO SPLINE CÚBICA}

As aplicações apresentadas em Meghir e Palme (2003) e Blundell et al (2004) suavizam a variável explicada do indivíduo controle através da utilização de mínimos quadrados aplicados à função spline cúbica. Ambos explicam de forma sucinta $\mathrm{o}$ procedimento. Smith, Price e Howser (1974) apresenta uma explicação detalhada do método, em especial, deduzindo a função spline cúbica e apresentando um algoritmo de suavização para aplicações em engenharia aeroespacial na agência espacial norte-americana NASA (National Aeronautics and Space Administration).

Smith, Price e Howser (1974) argumenta que o método de mínimos quadrados aplicados a uma função polinomial é uma técnica de suavização padrão para representar funcionalmente um conjunto de dados. O processo consiste em encontrar os coeficientes polinomiais que minimizam a soma dos quadrados das diferenças entre a curva polinomial e os valores da variável dependente, no conjunto de dados.

Além disso, aponta-se que a utilização deste tipo de ajuste polinomial isoladamente embora possa proporcionar uma representação mais próxima dos dados - apresenta a desvantagem de garantir a continuidade na representação polinomial ou nas suas derivadas sob a totalidade do conjunto de dados. Entretanto, aplicando o método de mínimos quadrados a uma função polinomial spline de ordem inferior, garante-se a continuidade da representação funcional e de suas derivadas, produzindo uma boa representação do conjunto de dados.

Desta forma, é comum a utilização do método com polinômio spline de ordem três, chamado função spline cúbica, que é caracterizada por um conjunto de polinômios de grau três, onde cada polinômio conecta um par de pontos, e de maneira que haja continuidade entre

polinômios adjacentes e que suas primeira e segunda derivadas sejam contínuas. Assim, o conjunto de dados pode ser representado por uma função contínua, com primeira e segunda derivadas contínuas.

A função resultante é considerada suavizada uma vez que tem primeira e segunda derivadas contínuas nos nós (pontos que separam um polinômio do outro). Fora dos nós extremos, a função é linear. O resultado suavizado é o valor previsto da regressão da variável explicada na função spline cúbica do escore de propensão. 


\section{APÊNDICE C - APÊNDICE DO CAPÍTULO 1}

Tabela A.1 - Gastos com Universidades Federais

\begin{tabular}{|c|c|c|c|}
\hline Universidade & 2000 & 2004 & 2010 \\
\hline FUNDAÇÃO UNIVERSIDADE FEDERAL DA GRANDE DOURADOS (UFGD) & 0 & 0 & 74.513 .219 \\
\hline FUNDAÇÃO UNIVERSIDADE FEDERAL DE CIÊNCIAS DA SAÚDE DE PORTO ALEGRE (UFCSPA) & 22.133 .058 & 18.210 .580 & 33.432 .338 \\
\hline FUNDAÇÃO UNIVERSIDADE FEDERAL DE RONDÔNIA (UNIR) & 50.578 .877 & 58.621 .878 & 84.596 .975 \\
\hline FUNDAÇÃO UNIVERSIDADE FEDERAL DO ABC (UFABC) & 0 & 0 & 128.860 .416 \\
\hline FUNDAÇÃO UNIVERSIDADE FEDERAL DO PAMPA - UNIPAMPA (UNIPAMPA) & 0 & 0 & 76.837 .094 \\
\hline FUNDAÇÃO UNIVERSIDADE FEDERAL DO TOCANTINS (UFT) & 0 & 52.128 .635 & 117.587 .285 \\
\hline FUNDAÇÃO UNIVERSIDADE FEDERAL DO VALE DO SÃO FRANCISCO (UNIVASF) & 0 & 12.177 .635 & 63.026 .732 \\
\hline UNIVERSIDADE DA INTEGRAÇÃO INTERNACIONAL DA LUSOFONIA AFRO-BRASILEIRA (UNILAB) & 0 & 0 & 3.095 .381 \\
\hline UNIVERSIDADE DE BRASÍLIA (UNB) & 627.853 .114 & 522.102 .707 & 843.343 .738 \\
\hline UNIVERSIDADE FEDERAL DA BAHIA (UFBA) & 357.278 .329 & 374.830 .162 & 382.498 .943 \\
\hline UNIVERSIDADE FEDERAL DA FRONTEIRA SUL (UFFS) & 0 & 0 & 9.102 .146 \\
\hline UNIVERSIDADE FEDERAL DA INTEGRAÇÃO LATINO-AMERICANA (UNILA) & 0 & 0 & 3.173 .809 \\
\hline UNIVERSIDADE FEDERAL DA PARAÍBA (UFPB) & 613.042 .375 & 345.447 .515 & 411.257 .914 \\
\hline UNIVERSIDADE FEDERAL DE ALAGOAS (UFAL) & 176.640 .363 & 178.154 .340 & 215.270 .431 \\
\hline UNIVERSIDADE FEDERAL DE ALFENAS (UNIFAL-MG) & 24.189 .595 & 22.903 .934 & 63.501 .250 \\
\hline UNIVERSIDADE FEDERAL DE CAMPINA GRANDE (UFCG) & 0 & 159.295 .389 & 215.338 .081 \\
\hline UNIVERSIDADE FEDERAL DE GOIÁS (UFG) & 221.561.174 & 238.528 .296 & 361.046 .090 \\
\hline UNIVERSIDADE FEDERAL DE ITAJUBÁ - UNIFEI (UNIFEI) & 35.979 .996 & 35.895 .075 & 65.099 .119 \\
\hline UNIVERSIDADE FEDERAL DE JUIZ DE FORA (UFJF) & 157.879 .262 & 161.250 .579 & 279.890 .065 \\
\hline UNIVERSIDADE FEDERAL DE LAVRAS (UFLA) & 67.545 .194 & 65.015 .054 & 119.197.019 \\
\hline UNIVERSIDADE FEDERAL DE MATO GROSSO (UFMT) & 223.855 .374 & 194.106.874 & 281.783 .114 \\
\hline UNIVERSIDADE FEDERAL DE MATO GROSSO DO SUL (UFMS) & 211.096.717 & 204.422.118 & 198.529 .426 \\
\hline UNIVERSIDADE FEDERAL DE MINAS GERAIS (UFMG) & 519.660 .978 & 544.715 .272 & 595.383 .350 \\
\hline UNIVERSIDADE FEDERAL DE OURO PRETO (UFOP) & 72.875 .322 & 75.098 .715 & 146.357 .045 \\
\hline UNIVERSIDADE FEDERAL DE PELOTAS (UFPEL) & 146.043 .007 & 144.420.077 & 211.713.312 \\
\hline UNIVERSIDADE FEDERAL DE PERNAMBUCO (UFPE) & 317.751 .714 & 334.973 .632 & 406.064 .467 \\
\hline UNIVERSIDADE FEDERAL DE RORAIMA (UFRR) & 33.797.123 & 40.411 .182 & 65.057 .571 \\
\hline UNIVERSIDADE FEDERAL DE SANTA CATARINA (UFSC) & 417.081.168 & 423.304.132 & 461.056 .105 \\
\hline UNIVERSIDADE FEDERAL DE SANTA MARIA (UFSM) & 268.558 .102 & 270.535 .006 & 308.868 .099 \\
\hline UNIVERSIDADE FEDERAL DE SÃO CARLOS (UFSCAR) & 116.042 .695 & 117.229 .233 & 202.092 .802 \\
\hline UNIVERSIDADE FEDERAL DE SÃO JOÃO DEL REI (UFSJ) & 32.844 .844 & 35.918 .374 & 114.677 .006 \\
\hline UNIVERSIDADE FEDERAL DE SÃO PAULO (UNIFESP) & 219.233.986 & 252.007 .142 & 450.276 .530 \\
\hline UNIVERSIDADE FEDERAL DE SERGIPE (UFS) & 106.334.334 & 111.525 .621 & 178.771 .240 \\
\hline UNIVERSIDADE FEDERAL DE UBERLÂNDIA (UFU) & 288.064 .250 & 311.039 .293 & 325.078 .179 \\
\hline UNIVERSIDADE FEDERAL DE VIÇOSA (UFV) & 198.233.765 & 199.323 .249 & 287.857 .820 \\
\hline UNIVERSIDADE FEDERAL DO ACRE (UFAC) & 75.192 .391 & 72.641 .895 & 103.090 .328 \\
\hline UNIVERSIDADE FEDERAL DO AMAPÁ (UNIFAP) & 20.885 .635 & 22.136 .833 & 38.537 .965 \\
\hline UNIVERSIDADE FEDERAL DO AMAZONAS (UFAM) & 162.463 .727 & 150.804 .191 & 226.180 .278 \\
\hline UNIVERSIDADE FEDERAL DO CEARÁ (UFC) & 329.030 .442 & 367.930 .966 & 464.907 .258 \\
\hline UNIVERSIDADE FEDERAL DO ESPÍRITO SANTO (UFES) & 194.098 .736 & 211.665 .444 & 284.793.247 \\
\hline UNIVERSIDADE FEDERAL DO ESTADO DO RIO DE JANEIRO (UNIRIO) & 96.048 .725 & 122.220 .100 & 111.640 .117 \\
\hline UNIVERSIDADE FEDERAL DO MARANHÃO (UFMA) & 169.849 .607 & 155.133 .582 & 221.148 .689 \\
\hline UNIVERSIDADE FEDERAL DO OESTE DO PARÁ (UFOPA) & 0 & 0 & 5.872 .838 \\
\hline UNIVERSIDADE FEDERAL DO PARÁ (UFPA) & 296.825 .153 & 315.837 .941 & 421.013 .555 \\
\hline UNIVERSIDADE FEDERAL DO PARANÁ (UFPR) & 361.572 .372 & 369.812 .901 & 405.631 .730 \\
\hline UNIVERSIDADE FEDERAL DO PIAUÍ (UFPI) & 143.229 .014 & 149.003 .358 & 259.449 .201 \\
\hline UNIVERSIDADE FEDERAL DO RECÔNCAVO DA BAHIA (UFRB) & 0 & 0 & 86.103 .782 \\
\hline UNIVERSIDADE FEDERAL DO RIO DE JANEIRO (UFRJ) & 954.054 .387 & 969.485 .557 & 947.672 .128 \\
\hline UNIVERSIDADE FEDERAL DO RIO GRANDE (FURG) & 124.871 .279 & 125.618 .779 & 139.413 .936 \\
\hline UNIVERSIDADE FEDERAL DO RIO GRANDE DO NORTE (UFRN) & 331.463 .890 & 350.602 .814 & 432.189 .800 \\
\hline UNIVERSIDADE FEDERAL DO RIO GRANDE DO SUL (UFRGS) & 438.723 .748 & 426.656 .726 & 519.069 .168 \\
\hline UNIVERSIDADE FEDERAL DO TRIÂNGULO MINEIRO (UFTM) & 84.127 .813 & 83.652 .445 & 72.550 .018 \\
\hline UNIVERSIDADE FEDERAL DOS VALES DO JEQUITINHONHA E MUCURI (UFVJM) & 8.005 .507 & 15.170 .102 & 81.492 .646 \\
\hline UNIVERSIDADE FEDERAL FLUMINENSE (UFF) & 455.768 .079 & 439.771 .759 & 575.035 .176 \\
\hline UNIVERSIDADE FEDERAL RURAL DA AMAZÔNIA (UFRA) & 39.197 .092 & 40.585 .683 & 58.200 .737 \\
\hline UNIVERSIDADE FEDERAL RURAL DE PERNAMBUCO (UFRPE) & 92.054 .712 & 94.444 .198 & 170.264 .075 \\
\hline UNIVERSIDADE FEDERAL RURAL DO RIO DE JANEIRO (UFRRJ) & 125.446 .944 & 126.714 .804 & 209.315.744 \\
\hline UNIVERSIDADE FEDERAL RURAL DO SEMI-ÁRIDO (UFERSA) & 33.008 .769 & 30.134 .772 & 70.741 .360 \\
\hline UNIVERSIDADE TECNOLÓGICA FEDERAL DO PARANÁ (UTFPR) & 115.184.099 & 127.400 .789 & 249.766 .156 \\
\hline Total & 10.177.258.837 & 10.271.019.345 & 13.938.316.052 \\
\hline
\end{tabular}

Obs.: As despesas estão distribuídas com base nas matrículas nos cursos de graduação presencial dos

Censos do Ensino Superior e se encontram em Reais de 2010.

Fonte: Elaboração própria 


\section{APÊNDICE D - APÊNDICE DO CAPÍTULO 2}

Gráfico A.1 - Efeitos Percentuais Regionais da Expansão sobre Valor Bruto da Produção no Período 2004-2010

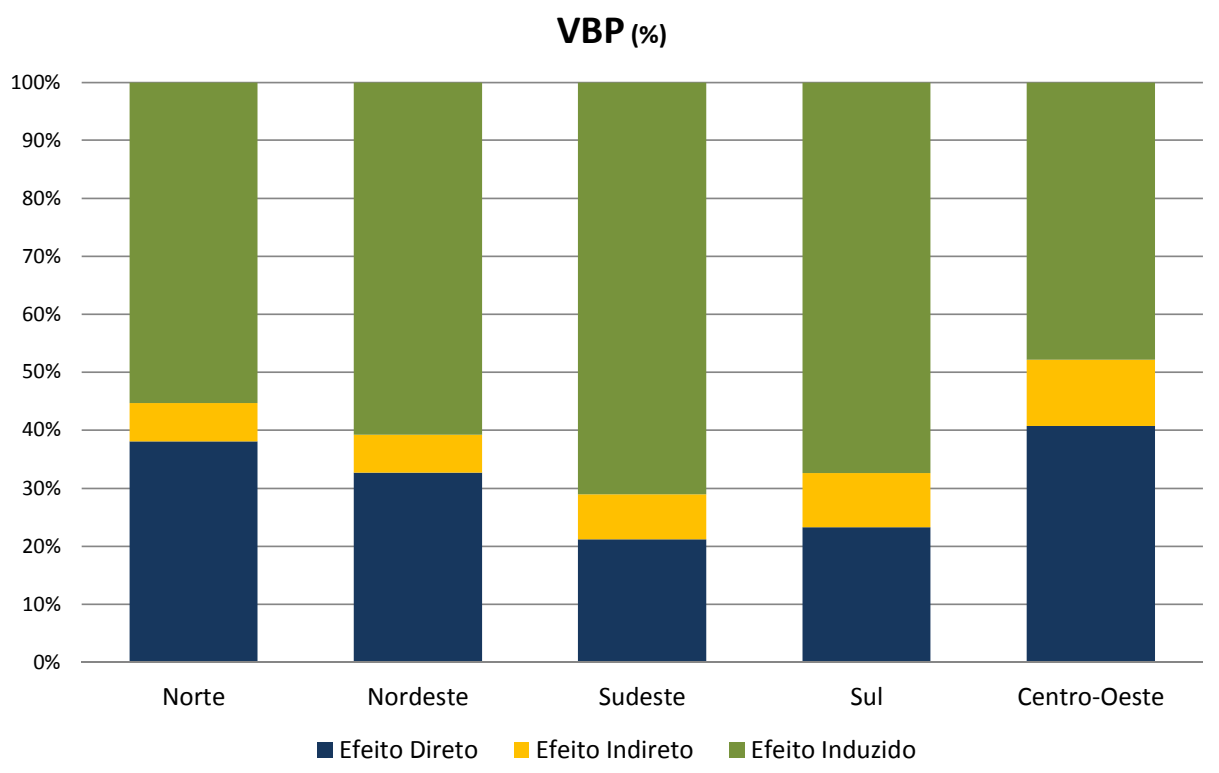

Fonte: Elaboração própria

Gráfico A.2 - Efeitos Percentuais Regionais da Expansão sobre Valor Adicionado no

Período 2004-2010

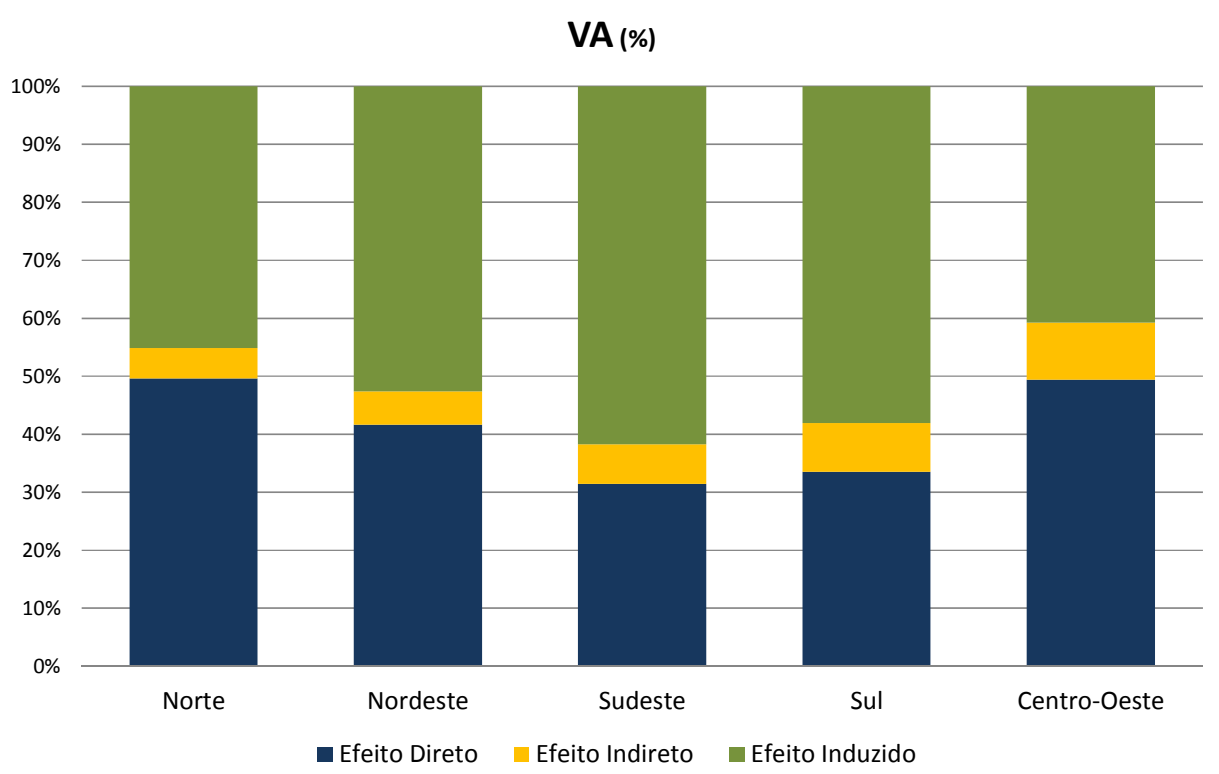

Fonte: Elaboração própria 
Gráfico A.3 - Efeitos Percentuais da Expansão Regionais sobre Pessoal Ocupado no Período 2004-2010

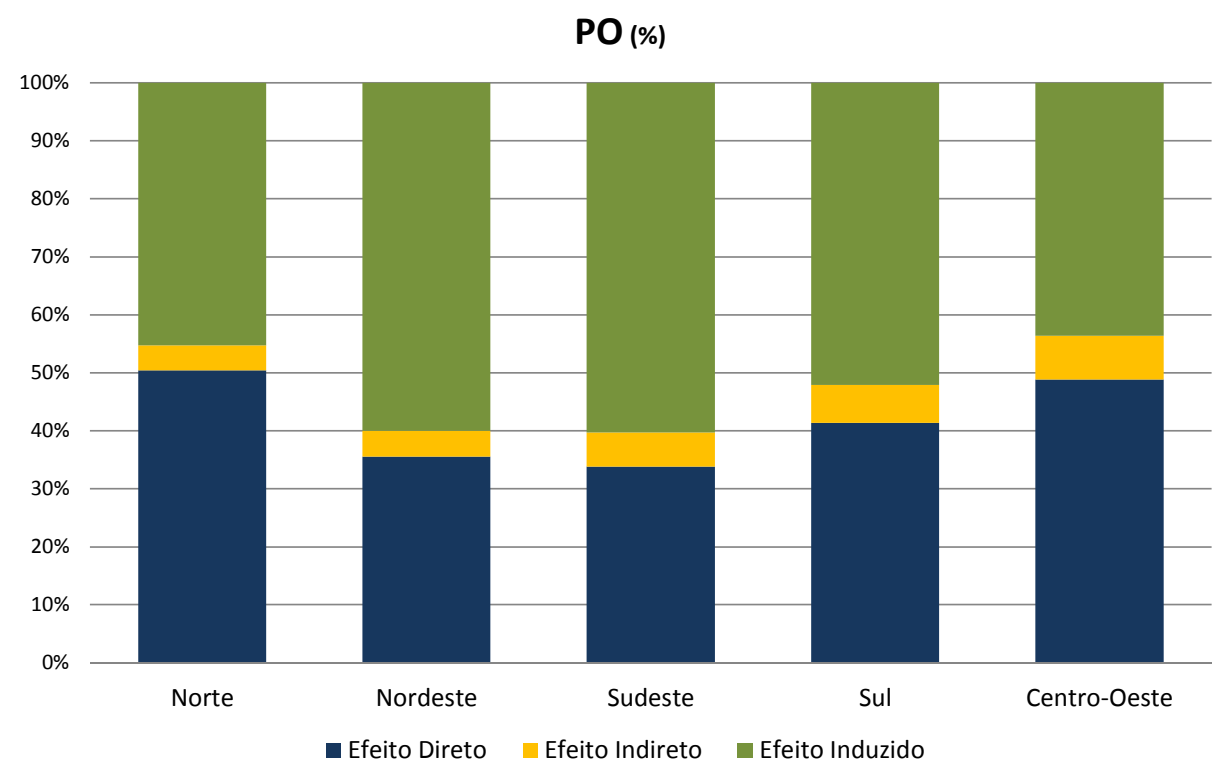

Fonte: Elaboração própria

Gráfico A.4 - Efeitos Percentuais Estaduais da Expansão sobre Valor Bruto da Produção no Período 2004-2010

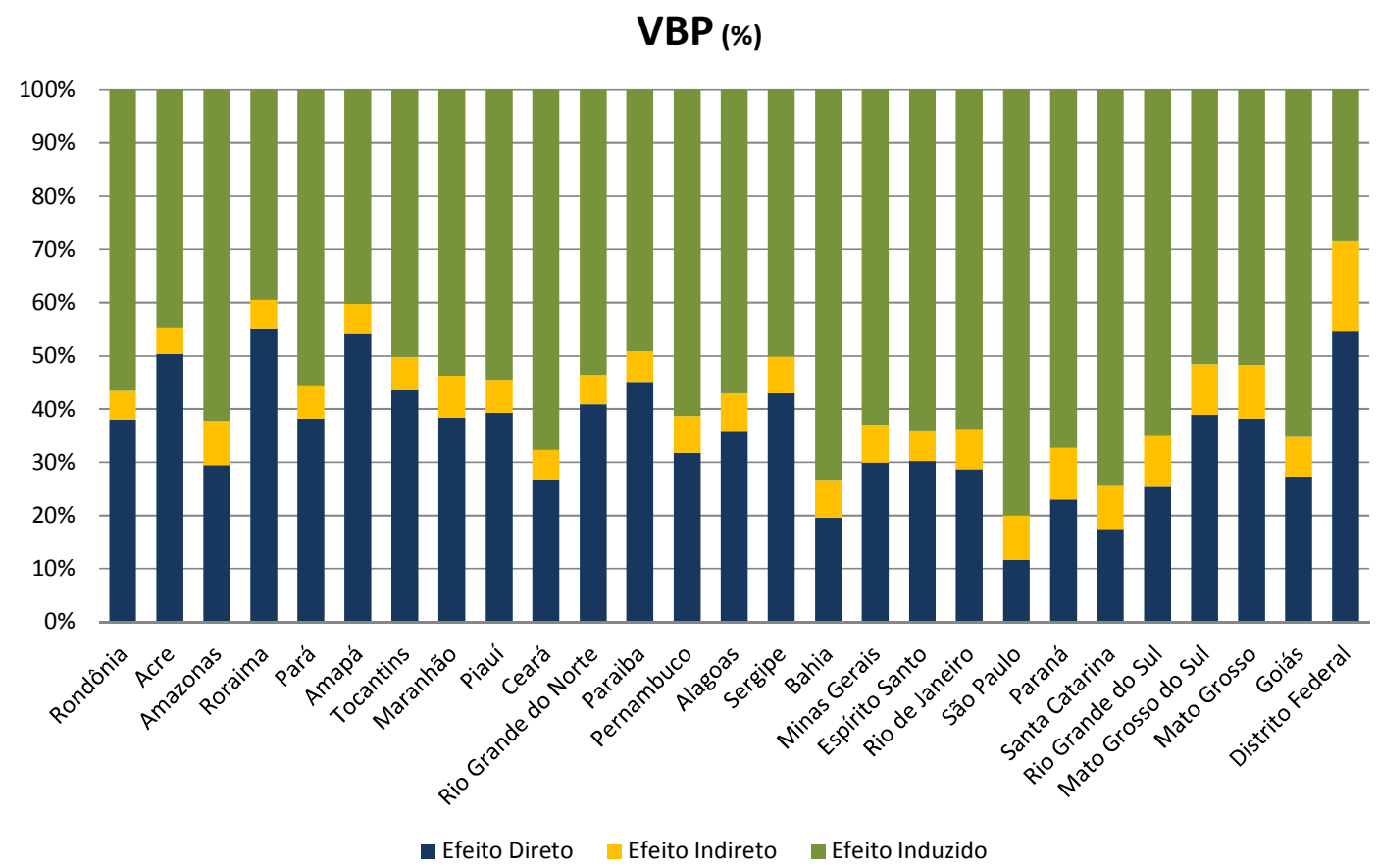

Fonte: Elaboração própria 
Gráfico A.5 - Efeitos Percentuais Estaduais da Expansão sobre Valor Adicionado no

Período 2004-2010

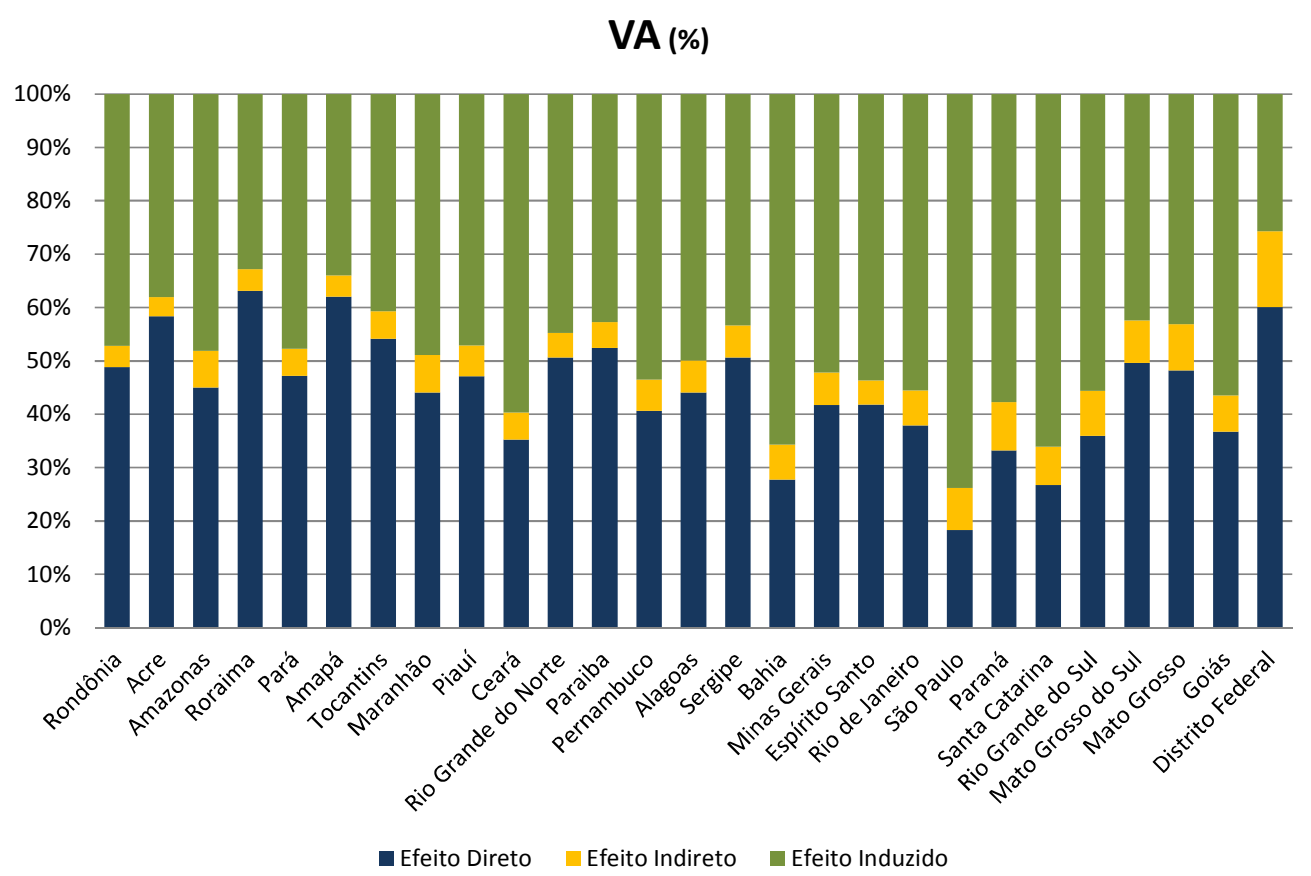

Fonte: Elaboração própria

Gráfico A.6 - Efeitos Percentuais Estaduais da Expansão sobre Pessoal Ocupado no Período 2004-2010

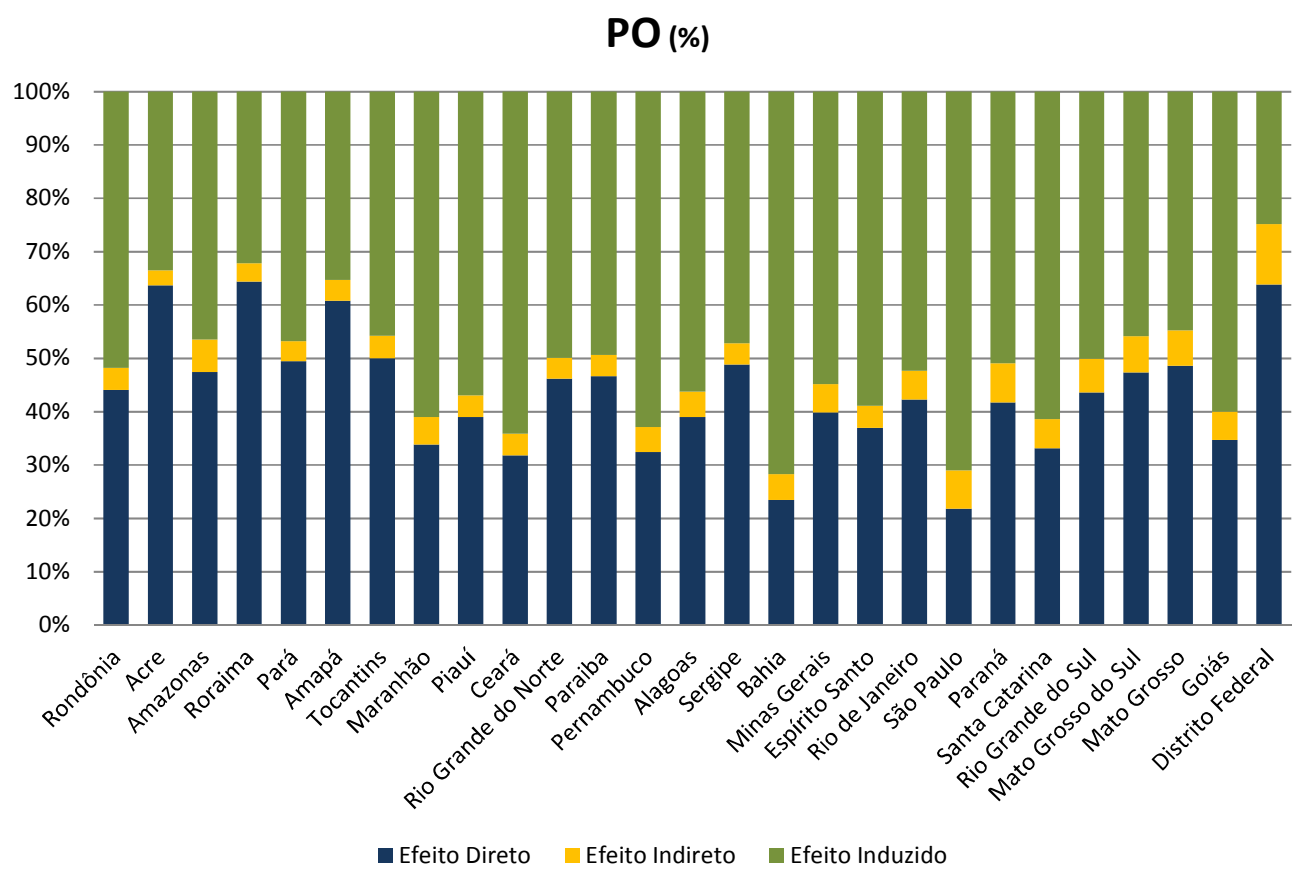

Fonte: Elaboração própria 
Gráfico A.7 - Efeitos Percentuais Setoriais da Expansão sobre Valor Bruto da Produção no Período 2004-2010

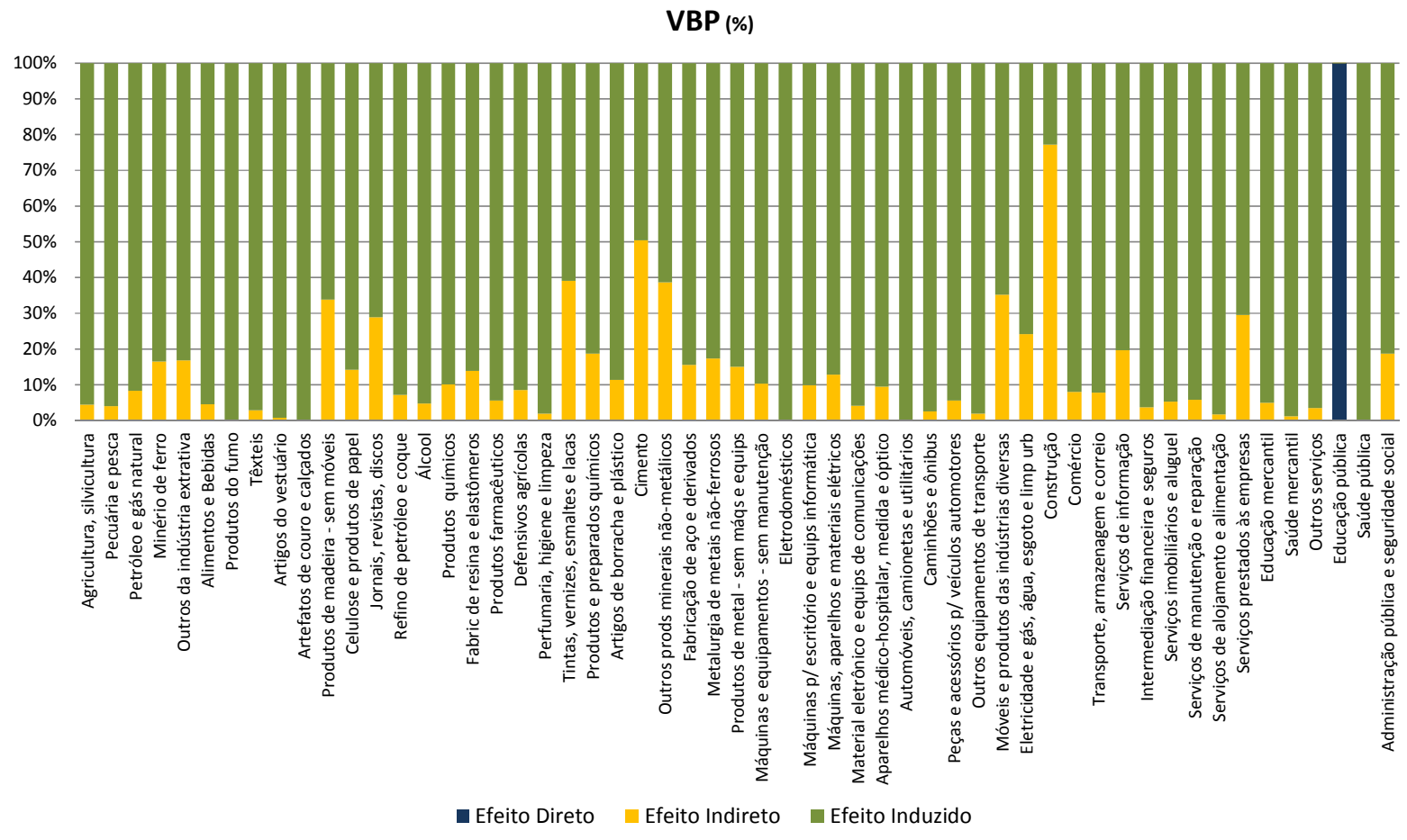

Fonte: Elaboração própria

Gráfico A.8 - Efeitos Percentuais Setoriais da Expansão sobre Valor Adicionado no

Período 2004-2010

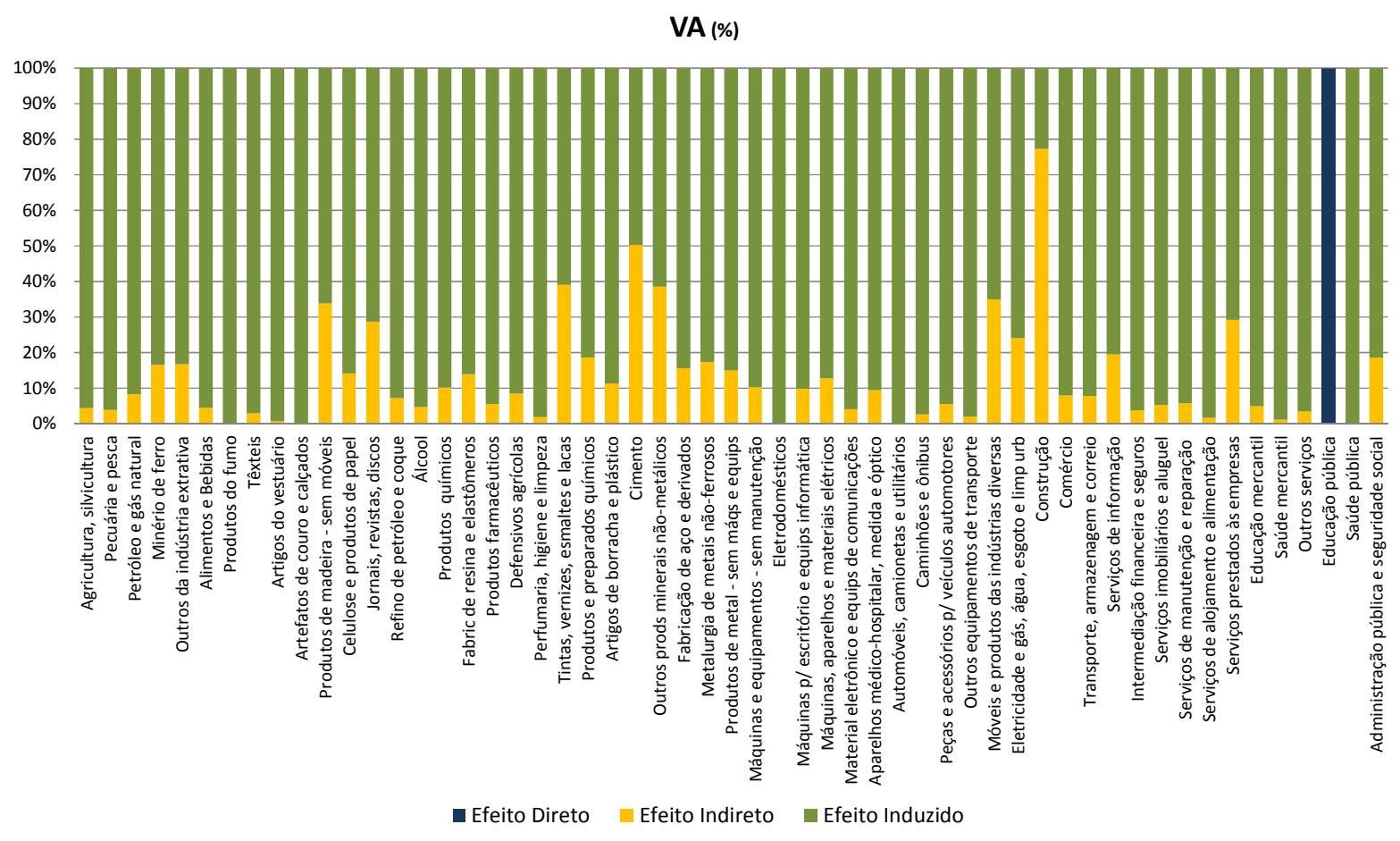

Fonte: Elaboração própria 
Gráfico A.9 - Efeitos Percentuais Setoriais da Expansão sobre Pessoal Ocupado no

Período 2004-2010

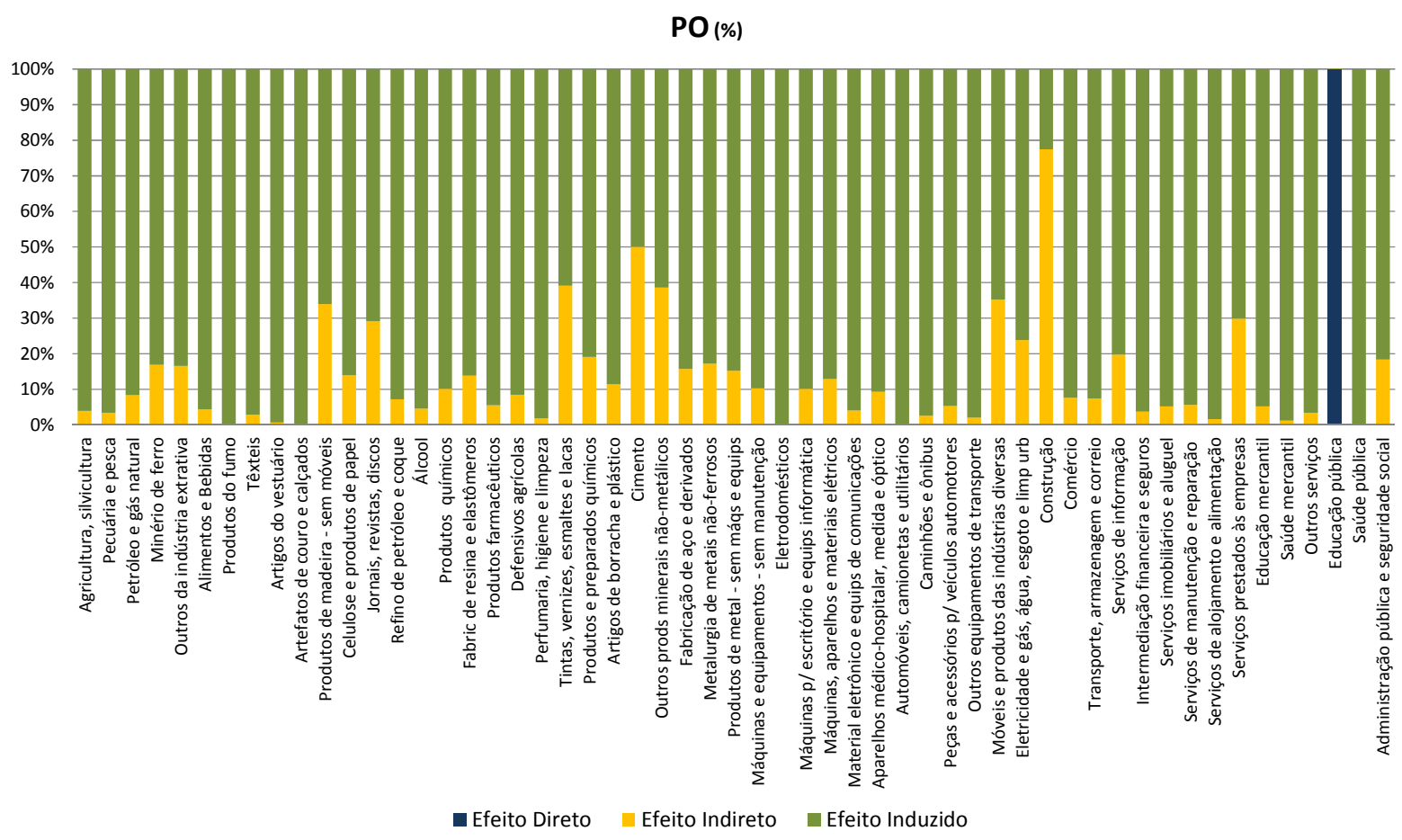

Fonte: Elaboração própria

Gráfico A.10 - Efeitos Percentuais da Expansão sobre Valor Bruto da Produção por Universidade no Período 2004-2010

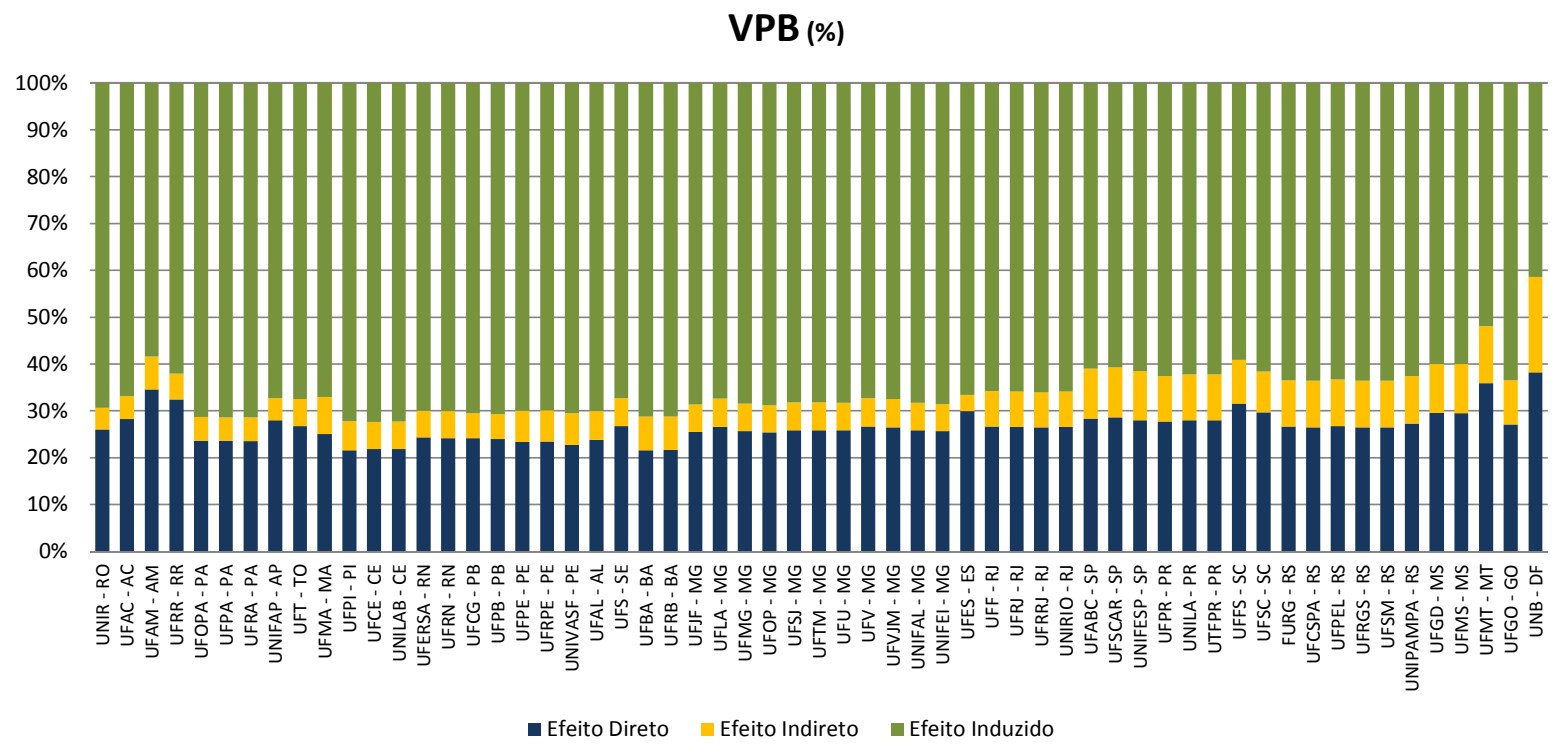

Fonte: Elaboração própria 
Gráfico A.11 - Efeitos Percentuais da Expansão sobre Valor Adicionado por Universidade no Período 2004-2010

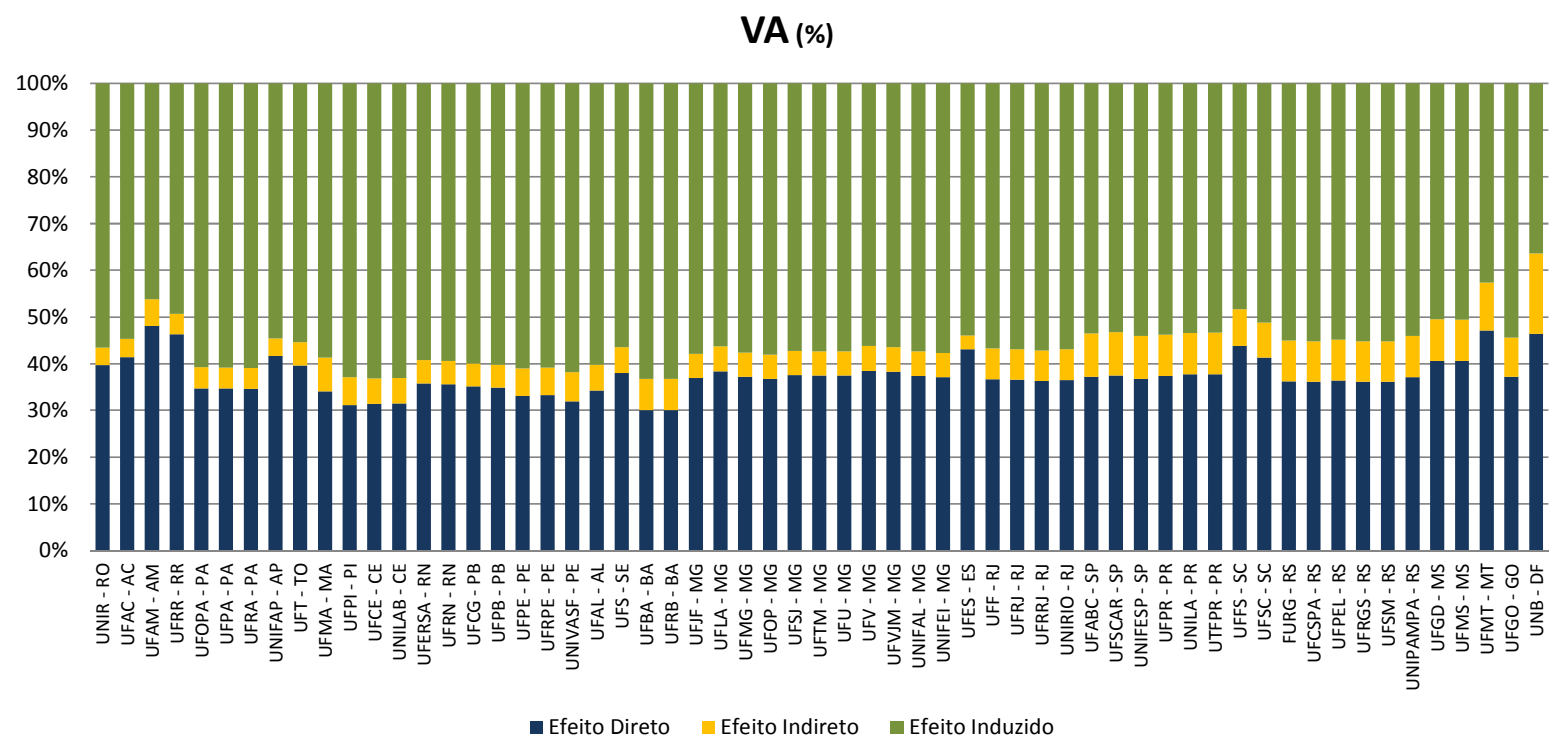

Fonte: Elaboração própria

Gráfico A.12 - Efeitos Percentuais da Expansão sobre Pessoal Ocupado por Universidade no Período 2004-2010

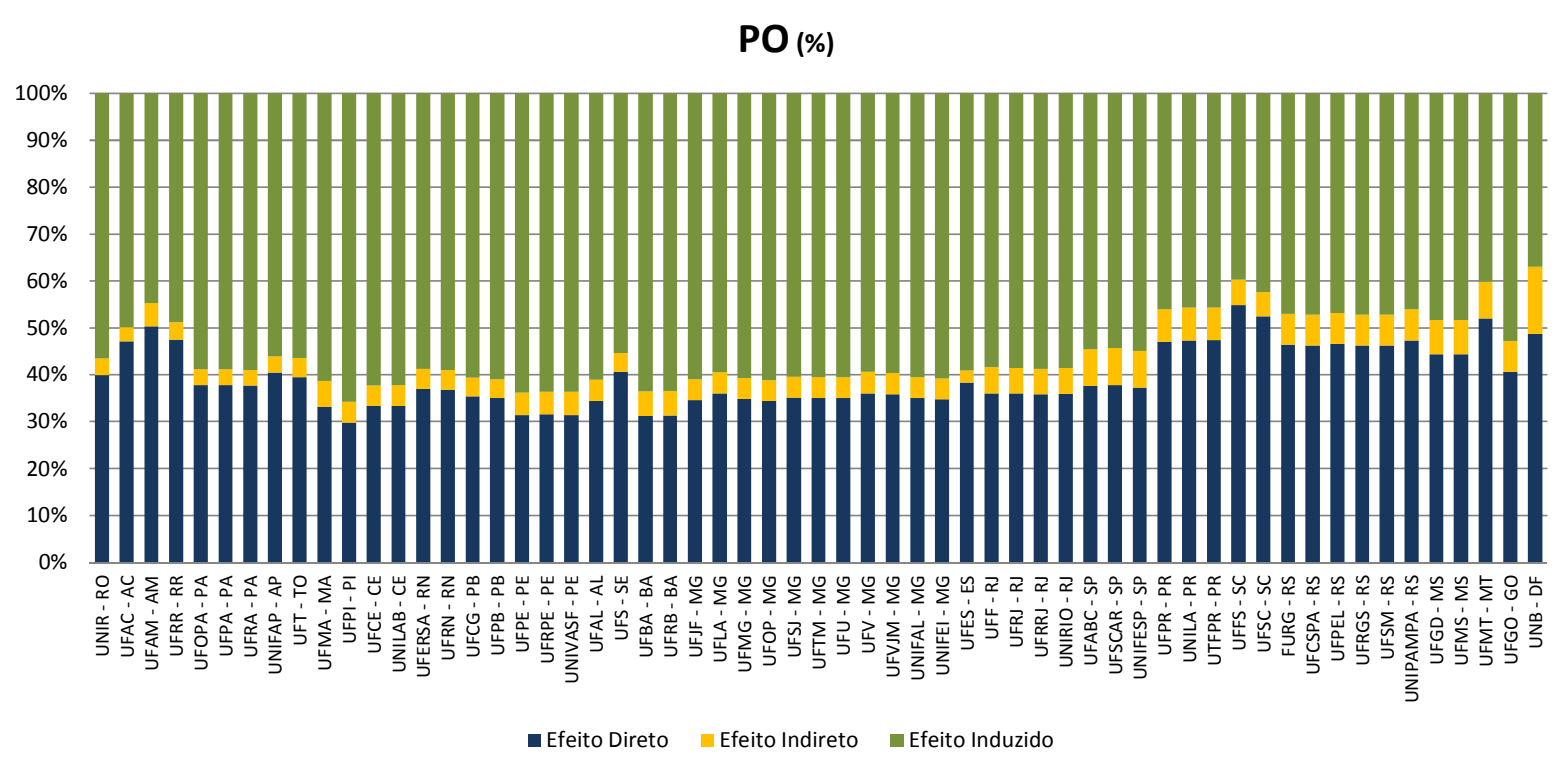

Fonte: Elaboração própria 
Gráfico A.13 - Efeitos Percentuais da Expansão das Universidades Novas sobre Valor Bruto da Produção no Período 2004-2010

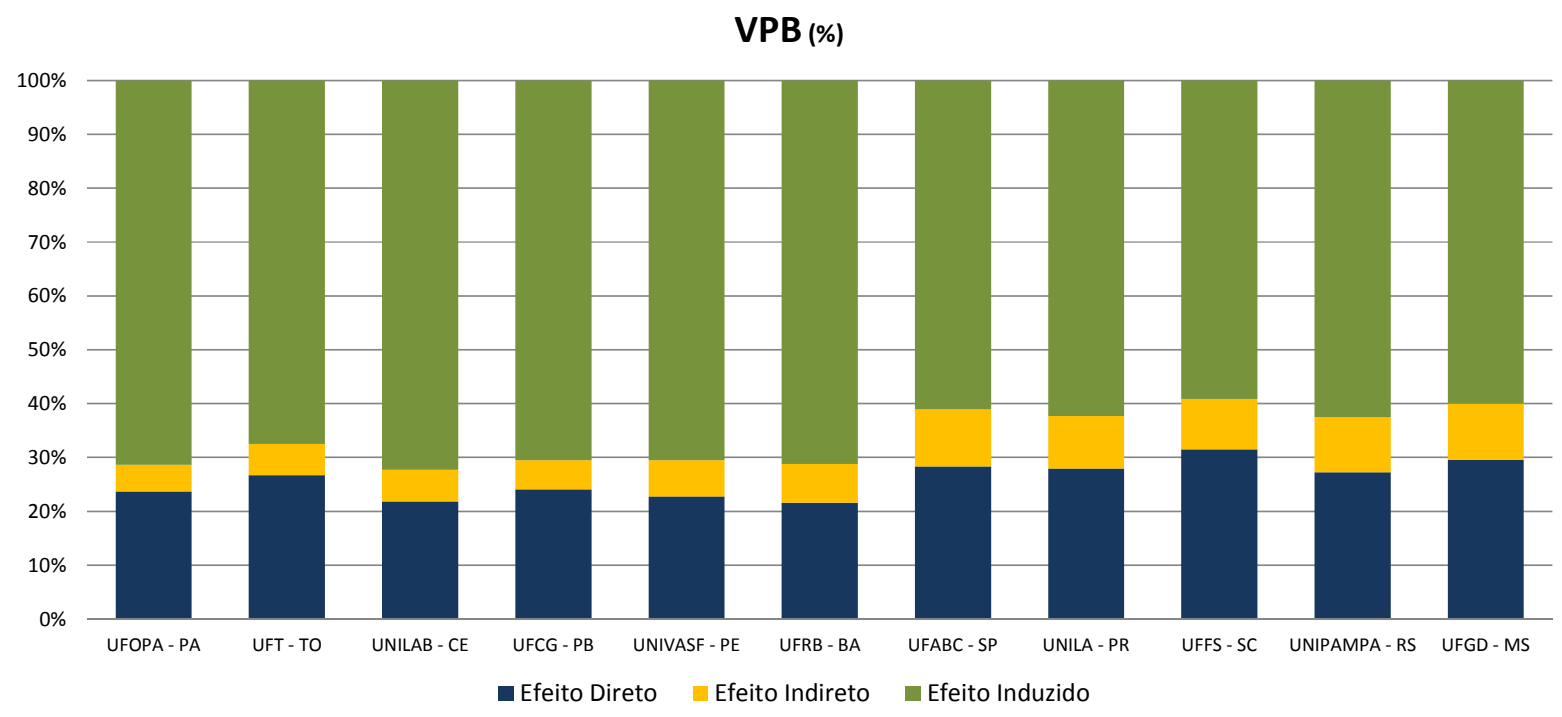

Fonte: Elaboração própria

Gráfico A.14 - Efeitos Percentuais da Expansão das Universidades Novas sobre Valor Adicionado no Período 2004-2010

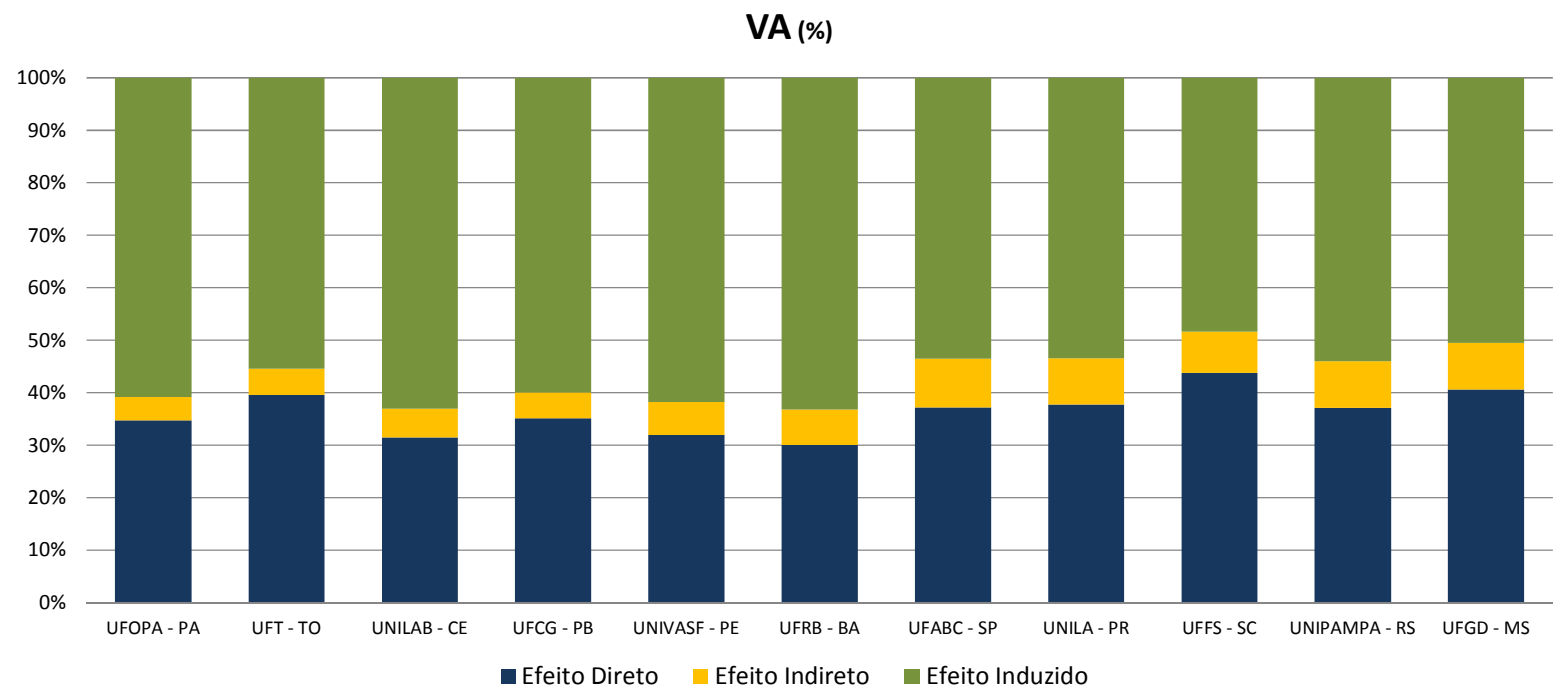

Fonte: Elaboração própria 
Gráfico A.15 - Efeitos Percentuais da Expansão das Universidades Novas sobre Pessoal Ocupado no Período 2004-2010

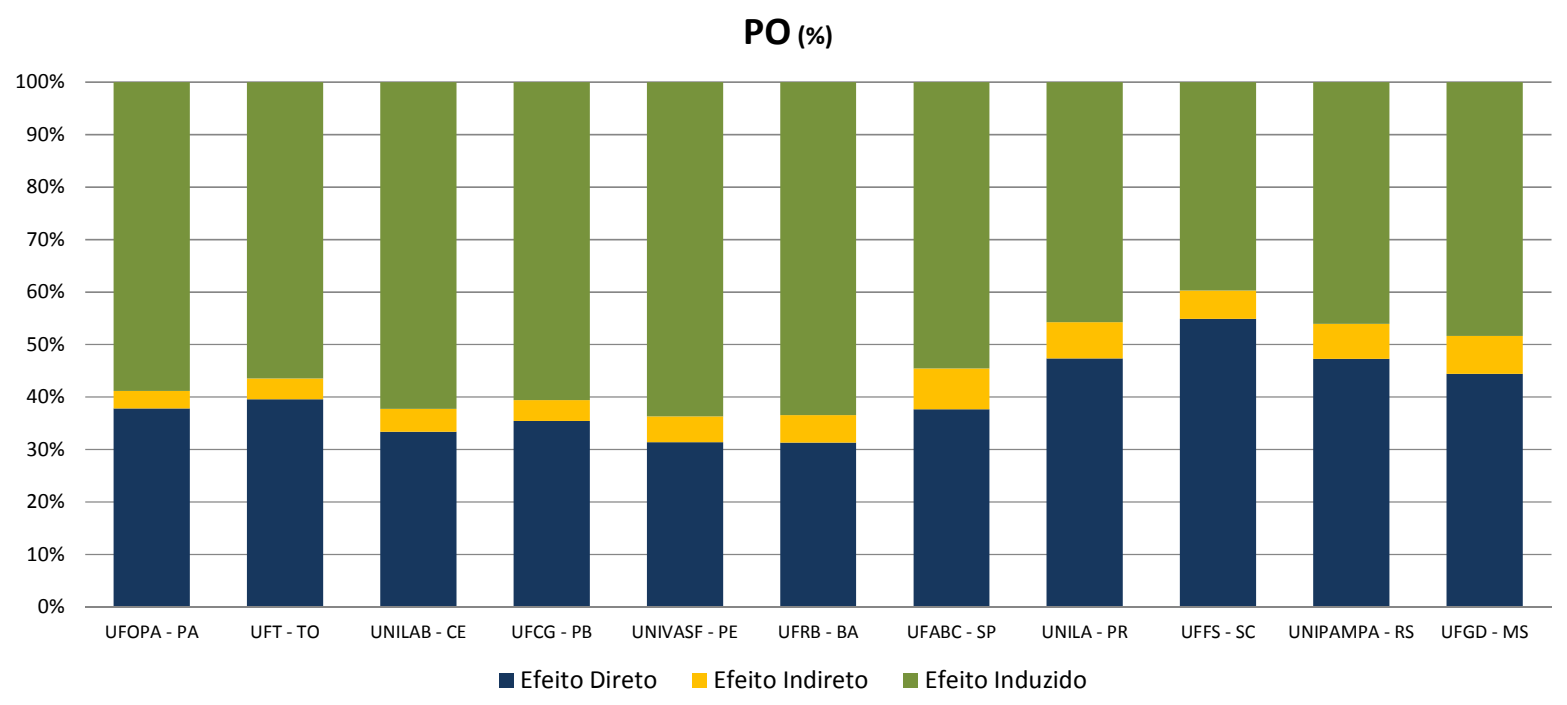

Fonte: Elaboração própria

Gráfico A.16 - Efeitos Percentuais da Expansão sobre Valor Bruto da Produção por Universidade para as Microrregiões com Maiores Efeitos Relativos sobre PIB no Período 2004-2010

VBP (em R\$ milhões)

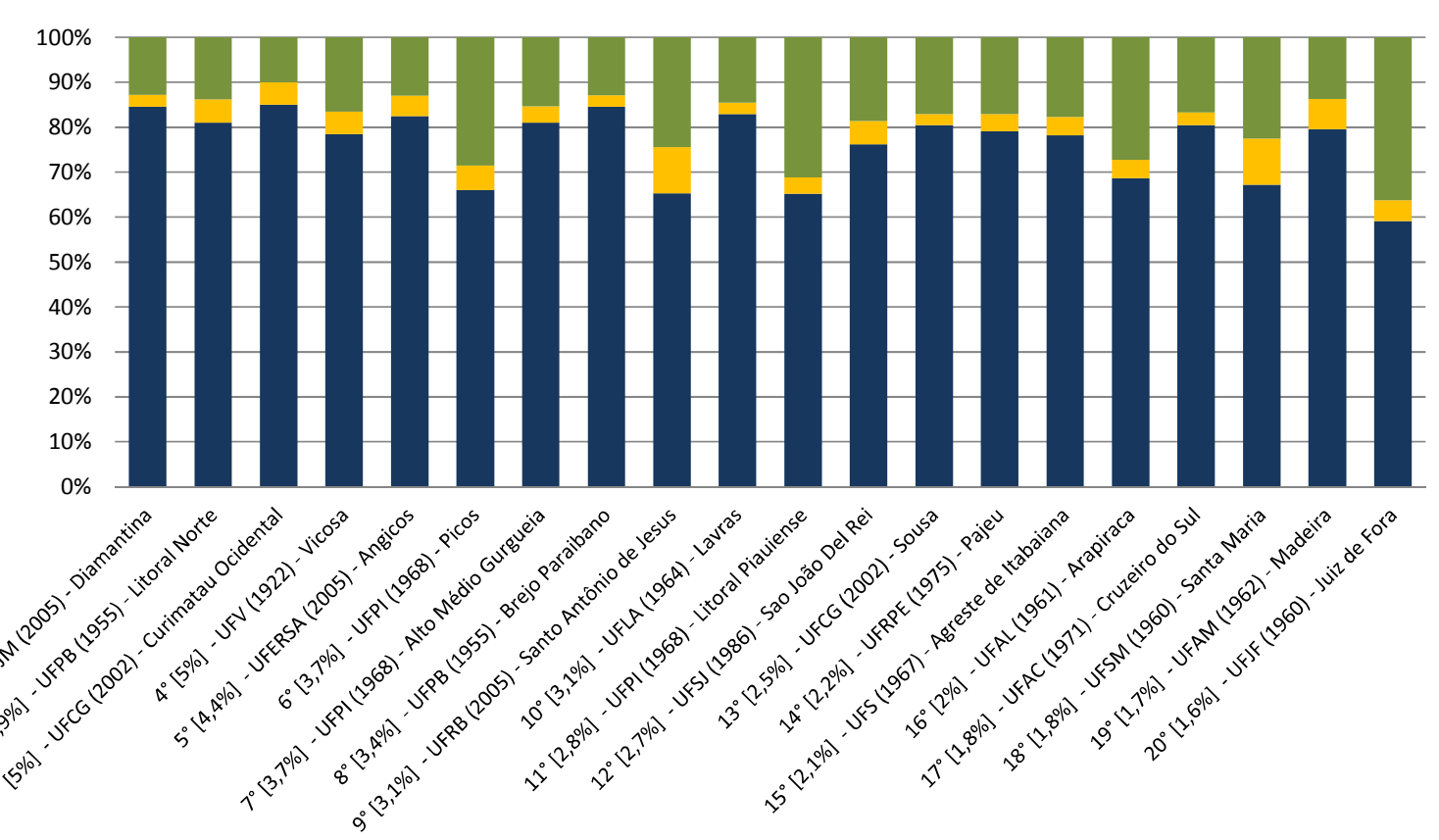

\footnotetext{
घ Efeito Direto $\square$ Eeito Indireto $\square$ Efeito Induzido

Fonte: Elaboração própria
} 
Gráfico A.17 - Efeitos Percentuais da Expansão sobre Valor Adicionado por Universidade para as Microrregiões com Maiores Efeitos Relativos sobre PIB no Período 2004-2010

VA (em R\$ milhões)
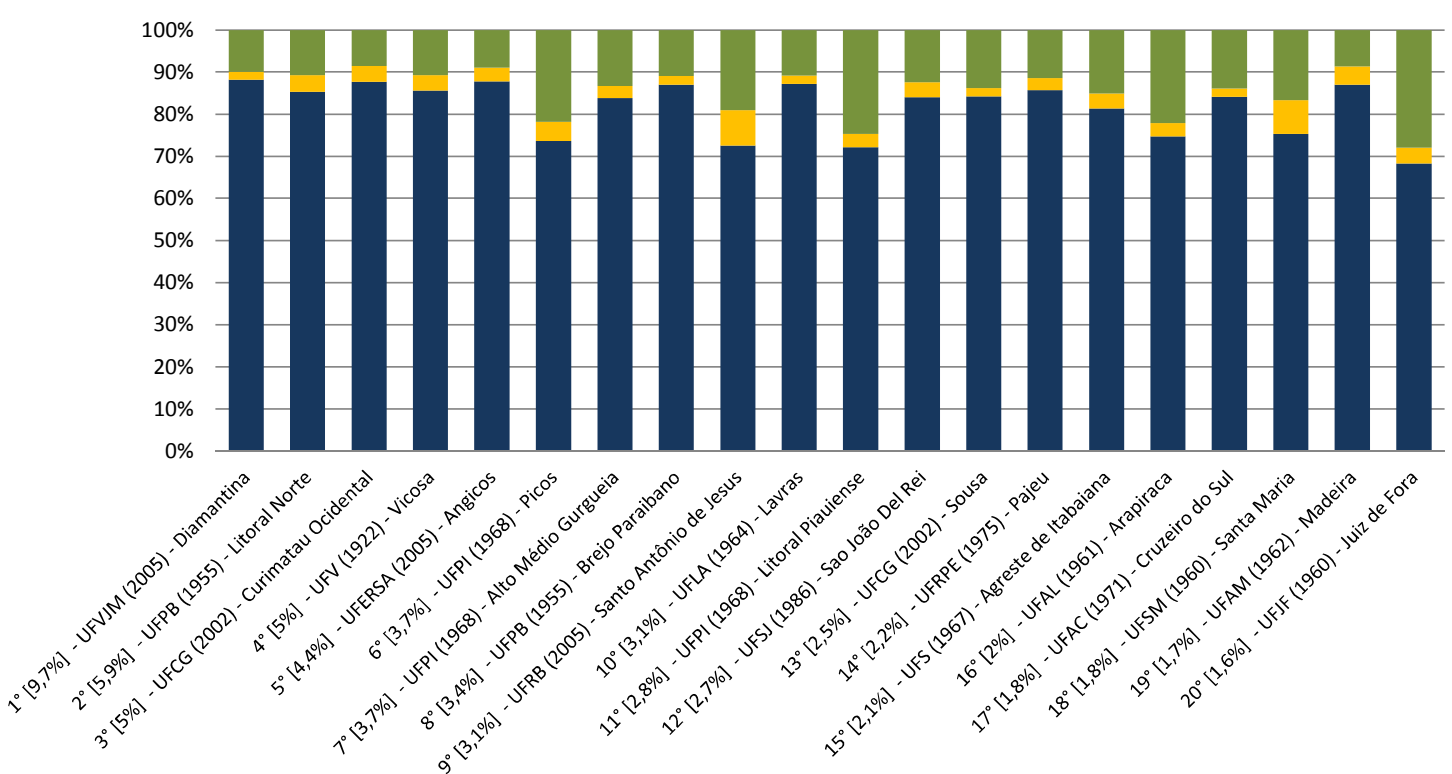

- Efeito Direto Efeito Indireto Efeito Induzido Fonte: Elaboração própria

Gráfico A.18 - Efeitos Percentuais da Expansão sobre Pessoal Ocupado por Universidade para as Microrregiões com Maiores Efeitos Relativos sobre PIB no Período 2004-2010

PO (em milhares)

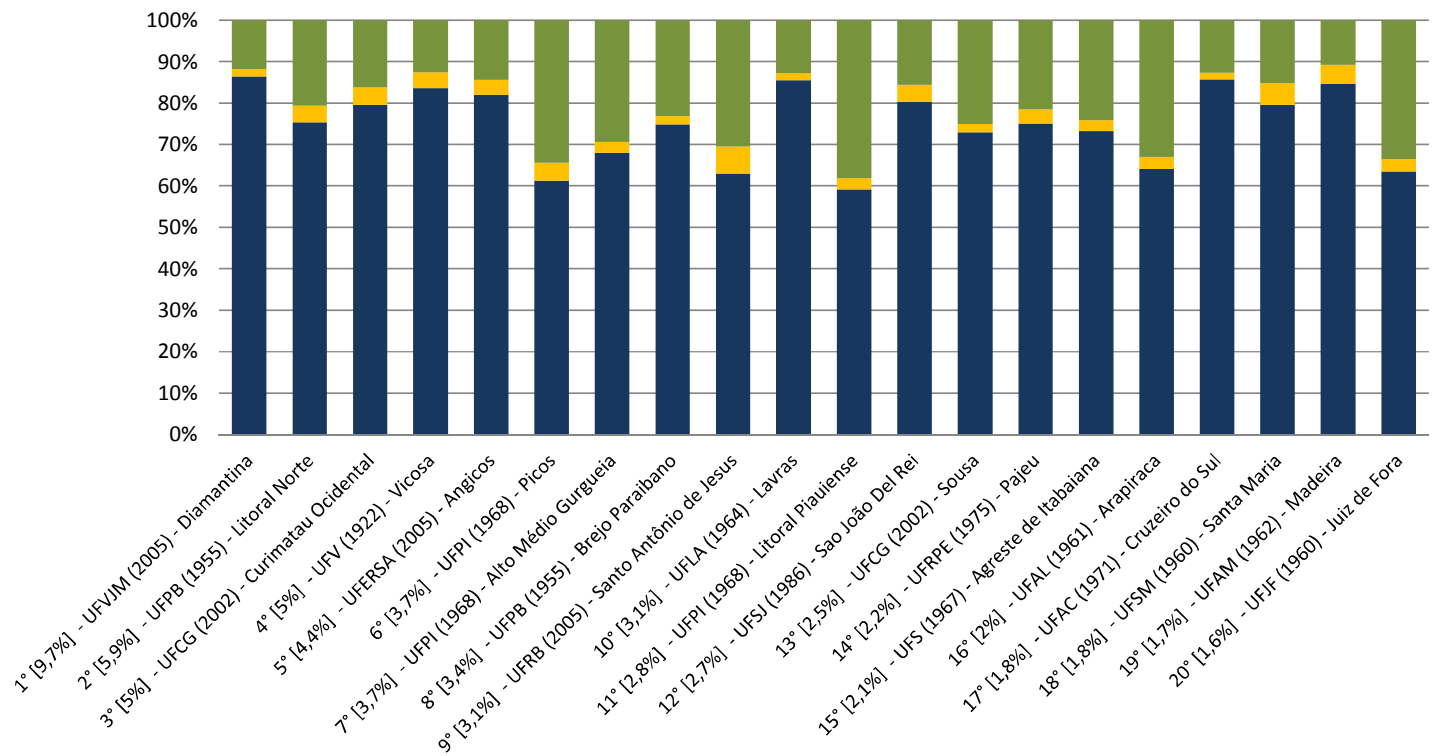


Gráfico A.19 - Efeitos Percentuais da Expansão sobre Valor Bruto da Produção para as Microrregiões com Maiores Efeitos Relativos sobre PIB no Período 2004-2010

VBP (em R\$ milhões)

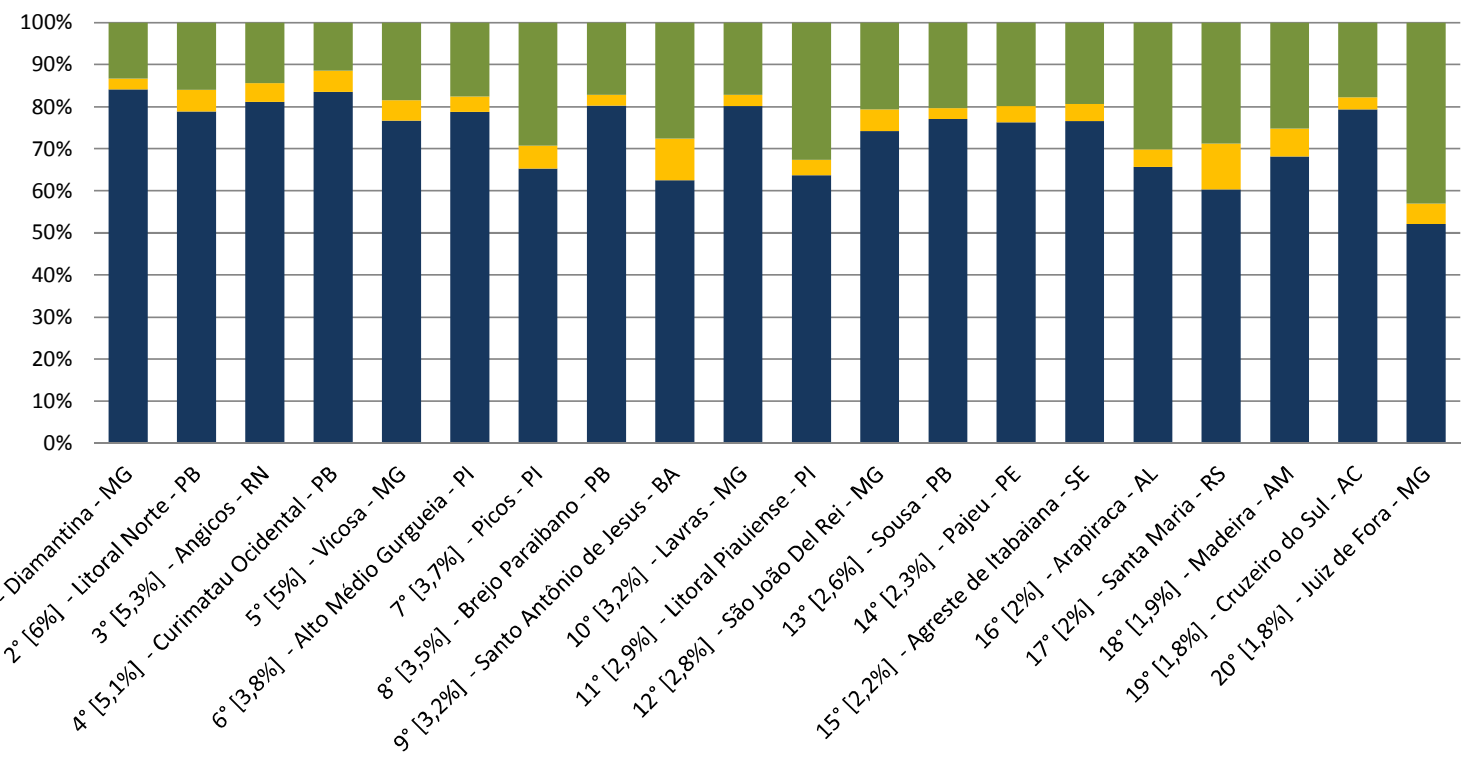

घfeito Direto $\square$ Efeito Indireto $\square$ Efeito Induzido

Fonte: Elaboração própria

Gráfico A.20 - Efeitos Percentuais da Expansão sobre Valor Adicionado para as

Microrregiões com Maiores Efeitos Relativos sobre PIB no Período 2004-2010

VA (em R\$ milhões)

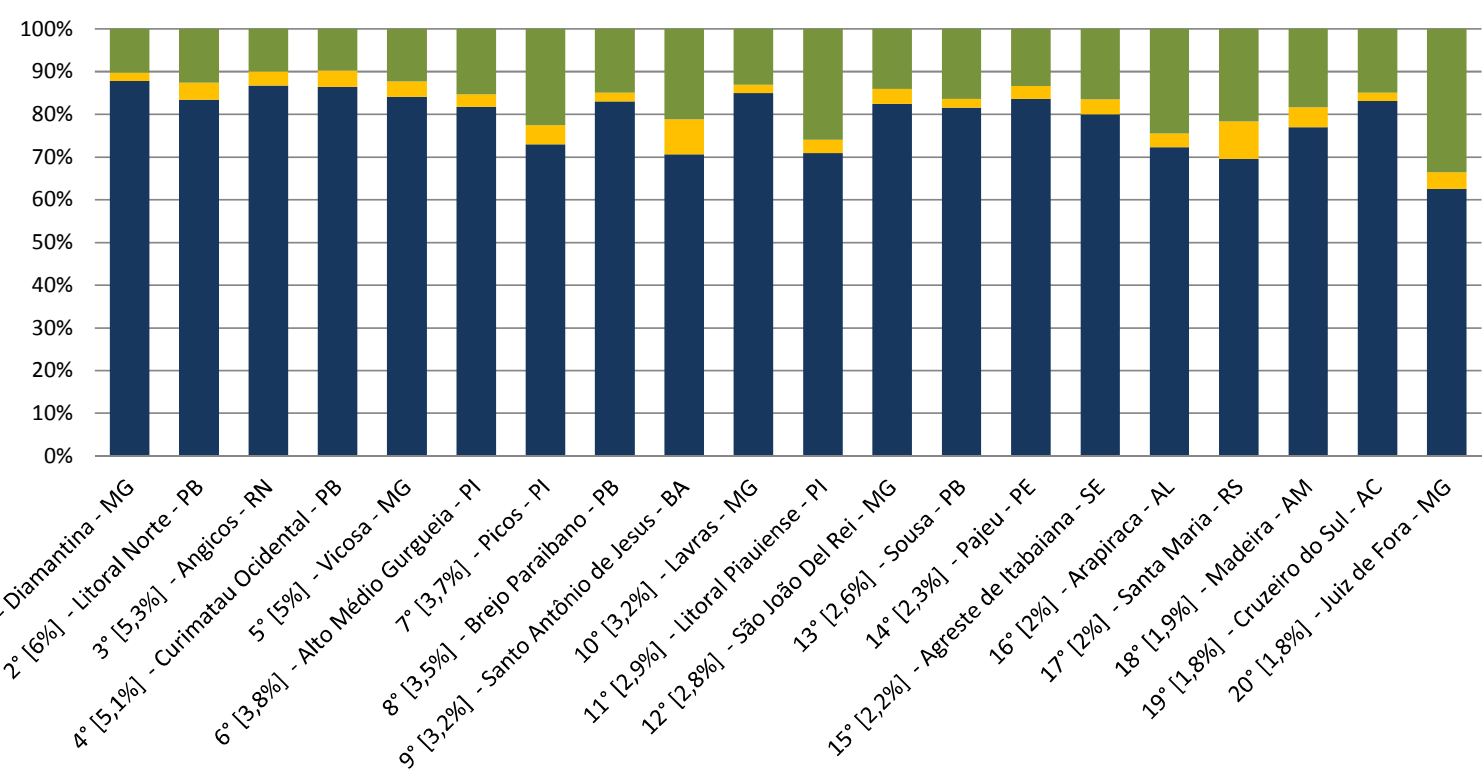

- Efeito Direto Efeito Indireto $\quad$ Efeito Induzido

Fonte: Elaboração própria 
Gráfico A.21 - Efeitos Percentuais da Expansão sobre Pessoal Ocupado para as Microrregiões com Maiores Efeitos Relativos sobre PIB no Período 2004-2010

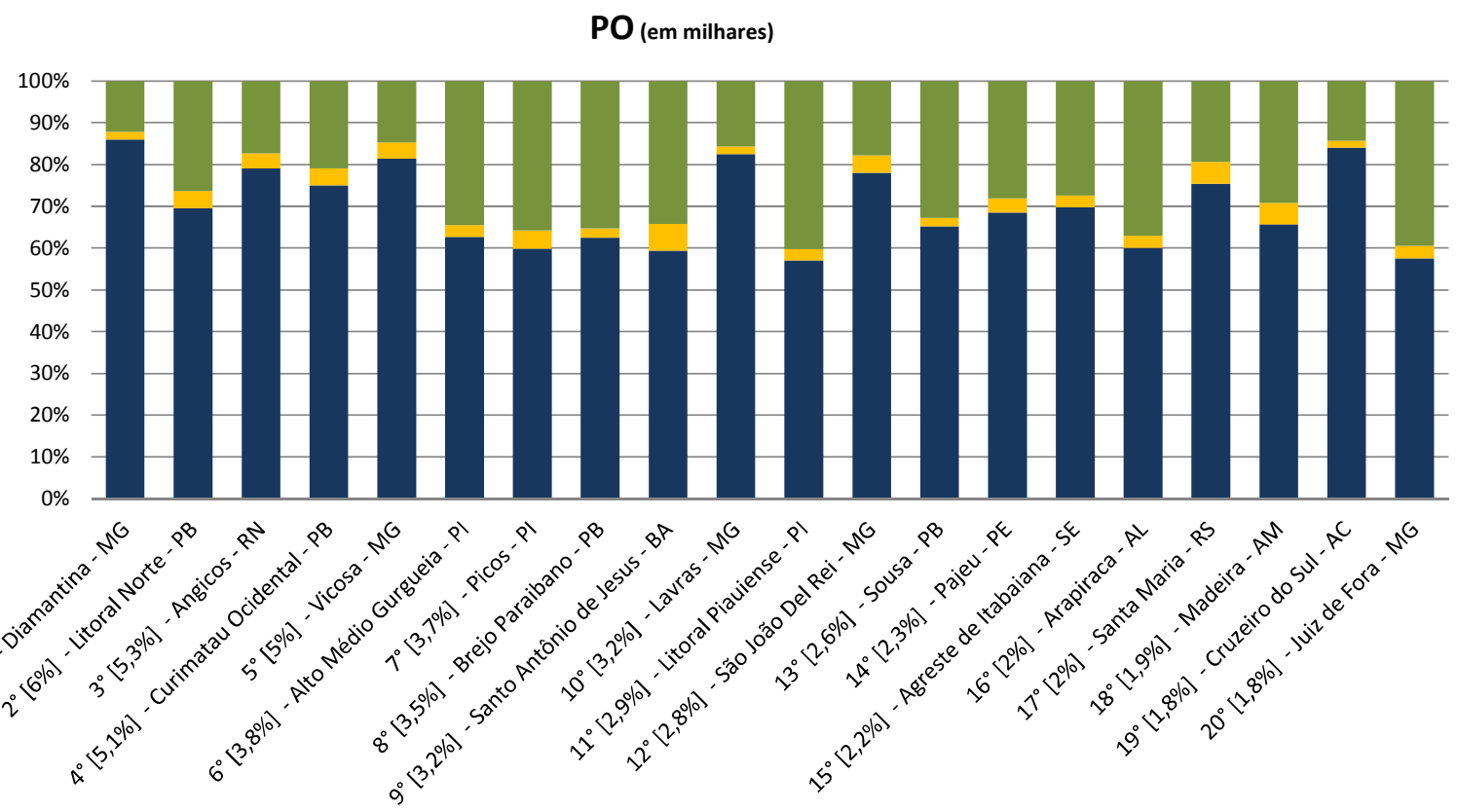

घ Efeito Direto $\quad$ Efeito Indireto $\quad$ Efeito Induzido

Fonte: Elaboração própria 


\section{APÊNDICE E - APÊNDICE DO CAPÍTULO 3}

Tabela A.2 - Estatísticas Básicas

\begin{tabular}{|c|c|c|c|c|c|}
\hline Variável & $\begin{array}{l}\text { Número de } \\
\text { Observações }\end{array}$ & Média & $\begin{array}{l}\text { Desvio- } \\
\text { Padrão }\end{array}$ & Mínimo & Máximo \\
\hline $\begin{array}{l}\text { Renda domiciliar per capita municipal } \\
1991\end{array}$ & 4.491 & 277,59 & 160,06 & 40,09 & $1.381,28$ \\
\hline População 1991 & 4.491 & 32.429 & 185.618 & 716 & 9.522 .506 \\
\hline $\begin{array}{l}\text { Renda domiciliar per capita municipal } \\
2000\end{array}$ & 5.490 & 386,43 & 210,43 & 61,83 & $1.976,90$ \\
\hline População 2000 & 5.490 & 30.655 & 185.384 & 355 & 10.300 .000 \\
\hline $\begin{array}{l}\text { Renda domiciliar per capita municipal } \\
2010\end{array}$ & 5.565 & 555,06 & 254,47 & 118,80 & $2.199,08$ \\
\hline População 2010 & 5.565 & 34.096 & 202.062 & 805 & 11.200 .000 \\
\hline Proporção de domicílios em área urbana & 5.565 & 0,6497 & 0,2150 & 0 & 1 \\
\hline Dummy Tratamento & 4.267 & 0,0281 & 0,1653 & 0 & 1 \\
\hline Dummy campus universitário já existente & 4.267 & 0,0265 & 0,1606 & 0 & 1 \\
\hline $\begin{array}{l}\text { População entre } 18 \text { e } 24 \text { anos cursando ou } \\
\text { com Ensino Médio Completo }\end{array}$ & 5.507 & 1.370 & 10.114 & 0 & 572.655 \\
\hline $\begin{array}{l}\text { Proporção de matrículas em instituições } \\
\text { estaduais }\end{array}$ & 5.507 & 0,0337 & 0,1719 & 0 & 1 \\
\hline $\begin{array}{l}\text { Proporção de matrículas em instituições } \\
\text { municipais }\end{array}$ & 5.507 & 0,0067 & 0,0766 & 0 & 1 \\
\hline $\begin{array}{l}\text { Proporção de matrículas em instituições } \\
\text { particulares }\end{array}$ & 5.507 & 0,0720 & 0,2489 & 0 & 1 \\
\hline $\begin{array}{l}\text { Dummy existência de curso oferecido por } \\
\text { universidade federal }\end{array}$ & 5.507 & 0,0370 & 0,1889 & 0 & 1 \\
\hline Dummy capital de unidade federativa & 5.507 & 0,0049 & 0,0699 & 0 & 1 \\
\hline Índice de Desenvolvimento Humano & 5.507 & 0,6993 & 0,0835 & 0,4670 & 0,9190 \\
\hline $\begin{array}{l}\text { Número de rodovias federais que passam } \\
\text { pelo município }\end{array}$ & 5.507 & 0,5397 & 0,7185 & 0 & 6 \\
\hline $\begin{array}{l}\text { Número de rodovias não-federais que } \\
\text { passam pelo município }\end{array}$ & 5.507 & 0,9642 & 1,2267 & 0 & 12 \\
\hline Distância à capital da unidade federativa & 5.507 & 253,20 & 163,68 & 0 & 1.476 \\
\hline $\begin{array}{l}\text { Dummy Coligação política prefeito- } \\
\text { presidente }\end{array}$ & 5.507 & 0,1507 & 0,3578 & 0 & 1 \\
\hline $\begin{array}{l}\text { Dummy Coligação política governador- } \\
\text { presidente }\end{array}$ & 5.507 & 0,0608 & 0,2390 & 0 & 1 \\
\hline Dummy Estadual Rondônia & 5.507 & 0,0094 & 0,0967 & 0 & 1 \\
\hline Dummy Estadual Acre & 5.507 & 0,0040 & 0,0631 & 0 & 1 \\
\hline Dummy Estadual Amazonas & 5.507 & 0,0113 & 0,1055 & 0 & 1 \\
\hline Dummy Estadual Roraima & 5.507 & 0,0027 & 0,0521 & 0 & 1 \\
\hline Dummy Estadual Pará & 5.507 & 0,0260 & 0,1591 & 0 & 1 \\
\hline Dummy Estadual Amapá & 5.507 & 0,0029 & 0,0538 & 0 & 1 \\
\hline Dummy Estadual Tocantins & 5.507 & 0,0252 & 0,1569 & 0 & 1 \\
\hline
\end{tabular}


Dummy Estadual Maranhão

Dummy Estadual Piauí

Dummy Estadual Ceará

Dummy Estadual Rio Grande do Norte

Dummy Estadual Paraíba

Dummy Estadual Pernambuco

Dummy Estadual Alagoas

Dummy Estadual Sergipe

Dummy Estadual Bahia

Dummy Estadual Minas Gerais

Dummy Estadual Espírito Santo

Dummy Estadual Rio de Janeiro

Dummy Estadual São Paulo

Dummy Estadual Paraná

Dummy Estadual Santa Catarina

Dummy Estadual Rio Grande do Sul

Dummy Estadual Mato Grosso do Sul

Dummy Estadual Mato Grosso

Dummy Estadual Goiás

Dummy Distrito Federal

\begin{tabular}{lllll}
5.507 & 0,0394 & 0,1946 & 0 & 1 \\
5.507 & 0,0401 & 0,1963 & 0 & 1 \\
5.507 & 0,0334 & 0,1797 & 0 & 1 \\
5.507 & 0,0301 & 0,1710 & 0 & 1 \\
5.507 & 0,0405 & 0,1971 & 0 & 1 \\
5.507 & 0,0336 & 0,1802 & 0 & 1 \\
5.507 & 0,0183 & 0,1342 & 0 & 1 \\
5.507 & 0,0136 & 0,1159 & 0 & 1 \\
5.507 & 0,0754 & 0,2640 & 0 & 1 \\
5.507 & 0,1549 & 0,3618 & 0 & 1 \\
5.507 & 0,0140 & 0,1174 & 0 & 1 \\
5.507 & 0,0165 & 0,1275 & 0 & 1 \\
5.507 & 0,1171 & 0,3216 & 0 & 1 \\
5.507 & 0,0725 & 0,2593 & 0 & 1 \\
5.507 & 0,0532 & 0,2245 & 0 & 1 \\
5.507 & 0,0848 & 0,2786 & 0 & 1 \\
5.507 & 0,0140 & 0,1174 & 0 & 1 \\
5.507 & 0,0229 & 0,1495 & 0 & 1 \\
5.507 & 0,0439 & 0,2050 & 0 & 1 \\
5.507 & 0,0002 & 0,0135 & 0 & 1 \\
\hline & & & &
\end{tabular}

Fonte: Elaboração própria 
Tabela A.3 - Modelo Probit de Escolha do Tratamento $(\mathbf{R}=\mathbf{0 , 1})$

\begin{tabular}{|c|c|}
\hline Variáveis & Tratamento \\
\hline Constante & $\begin{array}{c}-5,507 * * * \\
(1,429)\end{array}$ \\
\hline Dummy campus universitário já existente & $\begin{array}{c}-3,137 * * * \\
(0,555)\end{array}$ \\
\hline Proporção de matrículas em instituições estaduais & $\begin{array}{c}0,602 * * \\
(0,253)\end{array}$ \\
\hline Proporção de matrículas em instituições municipais & $\begin{array}{c}0,392 \\
(0,650)\end{array}$ \\
\hline Proporção de matrículas em instituições particulares & $\begin{array}{c}0,548 * * \\
(0,255)\end{array}$ \\
\hline Dummy existência de curso oferecido por universidade federal & $\begin{array}{c}1,215^{* * *} \\
(0,320)\end{array}$ \\
\hline População entre 18 e 24 anos cursando ou com Ensino Médio Completo & $\begin{array}{c}0,00006^{* *} \\
(0,00002)\end{array}$ \\
\hline Proporção de domicílios em área urbana & $\begin{array}{c}1,375^{* *} \\
(0,603)\end{array}$ \\
\hline Dummy capital de unidade federativa & $\begin{array}{c}-1,354^{*} \\
(0,721)\end{array}$ \\
\hline Índice de Desenvolvimento Humano & $\begin{array}{c}2,223 \\
(2,111)\end{array}$ \\
\hline Distância à capital da unidade federativa & $\begin{array}{c}0,001 \\
(0,001)\end{array}$ \\
\hline Dummy Coligação política prefeito-presidente & $\begin{array}{c}0,296^{*} \\
(0,180)\end{array}$ \\
\hline Dummy Coligação política governador-presidente & $\begin{array}{c}2,329 * * * \\
(0,499)\end{array}$ \\
\hline Dummy de população entre 20 e 50 mil habitantes & $\begin{array}{c}0,896^{* * * *} \\
(0,207)\end{array}$ \\
\hline Dummy de população entre 50 e 100 mil habitantes & $\begin{array}{c}1,272 * * * \\
(0,288)\end{array}$ \\
\hline Dummy de população entre 100 e 200 mil habitantes & $\begin{array}{c}1,409 * * * \\
(0,381)\end{array}$ \\
\hline Dummy de população entre 200 e 500 mil habitantes & $\begin{array}{c}1,834 * * * \\
(0,524)\end{array}$ \\
\hline Dummy de população acima de 500 mil habitantes & $\begin{array}{c}1,588 \\
(1,110)\end{array}$ \\
\hline Dummy de população da microrregião acima de 500 mil habitantes & $\begin{array}{c}-1,051 * * * \\
(0,306)\end{array}$ \\
\hline Dummies estaduais & $\operatorname{Sim}$ \\
\hline Número de Observações & 1553 \\
\hline Pseudo R-quadrado & 0,5135 \\
\hline LR Qui-Quadrado & $436,42 * * *$ \\
\hline
\end{tabular}

Obs.: (1) O desvio-padrão está entre parênteses. $* * *$ p-valor $<0,01, * *$ p-valor $<0,05, *$ p-valor $<0,1$;

Fonte: Elaboração própria 


\section{Tabela A.4 - Evolução do Número de Não-Tratados na Construção do Grupo de}

\section{Controle $(\mathbf{P}=\mathbf{0 , 0 5})$}

\begin{tabular}{lr}
\hline & Não-Tratados \\
\hline Número de Municípios* na base de dados inicial & 4123 \\
Número de Municípios* após filtro Evolução da renda no pré-tratamento & 3594 \\
Número de Municípios** após filtro Vizinhança & 1432 \\
Número de Municípios** para Diferenças-em-Diferenças & 109 \\
\hline
\end{tabular}

Obs.: * e ** indicam municípios nas agregações de AMC's nos períodos 1991-2000 e 20002010, respectivamente. Nos municípios para a estimação por Diferenças-em-Diferenças pode haver repetições, visto que o pareamento é com reposição.

Fonte: Elaboração própria

Tabela A.5 - Efeito da Expansão de Campi Universitários Federais sobre Renda per Capita $(\mathbf{P}=\mathbf{0 , 0 5})$

\begin{tabular}{lccc}
\hline \multicolumn{4}{c}{ Estimação por Diferenças-em-Diferenças com Pareamento por Escore de Propensão } \\
\hline Método & $(1)$ & $(2)$ & $(3)$ \\
\hline Pareamento com suavização da renda dos controles & Não & Sim & Sim \\
\hline Pareamento com suavização da renda dos tratados & Não & Não & Sim \\
\hline \multirow{2}{*}{ Número de Observações $=238$} & $0,032^{*}$ & $0,032^{* *}$ & $0,032^{* * *}$ \\
& $(0,016)$ & $(0,014)$ & $(0,008)$ \\
\hline
\end{tabular}

Obs.: $\quad 1$ - O desvio-padrão está entre parênteses; $* * *$ p-valor $<0,01, * *$ p-valor $<0,05, *$ p-valor $<0,1$;

2- A suavização da variável $\ln ($ renda per capita) é feita usando função spline cúbica do escore de propensão;

3- A Coluna (1) faz o pareamento sem suavização da renda, a Coluna (2) segue a metodologia de Blundell et al (2004), e a Coluna (3) segue o proposto por Meghir e Palme (2003);

4- A estimação do desvio-padrão da Coluna (1) segue Abadie e Imbens (2006), e as estimações do desvio-padrão das Colunas (2) e (3) usam o método de bootstrap com 1000 replicações, com cluster por município.

Fonte: Elaboração própria 
Tabela A.6 - Efeito da Expansão de Campi Universitários Federais com Interação pelo Tamanho Populacional do Município (P=0,05)

\begin{tabular}{lc}
\hline \multicolumn{2}{c}{$\begin{array}{c}\text { Estimação por Diferenças-em-Diferenças com Pareamento por } \\
\text { Escore de Propensão }\end{array}$} \\
\hline Método & $(1)$ \\
\hline Pareamento com suavização da renda dos controles & Não \\
\hline Pareamento com suavização da renda dos tratados & Não \\
\hline Tratamento & $0,059 * *$ \\
& $(0,029)$ \\
& $-2,67 \mathrm{E}-08$ \\
População & $5,59 \mathrm{E}-08$ \\
& $-3,34 \mathrm{E}-07 * * *$ \\
Tratamento . População & $9,19 \mathrm{E}-08$ \\
\hline & \\
\hline Obs.: $\quad$ 1- O desvio-padrão está entre parênteses; & \\
*** p-valor $<0,01, * *$ p-valor $<0,05, *$ p-valor $<0,1 ;$ \\
2- O desvio-padrão é estimado pelo método de bootstrap com 1000 \\
replicações, com cluster por município.
\end{tabular}

Tabela A.7 - Número de Municípios Tratados e Controles nos Subgrupos Amostrais $(\mathbf{P}=\mathbf{0 , 0 5})$

\begin{tabular}{cccc}
\hline Grupo & Controles & Tratados & Total \\
\hline 1 & 54 & 54 & 108 \\
2 & 55 & 55 & 110 \\
\hline Total & 109 & 109 & 218 \\
\hline
\end{tabular}

Obs.: Grupo 1 - municípios com até 65 mil habitantes; Grupo 2 - municípios com mais de 65 mil habitantes. Fonte: Elaboração própria 
Tabela A.8 - Efeito da Expansão de Campi Universitários Federais sobre Renda per Capita por Grupo $(\mathbf{P}=\mathbf{0 , 0 5})$

\begin{tabular}{lccc}
\hline \multicolumn{4}{c}{ Estimação por Diferenças-em-Diferenças com Pareamento por Escore de Propensão } \\
\hline Método & $(1)$ & $(2)$ & $(3)$ \\
\hline Pareamento com suavização da renda dos controles & Não & Sim & Sim \\
\hline Pareamento com suavização da renda dos tratados & Não & Não & Sim \\
\hline Grupo 1 & $0,052^{* *}$ & $0,054^{* * * *}$ & $0,054^{* * *}$ \\
Número de Observações $=108$ & $(0,023)$ & $(0,019)$ & $(0,010)$ \\
Grupo 2 & 0,011 & 0,01 & 0,01 \\
Número de Observações $=110$ & $(0,023)$ & $(0,020)$ & $(0,011)$ \\
\hline
\end{tabular}

Obs.: 1- O desvio-padrão está entre parênteses; $* * *$ p-valor $<0,01, * *$ p-valor $<0,05, *$ p-valor $<0,1$;

2- A suavização da variável $\ln$ (renda per capita) é feita usando função spline cúbica do escore de propensão;

3- A Coluna (1) faz o pareamento sem suavização da renda, a Coluna (2) segue a metodologia de Blundell et al (2004), e a Coluna (3) segue o proposto por Meghir e Palme (2003);

4- A estimação do desvio-padrão da Coluna (1) segue Abadie e Imbens (2006), e as estimações do desvio-padrão das Colunas (2) e (3) usam o método de bootstrap com 1000 replicações, com cluster por município.

Fonte: Elaboração própria

Tabela A.9 - Estimador da Análise de Sensibilidade ( $\Gamma$ ) para o Efeito do Tratamento sobre a Renda nos Municípios Tratados $(\mathbf{P}=\mathbf{0 , 0 5})$

\begin{tabular}{lccc}
\hline \multirow{2}{*}{ Sensibilidade para o Efeito sobre Renda } & \multicolumn{3}{c}{$\Gamma$} \\
\cline { 2 - 4 } & $\begin{array}{c}\text { Amostra } \\
\text { Inteira }\end{array}$ & Grupo 1 & Grupo 2 \\
\hline Renda Domiciliar Per Capita Municipal & 1,48 & 1,79 & 1,24 \\
\hline
\end{tabular}

Obs.: Os valores críticos correspondem ao menor valor de $\Gamma$ que produz um intervalo entre os estimadores mínimo e máximo de Hodges-Lehmann que contempla o valor zero.

Fonte: Elaboração própria 


\section{Tabela A.10 - Evolução do Número de Não-Tratados na Construção do Grupo de}

\section{Controle $(\mathbf{P}=\mathbf{0 , 2})$}

\begin{tabular}{lr}
\hline & Não-Tratados \\
\hline Número de Municípios* na base de dados inicial & 4123 \\
Número de Municípios* após filtro Evolução da renda no pré-tratamento & 3594 \\
Número de Municípios** após filtro Vizinhança & 1432 \\
Número de Municípios** para Diferenças-em-Diferenças & 121 \\
\hline Obs.: * e ** indicam municípios nas agregações de AMC's nos períodos 1991-2000 e 2000- \\
2010, respectivamente. Nos municípios para a estimação por Diferenças-em-Diferenças pode \\
haver repetições, visto que o pareamento é com reposição. \\
Fonte: Elaboração própria
\end{tabular}

Tabela A.11 - Efeito da Expansão de Campi Universitários Federais sobre Renda per Capita $(\mathbf{P}=\mathbf{0 , 2})$

\begin{tabular}{lccc}
\hline \multicolumn{4}{c}{ Estimação por Diferenças-em-Diferenças com Pareamento por Escore de Propensão } \\
\hline Método & $(1)$ & $(2)$ & $(3)$ \\
\hline Pareamento com suavização da renda dos controles & Não & Sim & Sim \\
\hline Pareamento com suavização da renda dos tratados & Não & Não & Sim \\
\hline \multirow{2}{*}{ Número de Observações $=238$} & $0,034^{* *}$ & $0,033^{* *}$ & $0,033^{* * *}$ \\
& $(0,015)$ & $(0,014)$ & $(0,008)$ \\
\hline
\end{tabular}

Obs.: 1- O desvio-padrão está entre parênteses;

*** p-valor $<0,01, * *$ p-valor $<0,05, *$ p-valor $<0,1$;

2- A suavização da variável $\ln ($ renda per capita) é feita usando função spline cúbica do escore de propensão;

3- A Coluna (1) faz o pareamento sem suavização da renda, a Coluna (2) segue a metodologia de Blundell et al (2004), e a Coluna (3) segue o proposto por Meghir e Palme (2003);

4- A estimação do desvio-padrão da Coluna (1) segue Abadie e Imbens (2006), e as estimações do desvio-padrão das Colunas (2) e (3) usam o método de bootstrap com 1000 replicações, com cluster por município.

Fonte: Elaboração própria 
Tabela A.12 - Efeito da Expansão de Campi Universitários Federais com Interação pelo

Tamanho Populacional do Município $(\mathrm{P}=0,2)$

Estimação por Diferenças-em-Diferenças com Pareamento por Escore de Propensão

\begin{tabular}{lc}
\hline Método & $(1)$ \\
\hline Pareamento com suavização da renda dos controles & Não \\
\hline Pareamento com suavização da renda dos tratados & Não \\
\hline \multirow{2}{*}{ Tratamento } & $0,049 *$ \\
& $(0,029)$ \\
População & $-6,97 \mathrm{E}-09$ \\
& $5,25 \mathrm{E}-08$ \\
Tratamento . População & $-1,72 \mathrm{E}-07$ \\
\end{tabular}

Obs.: $\quad$ 1- O desvio-padrão está entre parênteses;

$* * *$ p-valor $<0,01, * *$ p-valor $<0,05, *$ p-valor $<0,1$;

2- O desvio-padrão é estimado pelo método de bootstrap com 1000 replicações, com cluster por município.

Fonte: Elaboração própria

Tabela A.13 - Número de Municípios Tratados e Controles nos Subgrupos Amostrais $(\mathbf{P}=\mathbf{0 , 2})$

\begin{tabular}{cccc}
\hline Grupo & Controles & Tratados & Total \\
\hline 1 & 59 & 59 & 118 \\
2 & 62 & 62 & 124 \\
\hline Total & 121 & 121 & 242 \\
\hline
\end{tabular}

Obs.: Grupo 1 - municípios com até 65 mil habitantes;

Grupo 2 - municípios com mais de 65 mil habitantes.

Fonte: Elaboração própria 
Tabela A.14 - Efeito da Expansão de Campi Universitários Federais sobre Renda per Capita por Grupo $(\mathbf{P}=0,2)$

\begin{tabular}{lccc}
\hline \multicolumn{4}{c}{ Estimação por Diferenças-em-Diferenças com Pareamento por Escore de Propensão } \\
\hline Método & $(1)$ & $(2)$ & $(3)$ \\
\hline Pareamento com suavização da renda dos controles & Não & Sim & Sim \\
\hline Pareamento com suavização da renda dos tratados & Não & Não & Sim \\
\hline Grupo 1 & $0,053^{* *}$ & $0,053^{* * *}$ & $0,053^{* * *}$ \\
Número de Observações $=118$ & $(0,021)$ & $(0,018)$ & $(0,009)$ \\
Grupo 2 & 0,016 & 0,013 & 0,013 \\
Número de Observações $=124$ & $(0,021)$ & $(0,018)$ & $(0,009)$ \\
\hline
\end{tabular}

Obs.: 1 - O desvio-padrão está entre parênteses; $* * *$ p-valor $<0,01, * *$ p-valor $<0,05, *$ p-valor $<0,1$;

2- A suavização da variável ln(renda per capita) é feita usando função spline cúbica do escore de propensão;

3- A Coluna (1) faz o pareamento sem suavização da renda, a Coluna (2) segue a metodologia de Blundell et al (2004), e a Coluna (3) segue o proposto por Meghir e Palme (2003);

4- A estimação do desvio-padrão da Coluna (1) segue Abadie e Imbens (2006), e as estimações do desvio-padrão das Colunas (2) e (3) usam o método de bootstrap com 1000 replicações, com cluster por município.

Fonte: Elaboração própria

Tabela A.15 - Estimador da Análise de Sensibilidade ( $\Gamma$ ) para o Efeito do Tratamento sobre a Renda nos Municípios Tratados $(\mathbf{P}=\mathbf{0 , 2})$

\begin{tabular}{lccc}
\hline \multirow{2}{*}{ Sensibilidade para o Efeito sobre Renda } & \multicolumn{3}{c}{$\Gamma$} \\
\cline { 2 - 4 } & $\begin{array}{c}\text { Amostra } \\
\text { Inteira }\end{array}$ & Grupo 1 & Grupo 2 \\
\hline Renda Domiciliar Per Capita Municipal & 1,54 & 1,87 & 1,30 \\
\hline Obs.: Os valores críticos correspondem ao menor valor de $\Gamma$ que produz um intervalo entre os \\
estimadores mínimo e máximo de Hodges-Lehmann que contempla o valor zero. \\
Fonte: Elaboração própria
\end{tabular}


Tabela A.16 - Modelo Probit de Escolha do Tratamento (R=0,1) Controlando por Número de Rodovias

\begin{tabular}{|c|c|}
\hline Variáveis & Tratamento \\
\hline Constante & $\begin{array}{c}-4,935 * * * \\
(1,389)\end{array}$ \\
\hline Dummy campus universitário já existente & $\begin{array}{c}-3,186^{* * *} \\
(0,507)\end{array}$ \\
\hline Proporção de matrículas em instituições estaduais & $\begin{array}{c}0,623^{* *} \\
(0,249)\end{array}$ \\
\hline Proporção de matrículas em instituições municipais & $\begin{array}{c}0,312 \\
(0,653)\end{array}$ \\
\hline Proporção de matrículas em instituições particulares & $\begin{array}{c}0,403 \\
(0,259)\end{array}$ \\
\hline Dummy existência de curso oferecido por universidade federal & $\begin{array}{c}1,146 * * * \\
(0,316)\end{array}$ \\
\hline População entre 18 e 24 anos com Ensino Médio Completo & $\begin{array}{c}0,00004 * * \\
(0,00002)\end{array}$ \\
\hline Proporção de domicílios em área urbana & $\begin{array}{c}1,305 * * \\
(0,591)\end{array}$ \\
\hline Índice de Desenvolvimento Humano & $\begin{array}{c}1,304 \\
(2,045)\end{array}$ \\
\hline Dummy rodovia federal & $\begin{array}{c}0,157 \\
(0,167)\end{array}$ \\
\hline Dummy rodovia não-federal & $\begin{array}{l}-0,108 \\
(0,178)\end{array}$ \\
\hline Distância à capital da unidade federativa & $\begin{array}{c}0,001 * * \\
(0,000)\end{array}$ \\
\hline Dummy Coligação política prefeito-presidente & $\begin{array}{l}0,313 * \\
(0,178)\end{array}$ \\
\hline Dummy Coligação política governador-presidente & $\begin{array}{c}1,901 * * * \\
(0,456)\end{array}$ \\
\hline Dummy de população entre 20 e 30 mil habitantes & $\begin{array}{c}0,619^{* *} \\
(0,243)\end{array}$ \\
\hline Dummy de população entre 30 e 50 mil habitantes & $\begin{array}{c}1,195 * * * \\
(0,240)\end{array}$ \\
\hline Dummy de população entre 50 e 100 mil habitantes & $\begin{array}{c}1,364 * * * \\
(0,292)\end{array}$ \\
\hline Dummy de população entre 100 e 200 mil habitantes & $\begin{array}{c}1,526 * * * \\
(0,376)\end{array}$ \\
\hline Dummy de população entre 200 e 500 mil habitantes & $\begin{array}{c}1,573 * * * \\
(0,475)\end{array}$ \\
\hline Dummy de população acima de 500 mil habitantes & $\begin{array}{c}1,263 \\
(0,950)\end{array}$ \\
\hline Dummies estaduais & $\operatorname{Sim}$ \\
\hline Número de Observações & 1553 \\
\hline Pseudo R-quadrado & 0,5032 \\
\hline
\end{tabular}

Obs.: (1) O desvio-padrão está entre parênteses. *** p-valor $<0,01, * *$ p-valor $<0,05, *$ p-valor $<0,1$;

Fonte: Elaboração própria 


\section{APÊNDICE F - APÊNDICE DO CAPÍTULO 4}

Tabela A.17 - Estatísticas Básicas

\begin{tabular}{lrrrrrr}
\hline \multicolumn{1}{c}{ Variável } & $\begin{array}{c}\text { Número de } \\
\text { Observações }\end{array}$ & Média & $\begin{array}{c}\text { Desvio- } \\
\text { Padrão }\end{array}$ & Mínimo & Máximo \\
\hline Dummy de Partido de Coligação Política de 2004 eleito em 2008 & 5.565 & 0,7601 & 0,4271 & 0 & 1 \\
Dummy de Partido Político reeleito em 2008 & 5.565 & 0,3405 & 0,4739 & 0 & 1 \\
\hline
\end{tabular}

Fonte: Elaboração própria

Tabela A.18 - Modelo Probit de Escolha do Tratamento $(\mathrm{R}=\mathbf{0 , 1})$

\begin{tabular}{|c|c|}
\hline Variáveis & Tratamento \\
\hline Constante & $\begin{array}{c}-6,091 * * * \\
(1,343)\end{array}$ \\
\hline Dummy campus universitário já existente & $\begin{array}{c}-3,026 * * * \\
(0,542)\end{array}$ \\
\hline Proporção de matrículas em instituições estaduais & $\begin{array}{c}0,573 * * \\
(0,248)\end{array}$ \\
\hline Proporção de matrículas em instituições municipais & $\begin{array}{c}0,407 \\
(0,643)\end{array}$ \\
\hline Proporção de matrículas em instituições particulares & $\begin{array}{c}0,516 * * \\
(0,243)\end{array}$ \\
\hline Dummy existência de curso oferecido por universidade federal & $\begin{array}{c}1,159 * * * \\
(0,306)\end{array}$ \\
\hline População entre 18 e 24 anos cursando ou com Ensino Médio Completo & $\begin{array}{c}0,00006 * * \\
(0,00002)\end{array}$ \\
\hline Proporção de domicílios em área urbana & $\begin{array}{c}1,418 * * \\
(0,576)\end{array}$ \\
\hline Dummy capital de unidade federativa & $\begin{array}{c}-1,433 * * \\
(0,712)\end{array}$ \\
\hline Índice de Desenvolvimento Humano & $\begin{array}{c}2,93 \\
(2,000)\end{array}$ \\
\hline Distância à capital da unidade federativa & $\begin{array}{c}0,0005 \\
(0,0005)\end{array}$ \\
\hline Dummy Coligação política prefeito-presidente & $\begin{array}{l}0,314^{*} \\
(0,177)\end{array}$ \\
\hline Dummy Coligação política governador-presidente & $\begin{array}{c}2,234 * * * \\
(0,470)\end{array}$ \\
\hline Dummy de população entre 20 e 50 mil habitantes & $\begin{array}{c}0,954 * * * \\
(0,203)\end{array}$ \\
\hline Dummy de população entre 50 e 100 mil habitantes & $\begin{array}{c}1,374 * * * \\
(0,279)\end{array}$ \\
\hline Dummy de população entre 100 e 200 mil habitantes & $\begin{array}{c}1,484 * * * \\
(0,373)\end{array}$ \\
\hline Dummy de população entre 200 e 500 mil habitantes & $\begin{array}{c}1,842 * * * \\
(0,522)\end{array}$ \\
\hline Dummy de população acima de 500 mil habitantes & $\begin{array}{c}1,651 \\
(1,112)\end{array}$ \\
\hline Dummy de população da microrregião acima de 500 mil habitantes & $\begin{array}{c}-1,07 * * * \\
(0,307)\end{array}$ \\
\hline Dummies estaduais & $\operatorname{Sim}$ \\
\hline Número de Observações & 1867 \\
\hline Pseudo R-quadrado & 0,5216 \\
\hline LR Qui-Quadrado & $467,43 * * *$ \\
\hline
\end{tabular}

Obs.: (1) O desvio-padrão está entre parênteses.

*** $\mathrm{p}$-valor $<0,01, * * \mathrm{p}$-valor $<0,05,{ }^{*} \mathrm{p}$-valor $<0,1$;

Fonte: Elaboração própria 
Tabela A.19 - Evolução do Número de Não-Tratados na Construção do Grupo de Controle $(\mathbf{P}=\mathbf{0 , 0 5})$

\begin{tabular}{lr}
\hline & Não-Tratados \\
\hline Número de Municípios* na base de dados inicial & 4123 \\
Número de Municípios** após filtro Vizinhança & 1746 \\
Número de Municípios** para Diferenças-em-Diferenças & 113 \\
\hline
\end{tabular}

Obs.: * e ** indicam municípios nas agregações de AMC's nos períodos 1991-2000 e 20002010, respectivamente. Nos municípios para a estimação por Diferenças-em-Diferenças pode haver repetições, visto que o pareamento é com reposição.

Fonte: Elaboração própria

Tabela A.20 - Efeito da Expansão de Campi Universitários Federais sobre Reeleição Política em $2008(P=0,05)$

\begin{tabular}{lccc}
\hline \multicolumn{4}{c}{ Estimação por Diferenças-em-Diferenças com Pareamento por Escore de Propensão } \\
\hline Método & $(1)$ & $(2)$ & $(3)$ \\
\hline Pareamento com suavização de reeleição dos controles & Não & Sim & Sim \\
\hline Pareamento com suavização de reeleição dos tratados & Não & Não & Sim \\
\hline \multirow{2}{*}{ Partido Político Eleito em 2004 Vencedor em 2008 } & $0,1^{* *}$ & 0,099 & $0,099^{* *}$ \\
& $(0,049)$ & $(0,065)$ & $(0,045)$ \\
Partido Político da Coligação Eleita em 2004 Vencedor em 2008 & $0,27^{* * *}$ & $0,264^{* * *}$ & $0,264^{* * *}$ \\
& $(0,040)$ & $(0,084)$ & $(0,081)$ \\
\hline
\end{tabular}

Obs.: 1 - Número de observações $=226$

2- O desvio-padrão está entre parênteses;

*** p-valor $<0,01, * *$ p-valor $<0,05, *$ p-valor $<0,1$;

3- A suavização da variável binária reeleição é feita usando função spline cúbica do escore de propensão;

4- A Coluna (1) faz o pareamento sem suavização da variável reeleição, a Coluna (2) segue a metodologia de Blundell et al (2004), e a Coluna (3) segue o proposto por Meghir e Palme (2003); 5- A estimação do desvio-padrão da Coluna (1) segue Abadie e Imbens (2006), e as estimações do desvio-padrão das Colunas (2) e (3) usam o método de bootstrap com 1000 replicações, com cluster por município.

Fonte: Elaboração própria 
Tabela A.21 - Efeito da Expansão de Campi Universitários Federais com Interação pelo Tamanho Populacional do Município $(\mathbf{P = 0 , 0 5 )}$

\begin{tabular}{lcc}
\hline \multicolumn{3}{c}{ Estimação por Diferenças-em-Diferenças com Pareamento por Escore de Propensão } \\
\hline Variável Dependente: Reeleição & $\begin{array}{c}\text { Partido Político Eleito em } \\
\text { 2004 Vencedor em 2008 }\end{array}$ & $\begin{array}{c}\text { Partido Político da } \\
\text { Vencedor Elita em 2004 }\end{array}$ \\
\hline Pareamento com suavização de reeleição dos controles & Não & Não \\
\hline Pareamento com suavização de reeleição dos tratados & Não & Não \\
\hline \multirow{2}{*}{ Tratamento } & 0,065 & $0,165^{*}$ \\
& $(0,104)$ & $(0,087)$ \\
População & $-3,63 \mathrm{E}-08$ & $-1,23 \mathrm{E}-07$ \\
& $1,48 \mathrm{E}-07$ & $1,62 \mathrm{E}-07$ \\
Tratamento . População & $2,82 \mathrm{E}-09$ & $-1,08 \mathrm{E}-07$ \\
& $2,75 \mathrm{E}-07$ & $2,44 \mathrm{E}-07$ \\
\hline
\end{tabular}

Obs.: 1- O desvio-padrão está entre parênteses;

$* * *$ p-valor $<0,01, * *$ p-valor $<0,05, *$ p-valor $<0,1$;

2- O desvio-padrão é estimado pelo método de bootstrap com 1000 replicações, com cluster por município.

Fonte: Elaboração própria

Tabela A.22 - Número de Municípios Tratados e Controles nos Subgrupos Amostrais para Reeleição $(\mathbf{P}=\mathbf{0 , 0 5})$

\begin{tabular}{cccc}
\hline Grupo & Controles & Tratados & Total \\
\hline 1 & 56 & 56 & 112 \\
2 & 57 & 57 & 114 \\
\hline Total & 113 & 113 & 226 \\
\hline
\end{tabular}

Obs.: Grupo 1 - municípios com até 65 mil habitantes;

Grupo 2 - municípios com mais de 65 mil habitantes.

Fonte: Elaboração própria 
Tabela A.23 - Efeito da Expansão de Campi Universitários Federais sobre Reeleição Política em 2008 por Grupo $(P=0,05)$

\begin{tabular}{lccc}
\hline \multicolumn{4}{c}{ Estimação por Diferenças-em-Diferenças com Pareamento por Escore de Propensão } \\
\hline Método & $(1)$ & $(2)$ & $(3)$ \\
\hline Pareamento com suavização de reeleição dos controles & Não & Sim & Sim \\
\hline Pareamento com suavização de reeleição dos tratados & Não & Não & Sim \\
\hline Variável dependente: Partido Político Eleito em 2004 Vencedor em 2008 & & \\
Grupo 1 & 0,071 & 0,08 & $0,121^{* * *}$ \\
Número de Observações = 118 & $(0,082)$ & $(0,069)$ & $(0,032)$ \\
Grupo 2 & 0,089 & 0,08 & 0,039 \\
Número de Observações = 124 & $(0,071)$ & $(0,084)$ & $(0,048)$ \\
\hline Variável dependente: Partido Político da Coligação Eleita em & 2004 Vencedor em 2008 & \\
Grupo 1 & $0,197^{* * *}$ & $0,186^{* * *}$ & $0,168^{* * * *}$ \\
Número de Observações = 118 & $(0,074)$ & $(0,058)$ & $(0,039)$ \\
Grupo 2 & $0,266^{* * *}$ & $0,274^{* * *}$ & $0,291^{* * *}$ \\
Número de Observações = 124 & $(0,050)$ & $(0,085)$ & $(0,078)$ \\
\hline
\end{tabular}

Obs.: $\quad$ 1- Número de observações $=226$

2- O desvio-padrão está entre parênteses;

*** p-valor $<0,01, * *$ p-valor $<0,05, *$ p-valor $<0,1$;

3- A suavização da variável binária reeleição é feita usando função spline cúbica do escore de propensão;

4- A Coluna (1) faz o pareamento sem suavização da variável reeleição, a Coluna (2) segue a metodologia de Blundell et al (2004), e a Coluna (3) segue o proposto por Meghir e Palme (2003); 5- A estimação do desvio-padrão da Coluna (1) segue Abadie e Imbens (2006), e as estimações do desvio-padrão das Colunas (2) e (3) usam o método de bootstrap com 1000 replicações, com cluster por município.

Fonte: Elaboração própria

Tabela A.24 - Estimador da Análise de Sensibilidade ( $\Gamma$ ) para o Efeito do Tratamento sobre a Reeleição nos Municípios Tratados $(\mathbf{P}=0,05)$

\begin{tabular}{lccc}
\hline \multirow{2}{*}{ Sensibilidade para o Efeito sobre Reeleição } & \multicolumn{3}{c}{$\Gamma$} \\
\cline { 2 - 4 } & $\begin{array}{c}\text { Amostra } \\
\text { Inteira }\end{array}$ & Grupo 1 & Grupo 2 \\
\hline Partido Político Eleito em 2004 Vencedor em 2008 & 1,00 & 1,00 & 1,00 \\
Partido Político da Coligação Eleita em 2004 Vencedor em 2008 & 2,44 & 1,59 & 2,32 \\
\hline
\end{tabular}

Obs.: Os valores críticos correspondem ao valor de $\Gamma$ a um nível de significância de $10 \%$.

Fonte: Elaboração própria 
Tabela A.25 - Evolução do Número de Não-Tratados na Construção do Grupo de Controle $(\mathbf{P}=\mathbf{0 , 2})$

\begin{tabular}{lr}
\hline & Não-Tratados \\
\hline Número de Municípios* na base de dados inicial & 4123 \\
Número de Municípios** após filtro Vizinhança & 1746 \\
Número de Municípios** para Diferenças-em-Diferenças & 121 \\
\hline
\end{tabular}

Obs.: * e ** indicam municípios nas agregações de AMC's nos períodos 1991-2000 e 20002010, respectivamente. Nos municípios para a estimação por Diferenças-em-Diferenças pode haver repetições, visto que o pareamento é com reposição.

Fonte: Elaboração própria

Tabela A.26 - Efeito da Expansão de Campi Universitários Federais sobre Reeleição Política em $2008(P=0,2)$

\begin{tabular}{lccc}
\hline \multicolumn{4}{c}{ Estimação por Diferenças-em-Diferenças com Pareamento por Escore de Propensão } \\
\hline Método & $(1)$ & $(2)$ & $(3)$ \\
\hline Pareamento com suavização de reeleição dos controles & Não & Sim & Sim \\
\hline Pareamento com suavização de reeleição dos tratados & Não & Não & Sim \\
\hline Partido Político Eleito em 2004 Vencedor em 2008 & 0,08 & 0,08 & $0,08^{* *}$ \\
& $(0,052)$ & $(0,060)$ & $(0,036)$ \\
Partido Político da Coligação Eleita em 2004 Vencedor em 2008 & $0,231^{* * *}$ & $0,23^{* * *}$ & $0,23^{* * *}$ \\
& $(0,041)$ & $(0,063)$ & $(0,055)$ \\
\hline
\end{tabular}

Obs.: $\quad$ 1- Número de observações $=242$

2- O desvio-padrão está entre parênteses;

*** p-valor $<0,01, * *$ p-valor $<0,05, *$ p-valor $<0,1$;

3- A suavização da variável binária reeleição é feita usando função spline cúbica do escore de propensão;

4- A Coluna (1) faz o pareamento sem suavização da variável reeleição, a Coluna (2) segue a metodologia de Blundell et al (2004), e a Coluna (3) segue o proposto por Meghir e Palme (2003); 5- A estimação do desvio-padrão da Coluna (1) segue Abadie e Imbens (2006), e as estimações do desvio-padrão das Colunas (2) e (3) usam o método de bootstrap com 1000 replicações, com cluster por município.

Fonte: Elaboração própria 
Tabela A.27 - Efeito da Expansão de Campi Universitários Federais com Interação pelo

Tamanho Populacional do Município $(P=0,2)$

\begin{tabular}{lcc}
\hline \multicolumn{3}{c}{ Estimação por Diferenças-em-Diferenças com Pareamento por Escore de Propensão } \\
\hline Variável Dependente: Reeleição & $\begin{array}{c}\text { Partido Político Eleito em } \\
\text { 2004 Vencedor em 2008 }\end{array}$ & $\begin{array}{c}\text { Partido Político da } \\
\text { Veligacão Eleita em 2004 } \\
\text { Vencedor em 2008 }\end{array}$ \\
\hline Pareamento com suavização de reeleição dos controles & Não & Não \\
\hline Pareamento com suavização de reeleição dos tratados & Não & Não \\
\hline \multirow{2}{*}{ Tratamento } & 0,065 & $0,165^{*}$ \\
População & $(0,104)$ & $(0,087)$ \\
& $-3,63 \mathrm{E}-08$ & $-1,23 \mathrm{E}-07$ \\
Tratamento . População & $1,48 \mathrm{E}-07$ & $1,62 \mathrm{E}-07$ \\
& $2,82 \mathrm{E}-09$ & $-1,08 \mathrm{E}-07$ \\
\hline
\end{tabular}

Obs.: 1- O desvio-padrão está entre parênteses;

$* * *$ p-valor $<0,01, * *$ p-valor $<0,05, *$ p-valor $<0,1$;

2- O desvio-padrão é estimado pelo método de bootstrap com 1000 replicações, com cluster por município.

Fonte: Elaboração própria

Tabela A.28 - Número de Municípios Tratados e Controles nos Subgrupos Amostrais para Reeleição $(\mathbf{P}=\mathbf{0}, 2)$

\begin{tabular}{cccc}
\hline Grupo & Controles & Tratados & Total \\
\hline 1 & 59 & 59 & 118 \\
2 & 62 & 62 & 124 \\
\hline Total & 121 & 121 & 242 \\
\hline
\end{tabular}

Obs.: Grupo 1 - municípios com até 65 mil habitantes;

Grupo 2 - municípios com mais de 65 mil habitantes.

Fonte: Elaboração própria 


\section{Tabela A.29 - Efeito da Expansão de Campi Universitários Federais sobre Reeleição Política em 2008 por Grupo $(P=0,2)$}

\begin{tabular}{lccc}
\hline \multicolumn{4}{c}{ Estimação por Diferenças-em-Diferenças com Pareamento por Escore de Propensão } \\
\hline Método & $(1)$ & $(2)$ & $(3)$ \\
\hline Pareamento com suavização de reeleição dos controles & Não & Sim & Sim \\
\hline Pareamento com suavização de reeleição dos tratados & Não & Não & Sim \\
\hline Variável dependente: Partido Político Eleito em 2004 Vencedor em 2008 & & \\
Grupo 1 & 0,085 & 0,093 & $0,132^{* * *}$ \\
Número de Observações = 112 & $(0,079)$ & $(0,073)$ & $(0,036)$ \\
Grupo 2 & $0,117^{*}$ & 0,105 & 0,068 \\
Número de Observações = 114 & $(0,069)$ & $(0,097)$ & $(0,067)$ \\
\hline Variável dependente: Partido Político da Coligação Eleita em 2004 Vencedor em 2008 & \\
Grupo 1 & $0,24^{* * *}$ & $0,227^{* * *}$ & $0,196^{* * *}$ \\
Número de Observações = 112 & $(0,070)$ & $(0,077)$ & $(0,064)$ \\
Grupo 2 & $0,302^{* * *}$ & $0,3^{* *}$ & $0,33^{* * *}$ \\
Número de Observações = 114 & $(0,050)$ & $(0,119)$ & $(0,101)$ \\
\hline
\end{tabular}

Obs.: $\quad$ 1- Número de observações $=242$

2- O desvio-padrão está entre parênteses;

*** p-valor $<0,01, * *$ p-valor $<0,05, *$ p-valor $<0,1$;

3- A suavização da variável binária reeleição é feita usando função spline cúbica do escore de propensão;

4- A Coluna (1) faz o pareamento sem suavização da variável reeleição, a Coluna (2) segue a metodologia de Blundell et al (2004), e a Coluna (3) segue o proposto por Meghir e Palme (2003); 5- A estimação do desvio-padrão da Coluna (1) segue Abadie e Imbens (2006), e as estimações do desvio-padrão das Colunas (2) e (3) usam o método de bootstrap com 1000 replicações, com cluster por município.

Fonte: Elaboração própria

Tabela A.30 - Estimador da Análise de Sensibilidade ( $\Gamma)$ para o Efeito do Tratamento sobre a Reeleição nos Municípios Tratados $(P=0,2)$

\begin{tabular}{lccc}
\hline \multirow{2}{*}{ Sensibilidade para o Efeito sobre Reeleição } & \multicolumn{3}{c}{$\Gamma$} \\
\cline { 2 - 4 } & $\begin{array}{c}\text { Amostra } \\
\text { Inteira }\end{array}$ & Grupo 1 & Grupo 2 \\
\hline Partido Político Eleito em 2004 Vencedor em 2008 & 1,00 & 1,00 & 1,00 \\
Partido Político da Coligação Eleita em 2004 Vencedor em 2008 & 2,44 & 1,59 & 2,32 \\
\hline
\end{tabular}

Obs.: Os valores críticos correspondem ao valor de $\Gamma$ a um nível de significância de $10 \%$.

Fonte: Elaboração própria 